\title{
Basin Depth Mapping Beneath Wellington City Based on Residual Gravity Anomalies
}

\author{
By
}

Alistair Ian Stronach

School of Geography, Environment and Earth Sciences

Victoria University of Wellington 


\section{Abstract}

New Zealand's capital city of Wellington lies in an area of high seismic risk, which is further increased by the sedimentary basin beneath the Central Business District (CBD). Ground motion data and damage patterns from the 2013 Cook Strait and 2016 Kaikōura earthquakes indicate that two- and three-dimensional amplification effects due to the Wellington sedimentary basin may be significant. These effects are not currently accounted for in the New Zealand Building Code. In order for this to be done, three-dimensional simulations of earthquake shaking need to be undertaken, which requires detailed knowledge of basin geometry. This is currently lacking, primarily because of a dearth of deep boreholes in the CBD area, particularly in Thorndon and Pipitea where sediment depths are estimated to be greatest.

A new basin depth map for the Wellington CBD has been created by conducting a gravity survey using a modern Scintrex CG-6 gravity meter. Across the study area, 519 new high precision gravity measurements were made and a residual anomaly map created, showing a maximum amplitude anomaly of $-6.2 \mathrm{mGal}$ with uncertainties better than \pm 0.1 mGal. Thirteen two-dimensional geological profiles were modelled to fit the anomalies, then combined with existing borehole constraints to construct the basin depth map.

Results indicate on average greater depths than in existing models, particularly in Pipitea where depths are interpreted to be as great as $450 \mathrm{~m}$, a difference of $250 \mathrm{~m}$. Within $1 \mathrm{~km}$ of shore depths are interpreted to increase further, to $600 \mathrm{~m}$. The recently discovered basinbounding Aotea Fault is resolved in the gravity data, where the basement is offset by up to $13 \mathrm{~m}$, gravity anomaly gradients up to $8 \mathrm{mGal} / \mathrm{km}$ are observed, and possible multiple fault strands identified. A secondary strand of the Wellington Fault is also identified in the north of Pipitea, where gravity anomaly gradients up to $18 \mathrm{mGal} / \mathrm{km}$ are observed. 


\section{Acknowledgements}

Thanks firstly to my supervisor Tim Stern, for all his knowledge and help both theoretical and practical, and his work in organizing financial support.

Thanks to my classmate Sam Treweek, for all sorts of help over the last two years, as well as volunteering as a survey assistant. Thanks also to Pietro Di Nicola for help with surveying, and to El Mestel for some much needed proof reading.

Thanks to Cassandra Trinh-Le, for help with gear, many days of surveying and an unrelated yet unforgettable trip to the Southern Alps.

Thanks to Matt Hill at GNS, for help, advice and providing essential borehole data and sections from his own work on Wellington geology. Thanks also to Vaughan Stagpoole, Richard Kellett, Jenny Black and Wanda Stratford at GNS for other assistance and ideas.

Thanks to Aasha Pancha and the geotech team at Aurecon, for providing valuable information and allowing access to their data.

Thanks to my Dad, my Mum and my sister Eleanor for their support during my move back to New Zealand and study, and extra thanks to my Dad for more proof reading.

Thanks to the GSNZ and the Wellington Branch of the Royal Society for financial support, and especially to the NZSEE for the Postgraduate Research Scholarship.

Finally, thanks to the EQC for the funding which made this project possible. 


\section{Contents}

List of Figures $\quad$ xi

List of Tables $\quad$ xiv

1 Introduction 1

1.1 Project Background . . . . . . . . . . . . . . . . . . . . . . . . 1

1.1.1 Sedimentary Basin Amplification . . . . . . . . . . . . . . 2

1.1.2 Study Area: Wellington . . . . . . . . . . . . . . . . . 3

1.1.3 New Zealand Standards Site Class Specifications . . . . . . . . . . . 6

1.1.4 Basin Topography from Gravity Surveying . . . . . . . . . . . . . 6

1.2 Objectives . . . . . . . . . . . . . . . . . 8

1.3 Geological Setting . . . . . . . . . . . . . . . . . . . . . . 9

1.3.1 New Zealand . . . . . . . . . . . . . . . . . . . . . . . 9 9

1.3.2 Wellington Regional Tectonic Setting . . . . . . . . . . . . . . . 9

1.3.3 Stratigraphy . . . . . . . . . . . . . . . . . . 12

1.3.4 Geomorphology . . . . . . . . . . . . . . . . . . 16

1.4 Previous Studies . . . . . . . . . . . . . . . . . . . . 18

1.4.1 Hatherton and Sibson, 1969 . . . . . . . . . . . . . . . 18

1.4.2 Cowan \& Hatherton, 1968 . . . . . . . . . . . . . . . . . . . 21

1.4.3 Grant-Taylor et al., 1974 . . . . . . . . . . . . . . . . . 22

1.4.4 Hochstein \& Davey, 1974 . . . . . . . . . . . . . . . . . . . . . 23

1.4.5 Semmens, $2010 \ldots \ldots \ldots \ldots \ldots$

1.4.6 Vantassal et al., $2018 \ldots \ldots \ldots$. . . . . . . . . . 25

1.4.7 Kaiser et al., 2019 . . . . . . . . . . . . . . 26

1.5 Available Constraints . . . . . . . . . . . . . . . . . . . . . . 29

1.5.1 Density . . . . . . . . . . . . . . . . . 29

1.5 .2 Boreholes . . . . . . . . . . . . . . . . . . 30

1.5.3 Leapfrog Model . . . . . . . . . . . . . . . . . . . . . . . . . . 31

2 Methods 33 
2.1 Gravity Theory . . . . . . . . . . . . . . . . . 33

2.1 .1 Newton's Law of Gravitation _ . . . . . . . . . . . . . 33

2.1 .2 The Geoid . . . . . . . . . . . . . . . . 34

2.2 Calculating Expected Gravity _ . . . . . . . . . . . . . 35

2.2 .1 Variation of Gravity with Latitude . . . . . . . . . . . 35

2.2 .2 Free Air Correction . . . . . . . . . . . . . . . . . . 36

2.2 .3 Bouguer Plate Correction . . . . . . . . . . . . . . . . . . 36

2.2 .4 Terrain Correction . . . . . . . . . . . . . . . . . . . 37

2.2 .5 Building Correction . . . . . . . . . . . . . . . . . . . . . 42

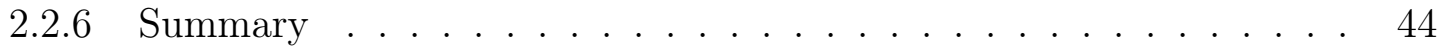

2.3 Gravity Data Acquisition . . . . . . . . . . . . . . . 45

2.3 .1 Equipment . . . . . . . . . . . . . . . . . . . . 45

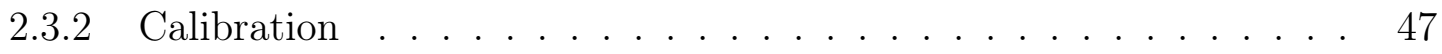

$2.3 .3 \quad$ Field Procedure . . . . . . . . . . . . . . . . . . . 47

2.4 Corrections to Measured Gravity _. . . . . . . . . . . . . . . 52

2.4.1 Relative and Absolute Gravity . . . . . . . . . . . . . . . 52

2.4 .2 Temporal Drift . . . . . . . . . . . . . . . . . . 53

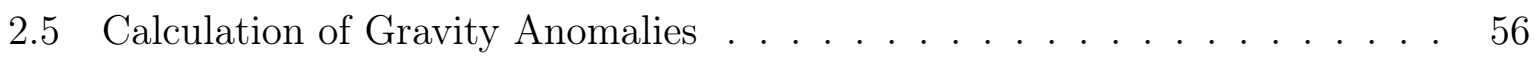

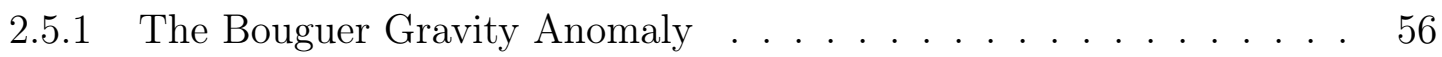

2.5.2 Regional-Residual Separation _. . . . . . . . . . . 57

2.5.3 Data Reduction Summary . . . . . . . . . . . . . . . . . . 61

2.5 .4 Uncertainties . . . . . . . . . . . . . . . . . . . 62

2.6 Gravity Anomaly Maps . . . . . . . . . . . . . . . . . . . . . . . . . 64

2.7 Gravity Modelling . . . . . . . . . . . . . . . . . . . . . . 64

2.7.1 Profile Modelling . . . . . . . . . . . . . . . . . . . 64

2.7.2 Three-Dimensional Basin Depth Modelling . . . . . . . . . . . . 69

$\begin{array}{lll}3 & \text { Results } & 71\end{array}$

3.1 Gravity Observations . . . . . . . . . . . . . . . . . . . . 71

3.1.1 Comparison with Historical Observations . . . . . . . . . . 74

3.1 .2 Repeats . . . . . . . . . . . . . . . . 76

3.2 Gravity Anomaly Maps . . . . . . . . . . . . . . . . . . . . . 77

3.2 .1 Bouguer Anomaly . . . . . . . . . . . . . . . . . 77

3.2 .2 Residual Anomaly . . . . . . . . . . . . . . . . . . . . 77

3.3 Two-Dimensional Profile Modelling . . . . . . . . . . . . . . . . . . . 82

3.3 .1 Profile Parameters . . . . . . . . . . . . . . . . . . . . . 82

3.3 .2 Profile Layout . . . . . . . . . . . . . . . . . . 82

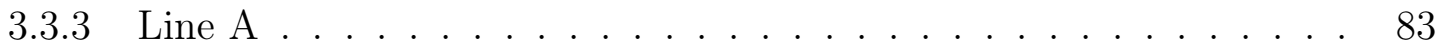


3.3 .4 Line B . . . . . . . . . . . . . . . 86

3.3.5 Line $\mathrm{C} \ldots \ldots \ldots \ldots \ldots$. . . . . . . . . . . . . . . 88

3.3 .6 Line D . . . . . . . . . . . . . . . . . . . . . . . . 91

3.3 .7 Line $\mathrm{F} \ldots \ldots \ldots \ldots$. . . . . . . . . . . . . . . . . . . . . . . .

3.3 .8 Line $\mathrm{G} \ldots \ldots \ldots \ldots$. . . . . . . . . . . . . . . 95

3.3 .9 Line $\mathrm{H} \ldots \ldots \ldots$. . . . . . . . . . . . . . . . . . . . 97

3.3 .10 Line $\mathrm{I} \ldots \ldots \ldots \ldots 9$

3.3 .11 Line $\mathrm{J} \ldots \ldots \ldots 101$

3.3 .12 Line $\mathrm{K} \ldots \ldots \ldots \ldots \ldots$. . . . . . . . . . . . . . . . . . . . . . . . .

3.3 .13 Line $\mathrm{N} \ldots \ldots \ldots \ldots \ldots$

3.3 .14 Line $\mathrm{T} \ldots \ldots \ldots \ldots \ldots 7 \ldots \ldots \ldots$

3.3 .15 Line $\mathrm{U} \ldots \ldots \ldots \ldots$. . . . . . . . . . . . . . 109

3.3 .16 Line $\mathrm{W} \ldots \ldots \ldots \ldots \ldots 111 \ldots \ldots \ldots \ldots \ldots$

3.3 .17 Profile Uncertainty . . . . . . . . . . . . . . . . . . . . 113

3.4 Three-Dimensional Basin Depth Modelling . . . . . . . . . . . . . 116

3.4 .1 Depth Uncertainty . . . . . . . . . . . . . . . . . . . . 119

3.5 Summary: Key Results . . . . . . . . . . . . . . . . . . . . . . . . . . . . 122

4 Discussion $\quad 123$

4.1 Depth Map Interpretation . . . . . . . . . . . . . . . . . . . . . 123

4.2 DC Shift and Greywacke Weathering . . . . . . . . . . . . . . 125

4.2.1 Weathering Mechanisms . . . . . . . . . . . . . 126

4.3 Future Work . . . . . . . . . . . . . . . . . . . . . . . . 127

4.4 Conclusions . . . . . . . . . . . . . . . . . . . . 135

A Notes on Density 137

A.0.1 Estimation Methods . . . . . . . . . . . . . . 138

B Wellington Seismic Response Observations 142

B.0.1 New Zealand Standard 1170.5:2004 . . . . . . . . . . . . . . . . . . 144

C Errors in Historical Gravity Observations 146

D Uncertainty in Regional-Residual Separation 148 


\section{List of Figures}

1.1 Sedimentary basin amplification effects . . . . . . . . . . . 2

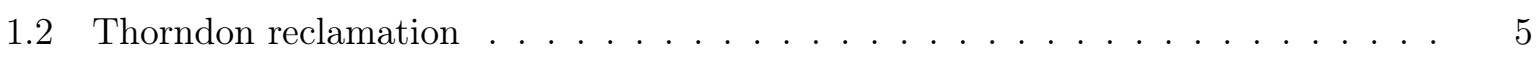

1.3 Wellington waterfront reclamation map . . . . . . . . . . . . . . . 5

1.4 Regional New Zealand tectonic setting . . . . . . . . . . . . . . . . . . . 10

1.5 Wellington region geology and tectonic setting . . . . . . . . . . . 11

1.6 Generalized stratigraphic column for Wellington City . . . . . . . . . . . . . . . . 14

1.7 Surface geology map for Wellington City . . . . . . . . . . . . . . . . . . . 15

1.8 Wellington Regional Map . . . . . . . . . . . . . . . . . . . . . 17

1.9 Wellington Bouguer gravity anomaly map from Hatherton and Sibson (1969) . . 18

1.10 Wellington CBD gravity anomaly map from Hatherton and Sibson (1969) . . . 20

1.11 Wellington Harbour gravity anomaly map from Cowan and Hatherton (1968) . . 21

1.12 Thorndon residual gravity anomaly map from Cowan and Hatherton (1968) . . . 22

1.13 Basin depth map and cross-section of Hochstein and Davey (1974) . . . . . . . . 23

1.14 Basement depth maps of Semmens (2010) and Grant-Taylor et al. (1974) . . . . . 25

1.15 Basement depths of Vantassel et al. (2018) as compared to Semmens (2010). . . . 26

1.16 Basement depth map of Kaiser et al. (2019) as compared to Semmens (2010). . . 28

1.17 Basement depth map of Kaiser et al. (2019) with borehole locations . . . . . . . . 32

2.1 Comparison of geoid, ellipsoid and topography . . . . . . . . . . . . . . 34

2.2 The free air correction $\ldots \ldots \ldots \ldots \ldots \ldots \ldots \ldots$

2.3 The Bouguer Plate Correction . . . . . . . . . . . . . . . . . . . . . 37

2.4 The Terrain Correction. . . . . . . . . . . . . . . . . . . . . . 38

2.5 A Hammer (1939) graticule used in terrain corrections . . . . . . . . . . . . . 38

2.6 Digital Elevation Model processing . . . . . . . . . . . . . . . . . 41

2.7 Final Digital Elevation Models _. . . . . . . . . . . . . . . . . . . . . 42

2.8 Final Digital Surface Model . . . . . . . . . . . . . . . . . . . . . . . . . . 43

2.9 Field setup on Aotea Quay . . . . . . . . . . . . . . . . . . . 46

2.10 Calibration measurement at GNS . . . . . . . . . . . . . . . . . . 48

2.11 CG-6 at a station on Te Ahumairangi hill . . . . . . . . . . . . . . . . . . 50

2.12 Tidal drift curve . . . . . . . . . . . . . . . . . . . . . . . 53

2.13 Instrument drift curve . . . . . . . . . . . . . . . . . . . . 56

2.14 An example of a regional - residual gravity anomaly separation . . . . . . . . . 58 
2.15 Map showing regional gravity stations. . . . . . . . . . . . . . . . . 59

2.16 Regional gravity anomaly polynomial order against goodness of fit . . . . . . . 60

2.17 Third order polynomial surface representing regional gravity anomaly . . . . . . . 60

2.18 Example of topography point sampling. . . . . . . . . . . . . . . . . . 65

2.19 Gravity profile across the Wellington Fault in the Hutt Valley (Kellett et al., 2017) 67

2.20 The effect of a DC shift and weathered greywacke on model fit. . . . . . . . . . 68

3.1 Location map for profiles and gravity stations . . . . . . . . . . . . . . 73

3.2 Location map for stations coinciding with historical stations . . . . . . . . . . . 75

3.3 Bouguer anomaly map . . . . . . . . . . . . . . . . . . . . . . . . . . 78

3.4 Residual anomaly map . . . . . . . . . . . . . . . . . . . . . . 79

3.5 Residual anomaly compared with Hatherton and Sibson (1969) in Te Aro . . . . 80

3.6 Residual anomaly compared with Hatherton and Sibson (1969) in Thorndon / Pipitea 81

3.7 Best fit geological profile for Line A . . . . . . . . . . . . . . . . . . 84

3.8 Possible dip range for the Aotea Fault on Line A . . . . . . . . . . . . . . 85

3.9 Best fit geological profile for Line B . . . . . . . . . . . . . . . . . . 87

3.10 Best fit geological profile for Line C . . . . . . . . . . . . . . . . . . . 89

3.11 Alternative Aotea Fault location for Line C . . . . . . . . . . . . . . . 90

3.12 Best fit geological profile for Line D . . . . . . . . . . . . . . . . . . . . 92

3.13 Best fit geological profile for Line F . . . . . . . . . . . . . . . . . . . . . 94

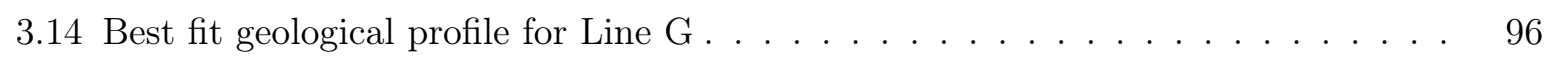

3.15 Best fit geological profile for Line H . . . . . . . . . . . . . . . . . 98

3.16 Best fit geological profile for Line I . . . . . . . . . . . . . . . . . 100

3.17 Best fit geological profile for Line J . . . . . . . . . . . . . . . . . 102

3.18 Best fit geological profile for Line K . . . . . . . . . . . . . . . . . . . 104

3.19 Best fit geological profile for Line N . . . . . . . . . . . . . . . . 106

3.20 Best fit geological profile for Line T . . . . . . . . . . . . . . . . . 108

3.21 Best fit geological profile for Line U . . . . . . . . . . . . . . . . 110

3.22 Best fit geological profile for Line $\mathrm{W} \ldots \ldots \ldots$. . . . . . . . . . . 112

3.23 Line B comparison of deepest and shallowest plausible basin scenarios . . . . . . 114

3.24 Line J comparison of deepest and shallowest plausible basin scenarios . . . . . . . 115

3.25 Preferred basin depth map . . . . . . . . . . . . . . . . . . . . . . . 117

3.26 Difference between preferred basin depth map and that of Kaiser et al. (2019) . . 118

3.27 Difference between preferred basin depth map and the deepest scenario . . . . . . 120

3.28 Difference between preferred basin depth map and the shallowest scenario . . . . 121

4.1 Basin topography interpretation . . . . . . . . . . . . . . . . . . . . . 129

4.2 A possible en-echelon interpretation of the Aotea Fault . . . . . . . . . . . . . 130

4.3 Geological profile for Line A using higher densities . . . . . . . . . . . . . . . 131

4.4 Interpretation from Waitangi Park seismic survey . . . . . . . . . . . . . . . 134

A.1 Wet bulk density as a function of porosity. . . . . . . . . . . . . . . 138 
B.1 Spectral accelerations for Wellington seismic stations in the Kaikoura earthquake. 143

B.2 Spectral accelerations divided into orthogonal components. . . . . . . . . . . . . . 144

B.3 Spectral amplification of the Cook Strait and Kaikōura earthquakes . . . . . . . . 145

C.1 Error in historical measurements . . . . . . . . . . . . . . . . . . . . . 147

D.1 Line B residuals resulting from the adoption of different regional gravity fields . . 149

D.2 Line B basin depth model comparison for different regional gravity fields . . . . . 150

D.3 Line J residuals resulting from the adoption of different regional gravity fields . . 151

D.4 Line J basin depth model comparison for different regional gravity fields . . . . . 151 


\section{List of Tables}

1.1 Wellington region major fault parameters . . . . . . . . . . . . . . 11

1.2 Data used for density estimations . . . . . . . . . . . . . . . . . . 30

3.1 List of gravity measurements made . . . . . . . . . . . . . . . . . . 72

3.2 Comparison of gravity measurements with historical observations . . . . . . . . . 74

3.3 Results for repeat measurements at gravity stations . . . . . . . . . . . . . 76

3.4 Key profile parameters . . . . . . . . . . . . . . . . . . . 82 


\section{Chapter 1}

\section{Introduction}

\subsection{Project Background}

It has long been known that variation in near-surface geology has the potential to cause severe ground amplification during earthquakes, demonstrated by observations of, for example, the 1891 Japan earthquake (Milne, 1898) and the 1906 San Francisco earthquake (Reid, 1910; Wood, 1910).

It has also become apparent that sedimentary basins have the potential to cause particularly severe, localized amplification of earthquake shaking, demonstrated most strikingly by the 1985 ms 8.1 earthquake in Michoacán, Mexico (McNally et al., 1986) that produced extensive damage and death $400 \mathrm{~km}$ away in Mexico City. Other well known examples include the $1994 \mathrm{M}_{\mathrm{w}} 6.7$ earthquake in Northridge, California (Gao et al., 1996), and the $1995 \mathrm{~m}_{\mathrm{w}} 6.9$ earthquake in Kobe, Japan (Kawase, 1996).

Recently the $2016 \mathrm{M}_{\mathrm{w}} 7.8$ earthquake in Kaikōura, New Zealand, caused significant damage to mid-rise buildings in Wellington City (Bradley et al., 2017), despite the multiple earthquakes making up this event being at least $60 \mathrm{~km}$ distant and mostly $>100 \mathrm{~km}$ distant (Hamling et al., 2017). Research indicates the amplification that caused this damage was due not only to presence of a sedimentary basin beneath Wellington but to its geometry as well (Bradley et al., 2018).

In this project a micro-gravity survey is undertaken across the Central Business District (CBD) of Wellington, New Zealand to better define the Wellington sedimentary basin geometry and help address the risk posed by amplification of earthquake shaking. 


\subsubsection{Sedimentary Basin Amplification}

Sedimentary basins cause amplification in several different ways. Usually, these are discussed as one-, two- or three-dimensional effects, based on how many dimensions need to be considered in order to construct an analytical model.

\section{One-Dimensional effects}

The simplest basin amplification effect is due to soft sediments overlying harder bedrock. The velocity of seismic waves is dependent on several factors, but is generally higher in harder, stronger mediums. In a one dimensional model of a single layer of soft sediment overlaying a half-space of hard bedrock, waves slow down as they enter the sediment from below. Conservation of energy then results in an increase in amplitude (Figure 1.1, Lee et al. (2003)), as seen in, for example, amplification of shaking in Washington DC during the $2011 \mathrm{M}_{\mathrm{w}} 5.8$ earthquake near Mineral, Virginia (Pratt et al., 2017).

The second effect observed in one dimensional (1D) analysis is resonance, in which seismic energy is repeatedly reflected from the basement interface, to the surface and back down. If the distance from basement to surface is roughly a multiple of half the wavelength, these waves can constructively interfere and generate a standing wave with increased amplitude at the nodes, leading to the basin amplifying certain frequencies of seismic energy. (Lee et al., 2003).

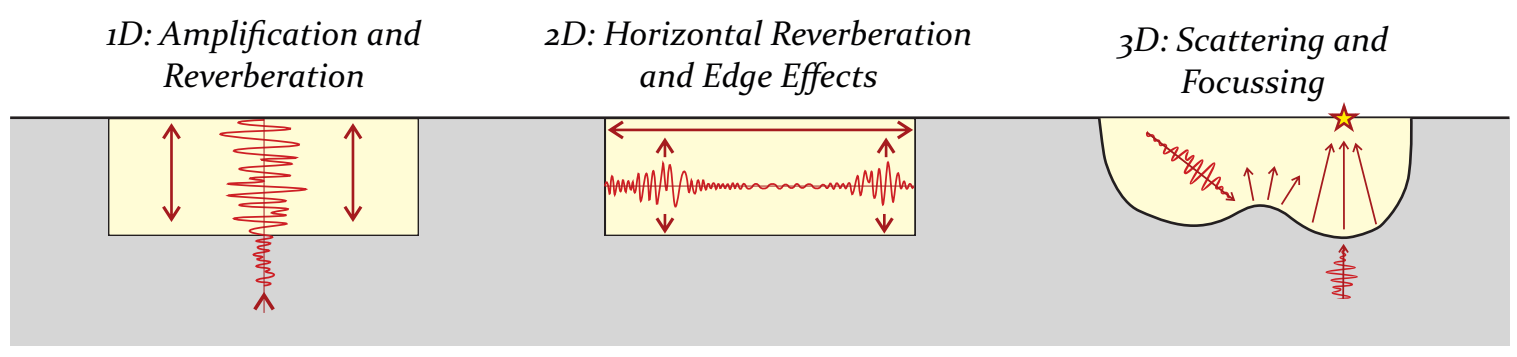

Figure 1.1: Some possible one-, two- and three-dimensional seismic amplification effects in sedimentary basins.

\section{Two-Dimensional effects}

When a basin is considered in two dimensions (2D), there can be horizontal resonance between the walls of the basin - particularly for surface waves, which are trapped at the surface and so some portion of their energy will always rebound from basin edges. Near the edges strong interference patterns can develop when phase conversion of incident $\mathrm{P}$ 
and $\mathrm{S}$ waves at the basin edge produces additional surface waves, which can then interfere with themselves or with the incident $\mathrm{P}$ or $\mathrm{S}$ waves. Standing waves can then be created with high amplitude nodes near basin edges (Figure 1.1). These basin edge effects will tend to be more severe the sharper, and steeper, the basin edge (Lee et al., 2003).

The $1995 \mathrm{~m}_{\mathrm{w}} 9.8$ earthquake in Kobe, Japan is the most well-known example of this, where reflections, phase conversion and interference from a series of steeply dipping faults resulted in an adjacent belt of particularly heavy damage (Kawase, 1996).

\section{Three-Dimensional effects}

The more dimensions considered in a model, the more complex the possible effects and the pattern of amplification (Figure 1.1), and generally the greater the total amplification. In three dimensions, patterns of interference and amplification due to variations in basin geometry become increasingly complicated and difficult to intuitively predict. Protrusions in the basin floor can cause scattering and increased shaking elsewhere. Bowl-like shapes can cause focussing of incident waves from beneath the basin, in the same manner as a concave lens (Lee et al., 2003).

For example, focussing was most famously observed in the $\mathrm{M}_{\mathrm{w}} 6.7$ Northridge earthquake, where severe damage was seen in a relatively localized area of a sedimentary basin, which initially appeared uncorrelated with the epicentre of the earthquake (Gao et al., 1996).

\subsubsection{Study Area: Wellington}

Wellington is the capital and third largest city of New Zealand, and lies in a tectonically active region, close to five major active faults (Semmens, 2010). Statistical estimates place the chance of an $\mathrm{M}_{\mathrm{w}} \geq 7.0$ earthquake in central New Zealand at $30 \%$ within the next decade (Gerstenberger et al., 2017).

The city is relatively densely populated, and along with the seat of government for New Zealand, contains a concentration of technical and financial services and crucial infrastructure such as the Cook Strait ferry terminals (WCC, 2019). It lies in an area of steep topography prone to landslides and has numerous infrastructure choke points dictated by this topography (Figure 1.8). These factors all place it at high earthquake risk in terms of both likelihood and probable severity of outcome. 
The specific project area is the Wellington CBD, which lies in a small, steep sided sedimentary basin (Begg, 1996), bounded on the NW by the Wellington Fault and the SE by the Aotea Fault, which was only recently identified offshore (Barnes et al., 2019). The onshore trace of this fault is not yet well defined. Sedimentary basin amplification effects are therefore an important part of the earthquake risk to Wellington, as seen in analysis of ground motion during both the $2013 \mathrm{M}_{\mathrm{w}}$ 6.6 Cook Strait (Francois-Holden et al., 2013) and $2016 \mathrm{M}_{\mathrm{w}} 7.8$ Kaikōura (Bradley et al., 2017) earthquakes (Appendix B).

\section{Waterfront Reclamation}

Large portions of the Wellington waterfront lie on reclaimed land, notably the extensively developed areas of Pipitea and Wellington Central (Figure 1.3). The Centerport complex, a major port and infrastructure hub, sits entirely on reclaimed land. Reclamation material has a particularly poor seismic response, as noted at CentrePort during the Kaikoura earthquake when significant damage was caused by liquefaction, lateral spreading and shaking (Vantassel et al., 2018).

Reclamation projects started in 1852, and have been completed in numerous stages at various times, using different methods. Reclamation from 1852 to 1913 used locally quarried stone and soil as well as rubbish and building debris. A single large project at the Thorndon Rail Yard undertaken from 1924 to 1932 was reclaimed using hydraulically pumped seabed sand and mud (Figure 1.2), which has the highest liquefaction and earthquake amplification potential of all the reclaimed areas. Reclamation from 1965 onwards used engineered fill, meaning gravelly material with specific grain sizes compacted to specific densities, which is likely to perform better than the older fill (Figure 1.3) (Semmens, 2010). 


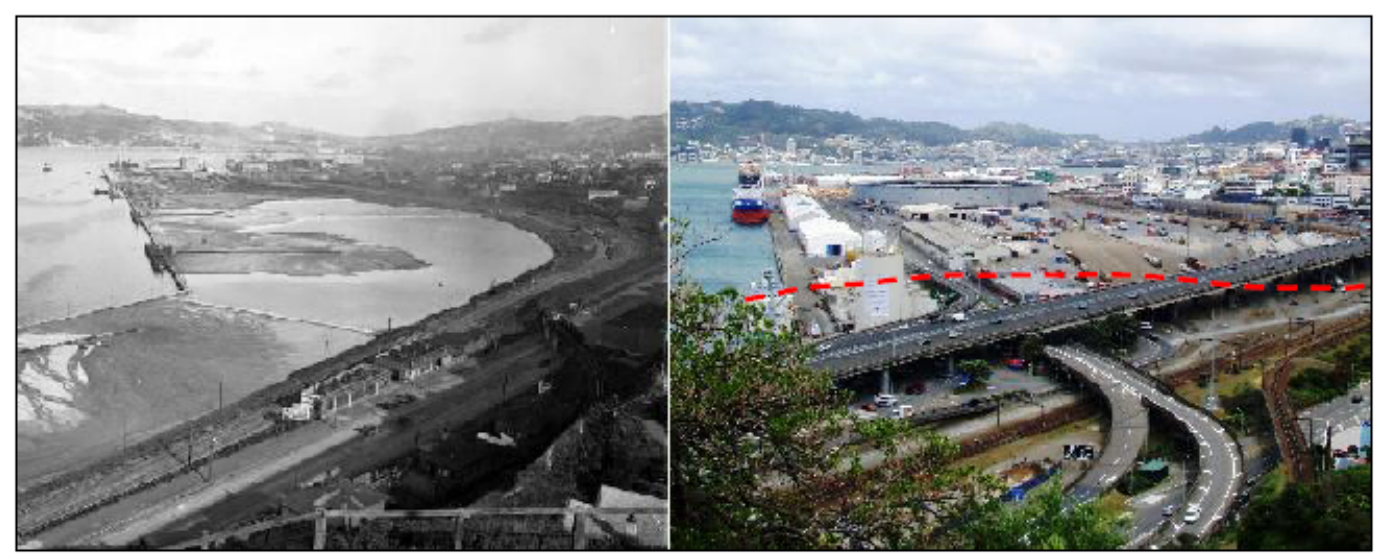

Figure 1.2: Left: The Thorndon rail yard reclamation project (Evening Post, ca. 1925). Right: The current rail yard, stadium and port (Semmens, 2009). Dashed red line is the approximate trace of the Wellington Fault. (Semmens, 2010)

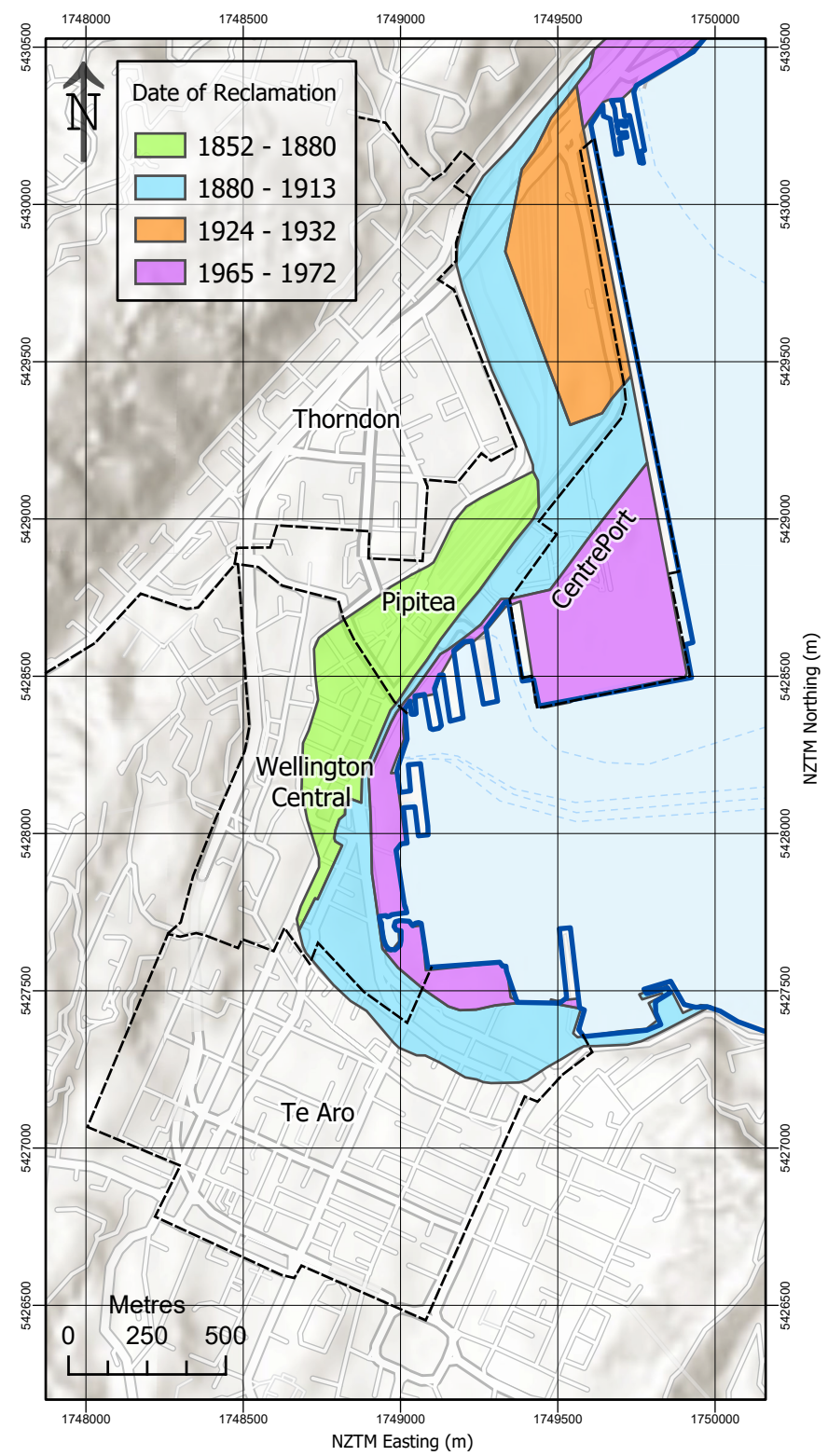

Figure 1.3: Map of the Wellington CBD, showing areas of waterfront reclamation coloured by date completed. 


\subsubsection{New Zealand Standards Site Class Specifications}

New Zealand Standard 1170.5:2004 (Standards New Zealand, 2004) sets out specifications for building design with the intention that buildings do not collapse and cause loss of life in an earthquake, and that critical structures, such as hospitals, remain operational. These specifications are based on a combination of the geomechanical soil properties of a site, and the soil (sediment) depth. In most cases the critical parametre is the fundamental resonance frequency of a site, which is a function of seismic velocity and depth, and therefore a 1D amplification effect.

No accommodation is currently made for $2 \mathrm{D}$ and $3 \mathrm{D}$ amplification effects. The Ministry of Business, Innovation and Employment (MBIE) hopes to take steps towards understanding basin effects in the Wellington CBD and to ultimately incorporate them into the New Zealand Building Code, prompted by for example unexpected damage to Statistics House during the Kaikōura earthquake ("Investigation into the performance of Statistics House in the 14 November 2016 Kaikōura Earthquake", 2017). MBIE currently suggests that 3D analysis of site response may be done for specific sites if deemed necessary, but do not give guidelines as to how or when this is to be done (Cubrinovski et al., 2016).

For these basin amplification effects to be reliably predicted, 3D ground motion simulations need to be undertaken. The Christchurch based research group QuakeCoRE are currently working on such simulations (QuakeCoRE, 2019). For the results to be meaningful, detailed knowledge of basin geometry is essential, which in the Wellington Basin is currently lacking, particularly in the Thorndon/Pipitea area where reclamation is most extensive and the basin is estimated to be the deepest (Figures 1.3, 1.17). There is only one site in Thorndon which has boreholes intersecting bedrock at greater than $40 \mathrm{~m}$ depth, that of both the Department of Corrections building and the now-demolished Department of Defence building.

\subsubsection{Basin Topography from Gravity Surveying}

In this project a gravity survey is used to generate a basin depth map. The term "gravity" is used here to indicate for the acceleration of an object due to the mass of the Earth, and it is used as such from here on. This technique is a non-invasive geophysical method, wherein variations in measured gravity at the surface, called gravity anomalies, are interpreted to be due to variations in density and therefore structure within the subsurface. The structures 
mapped can range in scale from global tectonics (Tassara \& Echaurren, 2012; Tirel et al., 2004), to sedimentary basins (Oldow \& Sprenke, 2006; Ibrahim \& Hinze, 1972), individual faults (Gasston et al., 2021), or caves (Martínez-Moreno et al., 2015).

The gravity signature of a particular structure depends on a combination of its size and its density contrast with the surrounding rock. Surveys with modern gravity metres are able to resolve structures as small as a buried cellar (Jacob et al., 2020; Panisova et al., 2013), given the high density contrast of a void to rock.

In sedimentary basins, density contrasts are between sediments and bedrock and are therefore lower. Correspondingly the smallest structures that can be resolved are larger. Examples of sedimentary basin topography mapping are numerous (Oldow \& Sprenke, 2006; Granser, 1987; Ibrahim \& Hinze, 1972), but most are on a scale of tens of kilometres. Few attempts have been made to map small, one kilometre scale sedimentary basins such as the Wellington Basin due to the high precision required. Fewer still have also been undertaken in an urban setting.

The closest recent analogue to this survey available in the literature is that of Dilalos et al. (2019) in the Athens basin, Greece. This basin is roughly $20 \mathrm{~km}$ across, an order of magnitude larger than the Wellington Basin at $\sim 1 \mathrm{~km}$. It is however a mostly urban area, and the study found gravity anomalies of similar magnitudes to those found here, requiring similar levels of precision.

\section{A Micro-Gravity Survey in Wellington City}

This project uses modern instruments to undertake a high precision gravity survey across the Wellington CBD. Victoria University of Wellington (VUW) purchased a Scintrex CG-6 gravity metre in 2018, which combined with high precision GPS, high resolution digital elevation models and existing boreholes, makes this project possible. Gravity anomalies an order of magnitude smaller than those measured in historic surveys, for example the New Zealand gravity map series (Reilly, 1972) can be measured, and observations are spaced as closely together as $25 \mathrm{~m}$. As a result, subsurface features as small as tens of metres in extent can be identified and modelled.

Only one micro-gravity survey has been undertaken across the whole of the Wellington CBD, that of Hatherton and Sibson (1969). Micro-gravity is a term used here to distinguish surveys that aim for this level of resolution from the larger scale surveys common in the 
past (for example Stern (1979)). This survey uses superior equipment to Hatherton and Sibson (1969) (Sections 1.4.1, 2.3.1), which results in greatly improved resolution, and makes possible detailed 3D modelling. A 3D model of the Wellington Basin has not been constructed from gravity data prior to this project.

\subsection{Objectives}

The project objectives are therefore as follows:

1. To undertake a high precision micro-gravity survey of the Wellington sedimentary basin, comprising $\sim 500$ new gravity measurements, with particular attention paid to the Aotea Fault location.

2. Generate a residual gravity anomaly map of the study area.

3. Using residual gravity anomalies, generate 2D geological models along profiles across the Wellington sedimentary basin.

4. Combine profile models with available constraints and interpretation to generate basement depth maps which can be used for earthquake shaking simulations. 


\subsection{Geological Setting}

\subsubsection{New Zealand}

New Zealand is the emergent part of a mostly submerged continent, Zealandia (Mortimer et al., 2017). The continent is tectonically active, sitting astride the Pacific-Australian plate boundary. Plate convergence is ongoing, with subduction of the Pacific Plate beneath the Australian Plate forming the Hikurangi Trough off the east coast of the North Island.

Convergence in this area is east-west, at a rate of $\sim 45 \mathrm{~mm} /$ year. Most of the convergence is accommodated on the subduction interface, while the right-lateral motion is mostly accommodated by the reverse/strike-slip North Island Shear Belt (Barnes et al., 2019) (Figure 1.5). Crustal shortening on this belt also uplifts the axial ranges of the North Island. Concurrent rotation of the North Island has resulted in rifting and the Taupo Volcanic Zone, a continental volcanic arc system responsible for the majority of New Zealand's volcanism (Walcott, 1987).

In the South Island, the plate boundary is obliquely convergent. Relative plate motion is $\sim 38 \mathrm{~mm} /$ year, of which $\sim 27 \mathrm{~mm} /$ year is horizontal displacement on the Alpine Fault, which over the last $\sim 25$ ma has resulted in a total dextral offset of $\sim 700 \mathrm{~km}$ (Lamb et al., 2015). Off the south coast of the South Island the subduction is reversed, with the Australian Plate subducting beneath the Pacific, forming the Puysegur Trench. Relative plate motion there is $\sim 37 \mathrm{~mm} /$ year, in a NE - SW direction (Edbrooke et al., 2017).

\subsubsection{Wellington Regional Tectonic Setting}

The Wellington region sits at the south-western end of the North Island Shear Belt. Numerous individual faults make up the shear belt, with the most significant in the region being the Wairarapa, Wellington, Ohariu, Shepherds Gully and Wairau Faults, all of which are active (Table 1.1) (Beanland, 1995).

The Wairarapa Fault is responsible for New Zealand's largest recorded earthquake in European times - the 1855 Wairarapa earthquake, estimated at $\mathrm{M}_{\mathrm{w}} 8.0-8.2$, producing $9-13 \mathrm{~m}$ of dextral coseismic offset and $0.5-2.7 \mathrm{~m}$ of vertical displacement, one of the largest coseismic offsets recognized in the world (Rodgers \& Little, 2006). While this was a major earthquake, the relatively low populations and preponderance of wooden housing meant casualties were low, between five to ten people (Grapes \& Downes, 1997). 


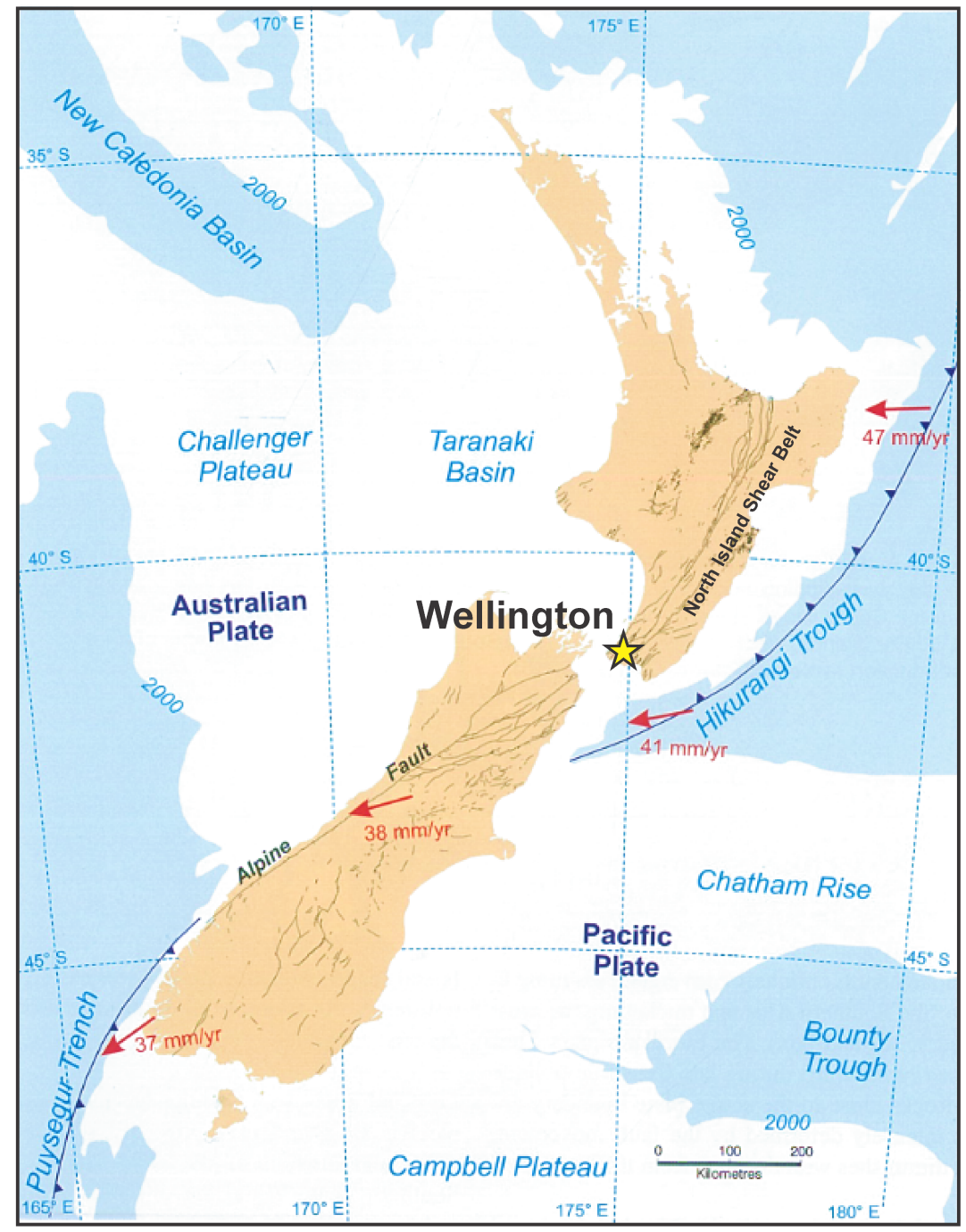

Figure 1.4: Regional setting of New Zealand, showing rates of relative tectonic plate motions (red) at the boundary. The $2000 \mathrm{~m}$ isobath shown roughly outlines the continent of Zealandia. From Edbrooke et al. (2017).

In the Wellington CBD the earthquake caused $\sim 1.5 \mathrm{~m}$ of uplift, exposing the intertidal wave-cut rock platform around the coastline. This made available valuable flat land for building and construction of coastal roads at the time (Ballance, 2017), but were the same earthquake to occur today, it would be catastrophic for the city.

The Wellington Fault has not produced any earthquakes during the European settlement period, but it has a lateral slip rate of $5.8 \pm 0.74 \mathrm{~mm} /$ year (Rhoades et al., 2011) and evidence of numerous past earthquakes, indicating that most of the movement probably occurs coseismically. The time of the most recent earthquake on the fault has been constrained to between $180-380$ years ago, and the recurrence interval has been calculated at $\sim 1,145$ years (Langridge et al., 2011), for earthquakes of $\mathrm{M}_{\mathrm{w}} 7.1-7.8$ (Berryman, 1990). Modelling places the probability of one of these earthquakes happening on the 
fault within the next 100 years at 11\%, making it the highest seismic risk to the city (Rhoades et al., 2011).

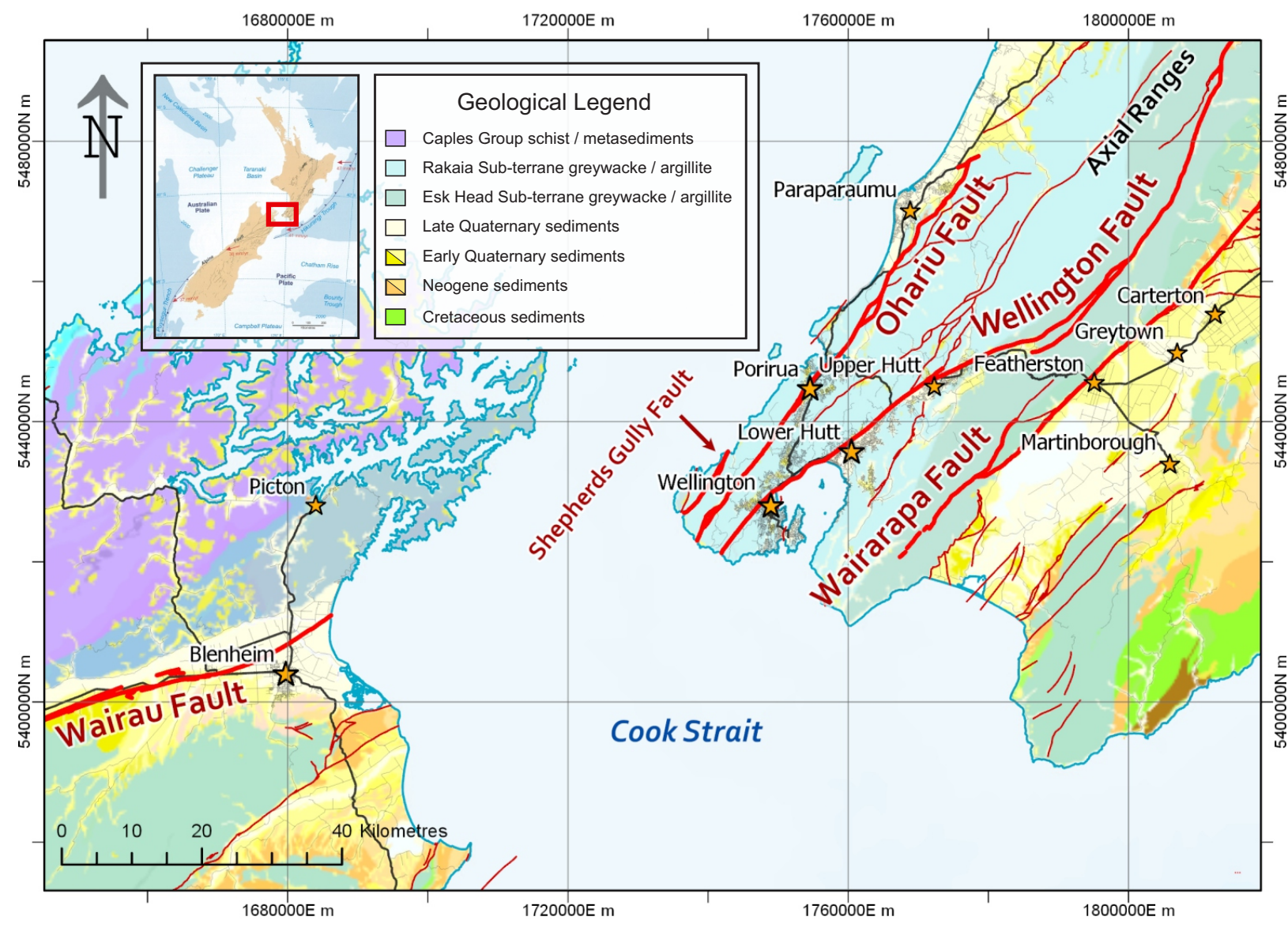

Figure 1.5: Wellington regional geology, from Begg and Johnston (2000). Fault traces from the Institute of Geological and Nuclear Sciences (GNS) active fault database (Langridge et al., 2016), with significant faults labelled.

\begin{tabular}{lll}
\hline Fault & Last earthquake (years B.P.) & Recurrence Interval (years) \\
\hline Wairarapa & 166 & $\sim 1,200$ \\
Wellington & $180-380$ & $\sim 1,100$ \\
Wairau & $\sim 2,000$ & $1,200-1,400$ \\
Ohariu & $1,050-1,100$ & $3,300-7,000$ \\
Shepherds Gully & $>1,200$ & $2,500-5,000$
\end{tabular}

Table 1.1: Major faults of the Wellington region, the time of their last known earthquake (years before present, 2021) and calculated recurrence interval. Data from Langridge et al. (2011), Rodgers and Little (2006), Zachariasen et al. (2006), Litchfield et al. (2004), and Van Dissen and Berryman (1996)

The Wairau, Ohariu and Shepherds Gully faults are all considered lesser but non-zero hazards due to their relatively long recurrence intervals. The Wairarapa Fault can also be considered a lesser hazard in the near term due to its recent large earthquake. The next greatest source of seismic hazard after the Wellington Fault is then a megathrust on the 
Hikurangi subduction interface (Stirling et al., 2002). Beneath Wellington this interface is strongly coupled (Wallace et al., 2004; Walcott, 1987), with an inference that strain is accumulating at a current rate of $20-25 \mathrm{~mm} /$ year (Wallace et al., 2012), which may be released periodically in large $\left(\mathrm{M}_{\mathrm{w}} 8.0+\right)$ thrust earthquakes (Wallace et al., 2009).

Finally there is risk from the Alpine Fault. The shaking induced in Wellington by a rupture on the Alpine Fault or the effect this would have on Wellington region faults is uncertain, but recent research has placed the probability of an Alpine Fault rupture within the next 50 years at $75 \%$, with an $82 \%$ chance of this being $\mathrm{M}_{\mathrm{w}} \geq 8.0$ (Howarth et al., 2021).

\subsubsection{Stratigraphy}

The Wellington region is comprised almost entirely of two rock types: basement greywacke and Quaternary sediments.

\section{Torlesse Terrane}

The Torlesse Terrane (also referred to as the Torlesse Composite Terrane or Torlesse Supergroup) is a large group of mostly Mesosoic aged sedimentary units which make up the "spine" of the country, comprising most of the Southern Alps from Otago to Marlborough, and the Tararuas and the Ruahines from Wellington to the Bay of Plenty (Edbrooke et al., 2017).

The Torlesse Terrane formed as a fold-thrust belt at a convergant margin, and has since been intensively deformed and folded (Suneson, 1993). It is dominated by greywacke, a highly indurated, usually medium grained, medium-grey, quartzo-feldspathic sandstone (Begg, 1996). Greywacke is often used more broadly in New Zealand to refer to the whole Torlesse Terrane, and the same is done in this thesis. The second most common rock type within the Torlesse Terrane is argillite, a highly indurated, dark grey to black mudstone, often laminated and occurring as thin interbeds within the greywacke (Begg, 1996). Greywacke forms the bedrock of the Wellington region (Figures 1.6, 1.7) (Begg, 1996).

\section{Quaternary Sediments}

Quaternary sediments rest unconformably on top of the Rakaia Subterrane in several distinct basins in the Wellington region. Sequences are often complex with thin individual 
beds, tending to be laterally discontinuous (Begg, 1996).

During the Pleistocene, sea level fluctuations meant Wellington Harbour was sometimes inundated during high sea levels, and became a lake or alluvial plain during sea level retreat (Begg \& Johnston, 2000). Pleistocene sediments in the Wellington Basin therefore range from colluvium and alluvium to marginal and shallow marine, with marine sediments less common. Former ground surfaces are marked by thin layers of peat or loess (Semmens, 2010), for example in Miramar (Begg et al., 1992).

Individual beds are usually a mix of gravel, sand and silt, with the ratios varying between beds. Generally Pleistocene sediments are denser than overlying Holocene sediments due to the depth of burial (Semmens, 2010).

During the higher sea levels of the Holocene, marine depositional settings are more common, but isolated alluvium and colluvium are still present, occupying former stream channels. Swamp deposits are present where the former Te Aro swamp extended from the Te Aro waterfront to the Basin Reserve (Semmens (2010), Figures 1.6, 1.7).

Anthropogenic reclamation sediments then overlie the Holocene sediments around the Wellington CBD waterfront, as described earlier in Section 1.1.2. 


\section{Example}

Depth $(m)$
Description

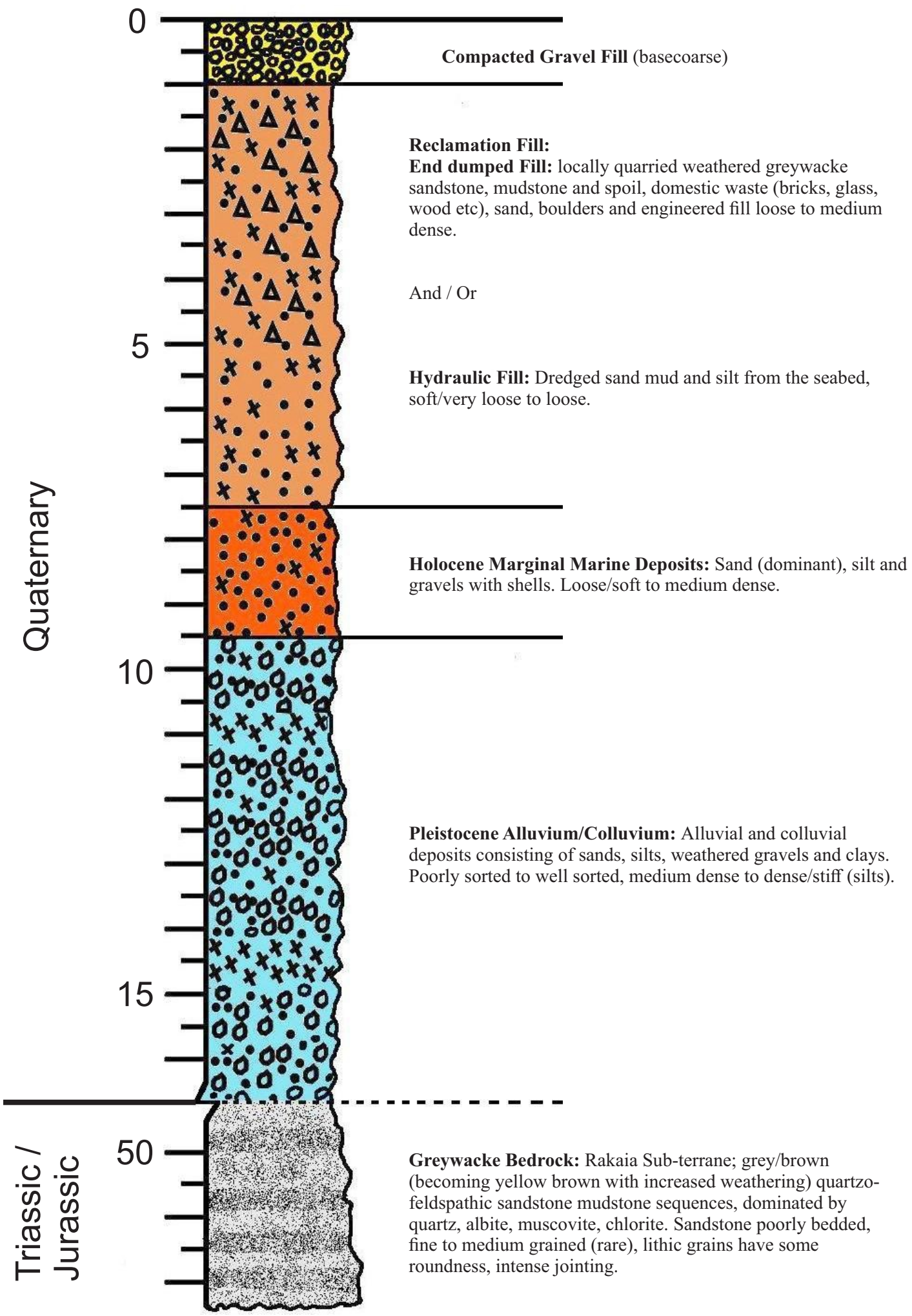

Figure 1.6: A generalized stratigraphic column for Wellington City, complied by Semmens (2010). Depths are examples only, and not all layers are present in all locations. 


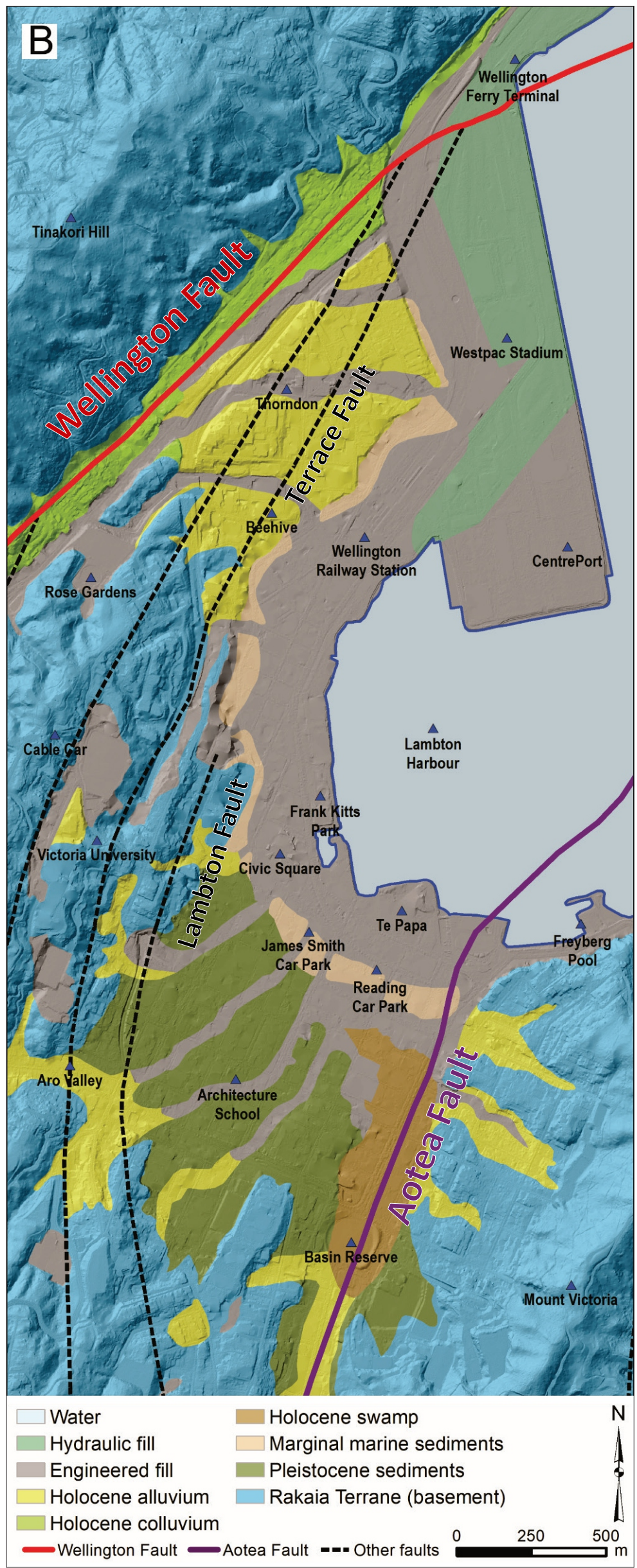

Figure 1.7: Surface geology map for Wellington City. Modified from Kaiser et al. (2019) and references therein. 


\subsubsection{Geomorphology}

The Torlesse Terrane rocks of the Wellington region were extensively eroded to a peneplain surface sometime between $4.0-0.4 \mathrm{Ma}$, by coastal or shallow marine processes. This surface is seen capping many of the hills around Wellington, particularly to the west of the Wellington Fault.

It was named the K-surface by Cotton (1957), due to its "key" nature in the landscape. Nowadays the $\mathrm{K}$ is also taken to refer to the type location for the surface, atop Mount Kaukau (Watson \& Norton, 2015). Its altitude ranges from 200 - 450 m, suggesting significant uplift since it was formed Semmens (2010). Uplift is also clearly observed and dated from raised beach terraces around the coast (Begg \& Johnston, 2000).

The general trend of the axial ranges is northeast - southwest, aligning with the faults of the North Island Shear Belt. The small sedimentary basins that exist within the ranges, including Wellington, result from pull apart movement on bends in the faults, as well as subsidence on the downthrown (usually eastern) side (Begg \& Johnston, 2000).

The ranges are exposed to the prevailing westerly weather from the Tasman Sea, resulting in high precipitation. Combined with high rates of uplift this causes rapid erosion and steep hillslopes. Tilting concurrent with uplift on these faults means the southeastern flanks of the hills are usually the steepest (Begg \& Johnston, 2000).

Consistently steep hillsides means landslides are common, and coseismic slip is a significant risk to infrastructure. The WCC (2019) report identifies several "road islands" that the region is likely to be split into in the event of a major earthquake, due to landslides breaking the narrow water, power, road and other infrastructure connections between them (Figure $1.8)$. 


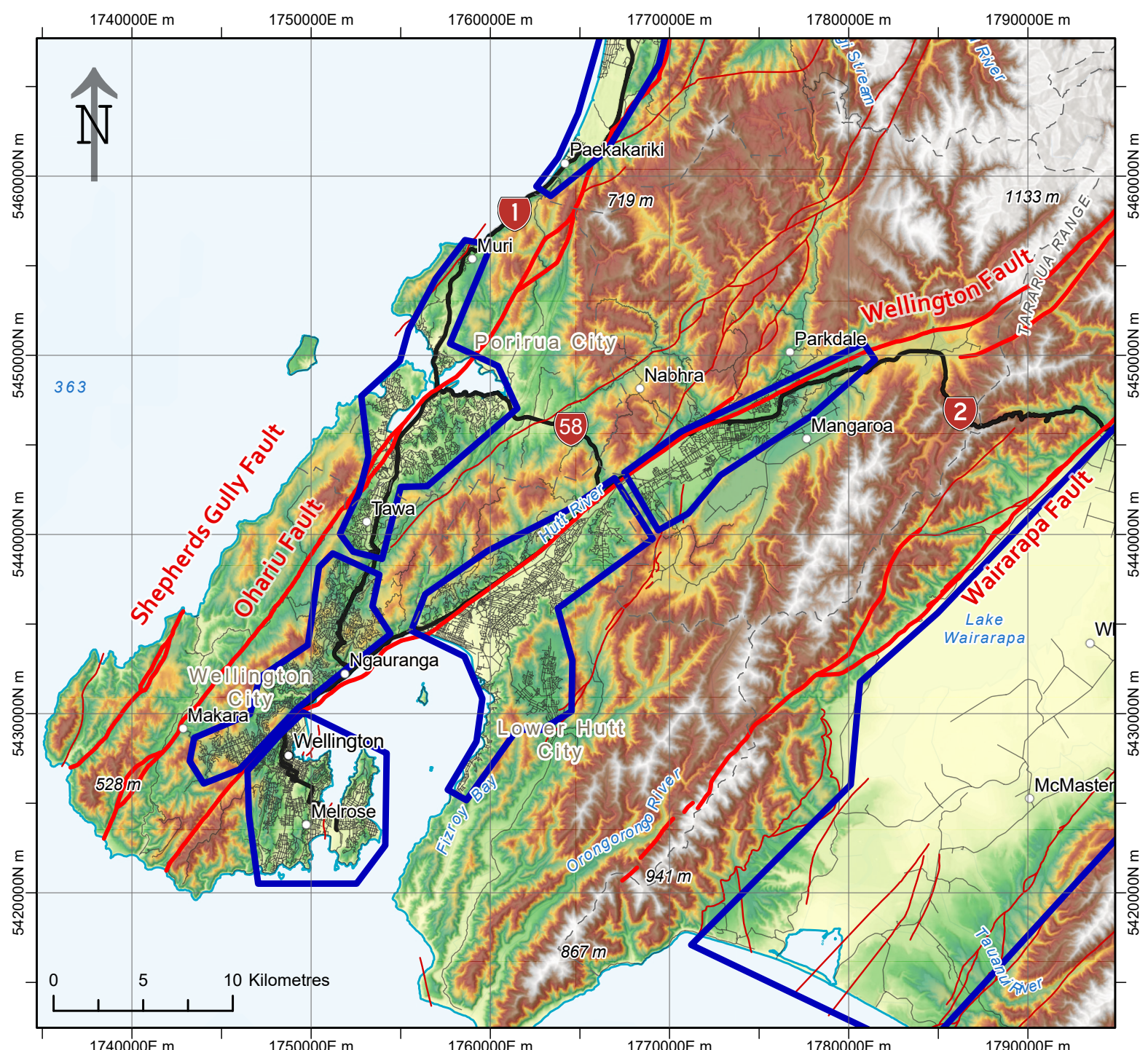

Figure 1.8: Elevation map of the Wellington region showing "road islands" (blue) that could be created in the event of a major earthquake. Major faults are in bright red, minor faults dark red. Roads are black. 


\subsection{Previous Studies}

This section details existing geophysical work done on basement depth in the Wellington CBD.

\subsubsection{Hatherton and Sibson, 1969}

The study of Hatherton and Sibson (1969) has remained to date the only micro-gravity survey undertaken across the whole Wellington CBD.

This survey comprises 445 gravity observations in total (Figure 1.9). Of these, 205 were existing observations made between 1948 and 1968, and an additional 240 were made by Hatherton and Sibson between 1968 and 1969 for the purposes of this survey. Approximately half of the observations were in this current project's study area of the CBD.

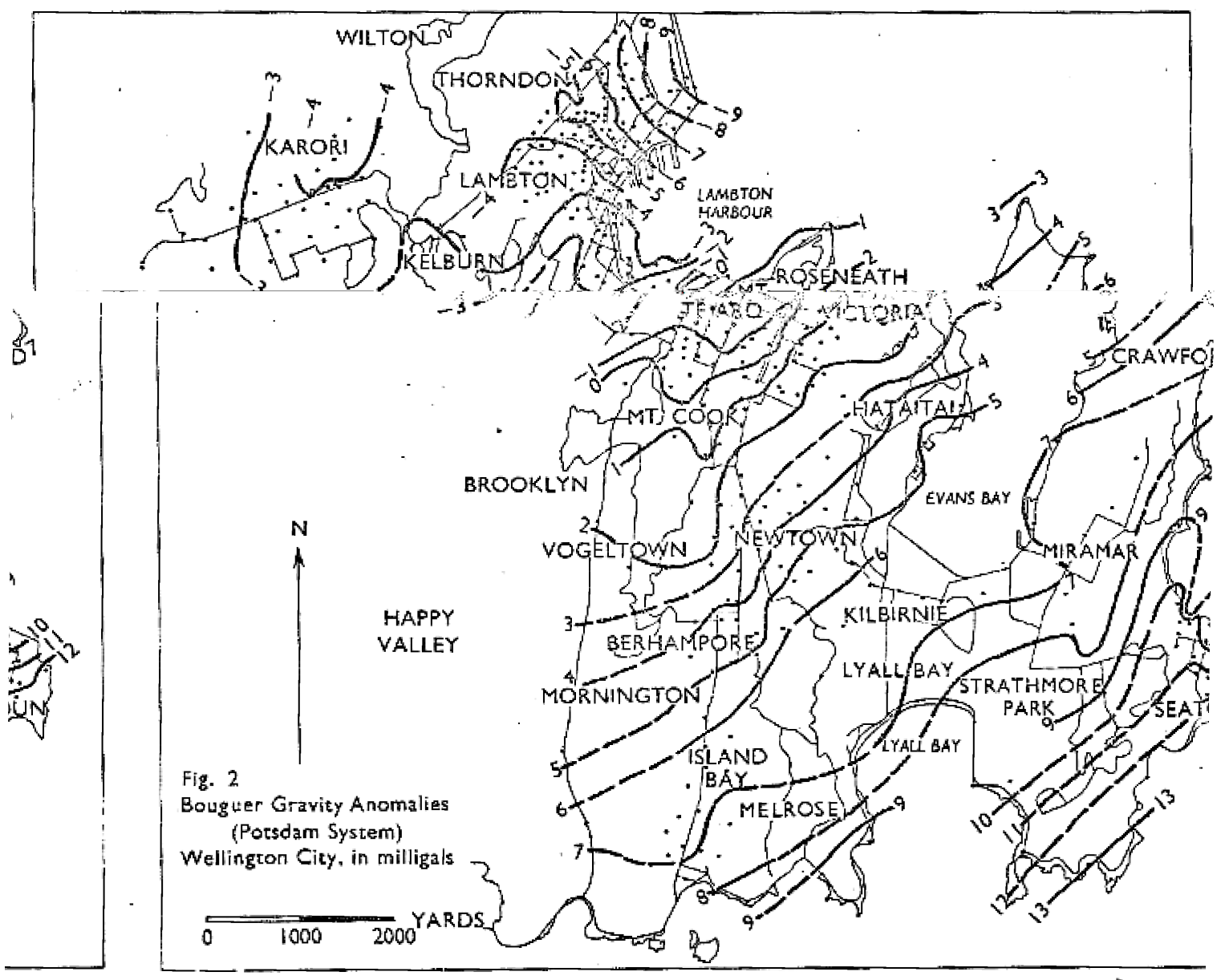

Figure 1.9: Bouguer gravity anomaly map across Wellington of Hatherton and Sibson (1969). Stations are black dots and anomaly contours are labelled in mGal.

The elevations of gravity stations were estimated from topographic maps. Accurate elevations are essential to account for the change in gravity with elevation. The authors give a 
height accuracy within Te Aro of 6 inches $(15.2 \mathrm{~cm})$ based on Motorway Maps, and state that elevations in Thorndon are more accurate than that, although do not give a value. Terrain corrections are calculated using a combination of field estimations as explained in Section 2.2.4, and a "GP092" computer program. The authors note that terrain corrections at the edges of the basin (which account for the gravitational effect of hills) are likely to be too low due to visual estimations.

The authors do not calculate uncertainties, but note that some idea of the uncertainty can be garnered from two observations in Te Aro $\sim 6 \mathrm{~m}$ apart which give a difference of $0.17 \mathrm{mGal}$ (the standard unit of gravity in geophysics, explained further in Section 2.1). Observations from Hatherton \& Sibson's survey are available, and a comparison is made between some of these with observations made in this project in Section 3.1.1. Significant variances are found in some cases, which can likely be ascribed to the less precise instruments and techniques used at the time. For this reason the Hatherton \& Sibson observations are not included in this project.

Figure 1.10 gives the resultant regional and residual gravity anomalies across the study area, which are also compared to results from this project in Section 3.2. 


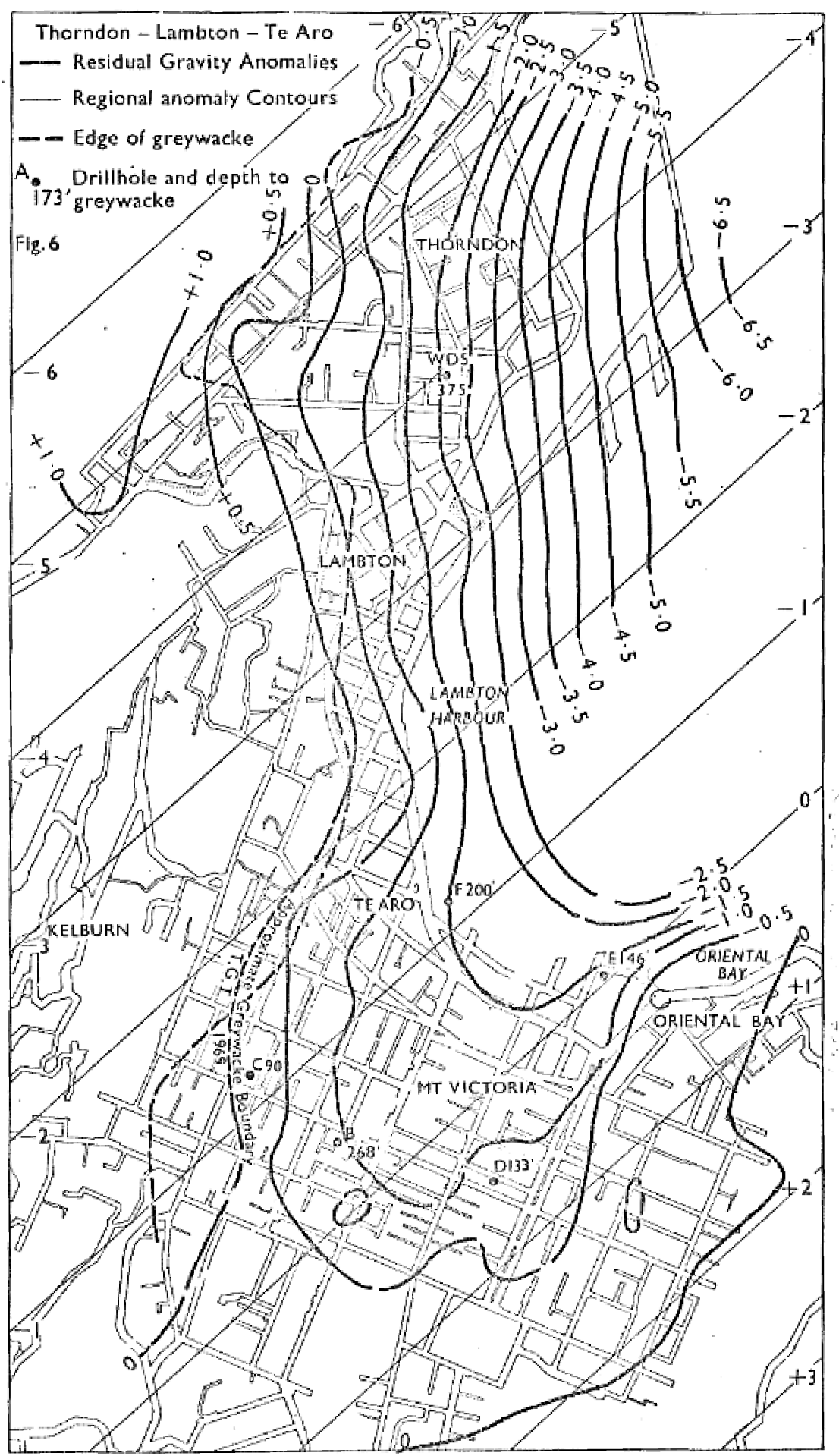

Figure 1.10: Regional and residual gravity anomaly map for the Wellington CBD of Hatherton and Sibson (1969). Adopted regional anomaly (mGal) in straight, light grey lines and residual anomaly (mGal) dark lines. 


\subsubsection{Cowan \& Hatherton, 1968}

Cowan and Hatherton (1968) published details of a larger survey the previous year, covering Thorndon, Wellington Harbour and the Hutt Valley (Figure 1.11). The Thorndon observations were presumably the same used in Hatherton and Sibson (1969), combined with marine observations and a number in the Hutt Valley. The anomaly map the authors publish for Thorndon (Figure 1.12) appears to show more detail in the contours, although this may be simply due to hand contouring. It also gives anomaly values nearly double those given in Hatherton and Sibson (1969). A different regional gradient appears to have been adopted, which likely explains the difference.

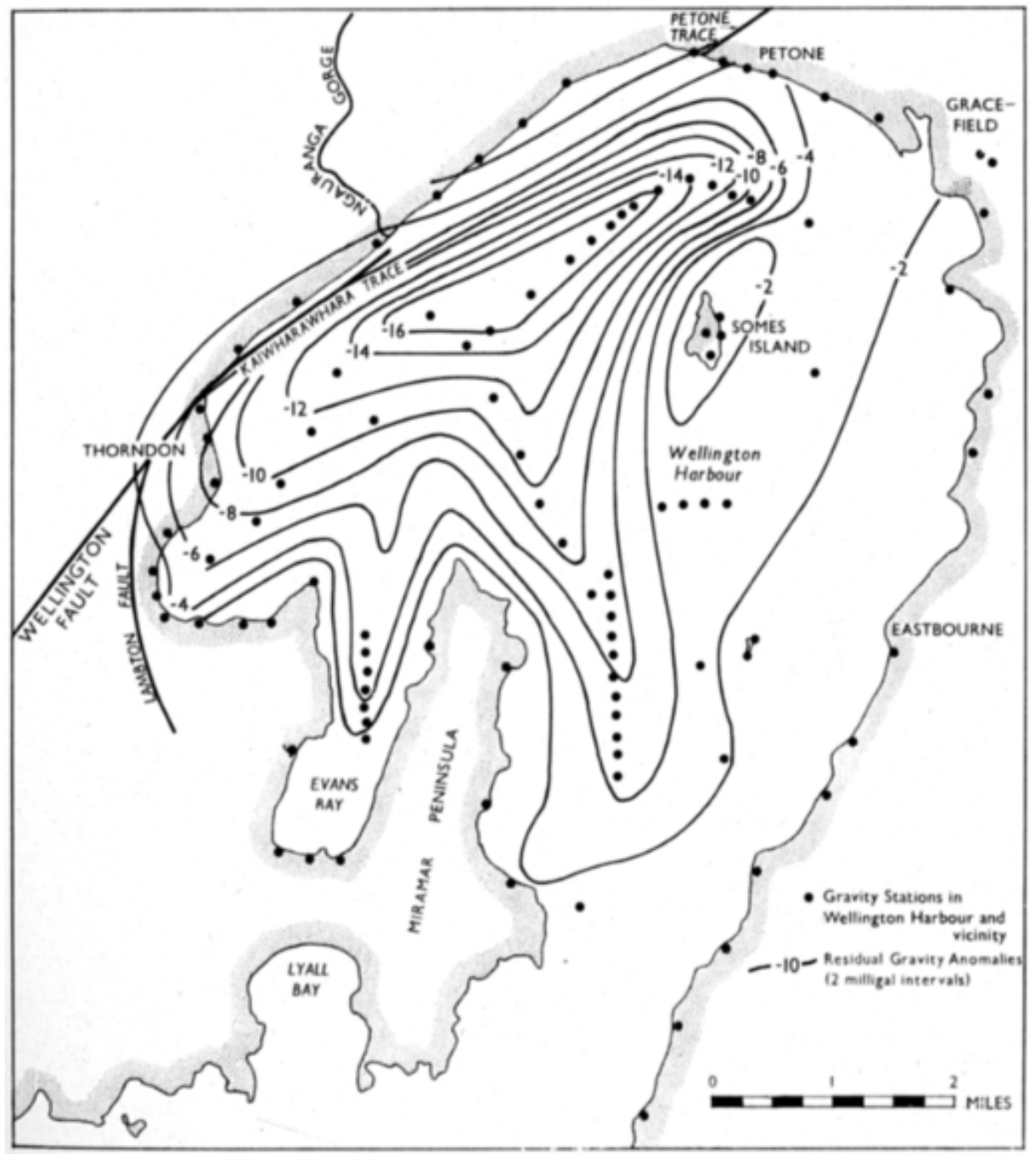

Figure 1.11: Wellington Harbour gravity anomaly map of Cowan and Hatherton (1968). Marine and shore stations are black dots, with land stations not shown. Anomaly contours in $\mathrm{mGal}$.

Cowan and Hatherton also give depths to basement in feet in Figure 1.12, estimated from forward modelling of the gravitational response of a basement interface which is flat to the 


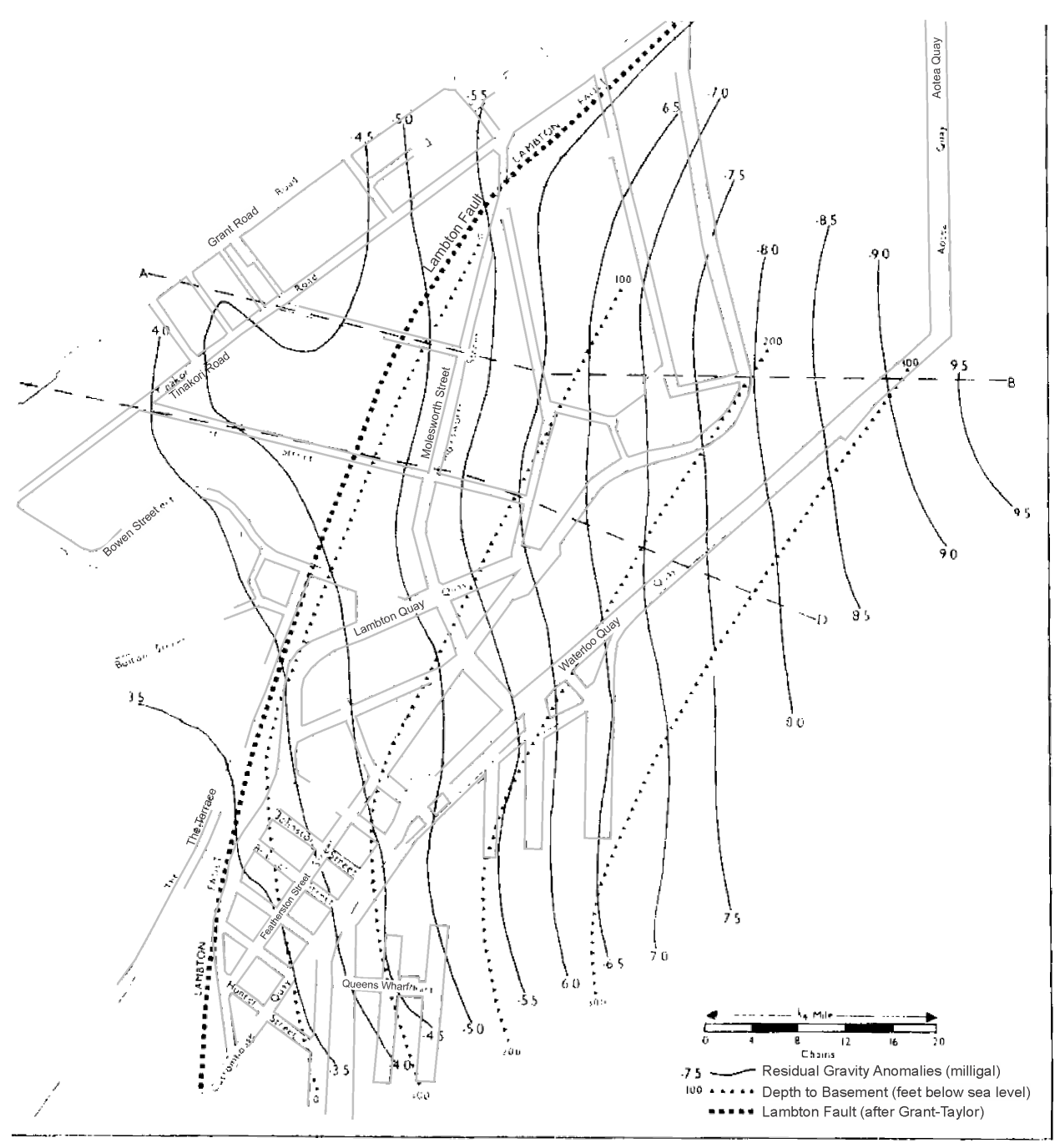

Figure 1.12: Thorndon residual gravity anomaly map from Cowan and Hatherton (1968), edited for clarity. Anomaly contours are labelled in mGal. Resultant estimate depth to basement contours are dotted lines, labelled in feet.

west of the Lambton Fault and shallowly dipping to the east of it, without any observable offset across it. They consider this to be the best fitting interpretation. The depth to the west is given as negligible, and the dip to the east is $7-8^{\circ}$, giving depths up to 300 feet (91 $\mathrm{m})$ at the foreshore. These are shallower depths than current estimates of up to $200 \mathrm{~m}$ (Kaiser et al., 2019; Semmens, 2010).

\subsubsection{Grant-Taylor et al., 1974}

Microzoning for Earthquake Effects in Wellington (Grant-Taylor et al., 1974) was a comprehensive engineering geological report for Wellington City. It included detail and maps on geology, soil dynamics, gravity and seismic surveys, expected amplification and fundamental periods and damage patterns from previous earthquakes. 
The basement depth map provided (Figure 1.14) was constructed from the gravity data presented in Hatherton and Sibson (1969) and borehole intersections, some of which were drilled for the Grant-Taylor et al. (1974) report. Maximum depth given in Te Aro was $\sim 70 \mathrm{~m}$, and in Thorndon $\sim 160 \mathrm{~m}$, significantly shallower than later estimates.

\subsubsection{Hochstein \& Davey, 1974}

Also published in 1974 were results from a seismic survey in the Wellington Harbour, by Hochstein and Davey (1974). This included an onshore-offshore seismic line at approximately the location of the Interislander Ferry Terminal, and some extrapolation of basin depth contours onshore in Pipitea (Figure 1.13). The survey did not resolve a vertical offset of the Wellington Fault at this location, but the authors did interpret a bedrock interface dipping at $\sim 40^{\circ}$.

They place the $300 \mathrm{~m}$ basin depth contour approximately $500 \mathrm{~m}$ offshore of the ferry terminal, and just onshore around the modern-day location of the Wellington Regional Stadium (referred to as "the stadium" in this thesis). This is $~ 150 \mathrm{~m}$ deeper than the map given in Grant-Taylor et al. (1974), and closer to modern day estimates (including those made in this study).

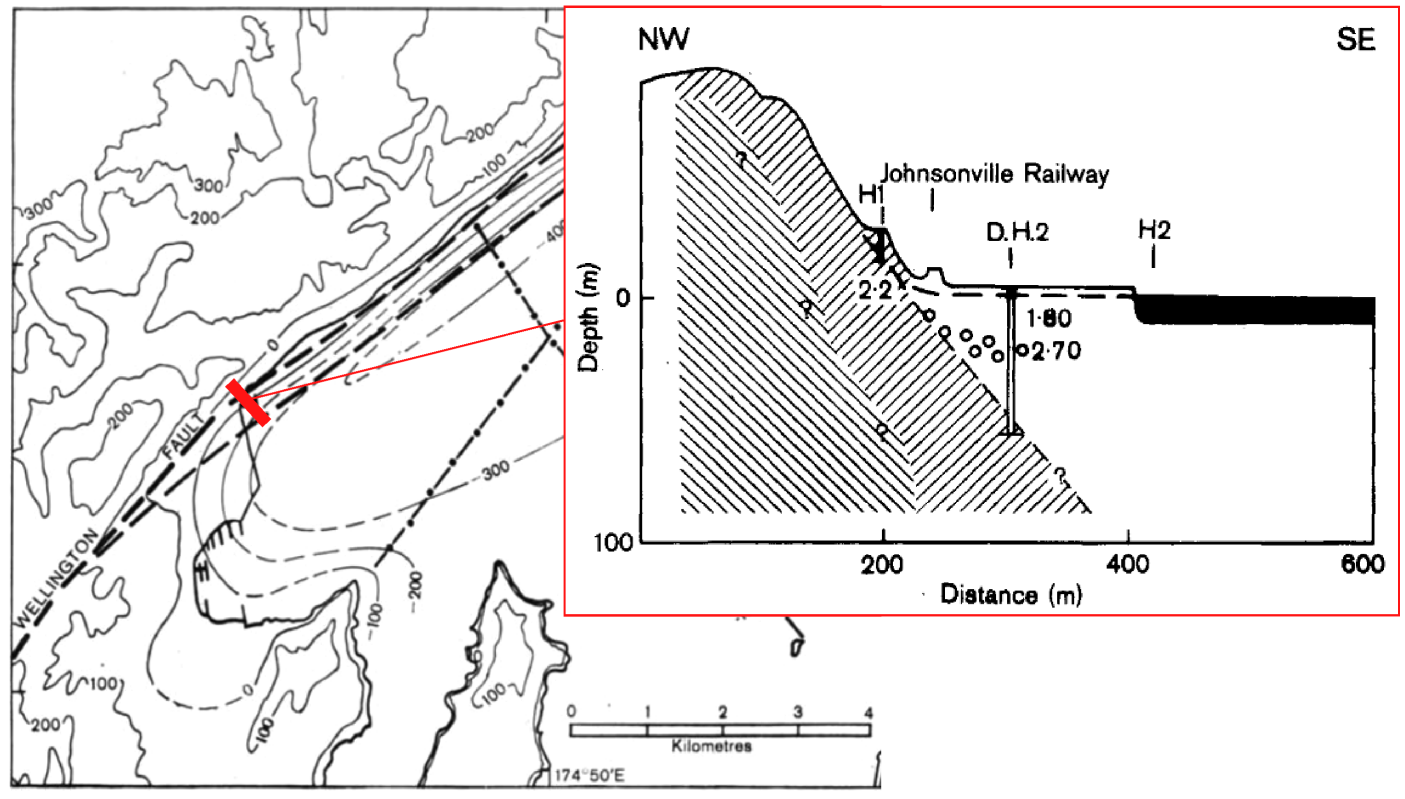

Figure 1.13: Basin depth map of Hochstein and Davey (1974), with the interpreted crosssection of their Thorndon seismic line (red). 


\subsubsection{Semmens, 2010}

The engineering geology Master's of Science thesis of Semmens (2010) included a greatly improved bedrock depth map, incorporating many more data than were available to GrantTaylor et al. (1974). Also published in this thesis were site class, site period, $v_{s} 30$ (the average shear wave velocity to $30 \mathrm{~m}$ depth, a commonly used geotechnical parameter), site amplification and liquefaction potential maps. The site class and site period maps are used routinely by engineering firms to determine building code requirements for individual sites.

Semmens' basement depth map was created primarily from a database of 1025 boreholes, test pits and site observations, and 12 passive seismic tests. Of the boreholes, 366 hit bedrock, although the vast majority of these are shallow. Only five boreholes intersect basement at greater than $100 \mathrm{~m}$. Where borehole data are not present, basement depths are interpolated or extrapolated best guesses based on surrounding basement topography or the estimated locations of buried stream channels, based on historical maps of stream locations which have now been diverted or buried.

The basement depth map is shown in Figure 1.14. Notable points are that the Aotea Fault is absent (having been identified in 2018 by Barnes et al. (2019)) and that depths are mostly greater than those of Grant-Taylor et al. (1974). In Te Aro the basement shape is broadly similar, but in east Thorndon a flat area is posited, possibly a buried shelf, and the basement is then shown dipping steeply away towards the centre of the harbour instead of flattening out as in Grant-Taylor et al. (1974). The maximum depth is $310 \mathrm{~m}$ at the north end of CentrePort. 


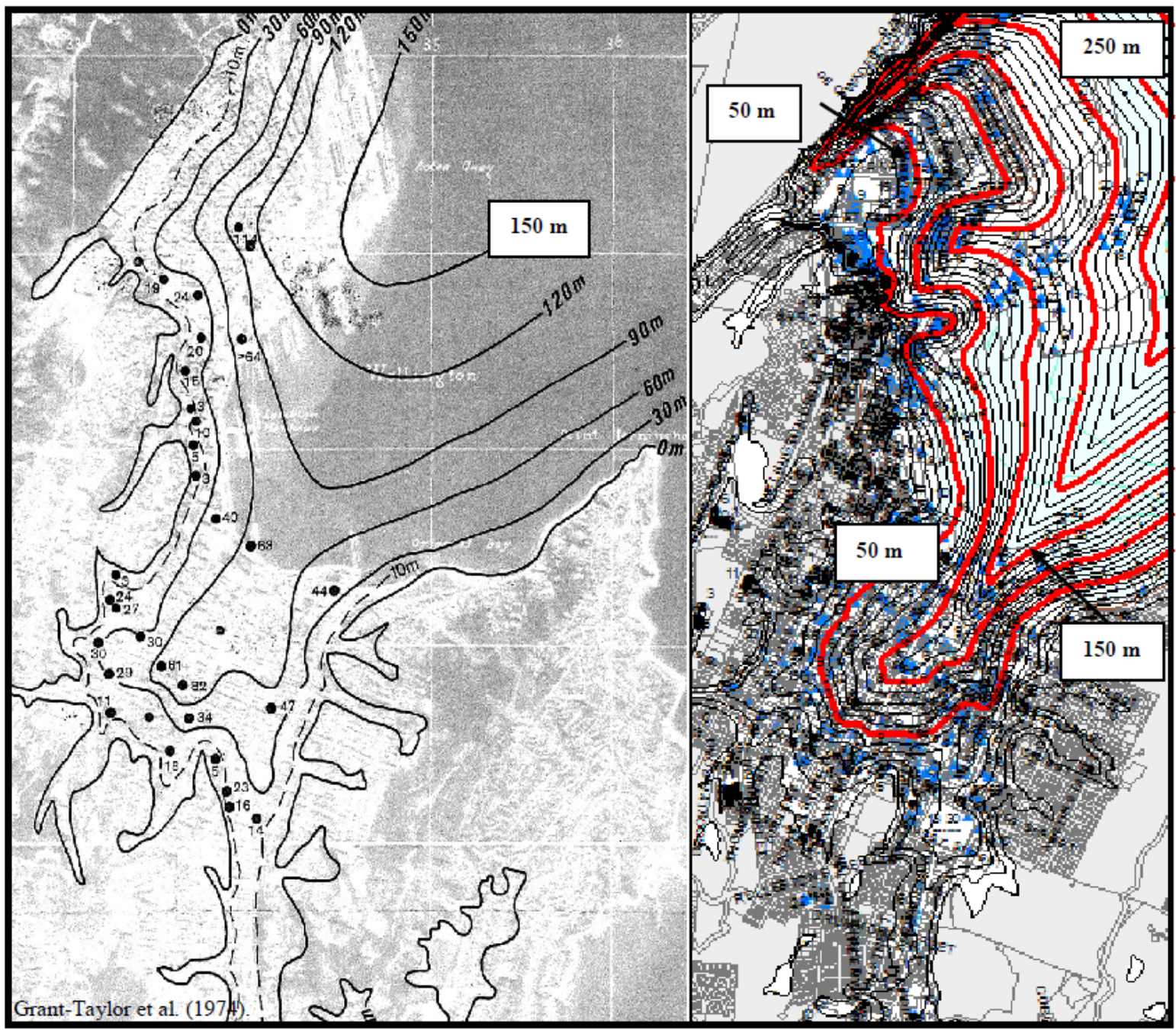

Figure 1.14: Left: Basement depth map of Grant-Taylor et al. (1974). Right: Basement depth map of Semmens (2010), with 50 m contours highlighted in red. Note greater depths given by Semmens across most of the city.

\subsubsection{Vantassal et al., 2018}

In response to the 2016 Kaikōura earthquake and associated damage at CentrePort, Vantassel et al. (2018) mapped depth to bedrock, shear wave velocity and site period across the port, using Horizontal to Vertical Spectral Ratio (HVSR) measurements and both active and passive surface wave analysis.

Interpreted depths are significantly shallower than Semmens (2010), with the exception of the central point, with a "hard rock" depth of $392 \mathrm{~m}$ (Figure 1.15). The Vantassel et al. depths are not used as constraints in this project due to their interpretive nature. 


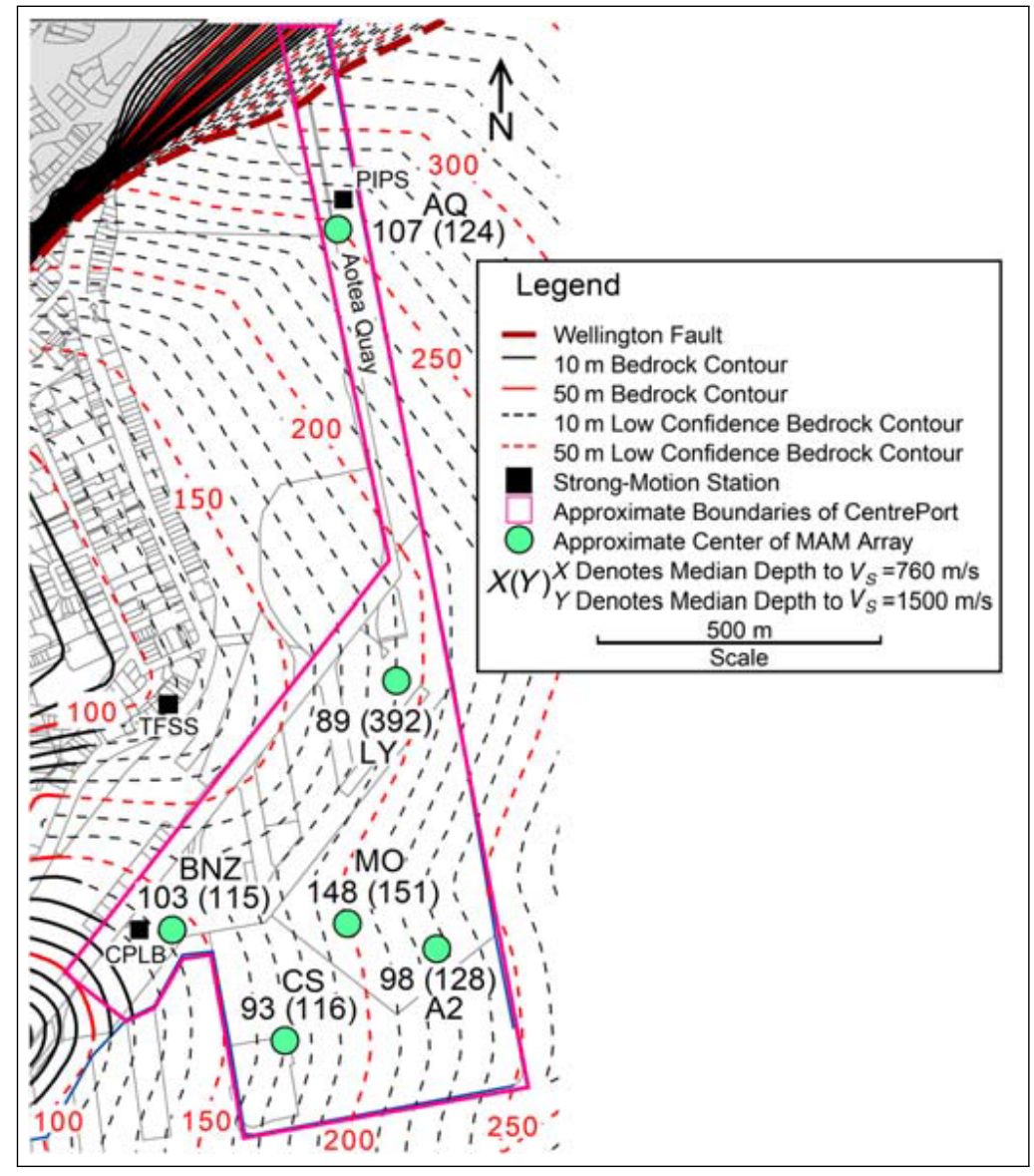

Figure 1.15: Depths to "soft" and "hard" rock at seismic sites marked by green circles, as interpreted by Vantassel et al. (2018). Basement depth contours of Semmens (2010) shown for comparison.

\subsubsection{Kaiser et al., 2019}

Kaiser et al. (2019) was the next major update of basement depths for all of Wellington City, as well as the geotechnical parameters of site period and site class. This work built on that of Semmens (2010), adding 700+ additional borehole logs and numerous SPT (Standard Penetrometer Test) and HVSR measurements. A new 3D geological and velocity model for the area was developed in Seequent Leapfrog Geo, a geological modelling package. This new model incorporates the Aotea Fault and extends the mapped area slightly to the north and south.

The Kaiser et al. (2019) basement depth map is shown in Figure 1.16. The Aotea Fault is now included in the Te Aro basin area, which is mapped as wider and steeper sided. Thorndon is the main area of change, with significantly shallower depths at the north and south ends of CentrePort $(\sim 100 \mathrm{~m}$ cf. $\sim 250 \mathrm{~m})$, in line with the data of Vantassel et al. (2018). This makes the area of greatest depth approximately the location of the stadium, at $210 \mathrm{~m}$. 
Extensive use has been made of depth interpretations from HVSR measurements in CentrePort, as deep boreholes are not present. The authors note that rapidly changing basement topography and proximity to the steep Wellington and Aotea faults introduce complex 2D and 3D effects to the HVSR measurements, making depth estimates less reliable in such areas. 


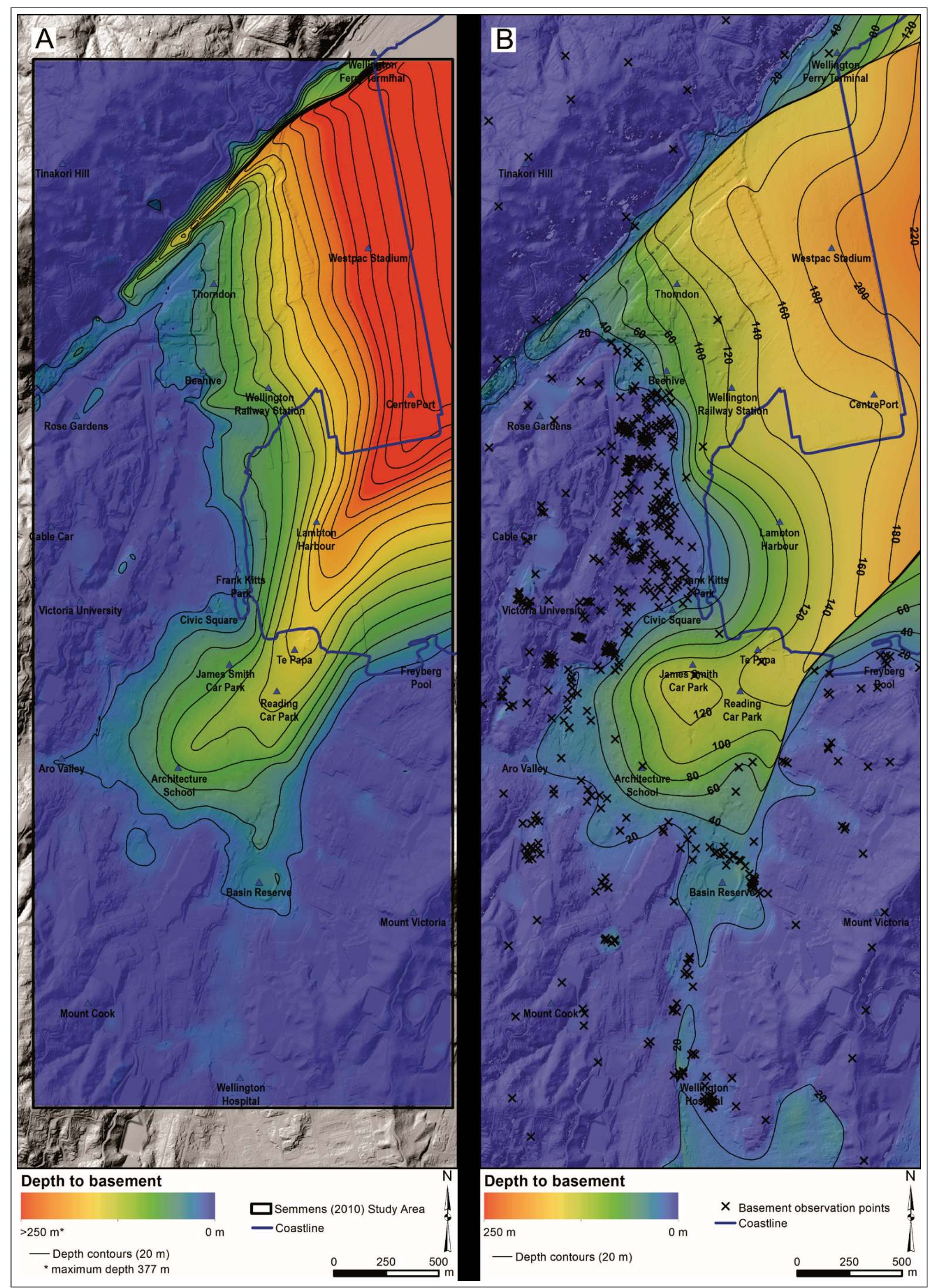

Figure 1.16: A) A Leapfrog 3D model of Semmens (2010) basement depths. B) Modelled basement depth from Kaiser et al. (2019). 


\subsection{Available Constraints}

In modelling gravity anomalies, as with other potential field anomalies, constraints are essential. This is because modelled solutions to an anomaly are always non-unique. This means that a theoretically infinite series of models can produce the exact same anomaly. In the case of gravity this can be visualized by considering that a sphere of constant mass will always produce the same anomaly, even as its radius and density are varied (Keary \& Brooks, 1992).

This is the inverse problem of potential field modelling, so called because the modeller is working backwards - first measuring the anomaly generated by a given model (the Earth) and then attempting to recreate the model that caused it. Sufficient constraints allow the possible model range to be greatly refined.

\subsubsection{Density}

Gravity anomalies are produced by a contrast in density between different rock types. The effective basement rock of this part of New Zealand is Mesozoic greywacke, which has a remarkably consistent particle density of $2.67 \pm 0.4 \mathrm{Mg} / \mathrm{m}^{3}$ (Hatherton \& Leopard, 1964). This value is extremely well defined as the average for crustal rocks worldwide (Hinze, 2003). While $\mathrm{Mg} / \mathrm{m}^{3}$ is not strictly an S.I. unit, it is convenient for and commonly used in gravimetry and discussions of rock density, so the same is done in this thesis.

In contrast with greywacke, the density of New Zealand sediments is variable (Hatherton \& Leopard, 1964), with the density of young sedimentary rocks usually falling within the range of $1.5-2.5 \mathrm{mg} / \mathrm{m}^{3}$ (Mussett et al., 2000). However a particular unit or rock type can vary significantly in density within this range, according to a number of factors. The primary control is compaction due to depth of burial and an associated decrease in the percentage volume of voids within the rock.

The sediments of the Wellington Basin have therefore been grouped into four units which are based on a combination of geotechnical parameters and depth of burial, following the same scheme as used in the Kaiser et al. (2019) Leapfrog model. The units are anthropogenic fill, near surface sediments, buried sediments and deeply buried sediments. For each unit an average in-situ density was estimated using three different methods - the Standard Penetration Test (SPT), downhole shearwave velocity $\left(v_{s}\right)$ and direct density 
measurements. These methods are elaborated on in Appendix (A.0.1).

These data for the three density estimation methods are summarized in Table 1.2. For simplicity the final values chosen for the units are rounded to the nearest 0.05 and therefore are, in order, 1.9, 2.0, 2.1 and $2.25 \mathrm{mg} / \mathrm{m}^{3}$.

\begin{tabular}{|c|c|c|c|c|c|c|c|c|c|c|c|c|c|c|}
\hline \multicolumn{2}{|c|}{ Data source: } & \multicolumn{13}{|c|}{ Boreholes } \\
\hline & & & & & & & & & & & & & & Calculated \\
\hline & & & 1 & 2 & 3 & 4 & 5 & 6 & 7 & 8 & 9 & 10 & & $\left(\mathrm{Mg} / \mathrm{m}^{3}\right)$ \\
\hline \multirow{8}{*}{ 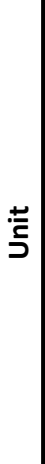 } & Fill & SPT N-Value & & 10 & 17 & & 17 & & 22 & 12 & 5 & & 14 & 1.84 \\
\hline & & $\mathrm{V}_{\mathrm{s}}(\mathrm{m} / \mathrm{s})$ & 210 & & & 163 & 328 & & & & & 192 & 223 & 1.88 \\
\hline & c. & SPT N-Value & 33 & 19 & 32 & 26 & 26 & 39 & 25 & 26 & 33 & & 29 & 1.96 \\
\hline & & $V_{s}(m / s)$ & 270 & & & 303 & 249 & & & & & 326 & 287 & 1.95 \\
\hline & Durind & SPT N-Value & 40 & 44 & 100 & 44 & 45 & 97 & 43 & 38 & 67 & & 58 & 2.07 \\
\hline & & $V_{s}(m / s)$ & 441 & & & 405 & 392 & & & & & 491 & 432 & 2.09 \\
\hline & Deeply & SPT N-Value & & & & 50 & 50 & & & & 96 & & 65 & 2.17 \\
\hline & Buried & $V_{s}(m / s)$ & 648 & & & 688 & 619 & & & & & 606 & 640 & 2.22 \\
\hline
\end{tabular}

\begin{tabular}{|c|c|c|c|c|c|c|c|c|}
\hline \multicolumn{2}{|c|}{ Data source: } & \multicolumn{2}{|c|}{ Petlab } & \multicolumn{2}{|c|}{ Semmens } & \multicolumn{2}{|c|}{ Hatherton \& Sibson } & \multirow[b]{2}{*}{$\begin{array}{l}\text { Weighted Average } \\
\text { Density }\left(\mathrm{Mg} / \mathrm{m}^{3}\right)\end{array}$} \\
\hline & & $\begin{array}{l}\text { Average } \\
\text { Density } \\
\left(\mathrm{Mg} / \mathrm{m}^{3}\right)\end{array}$ & $\begin{array}{c}\# \\
\text { Observations }\end{array}$ & $\begin{array}{c}\text { Average } \\
\text { Density } \\
\left(\mathrm{Mg} / \mathrm{m}^{3}\right)\end{array}$ & $\begin{array}{c}\# \\
\text { Observations }\end{array}$ & $\begin{array}{c}\text { Average } \\
\text { Density } \\
\left(\mathrm{Mg} / \mathrm{m}^{3}\right) \\
\end{array}$ & $\begin{array}{c}\text { \# } \\
\text { Observations }\end{array}$ & \\
\hline \multirow{4}{*}{ 蒙 } & Fill & & 0 & 2.02 & 25 & 0.00 & 0 & 1.91 \\
\hline & Surface & 1.96 & 11 & 2.07 & 251 & 2.03 & 11 & 2.01 \\
\hline & Buried & 2.13 & 17 & 2.07 & 436 & 2.12 & 16 & 2.08 \\
\hline & $\begin{array}{l}\text { Deeply } \\
\text { Buried }\end{array}$ & 2.09 & 12 & 0.00 & 0 & 2.36 & 3 & 2.25 \\
\hline
\end{tabular}

Table 1.2: Table of data used for density estimations of each unit. Top: average SPT N values and $v_{s}$ measurements across each unit for ten boreholes. From these are calculated densities using empirical relationships (Appendix A.0.1). Bottom: average measurements from Petlab, Semmens (2010) and Hatherton and Sibson (1969) for each unit, and then the weighted average of all data for each unit. Weighting has been split evenly between calculated and direct measurements.

\subsubsection{Boreholes}

The most direct constraint is boreholes. There are over 1500, mostly geotechnical, boreholes which have been drilled in the Wellington CBD. For this project a database of 1124 boreholes was obtained from GNS. Most of these are derived from the New Zealand 
Geotechnical Database (NZGD; https://www.nzgd.org.nz), a public database of geotechnical information maintained by MBIE. The remainder are from private engineering firms, and licensed for use in this project under the condition that information about specific holes is not shared. For this reason some boreholes which are included in modelling are not displayed on maps.

Of these 1124 boreholes, 247 hit basement. Of these, most are less than $15 \mathrm{~m}$ deep. Only 15 holes intersect basement below $50 \mathrm{~m}$, and six below $100 \mathrm{~m}$ (Figure 1.17). Given that depth to basement is over $50 \mathrm{~m}$ in most of the CBD, this speaks to the lack of data in key areas and the importance of the current project. Where boreholes do hit basement they provide a valuable spatial constraint at that point. In some cases a deep borehole does not hit basement, and this also provides a minimum basement depth.

\subsubsection{Leapfrog Model}

For each profile, a cross-section of version 4 of the GNS Leapfrog model of Wellington City geology as at March 2021 (Hill et al., 2020) has been extracted. This model is live and constantly maintained by GNS, so these sections may not be identical to those published in Hill et al. (2020).

This model is the current version of that presented in Kaiser et al. (2019). Depth comparisons in 3D are made with Kaiser et al. (2019), while in 2D they are made with Hill et al. (2020). On the larger city scale of the 3D basin depth maps, differences between the two models are expected to be minor. 


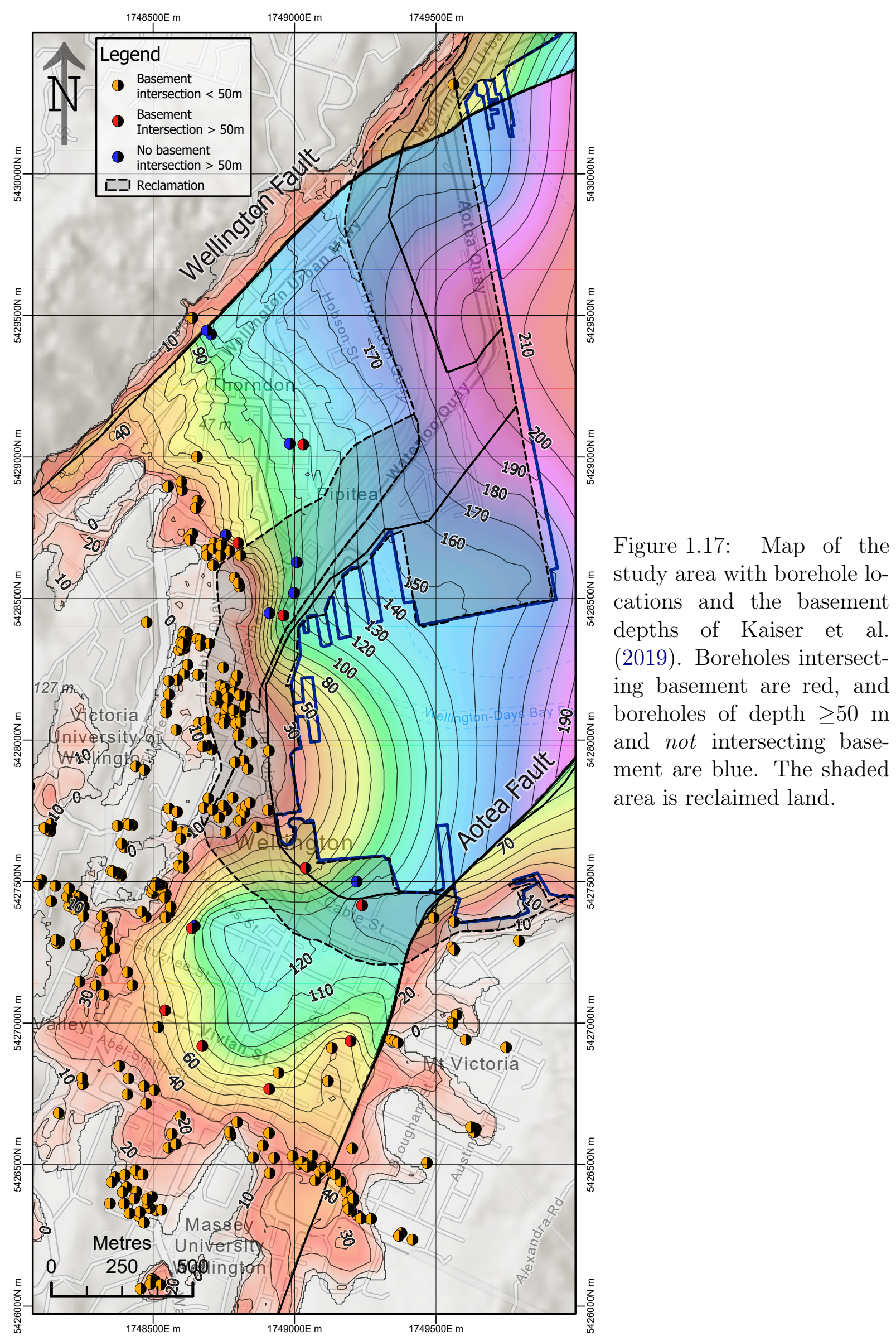




\section{Chapter 2}

\section{Methods}

\subsection{Gravity Theory}

\subsubsection{Newton's Law of Gravitation}

Newton's law of universal gravitation states that any two objects exert an attractive force $(F)$ on one another, proportional to the product of the two masses $\left(m_{1}\right.$ and $\left.m_{2}\right)$ and inversely proportional to the square of the distance between them $\left(r^{2}\right)$. This is expressed in equation 2.1 (Fowler et al., 1990):

$$
F_{g}=G \frac{m_{1} m_{2}}{r^{2}}
$$

Where $G$ is Newton's Gravitational Constant, equal to $6.674 \times 10^{-11}{ }^{3} \mathrm{~kg}^{-1} \mathrm{~s}^{-2}$.

This can be equated with Newton's second law of motion:

$$
F=m a
$$

To find the acceleration $(g)$ due to the force of gravity (Lowrie, 2007):

$$
\begin{gathered}
F=m a=m g=G \frac{m_{1} m_{2}}{r^{2}} \\
g=G \frac{M_{e}}{R_{e}^{2}}
\end{gathered}
$$




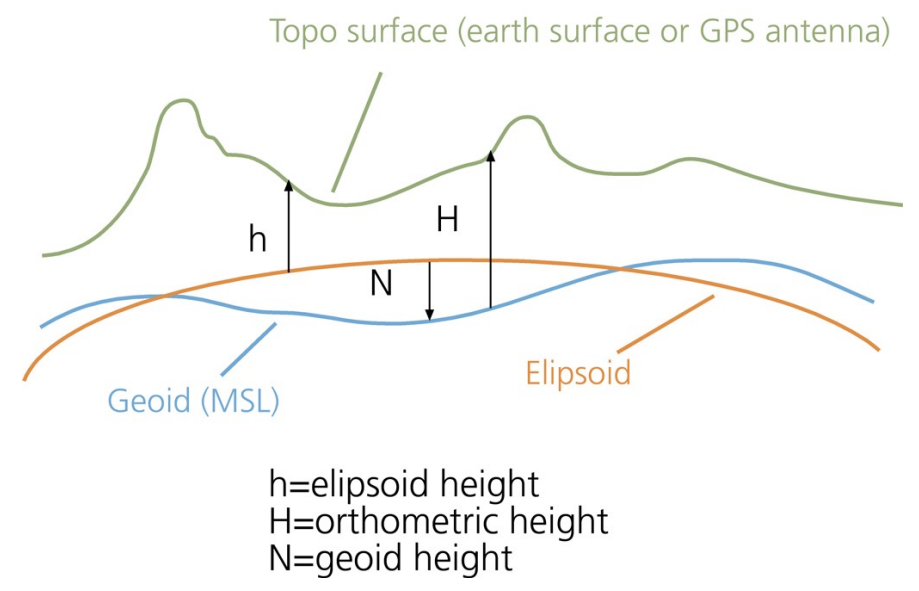

Figure 2.1: A comparison of topography (green), the reference ellipsoid (orange) and the geoid (blue). Orthometric height $(\mathrm{H})$, used in this survey, is the height of topography above or below the geoid. From Fraczek (2003).

As the mass of the object $m$ cancels out, the acceleration due to gravity is dependent only on the mass $M_{e}$ and radius of the Earth $R_{e}$. The S.I. units of acceleration are $\mathrm{m} / \mathrm{s}^{2}$, but the unit usually used in gravimetry is the Galileo, or Gal, and the milliGalileo, or mGal (Lowrie, 2007). One Gal is defined as $1 \mathrm{~cm} / \mathrm{s}^{2}$. As an example, the commonly used value for the acceleration due to Earth's gravity of $9.81 \mathrm{~m} / \mathrm{s}^{2}$ is therefore equivalent to 981 Gals.

\subsubsection{The Geoid}

As distribution of mass within the Earth is uneven, so is the force of gravity as measured at the Earth's surface. The gravity method aims to determine the most likely distribution of mass which would cause the measured strength of gravity.

This variation in gravity is partially represented by the geoid, which is the imaginary surface at which sea level would sit all over the Earth if the land were removed, and without the effects of tides, currents and wind. This is in contrast to the sphereoid, or reference ellipsoid, which is a mathematical ellipsoid which best fits the shape of the Earth. The difference between the geoid and the sphereoid is up to $107 \mathrm{~m}$ (in the Indian Ocean, the largest geoid "low") (Li \& Götze, 2001), and varies with latitude and longitude (Fowler et al., 1990).

In gravity surveys, elevations are those measured in relation to the geoid, (termed the orthometric height) and are roughly equivalent to elevation above sea level (Figure 2.1). 


\subsection{Calculating Expected Gravity}

A gravity anomaly is found by comparing calculated expected gravity with observed gravity at a particular location. This section details the process for calculating an expected value of gravity.

\subsubsection{Variation of Gravity with Latitude}

Gravity varies with latitude due to the equatorial bulge and rotation of the Earth. The former increases the effective radius of the Earth at the equator, and the latter introduces a centripetal acceleration acting in opposition to that of gravity which is latitude dependent - at its maximum at the equator, and zero at the poles (Lowrie, 2007).

Three empirical equations have been developed to approximate expected gravity on the reference ellipsoid at a given latitude. The first is known as the 1930 International Gravity Formula, adopted at the General Assembly of the International Union of Geodesy and Geophysics (IUGG) in Stockholm in 1930 (Li \& Götze, 2001):

$$
g_{1930}=978049\left(1+0.0052884 \sin ^{2}(\Phi)-0.0000059 \sin ^{2}(2 \Phi)\right)
$$

Where $\Phi$ is latitude of a site in degrees. This is in relation to a reference station in Potsdam, Germany, and to the International 1924 Ellipsoid. During the 1960s a campaign of more accurate global gravity measurements resulted in the International Gravity Standardization Net 1971 (IGSN71), which replaced Potsdam as the reference and is still in use today. In conjunction with this the Geodetic Reference System 1967 ellipsoid (GRS67) and the 1967 International Gravity Formula were developed (Li \& Götze, 2001):

$$
g_{1967}=978031.846\left(1+0.005278895 \sin ^{2}(\Phi)+0.000023462 \sin ^{4}(\Phi)\right)
$$

The next and currently used formula exists due to an improvement to the reference ellipsoid, to the Geodetic Reference System 1980 (GRS80). The accompanying International Gravity Formula was published in 1980 by Moritz (1984):

$$
g_{1980}=978032.7\left(1+0.0053024 \sin ^{2}(\Phi)-0.0000058 \sin ^{2}(2 \Phi)\right)
$$


This gives values $~ 10.3 \mathrm{mGal}$ greater than the 1930 formula at Wellington's latitude. In gravity surveys and in this study the 1980 International Gravity Formula gives the first approximation for expected gravity at a gravity station.

\subsubsection{Free Air Correction}

The first correction to this value is the free air correction. This accounts for the change of gravity with elevation, i.e. change with $R_{e}$ in equation 2.4. The free air correction is usually defined as (Lowrie, 2007):

$$
g_{f a}=-0.3086 h
$$

Where $h$ is the height above the geoid and the units of $g_{f a}$ are mGal. This means gravity decreases with increasing elevation, at a rate of $\sim 0.3 \mathrm{mGal} / \mathrm{m}$.

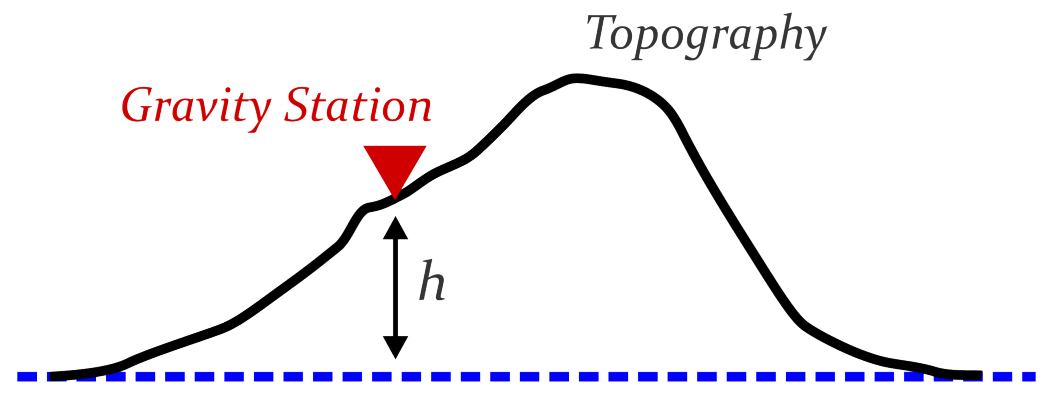

Geoid

Figure 2.2: The free air correction, applied to correct for the elevation $h$ of a gravity station (red) above the geoid (blue).

This is an approximation derived from the first derivative of equation 2.4 with respect to radius $R_{\mathrm{e}}$, using average values for gravity and radius. In reality the gravity gradient will vary by location, but this variance has an insignificant effect (Lillie, 1999).

\subsubsection{Bouguer Plate Correction}

The free air correction is so named because it accounts only for elevation, and assumes the observation is made in free air. In reality observations are made on the ground, and the effect of additional mass between the observation point and sea level must also be accounted for. The first order approximation for that is a slab of some set density, thickness equal to the elevation above the geoid and extending infinitely in all directions. This is 
called a Bouguer plate or slab after Pierre Bouguer, a French mathematician (1698-1758) who demonstrated that the strength of gravity decreases with altitude. The gravitational attraction of such a slab is (Lowrie, 2007):

$$
g_{b p}=2 \pi \rho G h
$$

where $g_{b p}$ is gravitational acceleration in $\mathrm{m} / \mathrm{s}^{2}, \rho$ is the density of the slab in $\mathrm{Mg} / \mathrm{m}^{3}$, $\mathrm{G}$ the universal gravitational constant, and $\mathrm{h}$ the height above the geoid in metres (and therefore thickness of the slab). This is a positive correction, so the slab is increasing net gravity.

In mGal, the Bouguer plate correction is often defined as (Keary \& Brooks, 1992):

$$
g_{b p}=0.04191 \rho h
$$

The density used is that of the most common or basement rocks in the survey area, which in this case, and usually, is $2.67 \mathrm{Mg} / \mathrm{m}^{3}$ (Section 1.5.1). There is a small error in the assumption that the slab is horizontal, where a surface of constant height above the geoid would be curved, but this is negligible (Vanicek et al., 2001).

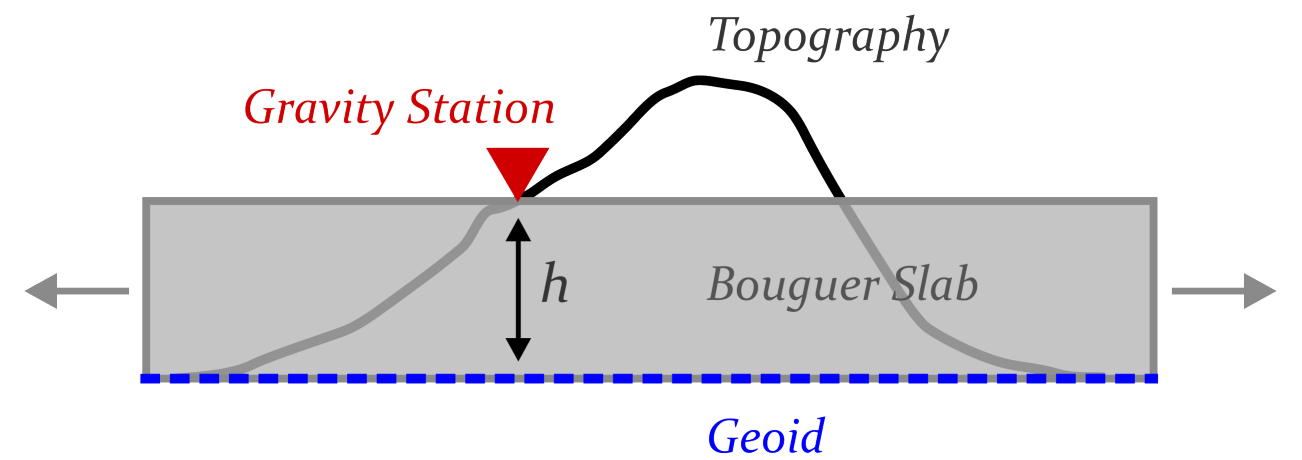

Figure 2.3: The Bouguer Plate Correction. The gravitational attraction of a theoretical slab (or plate) of thickness $h$ and density $2.67 \mathrm{Mg} / \mathrm{m}^{3}$ is calculated. The slab is presumed to be horizontal and infinite in all directions.

\subsubsection{Terrain Correction}

The surface of the Earth is not an infinite flat plain, but has topography. There must therefore be a correction to account for topography as well - additional mass above the surface of the theoretical slab (hills) and missing mass below (valleys). Both hills and 
valleys act to reduce the strength of gravity - hills as their gravity is acting counter to that of the mass below, and valleys as they reduce the total mass below (Lowrie, 2007) (Figure 2.4).

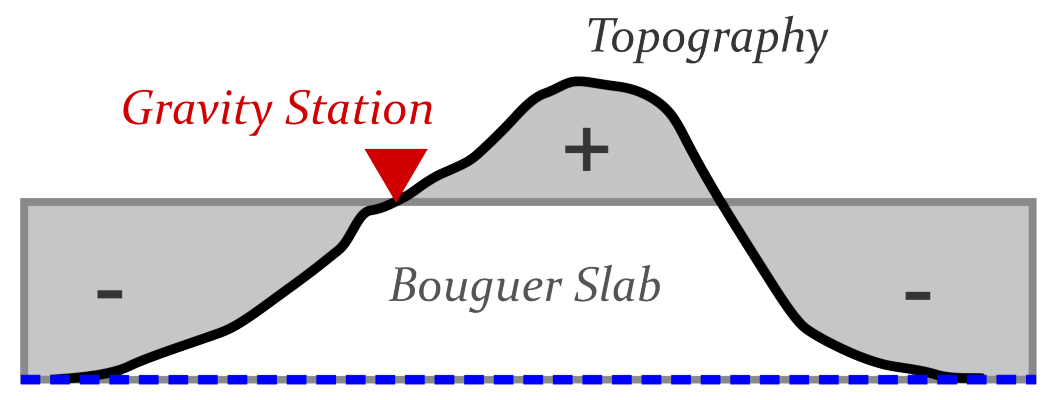

Geoid

Figure 2.4: The Terrain Correction. Mass additional to the Bouguer plate above the gravity station $(+)$ and mass missing from the plate below (-) due to topography both have the effect of reducing measured gravity.

\section{Hammer Zones}

Traditionally the terrain correction for gravity observations was made with the use of "Hammer zones", as set out by Hammer (1939). This involves dividing the terrain around a station into circular zones and compartments (Figure 2.5).

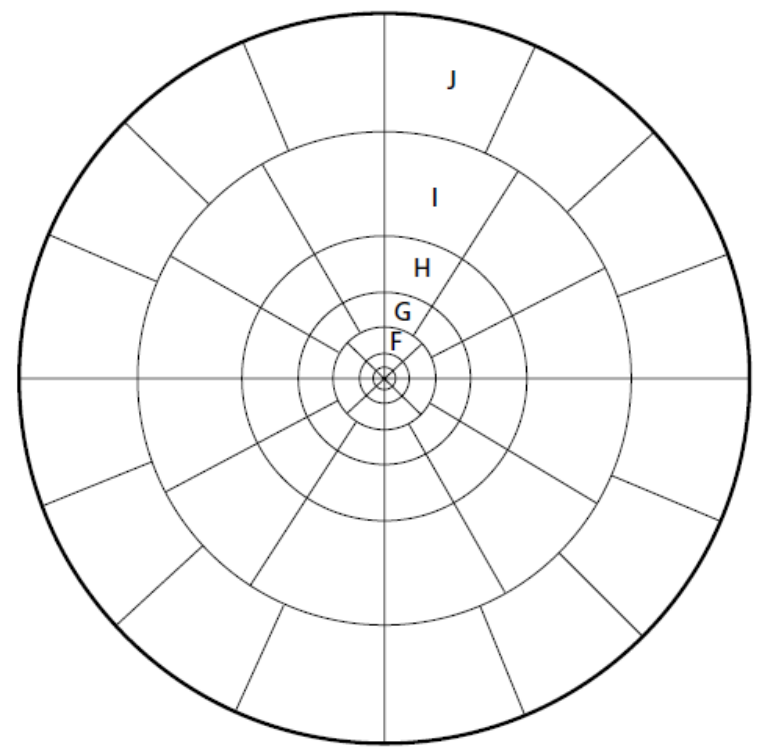

Figure 2.5: An example circular graticule used in calculation of terrain corrections with the method of Hammer (1939), showing zones F - J. The gravity station is located in the centre, with inner zones not labelled. From Keary and Brooks (1992).

Within each compartment the average height above or below the station is estimated, either by eye or more recently with a laser rangefinder. Outer zones would be estimated 
using a clear graticule overlay on a topographic map, usually out to a distance of $22 \mathrm{~km}$. Now, and in this project, they are done using Digital Elevation Models (DEMs) and a computer program which calculates the terrain correction for a site.

\section{Wellington LiDAR Dataset}

For this study, a $1 \mathrm{~m}$ resolution LiDAR (Light Detection And Ranging) dataset was used. LiDAR is a method for measuring distances using a laser, in which the beam is reflected off an object and the time taken for the reflection to arrive back at the origin measured. The dataset is available from Land Information New Zealand (LINZ) at:

https://data.linz.govt.nz/

The data are provided both as a DEM (Digital Elevation Model) and DSM (Digital Surface Model). The DSM represents whichever uppermost surface the laser hit, so it includes trees and buildings. The DEM is derived from the DSM, using statistical methods to determine which points belong to the ground surface and remove buildings, trees and other objects from the model (Ma, 2005). This does introduce some uncertainty into the DEM, most notably where large buildings are not entirely removed as their large flat roofs are misinterpreted as ground. These manifest as 'lumps' in the ground surface at the location of the building, up to $10 \mathrm{~m}$ high.

\section{New Zealand Bathymetry Dataset}

For offshore elevations, the New Zealand Regional Bathymetry (2016) dataset was used. This is a $250 \mathrm{~m}$ resolution bathymetry grid, compiled from surveys by multiple institutions and countries, publicly available from the National Institute of Water and Atmospheric Research (NIWA) at:

https://niwa.co.nz/our-science/oceans/bathymetry

While $250 \mathrm{~m}$ is low resolution, this is not of concern for multiple reasons:

1. The seafloor is naturally smoother than topography.

2. Wellington Harbour is not deep, mostly less than $20 \mathrm{~m}$.

3. The seafloor is usually not close to gravity stations.

4. The density contrast between water and sediment (at the boundary defined by the 
bathymetry) is $50 \%$ less than between air and sediment, so the precise location of this boundary has less effect than does topography.

5. In testing the effect of including bathymetry on terrain corrections was found to be from $0.08-0.04 \mathrm{mGal}$ on Line A, as given in the supplementary data file "TC_Sensitivity _ Testing.xls". Uncertainty in bathymetry can therefore be assumed to have a negligible effect.

It is worth noting that in an area closer to more varied submarine topography, such as Cook Strait Canyon, the effect of bathymetry would be more important.

\section{Digital Elevation / Surface Model Processing}

These data were processed using Arc GIS Pro. The first major processing step to generate a usable DEM for terrain corrections was to remove the building remnant artifacts. Polygon outlines for all buildings in the study area were created in ArcGIS Pro, using a combination of the LINZ "NZ Building Outlines" dataset (LINZ, 2020) and aerial photography.

These polygons were used to cut holes in the DEM, which were then infilled using Arc GIS Pro's "Topo to Raster" function. This function interpolates between points in a manner intended to honour the nature of topography - without generating the spurious peaks or dips which a polynomial for example may do (Esri, 2020b). Given that the largest holes are CBD blocks, which lie on nearly flat land, the interpolation can be considered to be reliable in these cases. The process is illustrated in Figure 2.6, for a typical area in central Te Aro.

The DEM was then stitched together with the bathymetry dataset. ArcGIS Pro's raster calculator function was used to replace all zero values in the DEM (representing sea) with the bathymetry values.

Terrain corrections were calculated in the geophysical software package Geosoft ${ }^{\circledR}$ Oasis Montaj (referred to here as Oasis). Software restrictions meant that the maximum allowable file size was $2 \mathrm{~Gb}$, so the combined DEM was split into two separate circular rasters, and both resampled at a lower resolution. An optimal combination of radii and resolutions was found that would give two files both close to but not more than $2 \mathrm{~Gb}$, and tests run to examine the effect on terrain corrections of both various radii and resolutions (Section 2.5.4). 

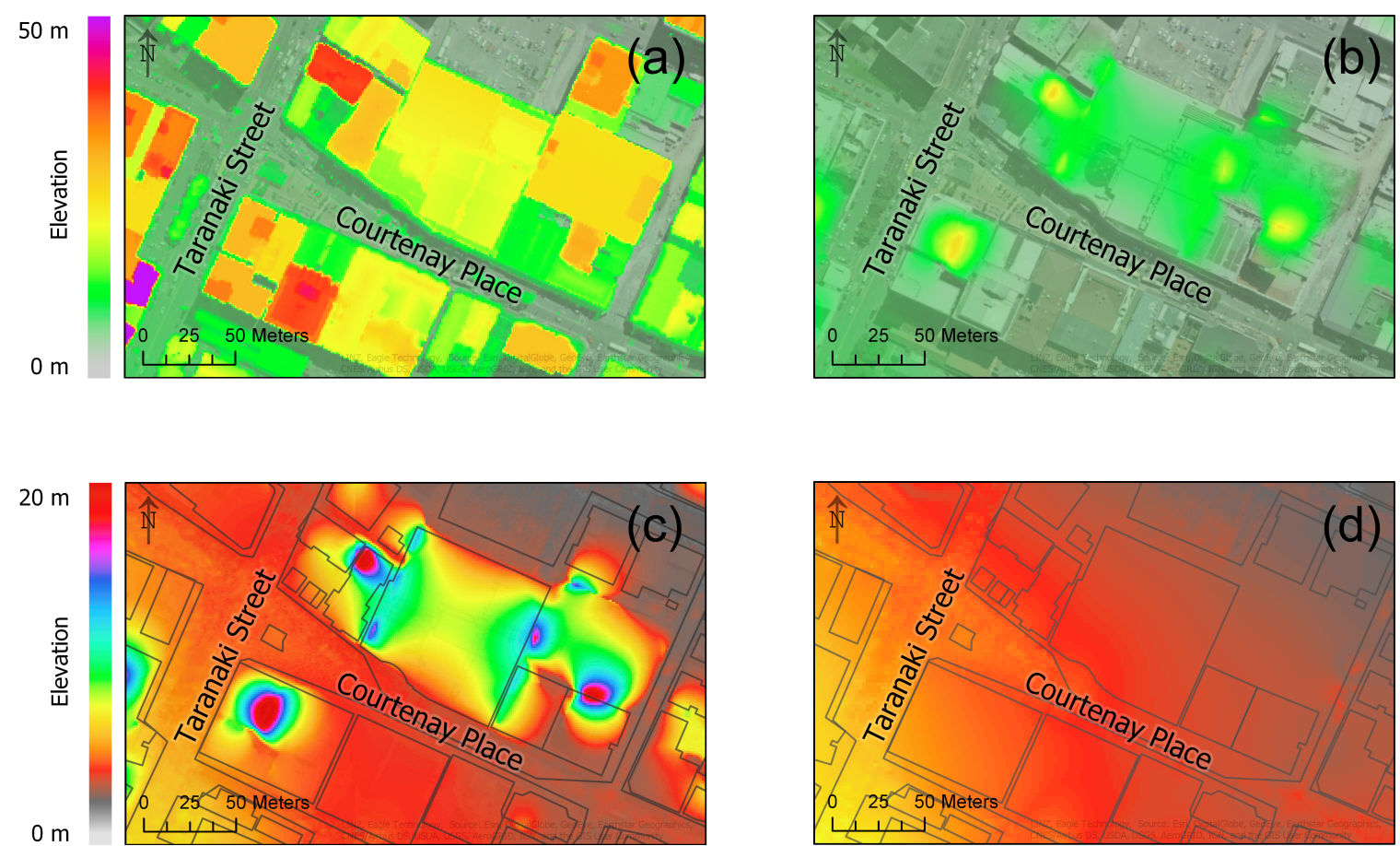

Figure 2.6: (a) A section of the Digital Surface Model (DSM) around Courtenay Place. Buildings are clearly visible in the elevation data. Note also trees in green. (b) The Digital Elevation Model (DSM) for the same location, with the same colour scale. Incompletely removed building artifacts are visible as green/yellow highlights. (c) Building outlines (grey) used to clip this section of the DEM. City block outlines have been drawn over the NZ Building Outlines layer. The colour scale is adjusted to highlight the artifacts. (d) After clipping and re-interpolation using the Topo to Raster function.

The final two outputs were an outer DEM of radius $28 \mathrm{~km}$ and resolution $4 \mathrm{~m}$, and an inner DEM of radius $10 \mathrm{~km}$ and resolution $2 \mathrm{~m}$ (Figure 2.7). These files were then input to Oasis' gravity and terrain correction module. This calculates terrain corrections for each gravity station's given coordinates and elevation. An important note is that the DEM elevations must be provided, not measured orthometric elevations. While the GPS elevations will be more accurate, if they were used Oasis would calculate terrain corrections as if the station were not on the ground, adding an error to every pixel.

Oasis calculates terrain corrections using a combination of methods. To a distance of 8 pixels from the station the effect is calculated for each cell using the flat topped square prism method described by Nagy (1966), and beyond this it uses the annular ring segment approximation described by Kane (1962) (Montaj, 2004). Inner and outer corrections are calculated separately, and then summed. 


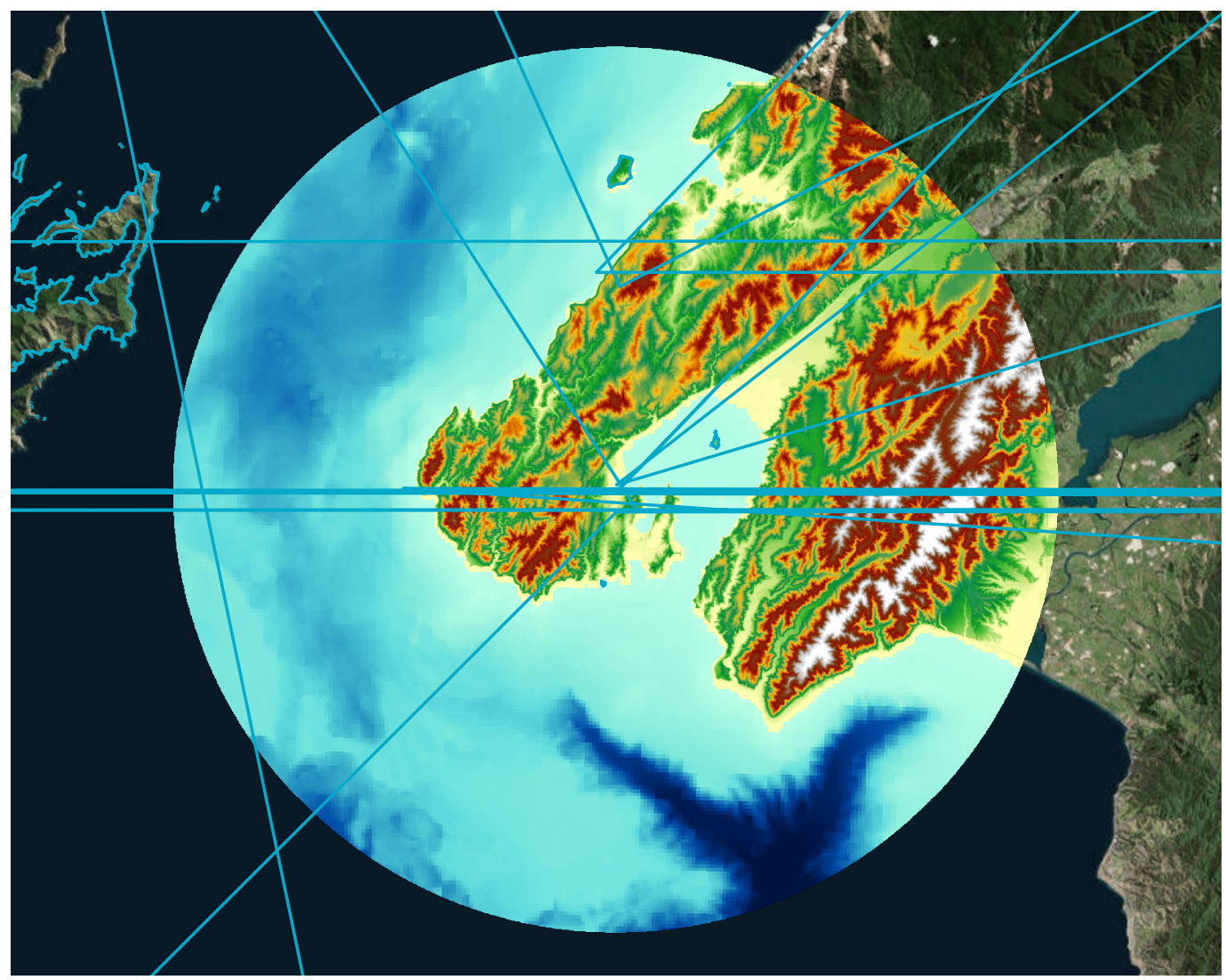

Figure 2.7: Completed Digital Elevation Models including topography and bathymetry. The inner DEM (black outline) is $2 \mathrm{~m}$ resolution and of a radius sufficient to encompass terrain up to $10 \mathrm{~km}$ from all gravity stations. The outer DEM (red outline) is $4 \mathrm{~m}$ resolution and of radius sufficient to encompass terrain up to $28 \mathrm{~km}$ from all gravity stations. Population centers are gold stars and the coastline is light blue.

\subsubsection{Building Correction}

An unusual feature of this project was the requirement for a Building Correction (BC). This requirement exists due to the high precision required for a micro-gravity survey, and the fact the survey area is urban, with mid- and high-rise buildings often close to gravity stations. Their gravity effect is small, but non-negligible: up to $0.2 \mathrm{mGal}$ in the case of stations adjacent to the tallest buildings. In order to account for it, the DSM and DEM were differenced in ArcGIS Pro, which resulted in a DSM containing only buildings, trees and other non-ground objects (Figure 2.8).

Within the CBD, the volume of trees and other objects is considered negligible. However, some parks and other large stands of trees in more outlying areas needed to be removed from the DSM, as they would otherwise cause an erroneously high correction (Figure 2.8). The density of wood in living trees is $\sim 0.75 \mathrm{mg} / \mathrm{m}^{3}$, but the volume represented by the 
trees in the DSM which is wood might be only $10 \%$. Therefore the density of this volume is $\sim 0.08 \mathrm{Mg} / \mathrm{m}^{3}$, which will exert a negligible gravity effect.

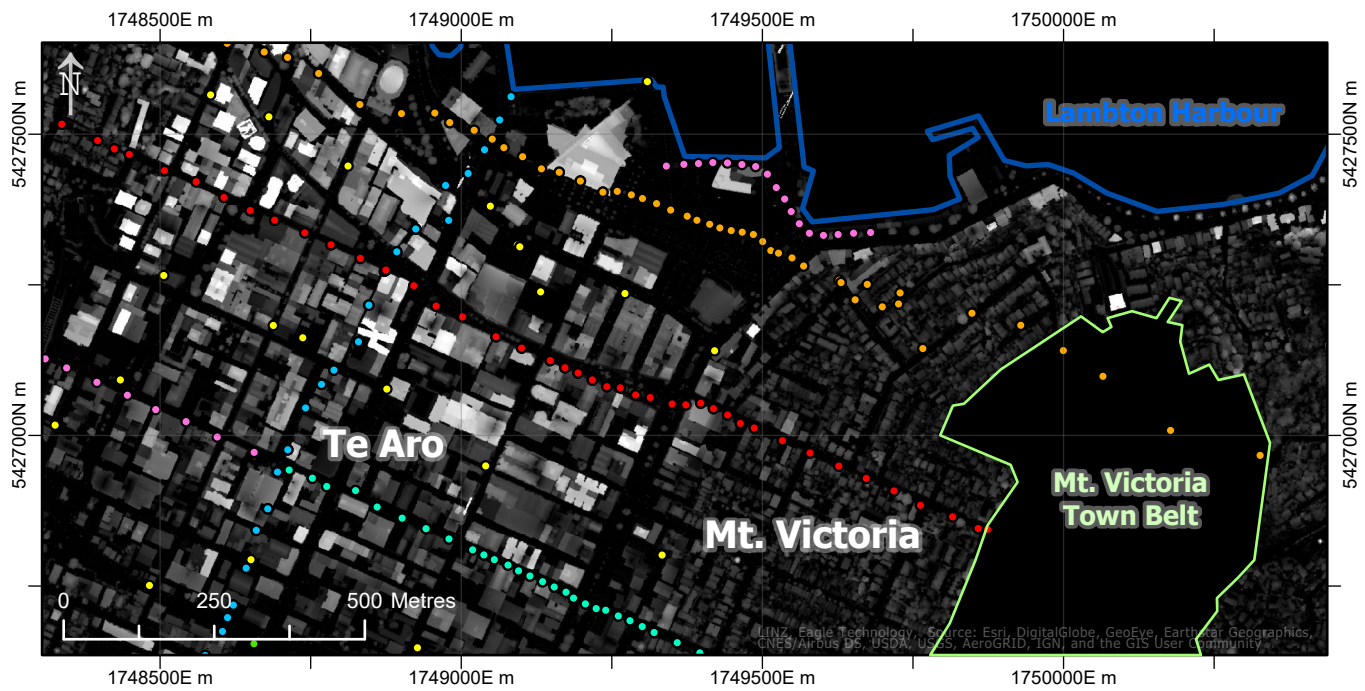

Figure 2.8: A section of the completed Digital Surface Model covering Te Aro and Mount Victoria. Gravity stations are circles colour coded by line. Note Mount Victoria Town Belt area outlined in green, where all height data were trees and have been removed.

An average density for buildings of $0.46 \mathrm{Mg} / \mathrm{m}^{3}$ was selected, based on work by $\mathrm{Yu}(2014)$ who found good correlation between theoretical and measured residual gravity profiles using this value for a line of concrete buildings in a new development in China. The author argues that a building correction is required for high precision, urban gravity surveys. A similar argument is made by Dilalos et al. (2018), who use an average density of $0.44 \mathrm{Mg} / \mathrm{m}^{3}$ during their gravity survey of Athens (Dilalos et al., 2019). As the latter value does not include the effect of basements, which will further increase the negative effect of buildings, the higher value given by $\mathrm{Yu}$ (2014) has been adopted for this study.

The DSM is used as an input to Oasis, station elevations set to zero and a density of $0.46 \mathrm{Mg} / \mathrm{m}^{3}$ given for the DSM "Terrain". A "Terrain Correction" is then calculated to a radius of $500 \mathrm{~m}$. Testing on the effect of calculating the correction to different radii was undertaken, and found that beyond $500 \mathrm{~m}$ the effect was negligible. Post calculation, a rough correction for gravity stations in more suburban areas where the dominant construction material was wood was made by multiplying the correction by either 0.66 or 0.50 depending on the estimated proportion of wood to concrete buildings. 


\subsubsection{Summary}

To summarize, the following formula gives calculated expected gravity at any particular gravity station:

$$
g_{c a l c}=g_{1980}+g_{f a}+g_{b p}-g_{t c}-g_{b c}
$$

Where $g_{1980}$ is the latitude correction, $g_{f a}$ the free air correction, $g_{b p}$ the Bouguer plate correction, $g_{t c}$ the terrain correction, and $g_{b c}$ the building correction. This is the expected value of gravity at the location of a gravity station under the assumption that the density of all terrain is $2.67 \mathrm{Mg} / \mathrm{m}^{3}$. This is compared with observed gravity at that station $\left(g_{o b s}\right)$, and the difference, known as a Bouguer Anomaly $\left(g_{b a}\right)$, inferred to be due to spatial variations in subsurface density from $2.67 \mathrm{Mg} / \mathrm{m}^{3}$ :

$$
g_{b a}=g_{o b s}-g_{c a l c}
$$




\subsection{Gravity Data Acquisition}

\subsubsection{Equipment}

\section{Scintrex CG-6 Autograv}

The Scintrex CG-6 Autograv is the most modern relative gravity meter currently available, and at time of writing the only one in New Zealand is owned by VUW. It has a read precision of $0.0001 \mathrm{mGal}$ and a standard deviation of $<0.0005 \mathrm{mGal}$ (Geomatrix Earth Science Ltd., 2020).

The CG-6 uses a fused quartz sensor, as compared to older gravity meters such as the common Lacoste and Romberg type, which measure the extension of a metal spring with a weight on the end (Keary \& Brooks, 1992). A screw system in these older meters is used to bring the weight back to a reference position, which is judged by eye. The revolutions of the screw are then converted to a reading in mGal. (Van Camp et al., 2017).

A quartz spring has the advantage of high strength, near linear elastic response and the ability to be welded into compact structures (Hugill, 2011). This avoids the necessity of clamping the mechanism to avoid damage during movement of the meter, as is required by metal spring designs (Geomatrix Earth Science Ltd., 2020). Measurements are made electronically, via an electrostatic nulling system, meaning that the weight is held stationary using electromagnets and the voltage required to do so measured and converted into mGal. This avoids errors due to visual observation.

Quartz springs do have two disadvantages as compared to metal, which are a higher temperature dependence and a greater drift (Van Camp et al., 2017). These are readily quantified however, and small variations in internal temperature are compensated for by the onboard computer's calculation of a temperature correction (Geomatrix Earth Science Ltd., 2020). Drift is addressed in Section 2.4.2.

The meter also makes automatic corrections for tilt (being off-level), tides, and filters out high frequency noise. The accompanying tripod and electronic level makes levelling the meter a simple process, and a good level for the instrument can be quickly established.

The greatest advantage of the CG-6 over older models then, is that it requires less skill to use which translates to faster and more consistent readings. An operator with a little 
practice can set up, take a reading and pack up in 5-10 minutes. In this project up to 40 stations were able to be measured in a day's field work.

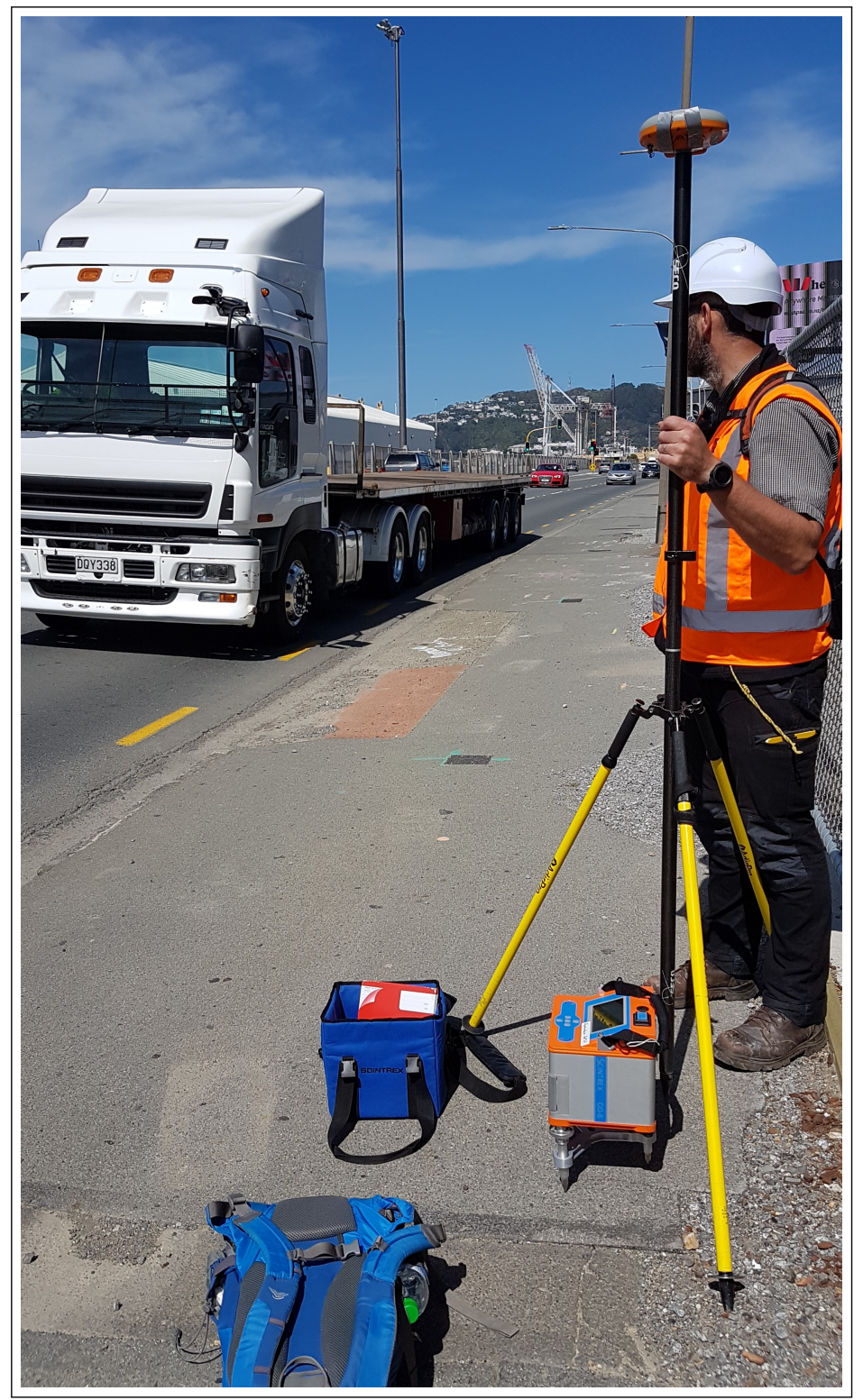

Figure 2.9: Field setup on Aotea Quay. The CG-6 is on its tripod near ground level, with the Septentrio GPS on a tripod adjacent held by Matt Hill (GNS). Note large truck in the background - this line suffered the most from traffic noise due to numerous heavy vehicles travelling at higher speeds.

\section{Septentrio Altus NR3 GNSS Receiver}

The Septentrio Altus NR3 is used to obtain 3D coordinate data for each gravity station. It is a Global Navigation Satellite System (GNSS) receiver as opposed to a Global Positioning System (GPS) receiver. This means it is able to use all available satellite constellations, of which GPS is one - GPS, GLONASS, Galileo and SBAS (Septentrio NV, n.d.). Often, and in this thesis, such units are simply referred to as GPS units. 
The GPS also uses Real Time Kinematic (RTK) positioning. This is a method of filtering out errors in positioning caused by atmospheric effects and multipathing using a base station with a known position. This gives up to $1 \mathrm{~cm}$ accuracy in in vertical and $0.6 \mathrm{~cm}$ in horizontal positions (Septentrio NV, n.d.). For this project the base station used is maintained by LINZ and stationed at Wellington Airport.

\subsubsection{Calibration}

In addition to tidal and instrument drift, gravity meters can also drift slowly in terms of their measurement scale. This means that over time, their scale divisions will no longer be exactly in mGal. They therefore need to be calibrated periodically, perhaps once per year. This is done by taking measurements at two or more sites of known absolute gravity (and therefore a known difference between them) and finding the factor of the known and measured differences. This is called the calibration factor, and can be used to multiply all measurements made with the meter to convert precisely to mGal.

During the course of the project the CG-6 was taken on a calibration run across four New Zealand Gravity Network sites with a wide mGal range between them. Each site was measured twice, along with the VUW station, in order that an accurate linear drift could be fitted in a manner similar to that described in Section 2.4.2. A least squares approach was taken using all pairs of differences to calculate the average calibration factor. This was found to be 0.999904 , which as expected for a modern meter is extremely close to 1 , and was used for all measurements in this project.

In addition, this run was used to tie the VUW station back to the New Zealand Gravity Network, giving it an absolute value of $980256.03 \mathrm{mGal}$. The results from the calibration run are given in the supplementary data file "Calibration.xls".

\subsubsection{Field Procedure}

On each day of surveying, a measurement was made at the VUW base station at the start and end of the day, in order to both tie measurements to an absolute value (Section 2.4.1) and to calculate instrument drift (Section 2.4.2). Approximately 30 gravity stations would usually then be measured in a day of surveying. 


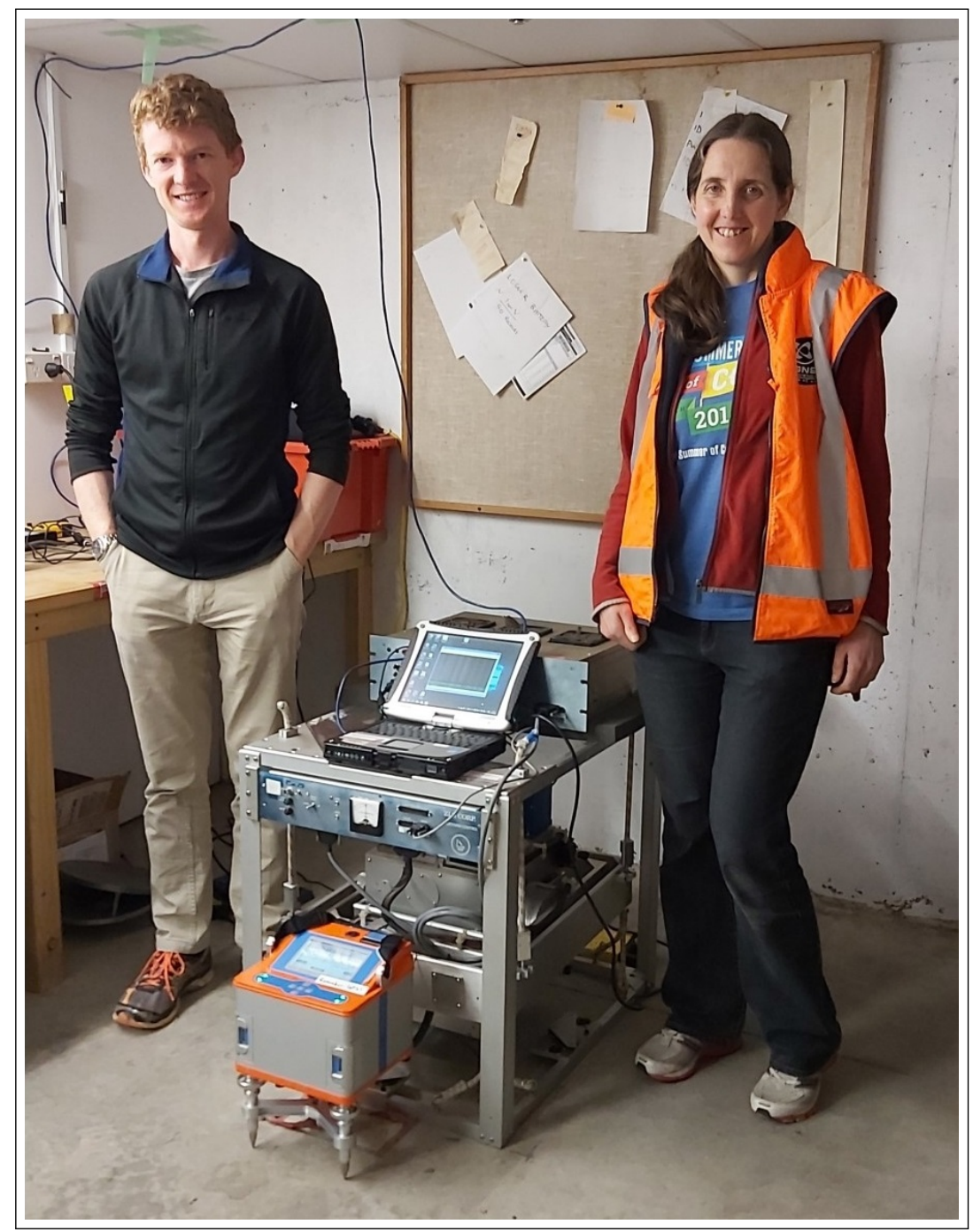

Figure 2.10: The CG-6 set up at the base station at GNS, Avalon, Lower Hutt, with the author on left and Jenny Black (GNS) on right. Behind the CG-6 is GNS' marine gravity meter in a gyroscopic mount. Photo courtesy of Vaughan Stagpoole, GNS.

\section{Site Selection}

Gravity station locations were planned using ArcGIS Pro, in lines as straight as possible, allowing for buildings. Most lines were designed to be perpendicular to the basin bounding Wellington and Aotea faults, in order to minimize the gravity effect of topography varying perpendicular to the line. Spacing was usually $50 \mathrm{~m}$, down to $25 \mathrm{~m}$ across the Wellington and Aotea faults, as seen for example in Figure 2.8. In the field, planned locations were used as a guide but the exact location often adjusted, while making efforts to keep lines as straight as possible (with the exception of regional points, discussed in Section 2.5.2). The usual reasons for adjustment of locations were as follows:

\section{Ground surface}

In any soft surface the meter tripod will sink slightly over time, and fall out of level. 
The best (hardest) surfaces were found to be brick and concrete. Old tarseal as used in footpaths was usually satisfactory, but fresh tarseal is soft and a poor surface to measure on, especially when warm. Grass and soil was variable but can be poor, particularly after rain. An example of a less desirable location is shown in Figure 2.11 .

\section{Traffic}

Vehicles travelling at the inner city speed limit of $30 \mathrm{~km} / \mathrm{h}$ were found to have a small but noticeable effect, increasing the standard error of a reading as reported by the meter. Foot traffic, as long as the meter was on a hard surface, had no effect. Heavy vehicles or those travelling faster were an issue in some places. In these cases the meter was often placed further from the road - a notable example was Aotea Quay, for Line J (Figure 2.9).

\section{Sky visibility}

With a clear field of view GPS accuracy is usually $1 \mathrm{~cm}$, but when tall buildings obscured part of the sky, or awnings extended over it this will drop. Up to $10 \mathrm{~cm}$ uncertainty was considered acceptable - referring to equation 2.8 , this would introduce only a 0.03 mGal uncertainty.

\section{Slope steepness}

Beyond about a $10^{\circ}$ slope the CG-6 tripod legs do not screw out far enough, so they were supported by a block of wood. This could introduce some instability and a slight levelling error as the legs sink into the wood, although generally the introduced error was small. Steep slopes also increase terrain correction uncertainty as larger average differences in elevation are closer to the meter (Section 2.2.4).

\section{Data Collection}

Data collection at each gravity station involved first setup and levelling of the CG-6. This is done with use of the supplied tripod, and the lights on the meter which tell the operator which way to adjust the screw legs (Figure 2.11). While on standby, the meter displays the current reading and the standard deviation and standard error of the last minute of measurements (Geomatrix Earth Science Ltd., 2020). Once levelled, the sensor was allowed to settle while small adjustments are made to maintain the level. Recording was not started until the standard deviation dropped to below 0.02 , which usually takes $30+$ 


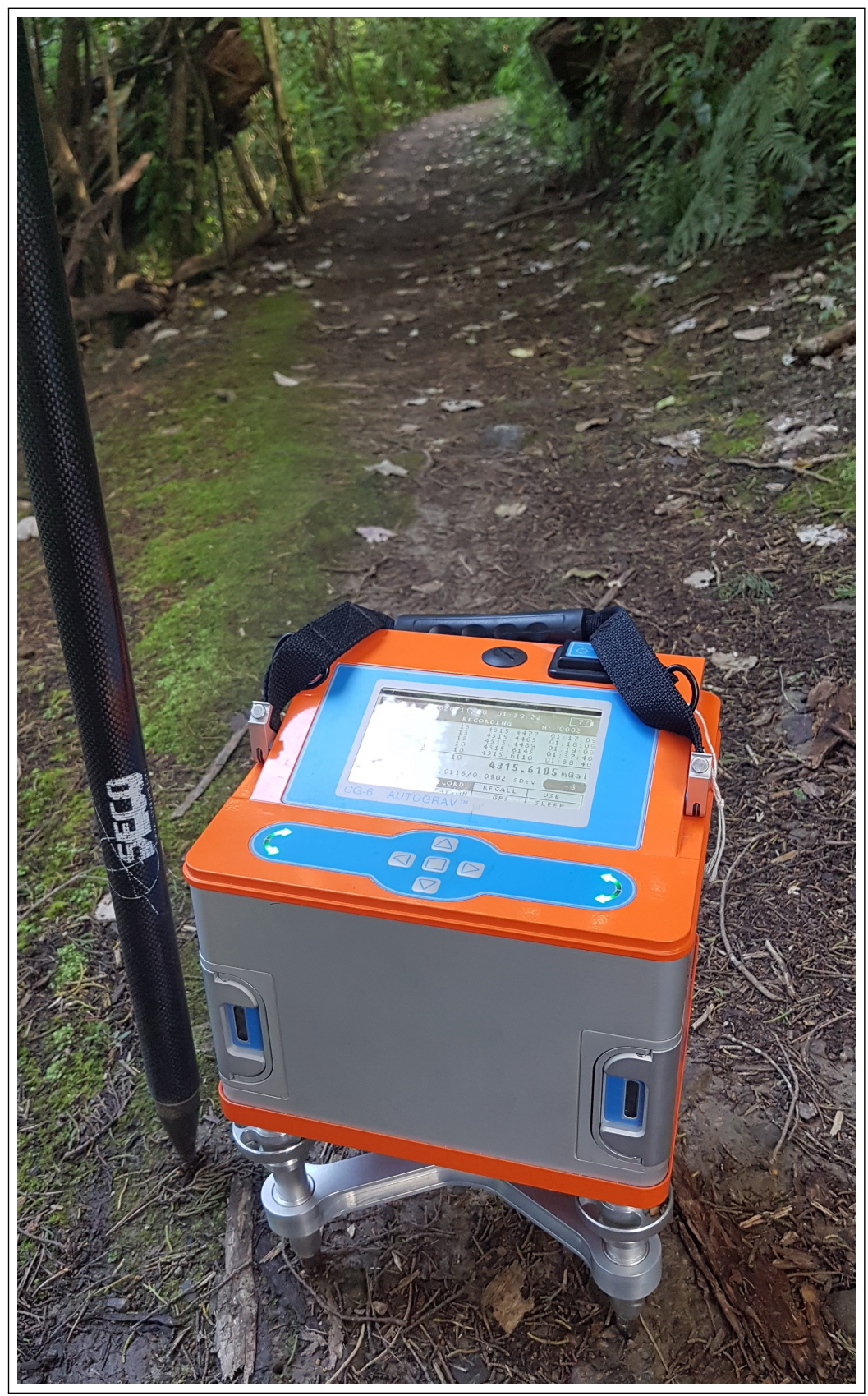

Figure 2.11: A station on Te Ahumairangi (formerly Tinakori) hill, above Thorndon. The CG-6 is level as indicated by the lit green arrows. Note soft ground, a steep slope and poor sky visibility due to tree cover. A measurement was still made here and at similar locations as these are on basement and form the start of the lines in Thorndon.

seconds. In more noisy environments it may not drop this low, and recording was started once it had stabilized.

While recording the meter takes a reading every second, and averages the readings over a minute to give a single measurement. It was set to make four of these measurements in a row, taking four measurements in total. These are later averaged during data processing. Four readings was chosen as it allows for one bad measurement to be discarded while still 
retaining three to be averaged.

A GPS reading was taken at each station. The GPS stands on a pole, placed as close as possible to the meter, with particular attention to ensuring the spike at the base of the pole was at the same elevation as the meter. On occasion a good GPS lock was not able to be obtained and co-ordinates were instead determined later from aerial photography and DEM elevations. The GPS records ellipsoidal height, so this is later converted to orthometric height through the LINZ online coordinate conversion tool:

https://www.geodesy.linz.govt.nz/concord/

This same tool was used to convert coordinates from the World Geodetic System 1984 (WGS84) to New Zealand Transverse Mercator (NZTM). The latter is a projected coordinate system used in New Zealand and measured in metres. All processing was done in NZTM and this is the coordinate system for all maps created for this thesis. 


\subsection{Corrections to Measured Gravity}

\subsubsection{Relative and Absolute Gravity}

Most gravity meters measure relative gravity, not absolute. While the relative difference measured between two stations will be correct, the absolute values are arbitrary, and will be different for every meter. In order to convert a relative measurement to an absolute measurement, readings must be made at a site of known absolute gravity, called a base station. Relative measurements in the field can then be converted to absolute (giving a value for $g_{o b s}$, equation 2.12), thus tying the survey into the New Zealand Gravity Network:

$$
g_{\text {absolute }}(\text { field })=g_{\text {absolute }}(\text { base })-g_{\text {relative }}(\text { base })+g_{\text {relative }}(\text { field })=g_{\text {obs }}
$$

\section{The New Zealand Gravity Network}

GNS Science maintains a catalogue of absolute gravity measurements across the country, called the New Zealand Gravity Network (Robertson \& Reilly, 1960). Most of the observations were made by the DSIR (Department of Scientific and Industrial Research) -and then GNS Science -using relative gravity meters (Stagpoole, 2018), and then tied back to the New Zealand Primary Gravity Network, a series of measurements made using absolute gravity meters in the 1960's (Robertson \& Reilly, 1960). This allows absolute values to be calculated.

The Primary Gravity Network stations were originally measured in the New Zealand Potsdam 1959 system, using the 1930 International Gravity Formula. They have since been remeasured and recalculated based on the IGSN71 system, using the 1980 International Gravity Formula. Many of these stations are no longer locateable due to having been located at railway stations or on roads which have since been demolished or realigned. For this reason gravity surveys are generally tied back to New Zealand Gravity Network stations, which are mainly on LINZ benchmarks (Stagpoole, 2018).

In this study, an absolute gravity station at VUW has been used to tie surveys back to the New Zealand Gravity Network. This station is not part of the network, but has itself been tied to the network GNS Science station at Avalon, Lower Hutt. 


\subsubsection{Temporal Drift}

The value of gravity at a station drifts over time. Temporal drift has two components: tidal drift and instrument drift. Corrections must be made for both in order to compare measurements between sites, as they will have been made at different times.

\section{Tidal Drift Correction}

At a given gravity station, the gravitational attraction of the sun, the moon, and the deformation of the solid Earth (the Earth tide) all combine to cause a periodic drift in the strength of gravity, up to $\sim 0.3 \mathrm{mGal}$ over the course of a day (Lowrie, 2007). On longer timescales, as the distance from Earth to the sun changes, seasonal drift can also be seen (Figure 2.12).

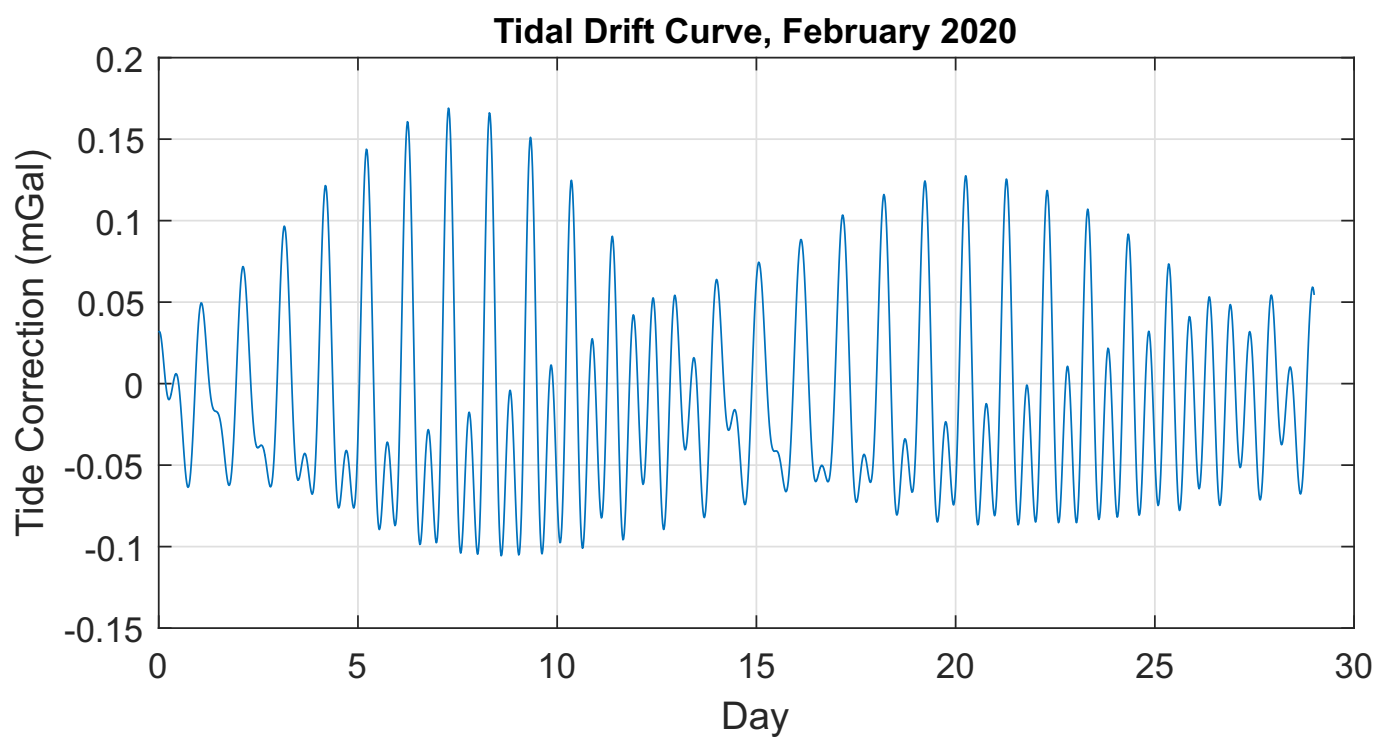

Figure 2.12: A plot of the tidal drift curve for the month of February, 2020. This is the correction in $\mathrm{mGal}$ to be added to a measurement to remove the effect of tides. This data were automatically generated by the Scintrex CG- 6 gravity meter when a drift calibration was run over the course of the month. Note the plot is visibly composed of three separate periodic functions; the monthly effect of the sun and the moon, and the daily effect of the Earth's spin with respect to the sun and moon.

Traditionally, the tidal correction is made via the construction of a drift curve. This is derived from numerous repeat measurements, either at a single base station or various stations over the course of the survey. If a base station is used, simply plotting the change in gravity over time will show the drift. A line or higher-order function may then be fitted through the points, and used to calculate the drift correction to be removed from each measurement in the survey. 
If multiple stations are used the procedure is slightly more complex (although in the field this may be more practical, depending on the location of the base station). In this case the difference between measurements at the same station is known, but the relative difference between stations is treated as an unknown. Sets of observations at each station may then be adjusted relative to one another, in order that the most plausible and simplest curve may then be fit to them (Lowrie, 2007).

The Scintrex CG-6 gravity meter automatically calculates a tide correction based on location (Geomatrix Earth Science Ltd., 2020). As tidal effects are periodic and well understood they may be calculated to a high degree of accuracy, and so the tide correction calculated by the meter is used and the construction of a drift curve is not required.

Note that the effect of the shifting mass of water itself (the sea tide) is not included in the tidal correction, because sea tides vary from place to place and are not as simply calculated as the effect of the sun and moon's positions and the Earth body tide. The following calculation demonstrates that the effect of the sea tide is negligible and can be disregarded:

In Wellington, the greatest tidal range from low to high is $\sim 1.5 \mathrm{~m}$ (LINZ, 2021b). Local mean sea level in Wellington is $0.39 \mathrm{~m}$ higher than $0 \mathrm{~m}$ elevation in the New Zealand Vertical Datum 2016 (NZVD 2016) (LINZ, 2021a), which is the standard datum for elevations in New Zealand and used in this project. Therefore at a high tide, sea level could be at $1.5 / 2+0.39=1.14 \mathrm{~m}$ elevation in NZVD 2016.

From equation 2.9, if this mass of water is treated as a Bouguer plate and assigned a density of $1,025 \mathrm{~kg} / \mathrm{m}^{3}$ it will have a gravitational attraction of:

$$
\begin{aligned}
g_{b p}=2 \pi \rho G h & =2 \pi \times 1,025 \times G \times 1.14 \\
& =4.90 \times 10^{-7} \mathrm{~m} \mathrm{~s}^{-2} \\
& =0.0490 \mathrm{mGal}
\end{aligned}
$$

However this would apply for a measurement taken at water level. The closest stations to the water are on wharves, approximately $2 \mathrm{~m}$ above water level. As an approximation then the Bouguer plate could be treated as having $1 / 3$ the density, and the correction is $0.0495 \times 1 / 3=0.016 \mathrm{mGal}$. Given that this is the maximum likely correction it can be 
safely disregarded.

\section{Instrument Drift Correction}

Instrument drift is unique to each gravity meter, and can vary with time. When a meter is read continuously at the same location, even after correction for tides a gradual drift in the reading will be seen. This is due to changes in the elastic properties of the spring due to changes in temperature, and/or slow creep of those properties over time due to imperfections in the spring (Lowrie, 2007).

Modern gravity meters have lower drift rates than older models. The documentation for the Scintrex CG-6 specifies a drift rate of under $0.1 \mathrm{mGal}$ per day (Geomatrix Earth Science Ltd., 2020). In practice it has been found to be significantly better, usually below $0.01 \mathrm{mGal}$ over an 8 hour period (Figure 2.13). This makes the drift correction negligible, but for assurance and the sake of completion it is still applied in this study.

The CG-6 can automatically apply a drift correction; however, this is simply a linear function fit to a series of measurements made during a drift calibration. As the drift rate varies with time, the greater the time elapsed since the drift calibration results, the less accurate the correction. For this study the drift correction is made by a measurement at the VUW base station at the beginning and end of each day, and a linear function fit between those observations. This then gives the correction to be subtracted at the time of each gravity station measurement.

Figure 2.13 illustrates a typical drift curve, and the effect of fitting a straight line to it for a given day. 


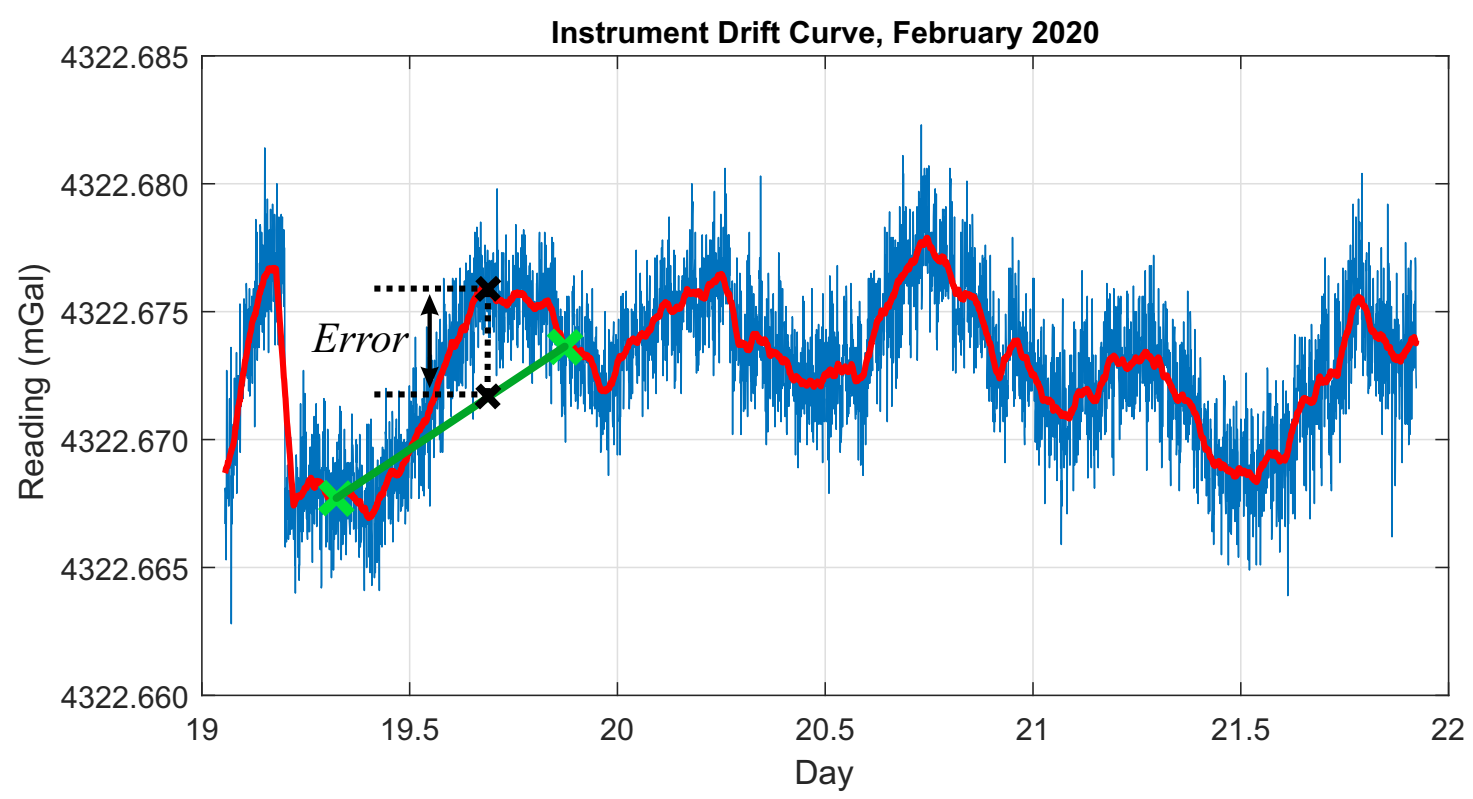

Figure 2.13: A plot of continuous instrument readings at one locality over three days in February, 2020. The meter was set to take one reading every minute. The red line is a moving two hour average. Note the slow but non-constant drift over a day of $<0.01 \mathrm{mGal}$. The green points represent measurements that might have been made before and after surveying on the $19^{\text {th }}$, and the green line the drift function that would have been fitted to them. The black shows the maximum error this approach would have during the day, of $\sim 0.004 \mathrm{mGal}$. The jump early on the $19^{\text {th }}$ is due to a manual levelling adjustment.

\subsection{Calculation of Gravity Anomalies}

\subsubsection{The Bouguer Gravity Anomaly}

The gravity at VUW is found by fitting a linear function between the two measurements made at the start and end of each survey day. At the time of each gravity station measurement, the relative value at VUW can then be calculated. Absolute gravity is then found using equation 2.13. The Bouguer gravity anomaly is then the difference between calculated expected gravity $\left(g_{\text {calc }}\right)$ at a location and the observed absolute gravity $\left(g_{o b s}\right)$, where $g_{\text {calc }}$ is given by equation 2.11 :

$$
g_{b a}=g_{o b s}-g_{c a l c}
$$

The Bouguer gravity anomaly is the most commonly used gravity anomaly for interpretation purposes on land. This is in contrast to the free air anomaly, which does not include the Bouguer plate correction and which assumes all measurements are made at a constant height and is therefore used for marine surveys (Keary \& Brooks, 1992). 


\subsubsection{Regional-Residual Separation}

A Bouguer anomaly can be thought of as the sum of the gravity fields due to the various structures beneath the Earth's surface. As gravity anomalies decay with the inverse square of distance to the source body (Section 2.1.1), the deeper the source of an anomaly, the larger that source must be in order to be detected at the surface. Correspondingly, at the surface the anomaly due to a deeper source will have a greater spatial extent. For analytical purposes it is often helpful to treat potential field anomalies as waves, so an anomaly due to deep structure will have a long wavelength.

The Bouguer anomaly can therefore be treated as a series of waves of different wavelengths superimposed on each other. In Wellington the dominant component of the Bouguer anomaly is the long wavelength field due to the subduction zone beneath the North Island. This leads to a steep SE to NW gradient (Walcott, 1987; Hatherton \& Sibson, 1969), which in this survey is defined as the regional field. Removal of a regional field will give a residual field, which is the target of a gravity survey. In a micro-gravity survey such as this, the shortest wavelength fields comprise the residual, as the sedimentary basin structures being targeted lie at the smallest end of what is possible to resolve with the gravity method.

The separation of regional and residual fields is essentially a filtering problem, so an often used technique is a Fourier transform and band-pass filter to isolate the target wavelengths (Dilalos et al., 2019; Pawlowski, 1994; Ulrych, 1968). Other techniques involve forward modelling of deep structure and removal of the resulting anomaly (Lowrie, 2007), or finite element analysis (Mallick et al., 2011; Mallick \& Sharma, 1997). Figure 2.14 shows an example result of a regional - residual separation.

In this study there appears to be a good wavelength separation between the regional and residual fields, and a simple polynomial fitting technique can be applied. Any intermediate wavelength fields which might introduce complications are expected to be minimal, as the 20-25 km of crust above the subduction interface is greywacke, with a highly homogeneous density (Henrys et al., 2013; Hatherton \& Leopard, 1964). It will therefore generate little to no gravity anomaly.

In this project, the regional field is approximated by a two-way polynomial, similar to, for example, Leão et al. (1996), El-Batroukh and Zentani (1980), and Stern (1979). Twenty measurements were made on bedrock sites encircling the study area, on the presumption 

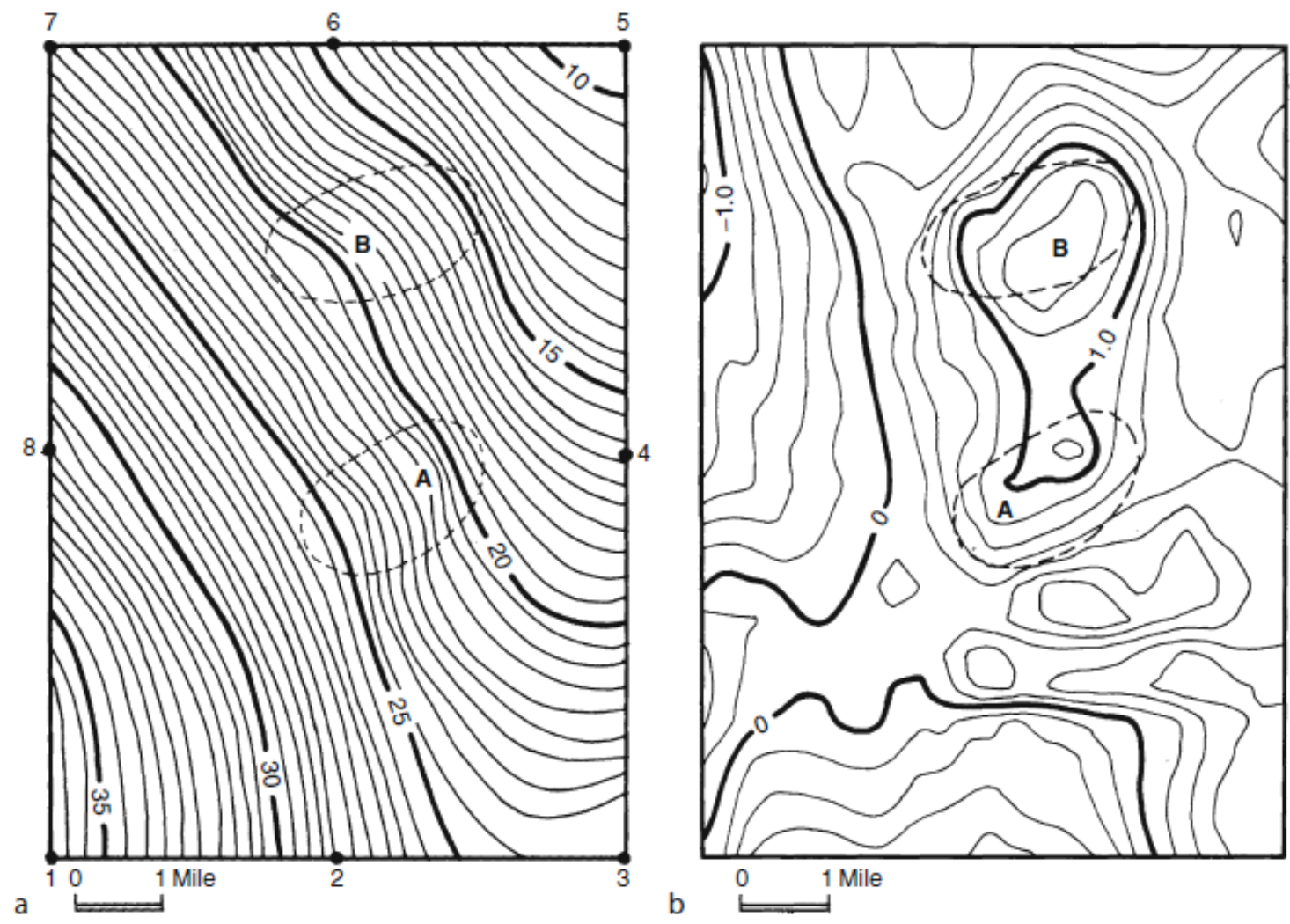

Figure 2.14: An example of a regional - residual gravity anomaly separation using finite element analysis. a) Bouguer anomaly map from Texas, U.S. Circled regions A and B denote oil fields proved by drilling. Note the slight deviation in contours indicating a shallow anomaly source. b) Residual gravity anomaly map, clearly showing the oil fields as a localized gravity high.

that almost all of the Bouguer anomaly at these sites will be sampling the regional anomaly and not affected by the target residual anomaly of the basin (Figure 2.15).

Bouguer anomalies from these stations and from a number of survey line stations which also lie on bedrock were loaded into the program MathWorks Matlab. Easting and Northing were designated $\mathrm{X}$ and $\mathrm{Y}$, and Bouguer anomaly $\mathrm{Z}$. The fit function was then used to find a best fitting two-dimensional polynomial for the data which would then describe the regional anomaly.

Polynomial orders from one to five were tested and a clear minimum in standard error was seen at the third order (Figure 2.16). This polynomial surface was therefore selected to represent the regional gravity anomaly. Note that usually a continuing improvement in fit, potentially with an inflection such as that seen in Stern (1979), would be expected with increasing polynomial order. In this case there is a minimum due to a weighting being assigned to each station in the polynomial calculation. Some anomalous stations were given lower weightings to maximize the fit for the majority. Stations on profile lines 


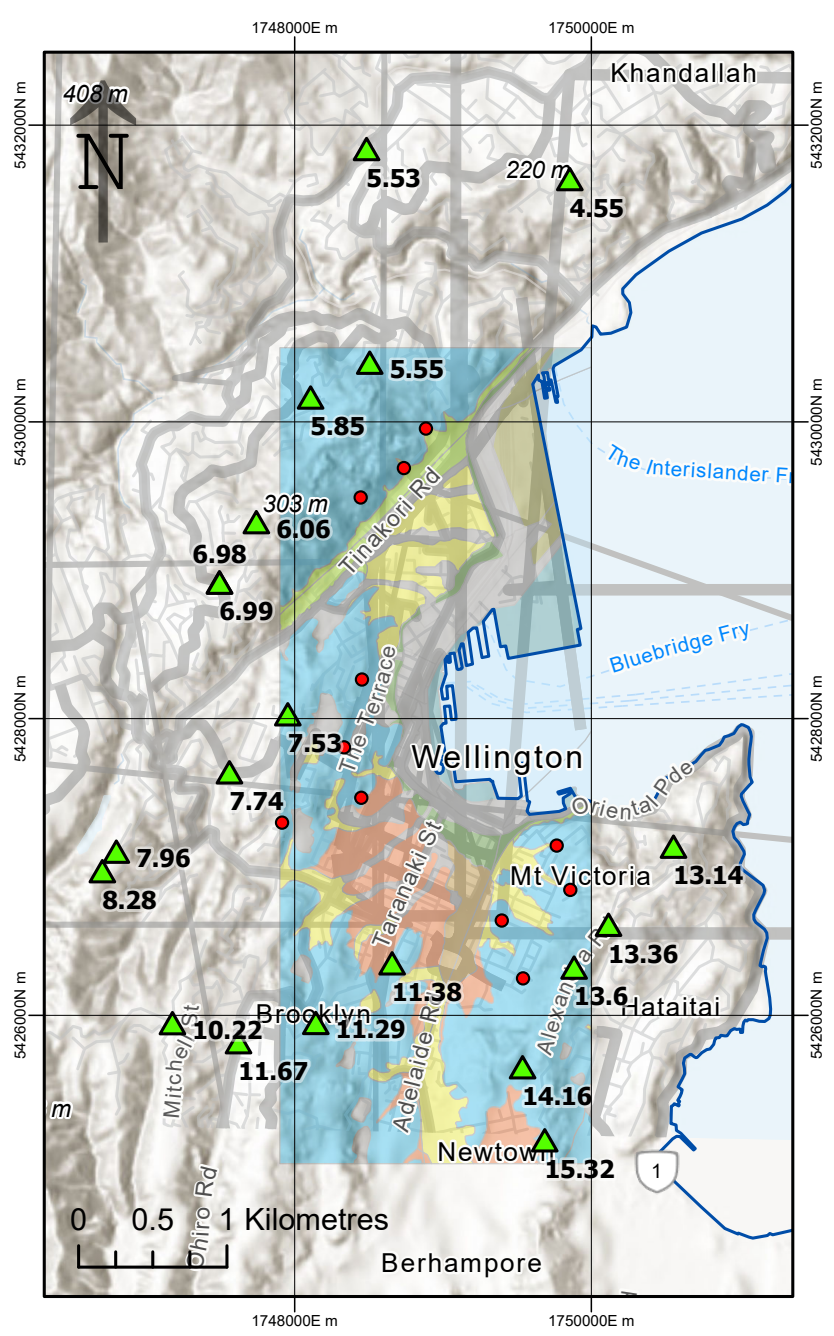

Figure 2.15: Map showing locations of the regional gravity stations (green triangles) and profile stations used in the regional gravity calculation (red circles). Bouguer anomalies are given for each regional station. The coloured rectangle in the centre is lithology - blue is greywacke and other colours basin sediments and fill.

were weighted higher to find as close to a zero residual as possible for the end of these lines. The chosen polynomial is shown in Figure 2.17, with a Standard Error (SE) of 0.07 and a Root-Mean-Square (RMS) error of $0.4 \mathrm{mGal}$.

The value of the polynomial was then found at the coordinates of every station, and this subtracted from the total Bouguer anomaly to find the residual anomaly:

$$
g_{\text {residual }}=g_{b a}-g_{\text {regional }}
$$

It is important to note that separation of residual and regional fields is a subjective process, there being room for interpretation in weighting of observations and selection of the polynomial order. There are not any such entities as "the" regional field and "the" residual field for a specific region. The range of possibilities in the regional anomaly, and their effect on the resulting geological models, is examined in Appendix D. 


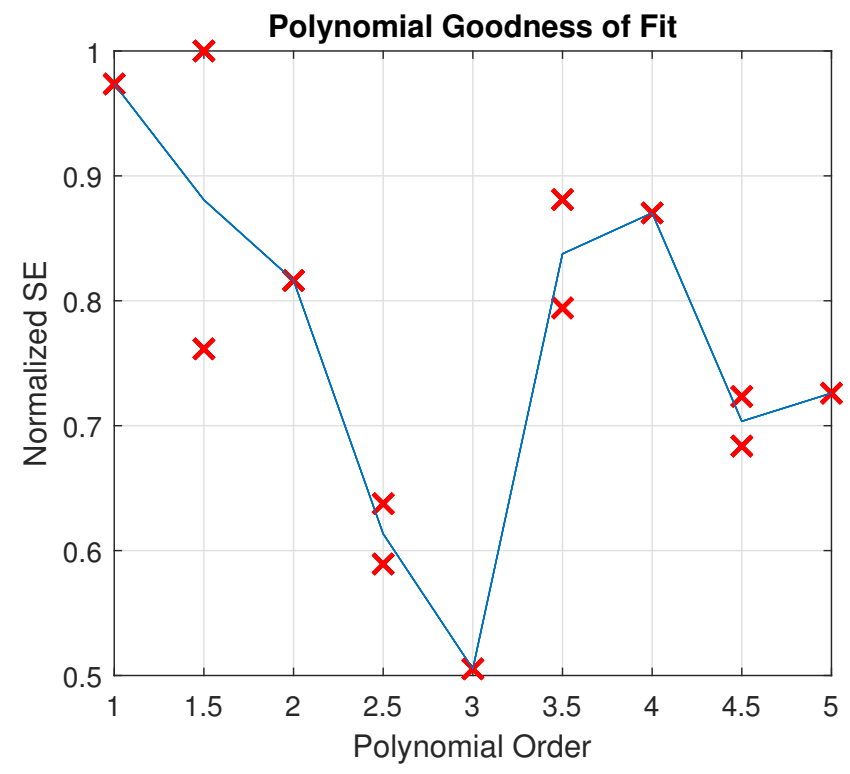

Figure 2.16: Goodness of fit of different order polynomials to the regional station Bouguer anomalies. Normalized Standard Error (SE) is plotted against polynomial order, where "half" orders refer to polynomials of different orders in the X and Y directions. The blue line represents the average of the half orders. Note a clear minimum at the third order.

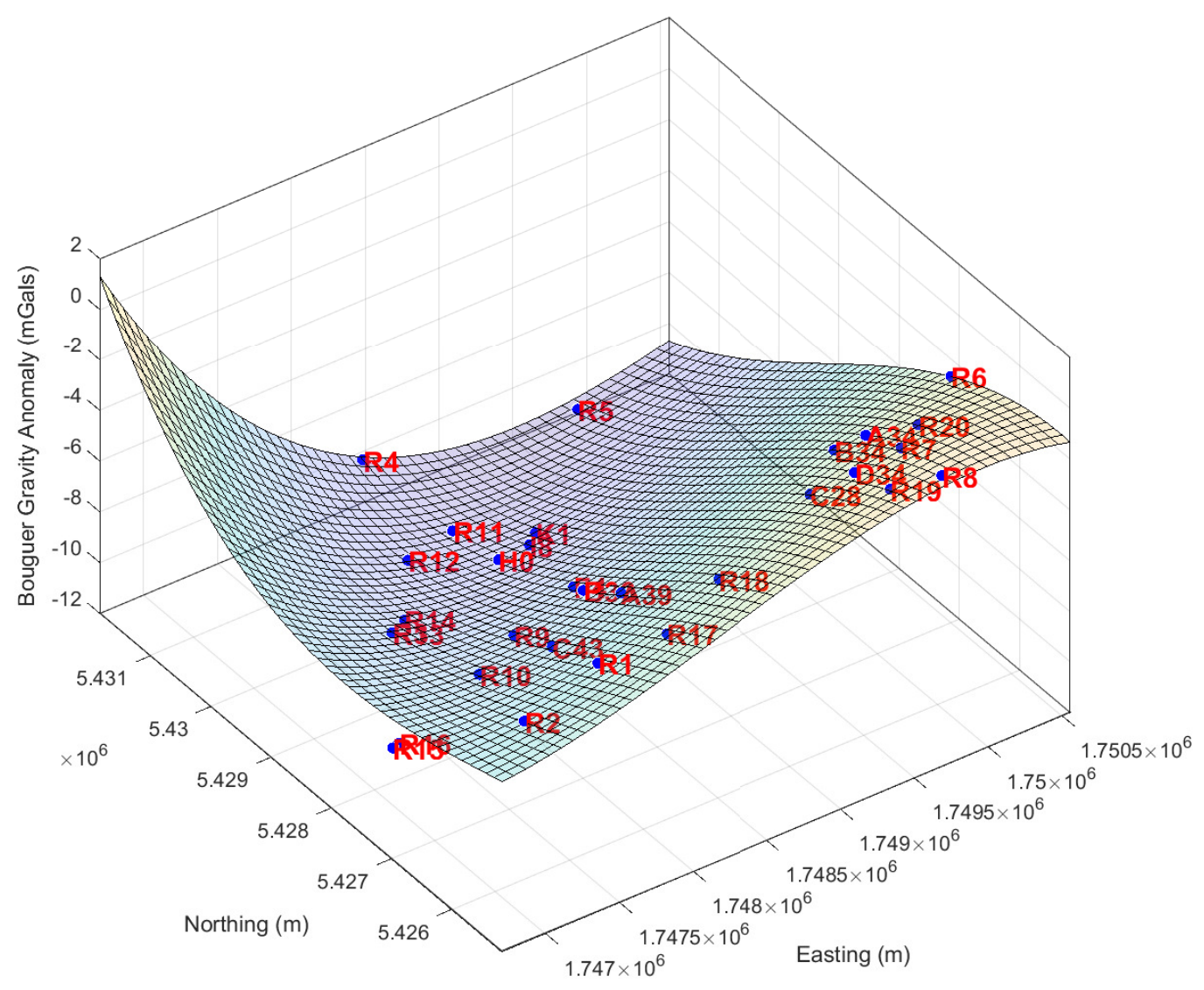

Figure 2.17: A surface representing the best fit third order polynomial through the basement gravity stations shown. 


\subsubsection{Data Reduction Summary}

The overall process of "reducing" observations to a gravity anomaly is referred to as data reduction. As a recap, the data reduction steps are as follows:

1. Calculate expected gravity at a location according to equation 2.11:

$$
g_{c a l c}=g_{1980}+g_{f a}+g_{b p}-g_{t c}-g_{b c}
$$

2. Measure relative gravity at a location and convert to absolute observed gravity according to equation 2.13:

$$
g_{\text {obs }}=g_{\text {absolute }}(\text { base })-g_{\text {relative }}(\text { base })+g_{\text {relative }}(\text { field })
$$

3. Calculate the Bouguer anomaly as the difference of the two, according to equation 2.14:

$$
g_{b a}=g_{o b s}-g_{c a l c}
$$

4. Remove the regional gravity anomaly to find the residual (local) gravity anomaly according to 2.15:

$$
g_{\text {residual }}=g_{b a}-g_{\text {regional }}
$$

The final $g_{\text {residual }}$ values are those used in geological modelling in the next step. 


\subsubsection{Uncertainties}

\section{Field Measurements}

\section{GPS Coordinates}

As described in Section 2.3.3, sources of error are poor accuracy due to poor satellite lock and incorrect placement of the GPS. GPS vertical accuracy was usually $1 \mathrm{~cm}$, and to account for other factors was usually recorded as $5 \mathrm{~cm}$.

GPS Horizontal accuracy is usually better than vertical accuracy, i.e. better than $1 \mathrm{~cm}$. The GPS was usually positioned within $50-25 \mathrm{~cm}$ of the CG-6, and this was used as the uncertainty for both Easting and Northing.

\section{Gravity measurements}

Four measurements of one minute each were taken at each station. Any clearly anomalous measurements were discarded, then the remainder were averaged. Usually there would be one or two anomalous measurements in a day of surveying. The range of the average measurements was used as the uncertainty, usually between 0.001 $0.01 \mathrm{mGal}$. Likewise, an uncertainty was found for measurements at VUW used in the calculation of drift and conversion to absolute gravity.

\section{Data Processing}

\section{Conversion to Absolute Gravity}

This relies on an accurate absolute measurement at the VUW station. However, any uncertainty in this measurement will introduce a constant, systematic error to all measurements. Because we are interested only in residual anomalies, not absolute gravity, this does not affect the uncertainty of the models. An uncertainty is assigned to the VUW value of $0.005 \mathrm{mGal}$, this being half the precision of the measurement, but this impacts only on the absolute gravity values.

\section{Terrain and Building Corrections}

These depend primarily on the accuracy of the DEM. As the inner terrain correction DEM has $2 \mathrm{~m}$ resolution, accuracy is good, but errors can still arise in areas of dense tree cover due to imperfectly removed trees, near imperfectly removed buildings and slopes with laterally rapid change in gradient. As mentioned in Section 2.2.4, the effect of decreasing DEM resolution on terrain corrections was tested, which 
necessarily introduces some uncertainty. Results are in the supplementary data file "TC_Sensitivity_Testing.xls", but as an example decreasing resolution from $2 \mathrm{~m}$ to $4 \mathrm{~m}$ introduced a maximum variance in terrain correction for Line A stations of $\sim 0.005 \mathrm{mGal}$, a negligible value.

Another test undertaken was to introduce error into the $2 \mathrm{~m}$ resolution DEM by adding a random value between -1 and $1 \mathrm{~m}$ to every pixel, as this was estimated to be the greatest probable error. This caused a maximum variance of $\sim 0.02 \mathrm{mGal}$. The average variance was $0.013 \mathrm{mGal}$, or $1.7 \%$, and this percentage was used as the terrain correction uncertainty. Details of this test are also in "TC_Sensitivity_Testing.xls". Independent testing on the building correction uncertainty was not undertaken as this would be negligible, and so the same value of $\pm 1.7 \%$ was used.

\section{Regional - Residual Separation}

As the regional - residual separation is a matter of interpretation, the uncertainty introduced by this process is not included in the formal uncertainty calculated for each residual anomaly. The effect of adopting different regional fields is discussed in Appendix D.

These uncertainties combined give an average of $\pm 0.04 \mathrm{mGal}$, with $95 \%$ of anomaly uncertainties less than $\pm 0.07 \mathrm{mGal}$, as detailed in the supplementary data file "Observations.xlsx". Where it is particularly higher than average, this is due to noisy measurements or the GPS being unable to get an RTK lock on the site, in which case the DEM elevation was used for calculation of the free air and Bouguer plate corrections.

This level of accuracy represents a significant improvement over historic gravity surveys. For example, Reilly (1972) reports estimated uncertainties of $> \pm 1.5 \mathrm{mGal}$ in the gravity anomalies used to construct the New Zealand gravity map series.

\section{Repeatability}

As an alternative measure of uncertainty, repeatability tests were undertaken. Fifteen gravity stations were remeasured on later dates, both with the CG-6 and the GPS, and the entire processing sequence repeated for this data. Results of this analysis are given in Section 3.1.2, but most repeats were within $0.02 \mathrm{mGal}$ of the original measurement. 


\subsection{Gravity Anomaly Maps}

Bouguer gravity anomaly and residual gravity anomaly maps have been produced using Oasis and ArcGIS Pro. Point data for all stations were loaded into Oasis, and $10 \mathrm{~m}$ resolution grids for both Bouguer anomaly and residual anomaly were created using the Kriging method (Oliver \& Webster, 2014). These were then transferred to ArcGIS Pro for the generation of figures.

\subsection{Gravity Modelling}

Two-dimensional gravity modelling is done in Geosoft ${ }^{\circledR}$ GM-SYS, an extension of Oasis Montaj. A vertical "profile" along a line of gravity stations is created, a background density is assigned to the crust of $2.67 \mathrm{Mg} / \mathrm{cm}^{3}$ and blocks of any arbitrary shape are created within it, each with an assigned density as per Table 1.2. GM-SYS calculates the theoretical gravity response of this model and displays it atop the measured anomaly data. The model is adjusted interactively to bring the calculated and measured anomalies into as close an alignment as possible.

Profiles are adjusted to fit constraints and each other as well as possible. Data from all profiles were then extracted into ArcGIS Pro for 3D modelling using interpolation between profiles.

\subsubsection{Profile Modelling}

The procedure for profile modelling is the same for each of the twelve profiles (displayed on the map in Figure 3.1). A straight line was first chosen in ArcGIS Pro as a best fit through the gravity stations to comprise the profile. For survey lines that terminate on a hill, the profile line was extended at least $200 \mathrm{~m}$ up those hills. For lines that end at the coast, it was extended up to $2 \mathrm{~km}$ away from the coast. These sections needed to be modelled, as the gravity anomaly generated by Earth structure beyond the ends of the survey lines will form a part of the anomaly measured at each station.

Along the line the DEM is point sampled at $25 \mathrm{~m}$ intervals. This creates a file of XYZ co-ordinates, which is imported into GM-SYS to form the terrain for the profile. Then the gravity observations are imported, as 4D data: XYZ and gravity anomaly (mGal). GM-SYS automatically fits a line to the gravity stations and projects each station onto 


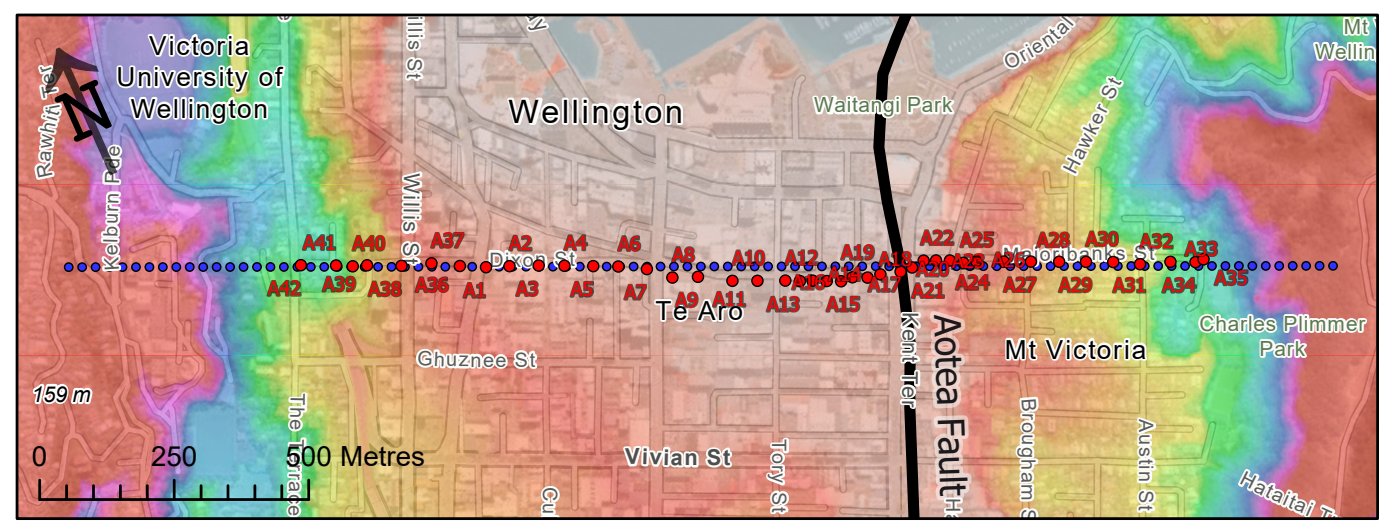

Figure 2.18: An example of the topography point sampling in ArcGIS Pro. Points (blue) have been created at $25 \mathrm{~m}$ intervals along a line of best fit though the Line A gravity stations (red). The DEM elevation (coloured background) at each of these points is exported for upload into GM-SYS.

the line. The coordinates of the stations are then converted to model co-ordinates, which start at $\mathrm{X}, \mathrm{Y}, \mathrm{Z}=0$ at the left hand (eastern) end of the line, with $\mathrm{X}$ increasing to the right, $\mathrm{Z}$ increasing down and $\mathrm{Y}$ increasing away from the viewer.

A rough outline of the expected shape of the basin is created, with a density being the average of the values in Table 1.2, of $\sim 2.15 \mathrm{mg} / \mathrm{cm}^{3}$. The limits of the basin are determined by the geological mapping in Figure 1.7. The basin shape is then adjusted to bring the calculated anomaly into near alignment with the observed anomaly. The reason for doing a rough model first is that it makes adjustment of fault locations easier, and avoids the trap a modeller might fall into of tweaking an existing complex model when what is required is a rethink of the overall shape.

Boreholes are then entered into the profile as "wells" with NZTM collar co-ordinates. Downhole depth interpretations for the units of anthropogenic fill, surface sediments, buried sediments, deeply buried sediments and greywacke are added. The holes are projected onto the profile line, and displayed as a guide during modelling. The Leapfrog model sections (see Section 1.5.3) are also loaded, and manually georeferenced to be displayed as a "backdrop".

The sedimentary basin can then be broken into the four separate units (or three if no fill is present), at the depths given by the boreholes and by the Leapfrog sections. The basin depth is again adjusted to fit the gravity anomaly. Generally the Leapfrog sections were used as a guide where no other information exists, e.g. outside of the range of the gravity stations and for the depths for the sedimentary units that do not contact the basement. 
Strong adherence to the sections as regards to basin depth was not attempted, as this would result in simply reproducing the Leapfrog model. Indeed, deviation between the two is significant in several areas as shown in the results section.

\section{Shift}

For each profile an adjustment, or "DC Shift", was applied to the residual anomalies. This is a constant value subtracted from all observed residual anomalies before they are loaded into Oasis for modelling. This DC shift is specific to each line, and is negative in each case. It was required in order to match borehole constraints, as without it, a model which honoured the boreholes had an often poor fit between calculated gravity and observations (Figure 2.20 A). A DC shift which allowed the basin depth to match most closely to borehole depths, without sharp changes in the gradient of the bedrock interface, was found by trial and error for each profile (Figure $2.20 \mathrm{~B}$ ). For most lines it was $\sim-0.5 \mathrm{mGal}$, but ranged from -0.13 to $-1.37 \mathrm{mGal}$. This means the "adjusted" residual anomaly modelled on the profiles is not the same as the observed residual anomaly.

For those profiles that do not have boreholes to bedrock, DC shifts were determined by profile intersections. Three profiles were designed as "tie-lines", crosscutting other profiles. Where profiles intersect, a dummy borehole was added to each with the depth to bedrock of the other profile. Profiles without boreholes to bedrock can then have DC shifts applied to align them with the cross cutting ones that do. In some cases a chain of profiles was created - the first had strong controls, intersected another one with weak or no controls which was given a DC shift to fit, and a third profile was made to fit the second.

\section{Weathered Greywacke}

On the Te Aro lines there was a misfit seen on the hills bounding the basin after addition of the DC shift. (Figure $2.20 \mathrm{~B}$ ). To fit the data it was necessary to add a lower density block to the hillsides around Te Aro, interpreted as weathered greywacke (Figure 2.20 C). The same interpretation was made by Kellett et al. (2017) for their survey in Upper Hutt (Figure 2.19). Kellett et al. (2017) used densities of $2.40-2.50 \mathrm{Mg} / \mathrm{cm}^{3}$ for a $100 \mathrm{~m}$ deep block, and $2.40 \mathrm{Mg} / \mathrm{cm}^{3}$ was also assigned here as it provided a good fit to the observations. The requirement for a DC shift and for a weathered greywacke unit is discussed further in Section 4.2. 

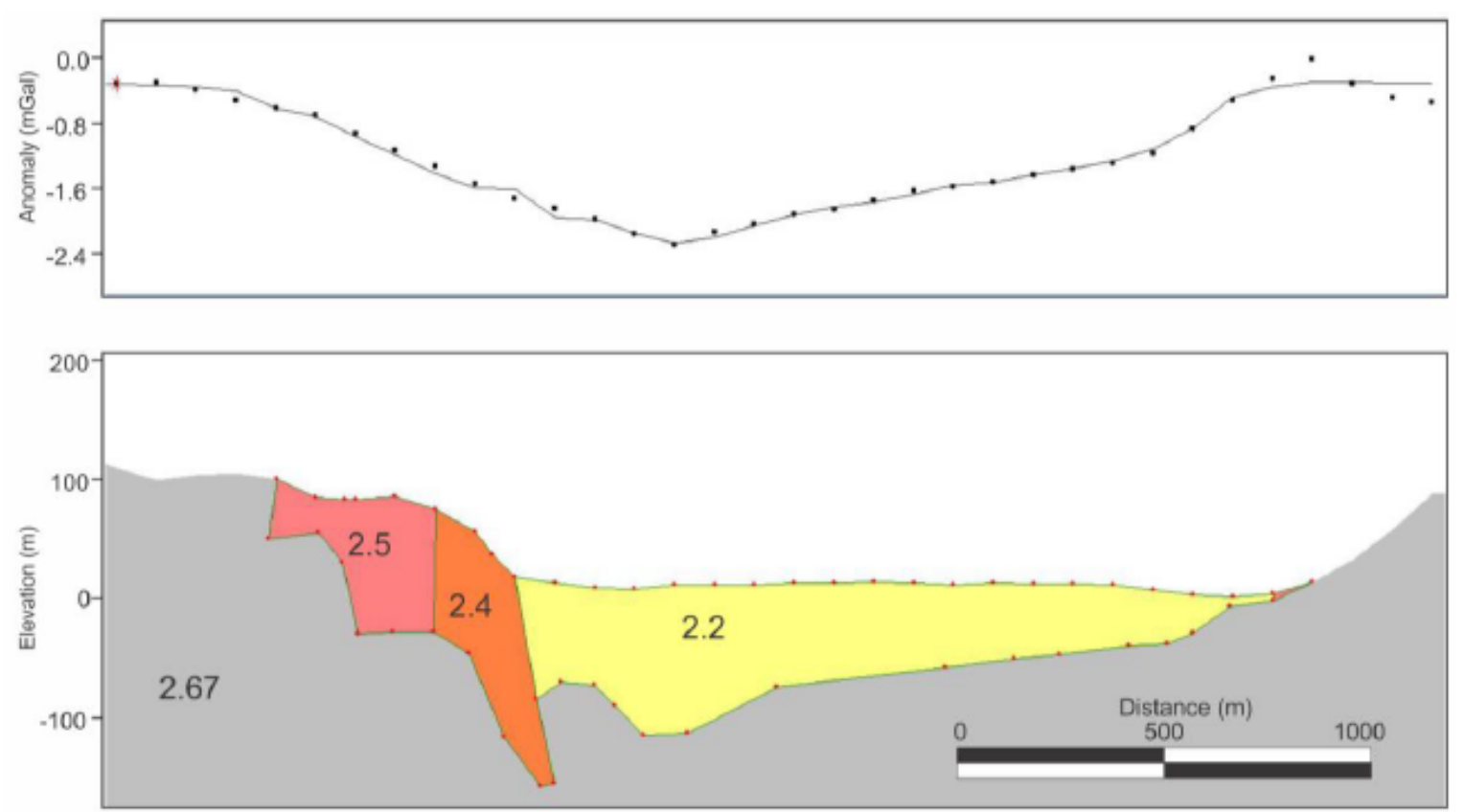

Figure 2.19: A gravity profile model presented by Kellett et al. (2017) for their line across the Wellington Fault in the Hutt Valley. A wedge of weathered greywacke is modelled to a depth of greater than $200 \mathrm{~m}$ adjacent to the Wellington Fault, with a density of $2.40 \mathrm{Mg} / \mathrm{cm}^{3}$. 


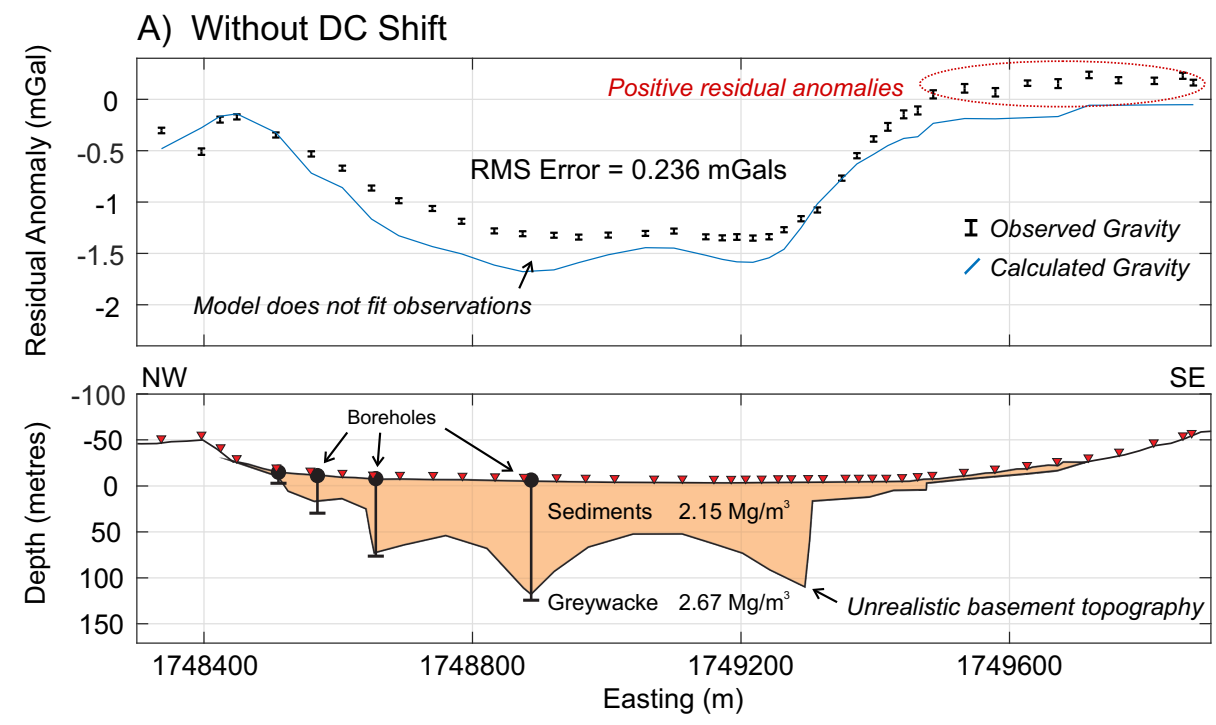

B) With $-0.80 \mathrm{mGal}$ DC Shift
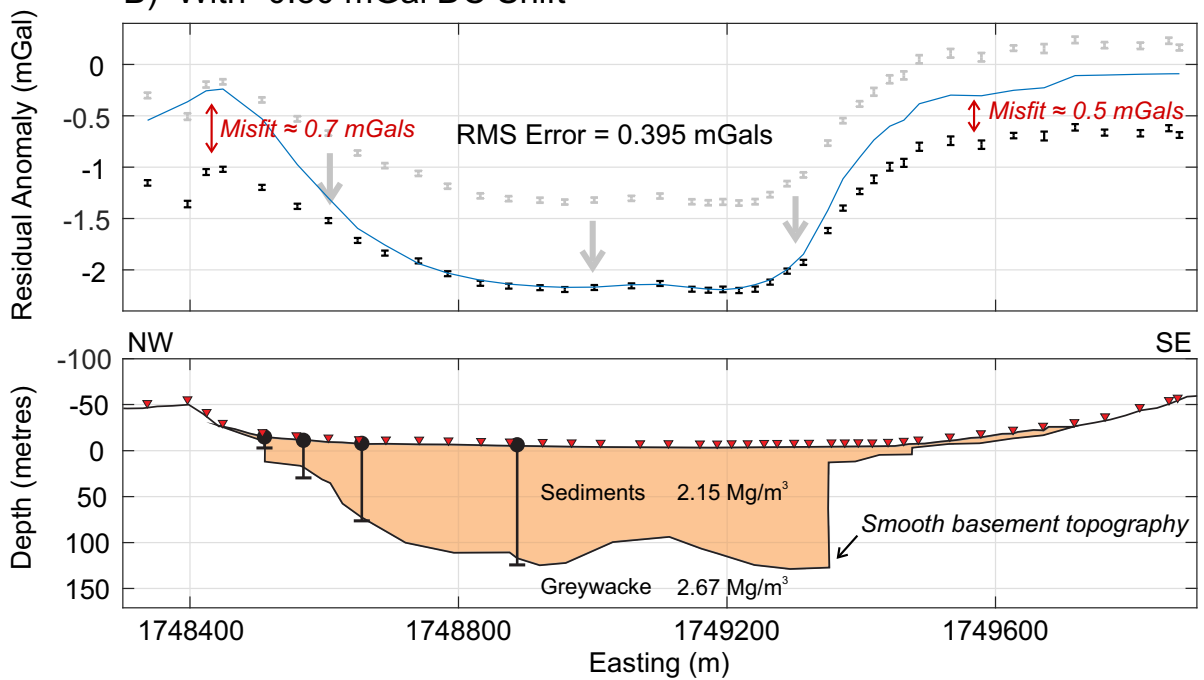

C) With Addition of Weathered Greywacke
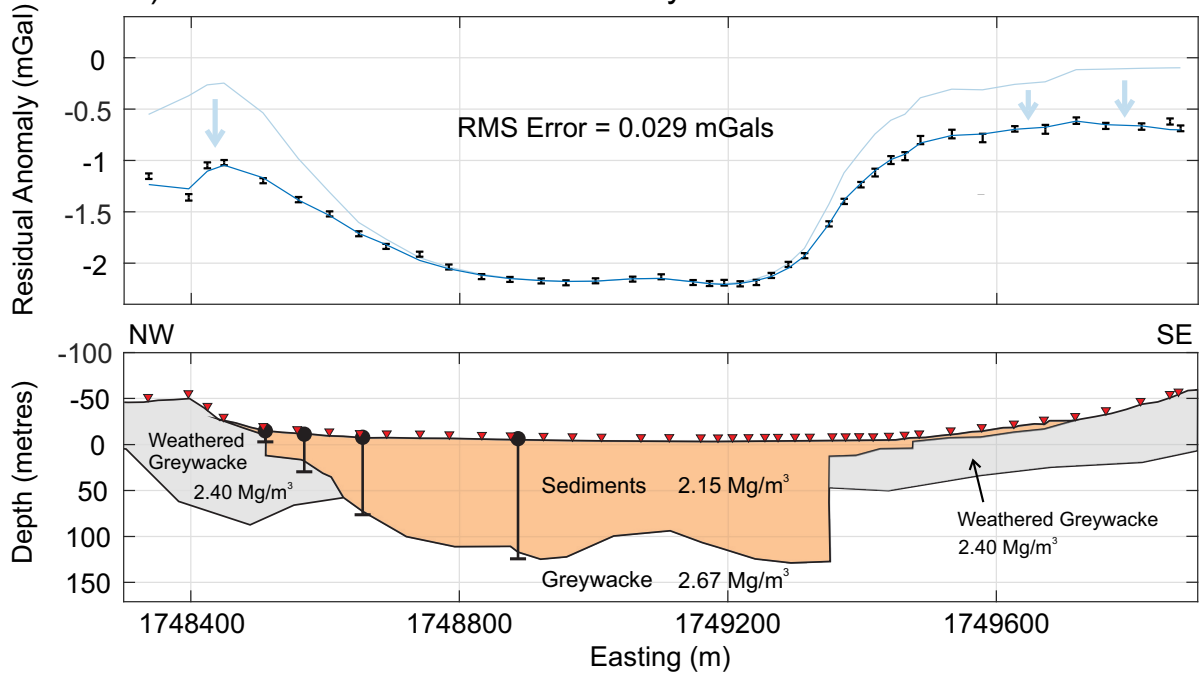

Figure 2.20: A) Line A geological profile with no DC shift, showing the poor fit resulting from honouring the borehole basement constraints. B) The addition of a $-0.8 \mathrm{mGal} \mathrm{DC}$ shift allowing the model to best fit basin observations while maintaining smooth, realistic basement topography. This introduces a misfit on the hills adjacent to the sedimentary basin. C) Addition of a zone of lower density, weathered greywacke on the hills which fits the gravity observations. 


\section{Urban Considerations}

State Highway One provided some unique complexities while modelling. Every line bar one (Line $\mathrm{G}$ ) crosses it, and at most of those sites it is either a tunnel or a deep depression in the terrain. Where it is simply a depression the DEM is sufficiently high resolution to capture it and so its effect is incorporated into the terrain correction. Where it is a tunnel, it has been modelled as a square of $\sim 30 \times 30 \mathrm{~m}$, at $10 \mathrm{~m}$ depth and with a density of zero.

For one line (Line I) where gravity stations were on a bridge, it was modelled as a zero density rectangle at the surface. In this case the SH1 depression had to be removed from the DEM and the terrain elevated to approximately the height of the bridge, as otherwise the effect of the depression would be accounted for twice - in the model and in the terrain correction. This was done via the Topo to Raster function in ArcGIS. In a final case for points at either end of a bridge, but not on it, the bridge itself was removed from the DEM as it would create an erroneously low terrain correction, by a small amount.

\subsubsection{Three-Dimensional Basin Depth Modelling}

Once all profiles were completed, the resulting depth data were combined to generate a basin depth map for the Wellington CBD. This was done by first extracting point data at $10 \mathrm{~m}$ horizontal spacing from GM-SYS, which resulted in a series of NZTM XYZ coordinates for the interface between each unit at $10 \mathrm{~m}$ spacing along the profile. This does have the drawback that overhangs are not captured - i.e. reverse faults, as this would result in two $\mathrm{Z}$ values for a given interface at a given $\mathrm{XY}$. The point data were then uploaded into ArcGIS for interpolation via the "Spline with Barriers" function.

A spline is a mathematical construct of multiple different polynomials fitted together. It has the advantage over polynomial interpolation that it avoids Runge's phenomenon of oscillation in unconstrained areas, particularly edges, for higher polynomial degrees (Ahlberg et al., 1967). The ArcGIS function creates a spline function that passes exactly through all the data points while minimizing curvature - i.e. minimizing the sum of the squares of the second derivative terms of the spline function (Esri, 2020a). 


\section{Faults}

The barriers function in Arc GIS allows specification of 2D lines representing faults to be considered as barriers for the purposes of interpolation, meaning when the best fit spline is being calculated for points on one side of the line points on the other side are not considered. Prior to this step, lines representing fault surface traces need to be created. These were made for the Wellington and Aotea faults, the major bounding faults of the basin. A short section of the Lambton Fault was also created across two lines. The GNS fault traces were used as a starting point, and edited to fit the interpretation of the profiles. This approach necessarily means all faults are considered to be vertical for the purposes of the 3D basin depth model.

\section{Boreholes}

Point data from boreholes are also included. All boreholes with greywacke logged were extracted from the GNS database, and downhole depth of the intersection plus elevation calculated. This was loaded into ArcGIS as point data and added to the point data from the GM-SYS profiles for use in the spline fitting. In addition, all boreholes both over $50 \mathrm{~m}$ deep and without a greywacke intersection were loaded into ArcGIS similarly, as these represent a minimum basement depth. The data were not used in the spline fitting, but as a visual check against the output to ensure it did not contradict any of the minimum depth points.

\section{Dummy Points}

Some dummy points were created and included in the spline fitting as well. This was done to force a more natural curve in certain places and avoid the overshoot type output which polynomials often have, where a polynomial between two points with the same or similar values will interpolate spuriously higher or lower values as it curves between them. 


\section{Chapter 3}

\section{Results}

\subsection{Gravity Observations}

In total, 565 gravity measurements were made (Table 3.1). Four hundred and four observations were used in the construction of 13 2D profiles (Figure 3.1). Forty-six were measurements made at VUW to calculate and correct for instrument drift, to link measurements into the New Zealand Gravity Network and to convert to absolute gravity. Ten were made during the calibration run, 15 were made to test repeatability, and 19 were made to construct a regional gravity field for subtraction from the total Bouguer anomaly.

The remaining 71 measurements were made for use only in the residual anomaly map, or for profiles for which modelling was not successful (Lines F, L \& M). Measurements and all corrections associated with data reduction for each station are given in the supplementary data file "Observations.xlsx". 


\begin{tabular}{|c|c|c|}
\hline Line/Group & No. Measurements & Purpose \\
\hline Line A & 42 & Profile \\
\hline Line B & 53 & Profile \\
\hline Line $\mathrm{C}$ & 41 & Profile \\
\hline Line D & 34 & Profile \\
\hline Line $\mathrm{G}$ & 32 & Profile \\
\hline Line $\mathrm{H}$ & 28 & Profile \\
\hline Line I & 31 & Profile \\
\hline Line $\mathrm{J}$ & 43 & Profile \\
\hline Line $\mathrm{K}$ & 16 & Profile \\
\hline Line $\mathrm{N}$ & 7 & Profile \\
\hline Line $\mathrm{T}$ & 26 & Profile/Undergraduate class \\
\hline Line $U$ & 34 & Profile \\
\hline Line W & 17 & Profile/Undergraduate class \\
\hline Profile Subtotal & 404 & \\
\hline Base Station & 46 & Drift correction and gravity network tie \\
\hline Calibration & 10 & Calibration run \\
\hline Group E & 26 & Residual anomaly map \\
\hline Line $\mathrm{F}$ & 18 & Possible profile/Residual anomaly map \\
\hline Line L & 7 & Possible profile/Residual anomaly map \\
\hline Line $\mathrm{M}$ & 4 & Possible profile/Residual anomaly map \\
\hline Rail Corridor & 12 & GNS survey/Residual anomaly map \\
\hline Repeats & 15 & Repeatability \\
\hline Regional & 19 & Regional gravity field calculation \\
\hline Miscellaneous & 4 & Opportunistic/Residual anomaly map \\
\hline Other Subtotal & 161 & \\
\hline Grand Total & 565 & \\
\hline
\end{tabular}

Table 3.1: List of gravity measurements grouped by profile line or purpose of measurement. 


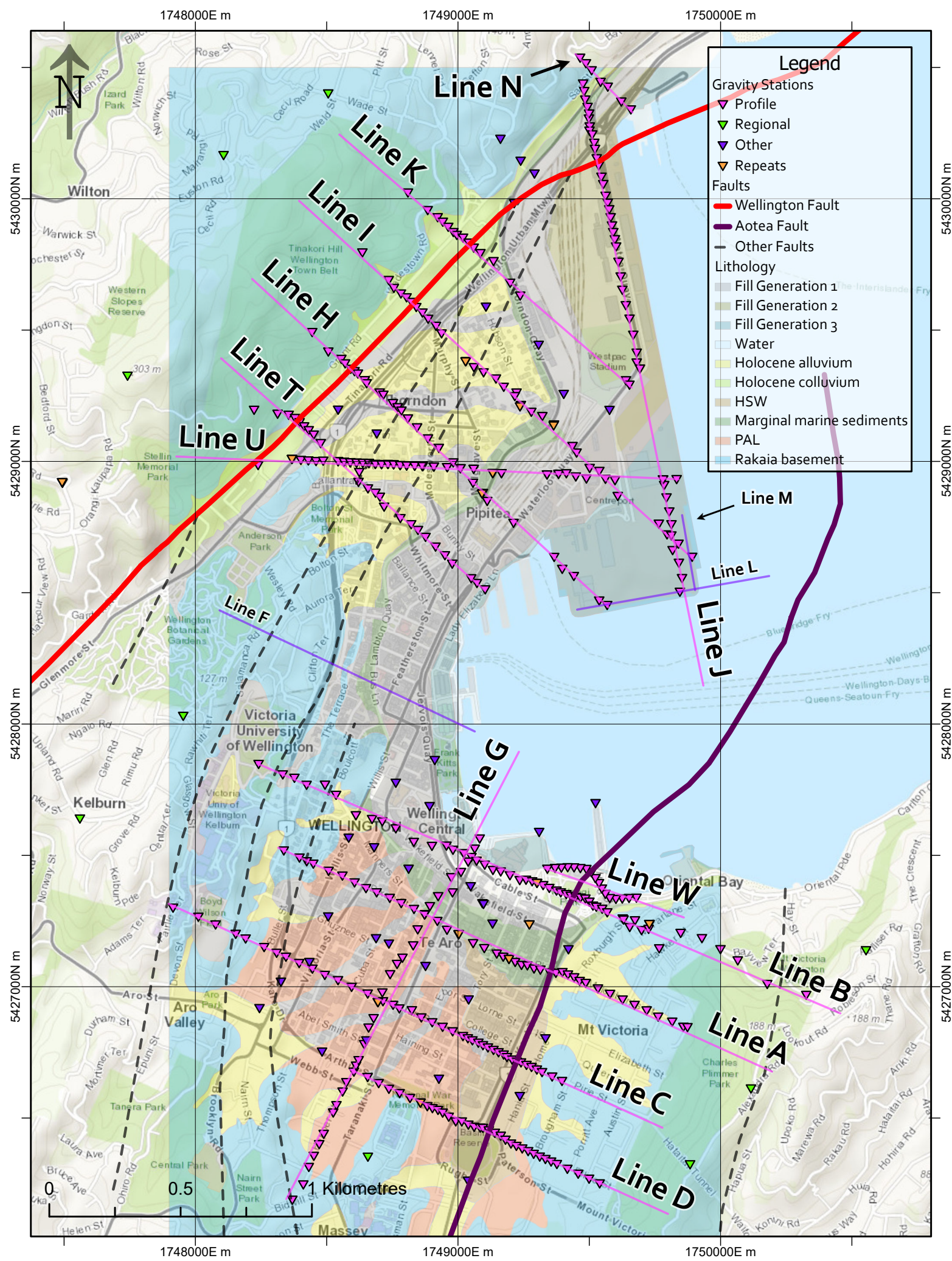

Figure 3.1: Location map for profiles and gravity stations measured for this project in the Wellington CBD. Some regional stations further afield are not shown. Lithology backdrop provided by Matt Hill, GNS Science. 


\subsubsection{Comparison with Historical Observations}

Historical gravity observations in Wellington were downloaded from the "E Tūhura - Explore Zealandia" (TEZ) website, maintained by GNS and accessible at:

https://data.gns.cri.nz/tez/index.html?map=TEZ-Geoscience

The location of some stations in this project were chosen to coincide with existing gravity stations, most of which were used in the Cowan and Hatherton (1968) and Hatherton and Sibson (1969) surveys. This was done simply to take the opportunity to compare modern measurements with the existing observations from $50+$ years ago.

mGal

\begin{tabular}{l|cc|cc|cc}
\cline { 2 - 7 } & \multicolumn{2}{c}{ Bouguer } & Anomaly & \multicolumn{2}{c}{ Terrain Correction } & \multicolumn{2}{c}{ Difference } \\
\hline Station & New & Old & New & Old & BA & TC \\
\hline R7 & 2.89 & 2.89 & 2.81 & 1.52 & 0.00 & 1.29 \\
A35 & 2.36 & 1.31 & 1.35 & 0.92 & 1.05 & 0.43 \\
D26 & 1.68 & 1.47 & 0.74 & 0.66 & 0.21 & 0.08 \\
A24 & 1.01 & 0.42 & 0.72 & 0.64 & 0.59 & 0.08 \\
R1 & 0.96 & 0.38 & 1.15 & 0.84 & 0.58 & 0.31 \\
E7 & 0.50 & -1.17 & 0.70 & 0.58 & 1.67 & 0.12 \\
E1 & 0.19 & -0.18 & 0.66 & 0.61 & 0.37 & 0.05 \\
A10 & -1.11 & -5.87 & 0.67 & 0.61 & 4.76 & 0.06 \\
E14 & -1.32 & -1.75 & 0.70 & 0.65 & 0.43 & 0.05 \\
E9 & -1.72 & -5.49 & 0.91 & 0.78 & 3.77 & 0.13 \\
E10 & -2.06 & -5.47 & 0.77 & 0.74 & 3.41 & 0.03 \\
U9 & -4.13 & -5.17 & 2.66 & 1.82 & 1.04 & 0.84 \\
T41 & -4.46 & -4.91 & 1.18 & 1.02 & 0.45 & 0.16 \\
H2 & -4.63 & -6.47 & 3.24 & 1.60 & 1.84 & 1.64 \\
T12 & -4.85 & -5.19 & 1.34 & 1.28 & 0.34 & 0.06 \\
T20 & -4.99 & -5.29 & 1.10 & 1.09 & 0.30 & 0.01 \\
T16 & -5.01 & -5.33 & 1.19 & 1.18 & 0.32 & 0.01 \\
R4 & -5.19 & -4.47 & 1.24 & 1.34 & -0.72 & -0.10 \\
T25 & -5.44 & -5.86 & 0.90 & 0.86 & 0.42 & 0.04 \\
K6 & -6.08 & -6.84 & 1.81 & 1.32 & 0.76 & 0.49 \\
I6 & -7.20 & -7.62 & 0.84 & 0.75 & 0.42 & 0.09 \\
I1 & -7.60 & -7.98 & 0.66 & 0.60 & 0.38 & 0.06 \\
\hline & & & & Average & $\mathbf{1 . 0 2}$ & $\mathbf{0 . 2 7}$ \\
& & & & & &
\end{tabular}

Table 3.2: List of gravity measurements made at stations near to historical stations. Bouguer anomalies are calculated using the 1930 gravity formula. Greater variances in Bouguer anomaly and terrain correction are highlighted red.

Table 3.2 gives a list of gravity stations which are within $15 \mathrm{~m}$ of historical stations, calculated Bouguer anomalies and terrain corrections for each, and the variance in each between 


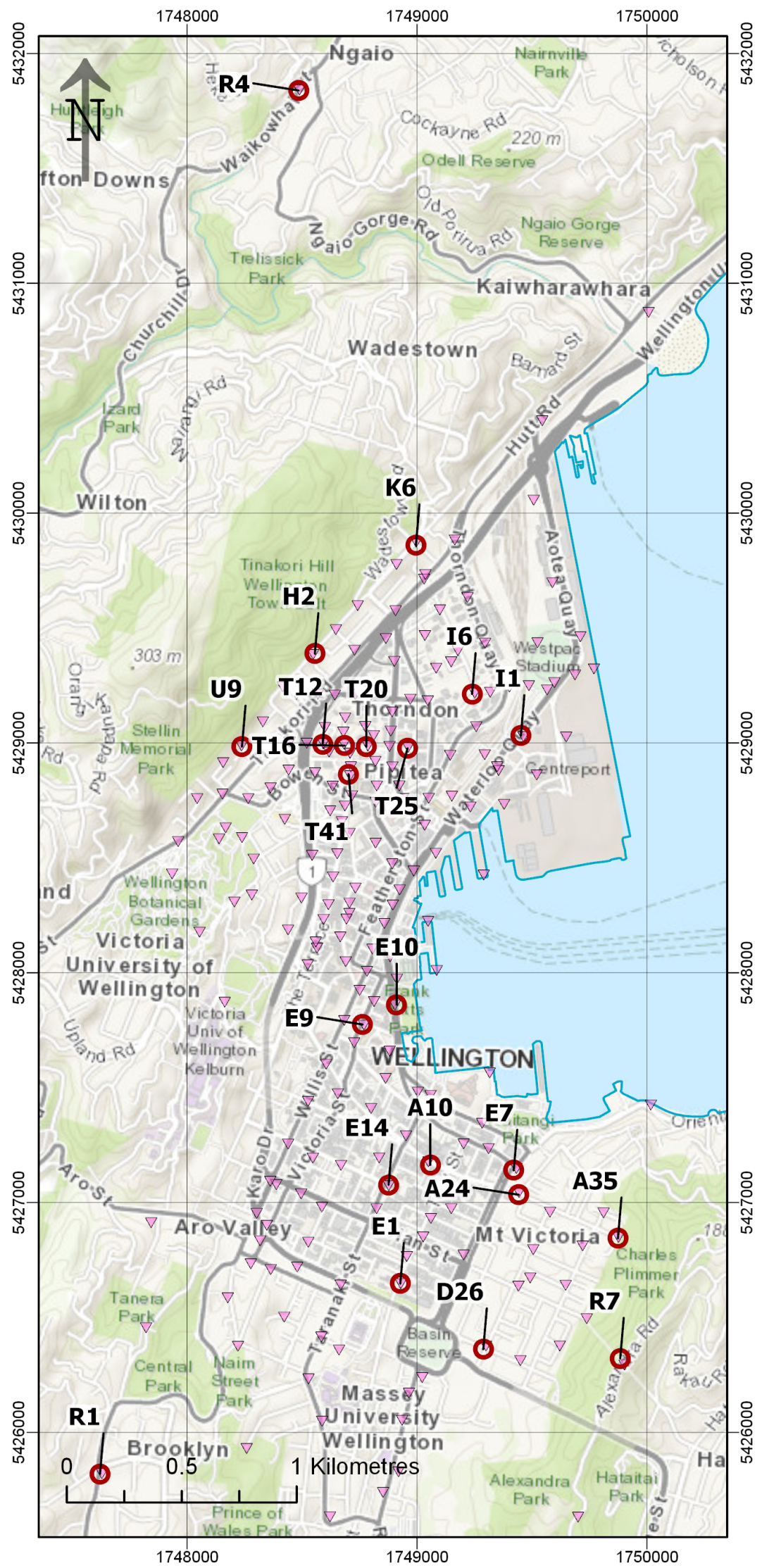

Figure 3.2: Location map for stations coinciding with historical stations. Historical stations are pink triangles, plotted using data downloaded from TEZ (GNS, 2021). 
old and new observations. Bouguer anomalies for new observations have been calculated using the 1930 International Gravity Formula (Section 2.2) to match the historical observations, and so do not correspond with the anomalies for these stations given elsewhere. Correlations between errors in terrain corrections, heights and Bouguer anomalies are examined in Appendix C, but a single source of error in the historical observations is not apparent.

\subsubsection{Repeats}

Fifteen repeat measurements were made at a random selection of stations over the course of data collection (Figure 3.1). Each was made on a different day from the original, and the entire processing sequence repeated. Repeats were consistent, with an average of $0.021 \mathrm{mGal}$ difference between pairs, and a maximum of $0.046 \mathrm{mGal}$ (Table 3.3). These all fall within calculated uncertainties for the given stations, giving high confidence in the repeatability of results.

\begin{tabular}{|c|c|c|c|c|c|}
\hline \multicolumn{6}{|c|}{ Repeat (mGal) } \\
\hline Station & 1 & 2 & 3 & Average (mGal) & Range (mGal) \\
\hline A9 & -1.32 & -1.34 & & -1.33 & 0.021 \\
\hline A 14 & -1.34 & -1.36 & & -1.35 & 0.024 \\
\hline B12 & -1.29 & -1.32 & -1.32 & -1.31 & 0.025 \\
\hline B29 & -0.26 & -0.25 & & -0.26 & 0.010 \\
\hline D6 & -0.44 & -0.45 & & -0.45 & 0.000 \\
\hline E6 & -1.40 & -1.45 & & -1.42 & 0.046 \\
\hline $\mathrm{C} 29 / \mathrm{G} 17$ & -1.08 & -1.05 & & -1.07 & 0.024 \\
\hline $\mathrm{H} 20$ & -2.65 & -2.63 & & -2.64 & 0.025 \\
\hline I3 & -4.42 & -4.45 & & -4.44 & 0.024 \\
\hline I6 & -3.69 & -3.71 & & -3.70 & 0.022 \\
\hline $\mathrm{I} 23$ & -2.51 & -2.50 & & -2.50 & 0.010 \\
\hline $\mathrm{R} 3 / \mathrm{R} 13$ & -8.86 & -8.88 & & -8.87 & 0.015 \\
\hline $\mathrm{T} 28$ & -2.83 & -2.81 & & -2.82 & 0.020 \\
\hline U10 & -0.44 & -0.41 & & -0.43 & 0.033 \\
\hline
\end{tabular}

Table 3.3: List of repeat measurements at gravity stations. Two stations were renamed when the repeat was measured. Greater differences between measurements are shaded red. 


\subsection{Gravity Anomaly Maps}

\subsubsection{Bouguer Anomaly}

The Bouguer anomaly map (Figure 3.3) shows the large scale trend of increasing anomaly to the NW due to the deep subduction zone beneath the North Island, with the anomaly increasing from $-2 \mathrm{mGal}$ at Mount Victoria to $-10 \mathrm{mGal}$ in Wadestown. This is overprinted by a strong local gravity low off the coast of Thorndon/CentrePort.

\subsubsection{Residual Anomaly}

Removal of the adopted regional gravity field gives the residual anomaly (Figure 3.4). A comparison with the residual anomaly of Hatherton and Sibson (1969) finds a similar shape and values, with a maximum anomaly in Te Aro of -1.5 mGal (Figure 3.5) and in Pipitea of -6.2 mGal (Figure 3.6).

In both studies there is a strong west-east gradient across Thorndon and Pipitea, with Hatherton and Sibson (1969) recording anomalies roughly $0.2 \mathrm{mGal}$ lower than those found in this study. The main area of difference is in the southeast of CentrePort, on reclaimed land which did not exist at the time of Hatherton \& Sibson's study. 


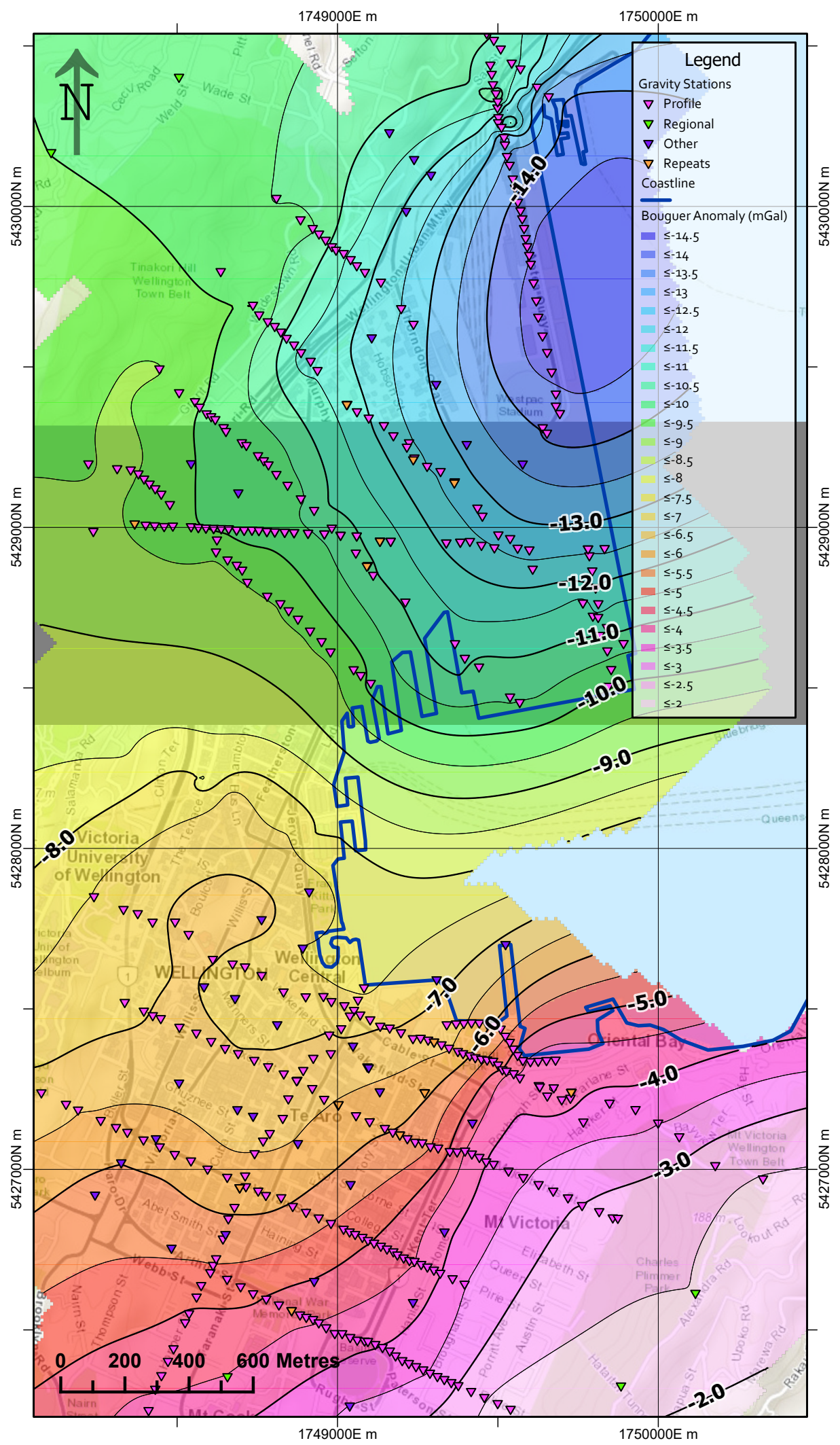

Figure 3.3: Bouguer anomaly map, in mGal. 


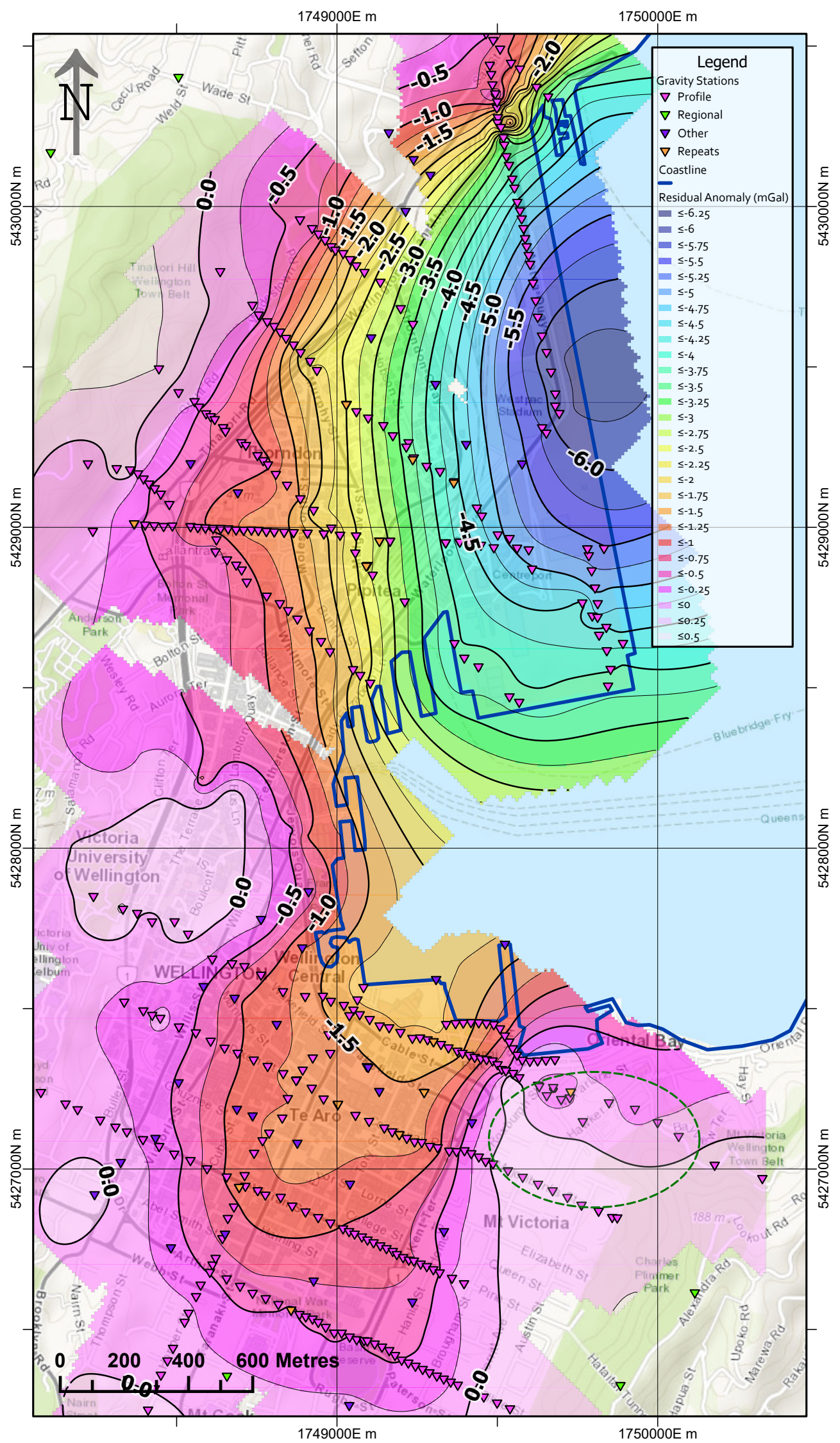

Figure 3.4: Residual anomaly map, contoured in mGal. The green circled area highlights variation in residual anomaly over bedrock. 


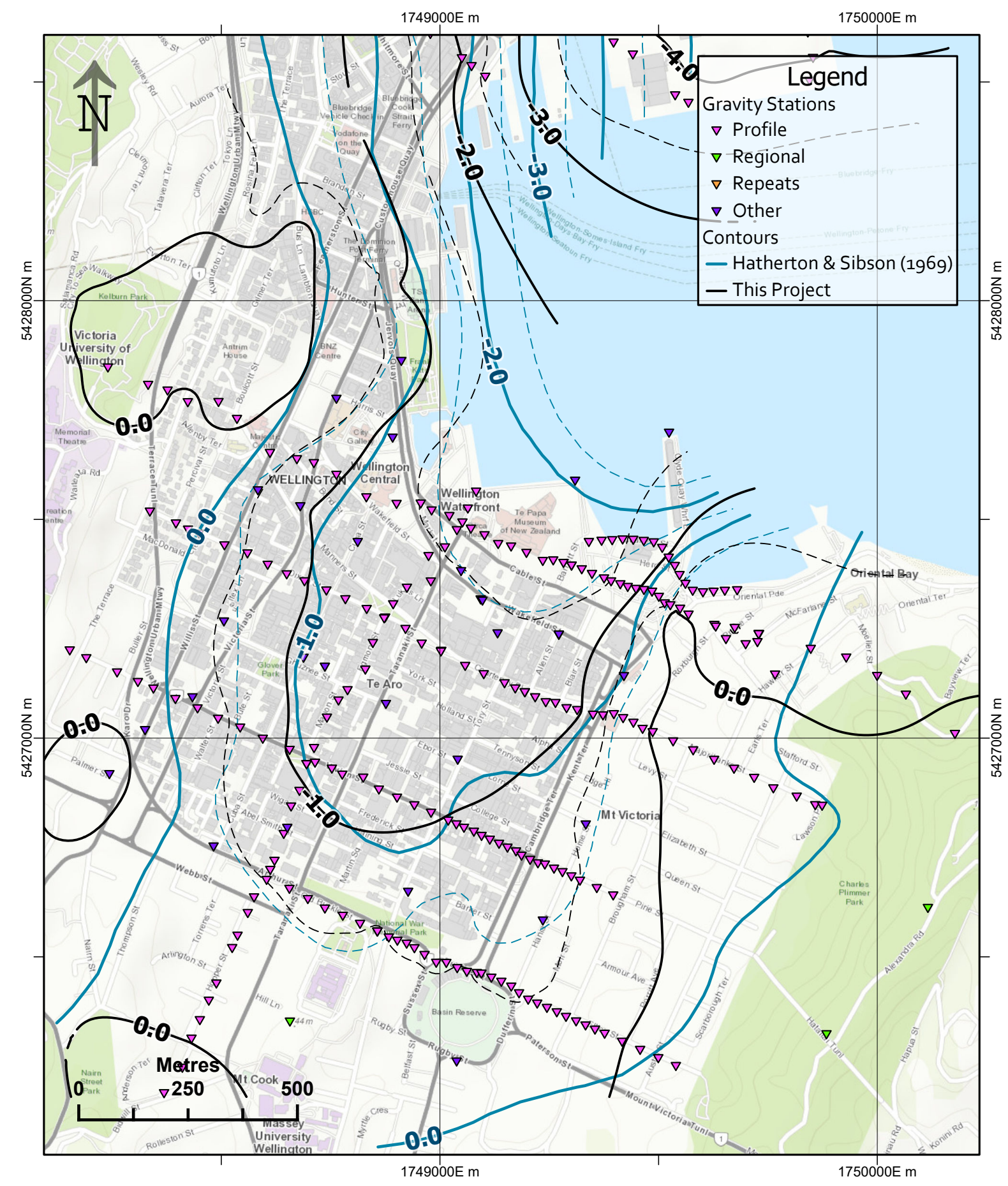

Figure 3.5: Map of Te Aro comparing the residual anomaly of Hatherton and Sibson (1969) with the residual anomaly found in this project. Hatherton \& Sibson's map has been georeferenced into ArcGIS Pro using street corners as known locations, and contours then traced manually. Contours are labelled in mGal. 


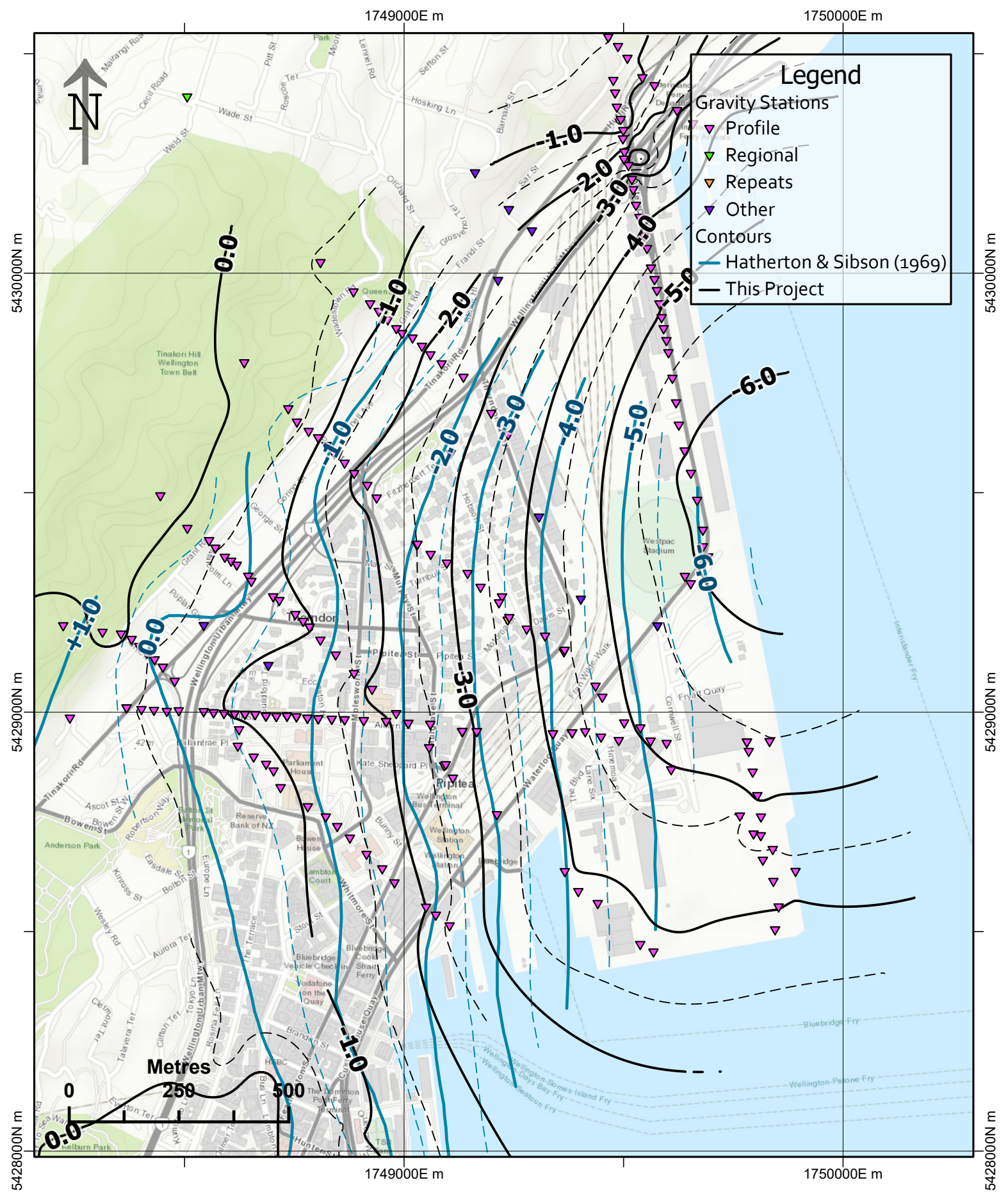

Figure 3.6: Map of Thorndon and Pipitea comparing the residual anomaly of Hatherton and Sibson (1969) with the residual anomaly found in this project. Hatherton \& Sibson's map has been georeferenced into ArcGIS Pro using street corners as known locations, and contours then traced manually. Contours are labelled in mGal. 


\subsection{Two-Dimensional Profile Modelling}

\subsubsection{Profile Parameters}

\begin{tabular}{l|c|c|c|c|c|c}
\hline Line & $\begin{array}{l}\text { Length } \\
(\mathbf{m})\end{array}$ & \# Stations & $\begin{array}{l}\text { Max Anom. } \\
\text { (mGal) }\end{array}$ & $\begin{array}{l}\text { DC Shift } \\
(\mathbf{m G a l})\end{array}$ & $\begin{array}{l}\text { RMS Error } \\
(\mathbf{m G a l})\end{array}$ & $\begin{array}{l}\text { Max Depth } \\
(\mathbf{m})\end{array}$ \\
\hline $\mathbf{A}$ & 1,678 & 42 & -1.35 & -0.85 & 0.03 & 130 \\
$\mathbf{B}$ & 2,263 & 53 & -1.74 & -0.70 & 0.10 & 155 \\
$\mathbf{C}$ & 1,622 & 41 & -1.21 & -0.60 & 0.02 & 100 \\
$\mathbf{D}$ & 1,028 & 34 & -0.57 & -0.13 & 0.03 & 30 \\
$\mathbf{F}$ & 844 & 18 & -1.54 & -0.40 & 0.18 & $\mathrm{~N} / \mathrm{A}$ \\
$\mathbf{G}$ & 1,529 & 32 & -1.89 & -1.30 & 0.06 & $\mathrm{~N} / \mathrm{A}$ \\
$\mathbf{H}$ & 1,530 & 28 & -3.85 & -0.65 & 0.11 & 270 \\
$\mathbf{I}$ & 1,709 & 31 & -5.05 & -0.45 & 0.07 & 420 \\
$\mathbf{J}$ & 1,970 & 43 & -6.18 & -0.42 & 0.06 & 450 \\
$\mathbf{K}$ & 1,116 & 16 & -5.85 & -0.30 & 0.04 & 450 \\
$\mathbf{N}$ & 276 & 7 & -3.60 & -1.10 & 0.11 & 600 \\
$\mathbf{T}$ & 1,114 & 26 & -2.62 & -0.45 & 0.05 & 235 \\
$\mathbf{U}$ & 1,595 & 34 & -5.48 & -0.70 & 0.03 & 425 \\
$\mathbf{W}$ & 357 & 17 & -1.74 & -0.62 & 0.05 & 150 \\
\hline
\end{tabular}

Table 3.4: Key parameters for each profile. Note Lines $F$ and $G$ do not reach a maximum basin depth. Greater RMS errors are highlighted red.

\subsubsection{Profile Layout}

Each profile figure has three separate components, as follows:

Top: Plan view. Background pattern is geology at ground level. Small crosses are gravity stations, large crosses are the boreholes plotted on the profile, and diamonds are intersections with other profiles.

Middle: Gravity anomalies. Small circles are the adjusted residual gravity anomaly (refer to Section 2.7.1), and the black line is the calculated gravity anomaly due to the geological model at bottom. The red line represents error at each observation, and the blue line represents zero error. The total Root Mean Square (RMS) error between the calculated and observed gravity anomalies is displayed.

Bottom: Modelled geological profile. Te Aro profiles are plotted with a 1.5 x vertical exaggeration, and Thorndon/Pipitea profiles are plotted without exaggeration. Coloured patterns represent the different density units: Fill, Surface, Buried, Deeply Buried, Greywacke 
and Weathered Greywacke, with labels and densities displayed. Triangles are gravity stations. Key boreholes are displayed with downhole interpretations of unit contacts. In some cases a key borehole was used for modelling but is not displayed for confidentiality reasons. The purple line is the bedrock contact from the model of Hill et al. (2020), and the red line is an interpreted fault from that model.

\subsubsection{Line A}

Profile Parameters

\begin{tabular}{c|c|c|c|c|c}
\hline $\begin{array}{l}\text { Length } \\
(\mathbf{m})\end{array}$ & \# Stations & $\begin{array}{l}\text { Max Anom. } \\
\text { (mGal) }\end{array}$ & $\begin{array}{l}\text { DC Shift } \\
\text { (mGal) }\end{array}$ & $\begin{array}{l}\text { RMS Error } \\
(\mathbf{m G a l})\end{array}$ & $\begin{array}{l}\text { Max Depth } \\
(\mathbf{m})\end{array}$ \\
\hline 1,678 & 42 & -1.35 & -0.85 & 0.03 & 130
\end{tabular}

Line A strikes NW-SE across Te Aro, following Dixon Street, Courtenay Place and Majoribanks Street (Figure 3.7). The residual anomaly shows a classic S shape across the expected location of the Aotea Fault on the eastern side of the basin, with a maximum gradient of $8 \mathrm{mGal} / \mathrm{km}$.

The model is constrained by two deep $(80+\mathrm{m})$ boreholes which intersect basement, as well as a third one (not shown) which does not, but provides a minimum depth constraint. The greatest divergence between this profile and the model of Hill et al. (2020) is on the downthrown side of the Aotea Fault, where this model is $30 \mathrm{~m}$ deeper, at $130 \mathrm{~m}$.

The Aotea Fault is interpreted to be near vertical, and lies almost exactly at the same location as it does in the model of Hill et al. (2020). However, its location is only well constrained so long as it is assumed to be vertical. Normal and reverse orientations for the fault were tested and it was found that the dip could range from $47^{\circ}$ normal and $57^{\circ}$ reverse while retaining the same total RMS error of 0.028 (Figure 3.8). Were a surface trace of the fault visible, this could be better constrained, likely to within $10^{\circ}$.

A second offset or splay of the Aotea Fault is modelled to the east of the main offset, with a vertical displacement of $10 \mathrm{~m}$. This is only weakly supported by the anomaly, but it does align with a similar offset on Line B, where it is more strongly supported. There is also a $20 \mathrm{~m}$ offset modelled at the eastern end, where the line crosses Willis Street. This could be the Lambton Fault, or a splay of it. It is also not strongly supported by the anomaly, but gives a small improvement in fit. Note that the Hill et al. (2020) model does not model either the Aotea Fault splay or Lambton Fault. 


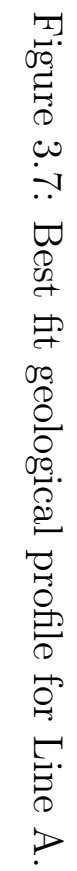

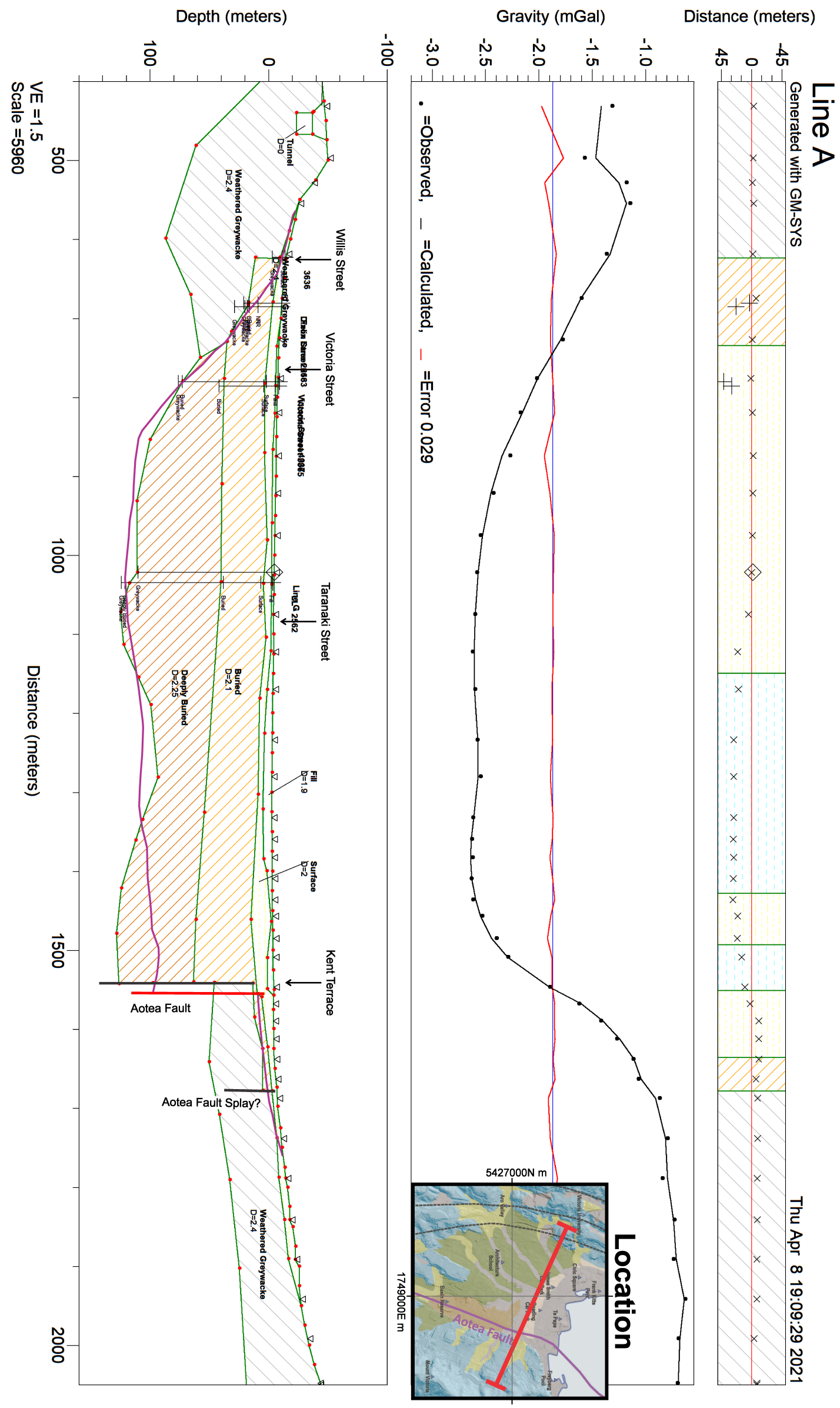




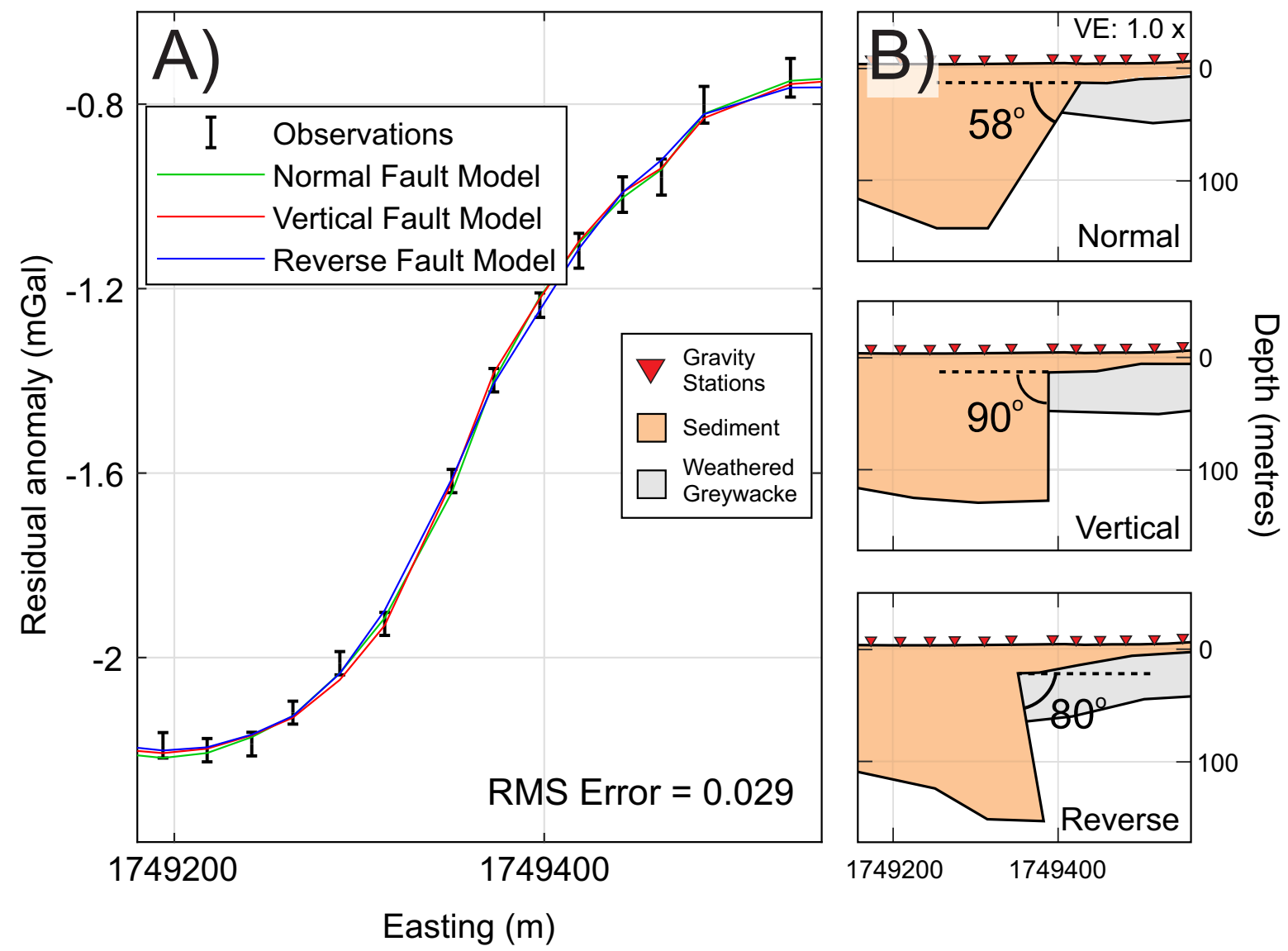

Figure 3.8: A) Calculated gravity for the three Aotea Fault models compared with observed gravity. B) Three fault dip models, all of which fit equally well to the observations, with an RMS error of $0.028 \mathrm{mGal}$. 


\subsubsection{Line B}

Profile Parameters

\begin{tabular}{c|c|c|c|c|c}
\hline $\begin{array}{l}\text { Length } \\
(\mathbf{m})\end{array}$ & \# Stations & $\begin{array}{l}\text { Max Anom. } \\
\text { (mGal) }\end{array}$ & $\begin{array}{l}\text { DC Shift } \\
\text { (mGal) }\end{array}$ & $\begin{array}{l}\text { RMS Error } \\
\text { (mGal) }\end{array}$ & $\begin{array}{l}\text { Max Depth } \\
(\mathbf{m})\end{array}$ \\
\hline 2,263 & 53 & -1.74 & -0.70 & 0.10 & 155
\end{tabular}

Line B is parallel to Line A, running from Kelburn Park in the west, past Te Papa and through Waitangi Park to finish on Mount Victoria (Figure 3.9).

The Line B residual anomaly does not show the $\mathrm{S}$ shape of Line A across the Aotea Fault, instead rising at a steady, steep gradient from west to east. The observations further to the east, on Mount Victoria, do not fit this Line B trend. Additional stations and repeats were measured there and further east in an attempt to resolve the misfit, but a cluster of eight stations immediately atop the hill still do not fit any clear trend. This area is both steep and highly developed, so the misfit could be due to errors in the DEM and hence the terrain corrections for these stations. It could also be related to the weathering profile of the hillside in this location, as the weathered zone is modelled up to $100 \mathrm{~m}$ deep.

This profile has several constraints, including the $152.3 \mathrm{~m}$ deep Te Papa borehole, the deepest in the city, which intersects basement at $137.1 \mathrm{~m}$. The $45.1 \mathrm{~m}$ deep borehole in Waitangi Park also provides a constraint on the upthrown side of the Aotea Fault, intersecting basement at $44.5 \mathrm{~m}$. The deepest point in Te Aro, of $155 \mathrm{~m}$, is modelled on this line adjacent to the Aotea Fault.

Also displayed is the $62.2 \mathrm{~m}$ borehole on the waterfront (near centre, Figure 3.9), which logged greywacke at $61.0 \mathrm{~m}$ depth. This has been interpreted as an error, as no interpretation of the gravity data fits that depth. It is possible the borehole intersected a greywacke boulder rather than bedrock, as a $1.2 \mathrm{~m}$ intersection is relatively short. Alternatively an angular conglomerate could have been misinterpreted as weathered greywacke.

This borehole was drilled in 1969, and in the GNS borehole database has been assigned a data quality score of 2 out of 5 , with 5 being the highest quality (i.e. most reliable). The low quality score gives some justification for disregarding the logged intersection in this borehole. The Line B profile is up to $86 \mathrm{~m}$ deeper than the model of Hill et al. (2020) on the western side of the basin, primarily because the Hill et al. model honours this borehole. Also modelled here are the two additional offsets seen on the Line A profile, which again give a weak improvement in fit. 


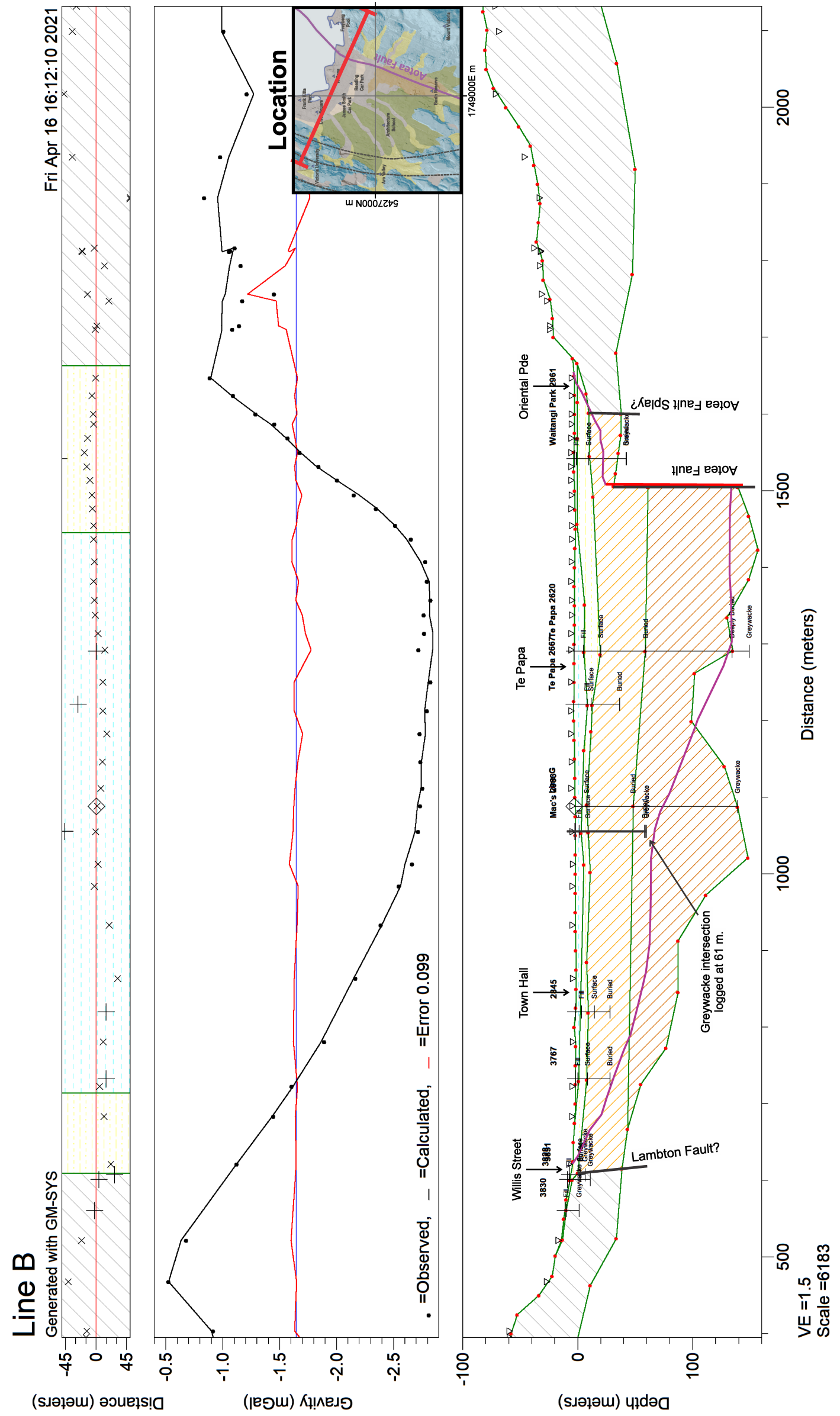

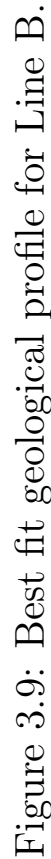




\subsubsection{Line $\mathrm{C}$}

\section{Profile Parameters}

\begin{tabular}{c|c|c|c|c|c}
\hline $\begin{array}{l}\text { Length } \\
(\mathbf{m})\end{array}$ & \# Stations & $\begin{array}{l}\text { Max Anom. } \\
\text { (mGal) }\end{array}$ & $\begin{array}{l}\text { DC Shift } \\
\text { (mGal) }\end{array}$ & $\begin{array}{l}\text { RMS Error } \\
\text { (mGal) }\end{array}$ & $\begin{array}{l}\text { Max Depth } \\
(\mathbf{m})\end{array}$ \\
\hline 1,622 & 41 & -1.21 & -0.60 & 0.02 & 100
\end{tabular}

Line $\mathrm{C}$ is parallel to Lines $\mathrm{A}$ and $\mathrm{B}$, running from VUW in the west, along Vivian and Pirie Streets to finish in the suburb of Mount Victoria (Figure 3.10).

Across the western half of the profile the modelled depths match those of Hill et al. (2020) well, but in the eastern half they are $\sim 20 \mathrm{~m}$ deeper. There are three boreholes in this section which this model does not fit well. It was found that either the Frederick Street borehole or these three could be fitted, but not both. The borehole data indicate some possible complex topography along this line, with rapid changes in depth along strike. This could be evidence of a buried greywacke ridge, extending northwest from the outcrop at the War Memorial (See Figure 4.1), and is perhaps part of the reason for the poor fit to the boreholes.

The largest point of discrepancy is the location of the Aotea Fault. Here it is interpreted to lie $110 \mathrm{~m}$ east of its location in Hill et al. (2020), which is well supported by shape of the anomaly at this end of the profile. This location coincides with a steeper section of Pirie Street, which could be the fault scarp.

As a test, the best fitting model was created in which the Aotea Fault would have a surface trace in the Hill et al. location (Figure 3.11). It was not possible to fit the anomaly well within this scenario, even with greater depth of sediment and weathered greywacke on the upthrown side of the fault, and a strongly reversed dip. 


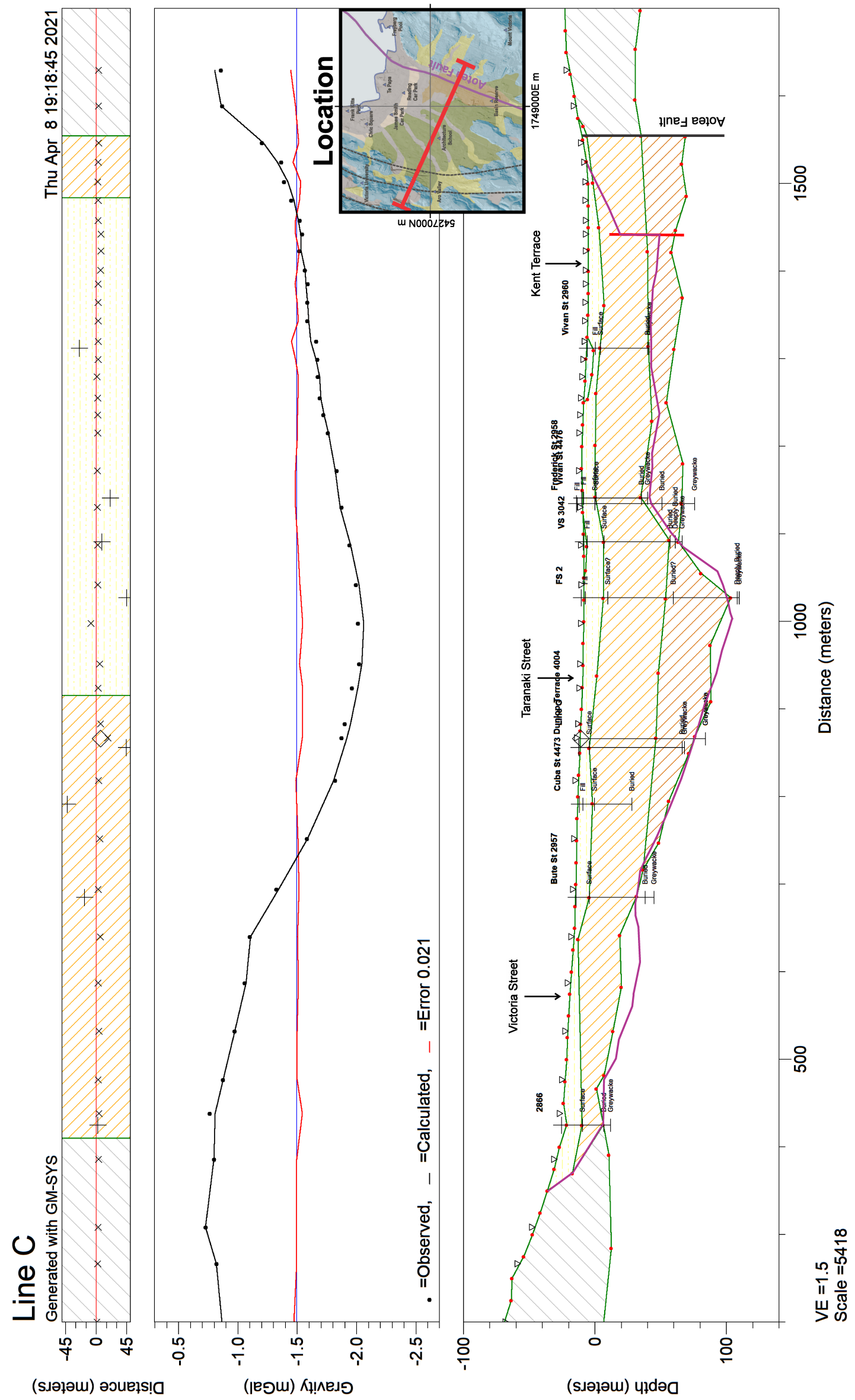

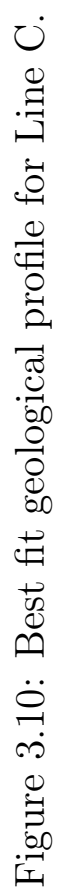




\section{Line C: Test of Hill et al. (2020) Aotea Fault Location}
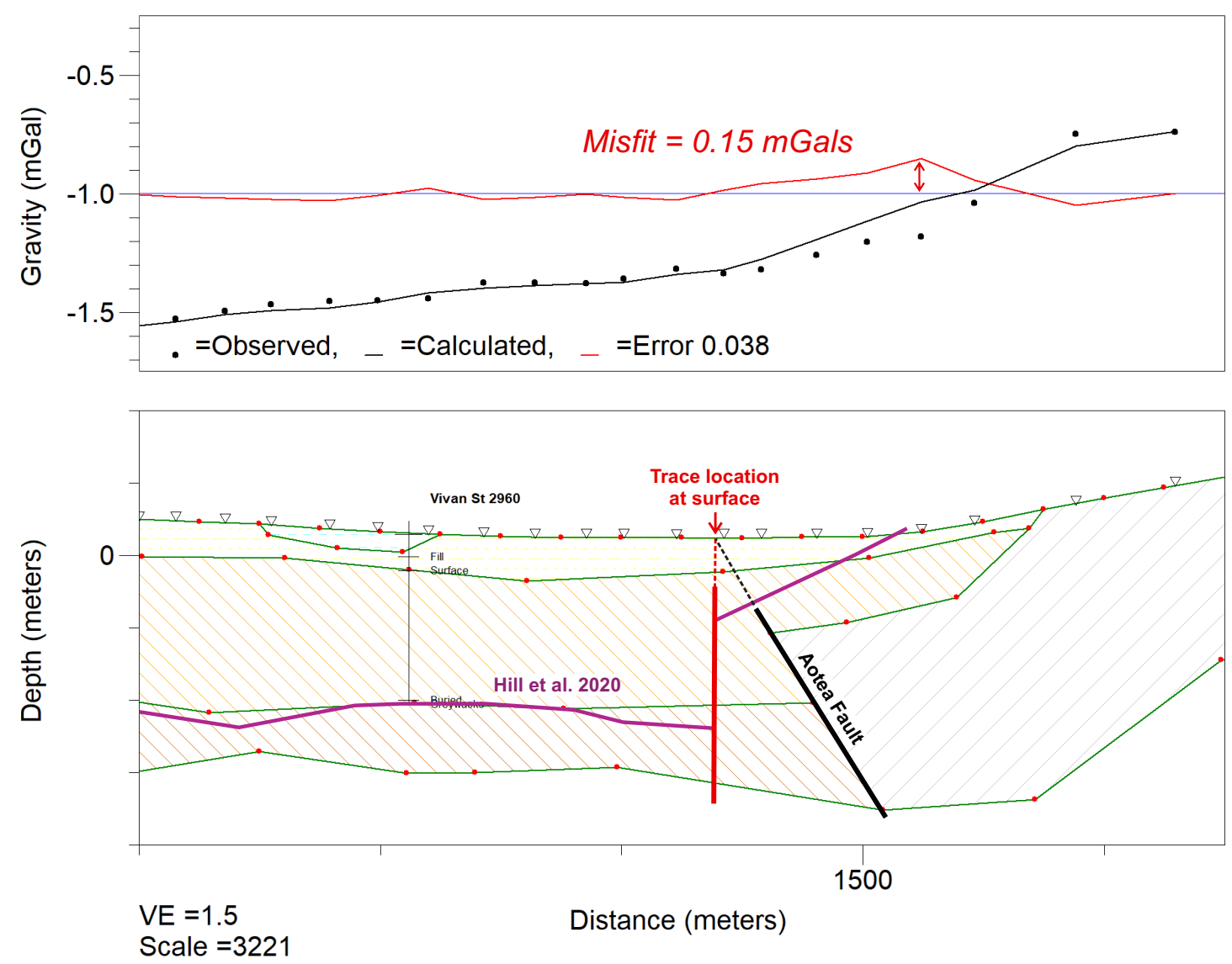

Figure 3.11: The best fitting model for Line $\mathrm{C}$ with an Aotea Fault trace in the Hill et al. (2020) location. Note the misfit of the calculated gravity to the observations around the fault location. 


\subsubsection{Line D}

Profile Parameters

\begin{tabular}{c|c|c|c|c|c}
\hline $\begin{array}{l}\text { Length } \\
(\mathbf{m})\end{array}$ & \# Stations & $\begin{array}{l}\text { Max Anom. } \\
\text { (mGal) }\end{array}$ & $\begin{array}{l}\text { DC Shift } \\
\text { (mGal) }\end{array}$ & $\begin{array}{l}\text { RMS Error } \\
\text { (mGal) }\end{array}$ & $\begin{array}{l}\text { Max Depth } \\
(\mathbf{m})\end{array}$ \\
\hline 1,028 & 34 & -0.57 & -0.13 & 0.03 & 30
\end{tabular}

Line D is parallel to the previous three but shorter, starting roughly mid-basin at the intersection of Taranaki and Buckle (State Highway 1) Streets, then running past the Basin Reserve and up Ellice Street to Mount Victoria (Figure 3.12).

There is good borehole control all along this line, so it was not expected to give much new information. Instead, it is a check on the method, that the gravity data fits known basement depths. Variance between this model and Hill et al. (2020) across most of the profile is $<10 \mathrm{~m}$, but exceptions are the bedrock outcrop at the National War Memorial and the area of maximum depth around the Basin Reserve. At the former site the outcrop is not resolved and basin depth is modelled as $24 \mathrm{~m}$. At the latter, the depth is modelled at $29 \mathrm{~m}$ as opposed to Hill's $41 \mathrm{~m}$.

The Aotea Fault offset is also placed to the east, at a location well supported by the anomaly gradient, but $260 \mathrm{~m}$ from its location in Hill et al. (2020). The Hill et al. model is well supported by boreholes, so the gravity model must be partially in error. This could be due to the location of the line parallel to the near edge of the basin, meaning there is topography in the $\mathrm{Y}$ direction not accounted for by the 2D model. A second possibility relates to borehole records that indicate near surface greywacke is "completely weathered" (Borehole ID 149050, NZGD). The geotechnical ground investigation undertaken during the construction of the State Highway 1 underpass nearby also found that basement greywacke was completely weathered, and stated in reference to it that "although described as a rock, it had soil like behaviour and was described as such" (Grose et al., 2015).

If the greywacke here is so weathered as to be essentially sediment, then the basement modelled in this profile could equate to the depth of competent rock. This is sometimes referred to as "engineering basement", which is the boundary which will reflect the most seismic energy (Figure 1.1), and so is a more relevant parameter than lithological basement when considering seismic amplification. This means the basin depths found here (Figure 3.12) may still be applicable for modelling of earthquake shaking. 


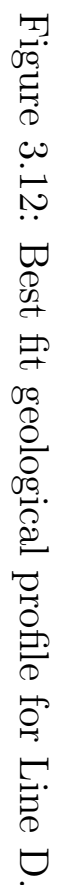

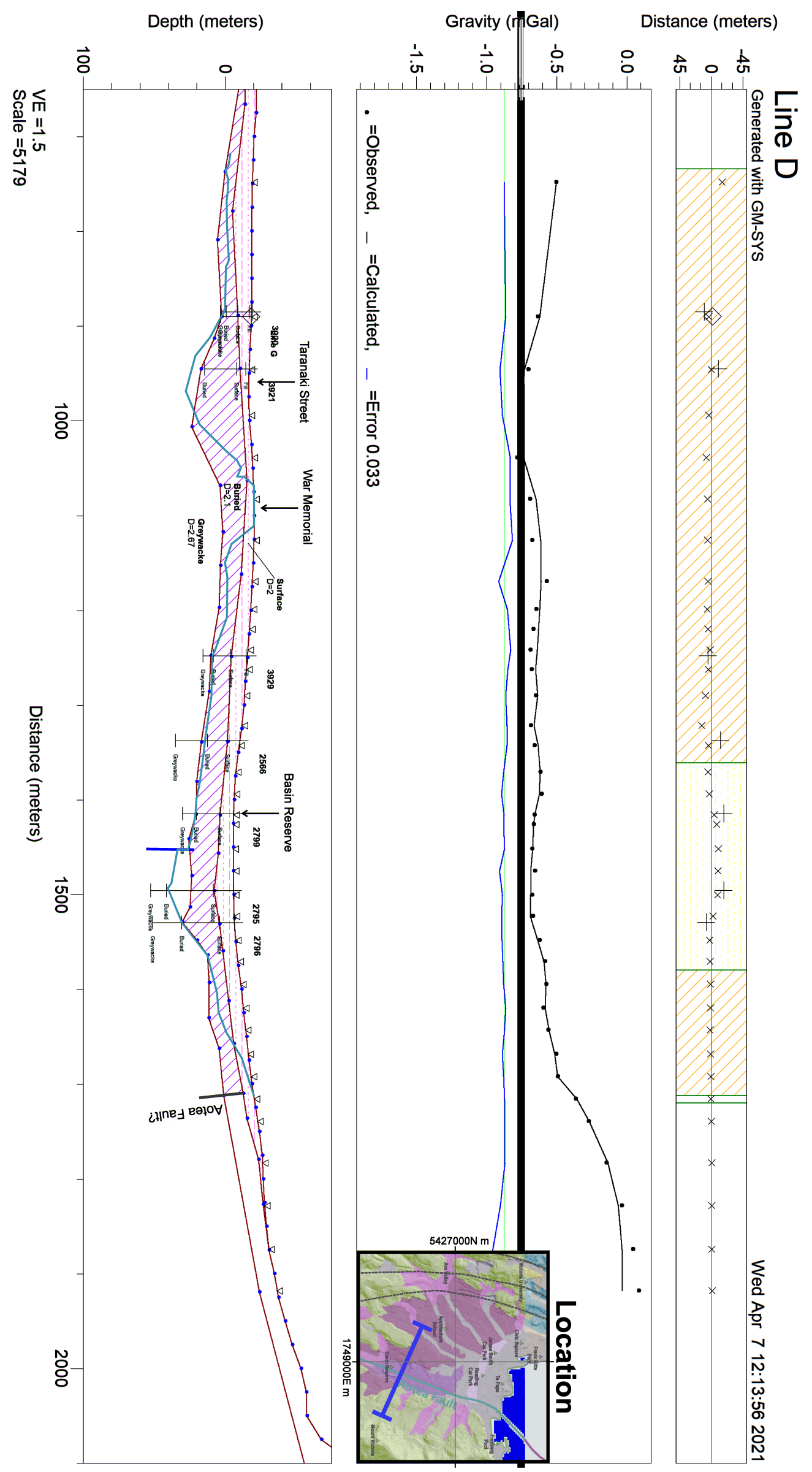




\subsubsection{Line F}

Profile Parameters

\begin{tabular}{c|c|c|c|c|c}
\hline $\begin{array}{l}\text { Length } \\
(\mathbf{m})\end{array}$ & \# Stations & $\begin{array}{l}\text { Max Anom. } \\
\text { (mGal) }\end{array}$ & $\begin{array}{l}\text { DC Shift } \\
\text { (mGal) }\end{array}$ & $\begin{array}{l}\text { RMS Error } \\
\text { (mGal) }\end{array}$ & $\begin{array}{l}\text { Max Depth } \\
(\mathbf{m})\end{array}$ \\
\hline 844 & 18 & -1.54 & -0.40 & 0.18 & N/A
\end{tabular}

Line F runs through Wellington Central, from the Botanic Gardens, across the Terrace and Lambton Quay to end on Queen's Wharf (Figure 3.13). This profile crosses the estimated trace of both the Terrace and Lambton Faults (Figures 1.7, 3.1).

The Line F anomaly appears discontinuous across the Terrace and the Terrace Fault scarp, with a large positive jump where a negative anomaly would be expected. An offset for the Terrace Fault is modelled, but is not strongly supported by the anomaly. Weathered greywacke has been extended beneath most of the profile, as boreholes constrain the basin depth too shallowly to fit the observations otherwise. The profile was challenging to model, and a good fit to the observations could not be obtained. The best fitting model is presented here, but as its estimated reliability is low it is not included in the basement depth maps.

Closely spaced, tall buildings in this area mean the DEM will have been interpolated between a small number of LiDAR points which hit ground level. Combined with steep topography that makes it relatively unreliable. These buildings also interfered with the GPS for some stations, meaning DEM elevations had to be used. Errors in GPS location also translate to errors in terrain correction. These factors combined with probable complex fault-related subsurface topography are likely to be the cause of the modelling difficulties. 


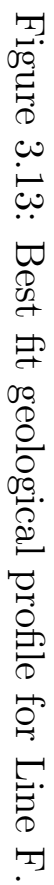

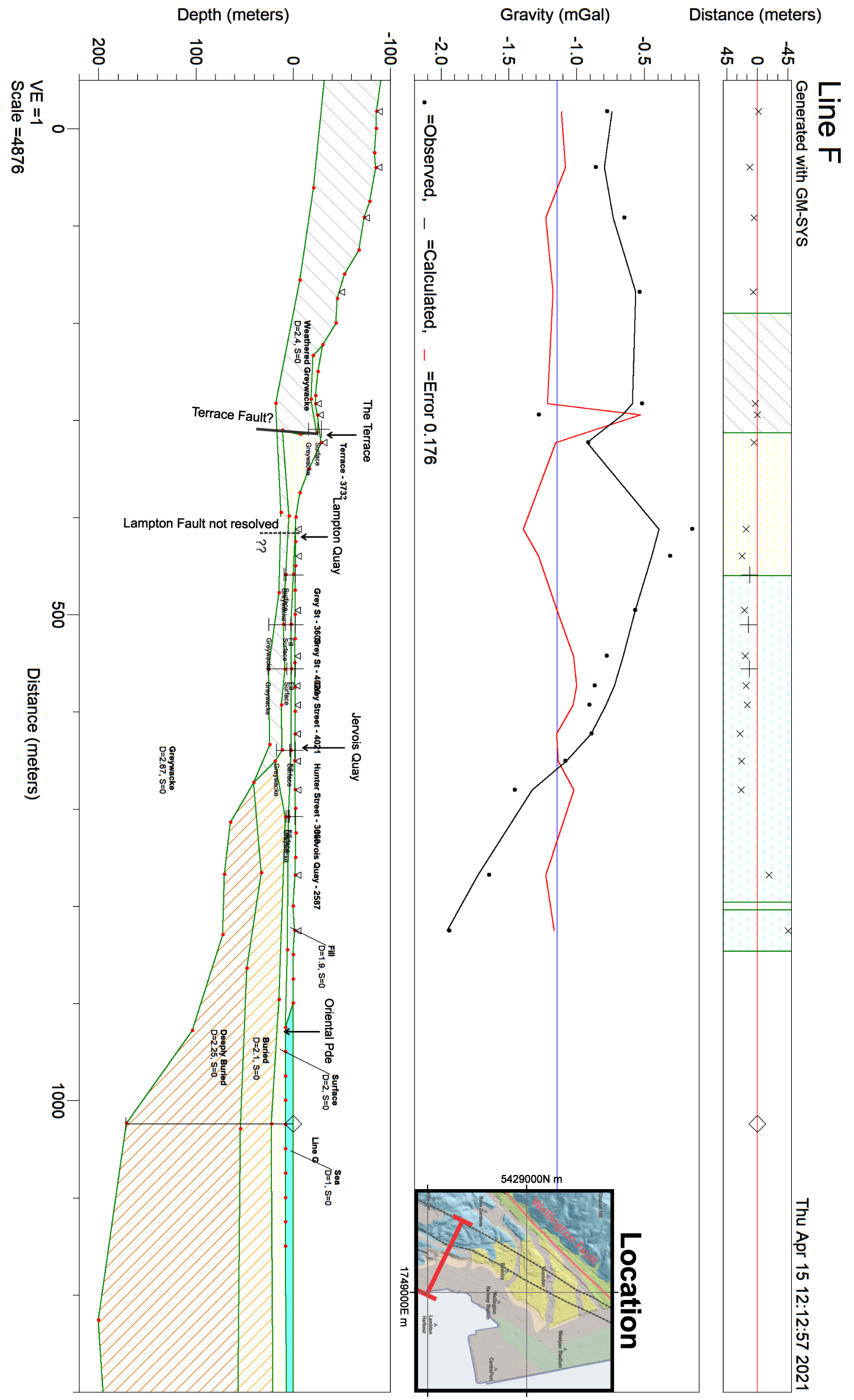




\subsubsection{Line G}

Profile Parameters

\begin{tabular}{c|c|c|c|c|c}
\hline $\begin{array}{l}\text { Length } \\
(\mathbf{m})\end{array}$ & \# Stations & $\begin{array}{l}\text { Max Anom. } \\
\text { (mGal) }\end{array}$ & $\begin{array}{l}\text { DC Shift } \\
\text { (mGal) }\end{array}$ & $\begin{array}{l}\text { RMS Error } \\
\text { (mGal) }\end{array}$ & $\begin{array}{l}\text { Max Depth } \\
(\mathbf{m})\end{array}$ \\
\hline 1,529 & 32 & -1.89 & -1.30 & 0.06 & N/A
\end{tabular}

Line $\mathrm{G}$ is a "tie-line", running SW - NE through Te Aro, crosscutting lines A, B, C and D and running close to key borehole locations (Figure 3.14). The model is also extended offshore beyond the observations, crosscutting lines T, H, I, J and K, in order that it can be fitted to those profiles. Changes in this model at this distance from the end of the last observation (up to $1.7 \mathrm{~km}$ ) have only a small effect on the fit. Anomalies from lines $\mathrm{H}$ and $\mathrm{J}$ were added to the observations to aid in modelling.

This line has the largest DC shift of all. Correspondingly the model has the greatest depth of weathered greywacke on its starting hillside, of up to $100 \mathrm{~m}$, and this also extends beneath the basin for roughly half the profile. This approach was required due to borehole data which constrain the bedrock to a shallow depth for the first $\sim 500 \mathrm{~m}$ of the profile, and then require rapidly increasing depth to the north, while the residual anomaly does not increase rapidly. 


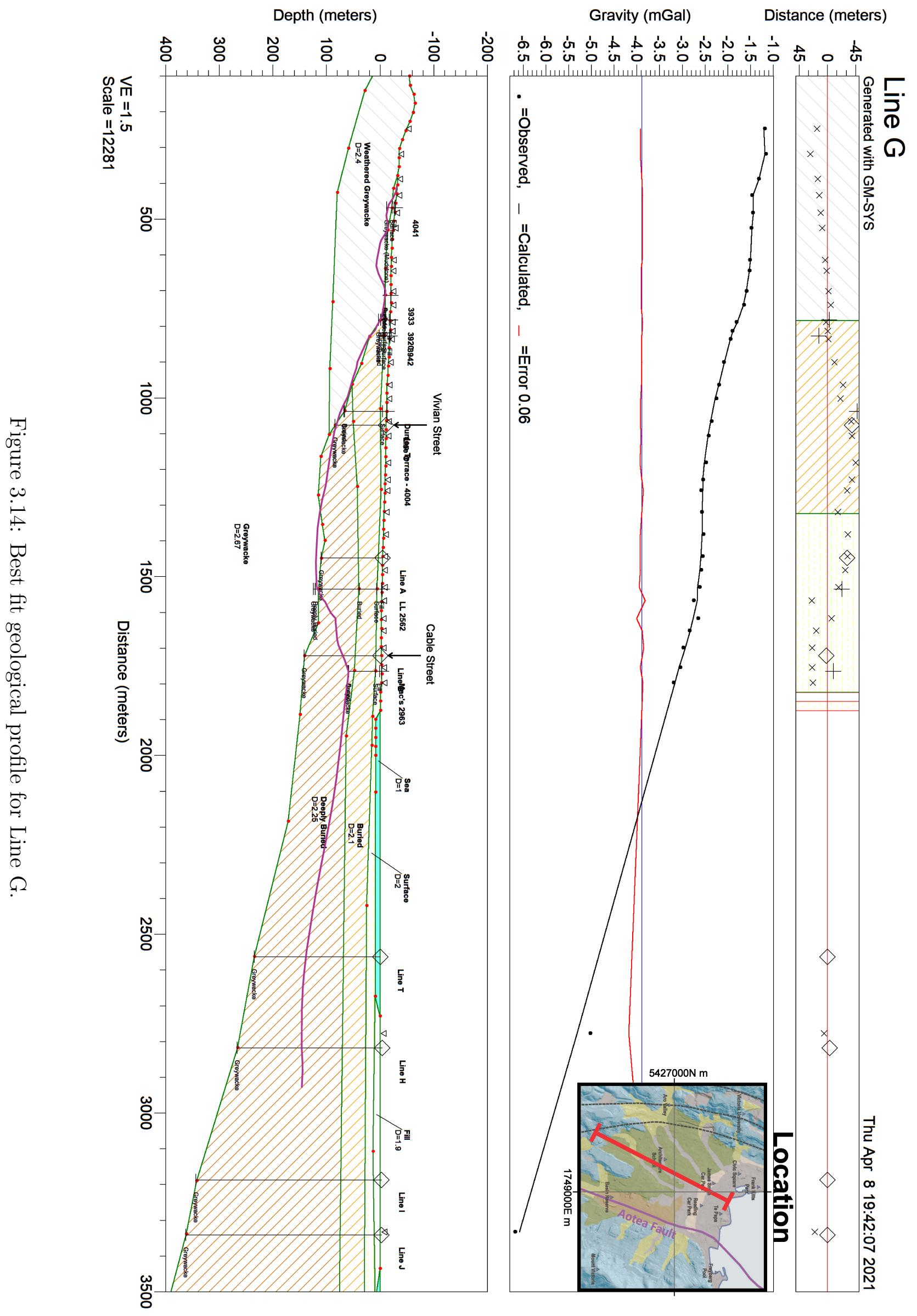




\subsubsection{Line $\mathrm{H}$}

Profile Parameters

\begin{tabular}{c|c|c|c|c|c}
\hline $\begin{array}{l}\text { Length } \\
(\mathbf{m})\end{array}$ & \# Stations & $\begin{array}{l}\text { Max Anom. } \\
\text { (mGal) }\end{array}$ & $\begin{array}{l}\text { DC Shift } \\
\text { (mGal) }\end{array}$ & $\begin{array}{l}\text { RMS Error } \\
\text { (mGal) }\end{array}$ & $\begin{array}{l}\text { Max Depth } \\
(\mathbf{m})\end{array}$ \\
\hline 1,530 & 28 & -3.85 & -0.65 & 0.11 & 270
\end{tabular}

Lines H - U are in Thorndon and Pipitea. Line H starts on the lower slope of Te Ahumairangi Hill and runs SW, past the National Library of New Zealand, to cross Thorndon Quay and finish at the south shore of the CentrePort complex (Figure 3.15). Thorndon streets for the most part do not run perpendicular to the Wellington Fault, making station placement difficult.

All the Thorndon lines show a steeper residual anomaly gradient than those in Te Aro. Line $\mathrm{H}$ has a typical average gradient for Thorndon of $-2.7 \mathrm{mGal} / \mathrm{km}$. Near the centre of Line $\mathrm{H}$ is one of only two sites with deep boreholes in Thorndon, with four holes within $75 \mathrm{~m}$ of each other. This is a valuable control point for the area.

As in most of Thorndon and Pipitea, Line $\mathrm{H}$ does not agree well with the Hill et al. (2020) model. From the Wellington Fault to $650 \mathrm{~m}$ along the profile the modelled depth is consistently $\sim 50 \mathrm{~m}$ less than Hill et al. (2020). From then on it is greater, up to a maximum depth of $270 \mathrm{~m}$ beneath the southern extent of CentrePort, where Hill et al. predict $150 \mathrm{~m}$. 


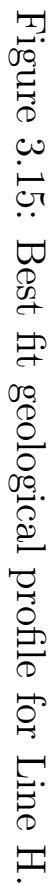
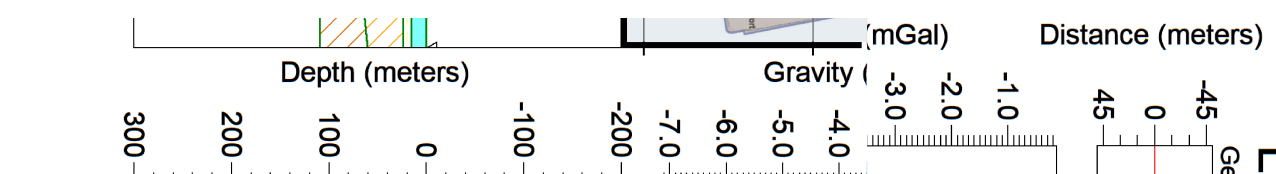

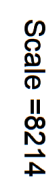

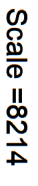

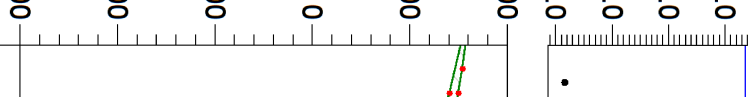

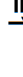

음

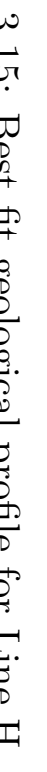

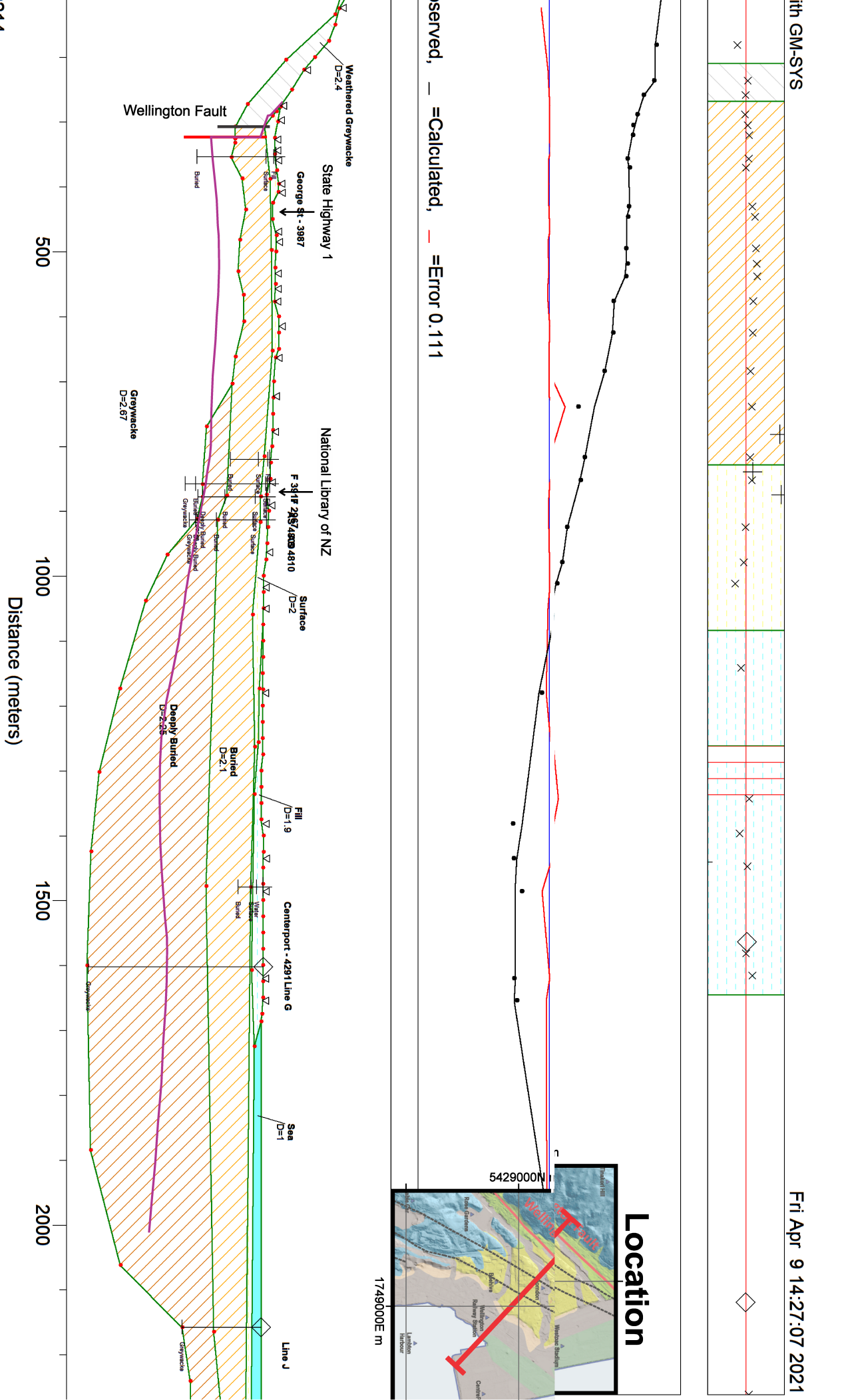




\subsubsection{Line I}

Profile Parameters

\begin{tabular}{c|c|c|c|c|c}
\hline $\begin{array}{l}\text { Length } \\
(\mathbf{m})\end{array}$ & \# Stations & $\begin{array}{l}\text { Max Anom. } \\
\text { (mGal) }\end{array}$ & $\begin{array}{l}\text { DC Shift } \\
\text { (mGal) }\end{array}$ & $\begin{array}{l}\text { RMS Error } \\
\text { (mGal) }\end{array}$ & $\begin{array}{l}\text { Max Depth } \\
(\mathbf{m})\end{array}$ \\
\hline 1,709 & 31 & -5.05 & -0.45 & 0.07 & 420
\end{tabular}

Line I is to the NE of and parallel to Line H, running from Te Ahumairangi Hill through Thorndon, crosscutting streets and the Wellington Girls' College field, across the railway lines and finishing on the shore at CentrePort (Figure 3.16). The line crosses the Murphy Street bridge over State Highway 1. The effect of the SH1 void can be clearly seen on the two stations above it, increasing their negative residual anomaly by $\sim 0.3 \mathrm{mGal}$ from the trend of the other stations. This shows the importance of accurate DEMs and terrain corrections.

The Line I geological model is similar in shape to Line $\mathrm{H}$, but deeper. The basement for $400 \mathrm{~m}$ east of the Wellington Fault is relatively flat at $\sim 70 \mathrm{~m}$ deep, $50 \mathrm{~m}$ shallower than Hill et al. This could be a buried wave-cut platform (Figure 4.1). There is then a steep drop to what may be a second, older platform at $\sim 160 \mathrm{~m}$ deep, from $700 \mathrm{~m}$ to $900 \mathrm{~m}$ along strike. Bedrock then drops steeply again, in a bowl shape, to the maximum depth of $420 \mathrm{~m}$ beneath CentrePort, and rises symmetrically to the end of the profile.

This line sits on the opposite side from Line I of the two George Street boreholes, at $205 \mathrm{~m}$ distance (noting that only one is shown on the profile). The modelled depth on Lines $\mathrm{H}$ and I are shallower than those boreholes - they are 117 and $122 \mathrm{~m}$ deep, and neither intersected greywacke. The interpretation for this is that they lie in a buried valley, corresponding with the small steep valley seen in Te Ahumairangi Hill above George Street (Figure 4.1).

As there are no other deep boreholes the Hill et al. (2020) model has little control in this part of the study area, and simply extrapolates a constant depth a little greater than the minimum provided by the George Street boreholes. 


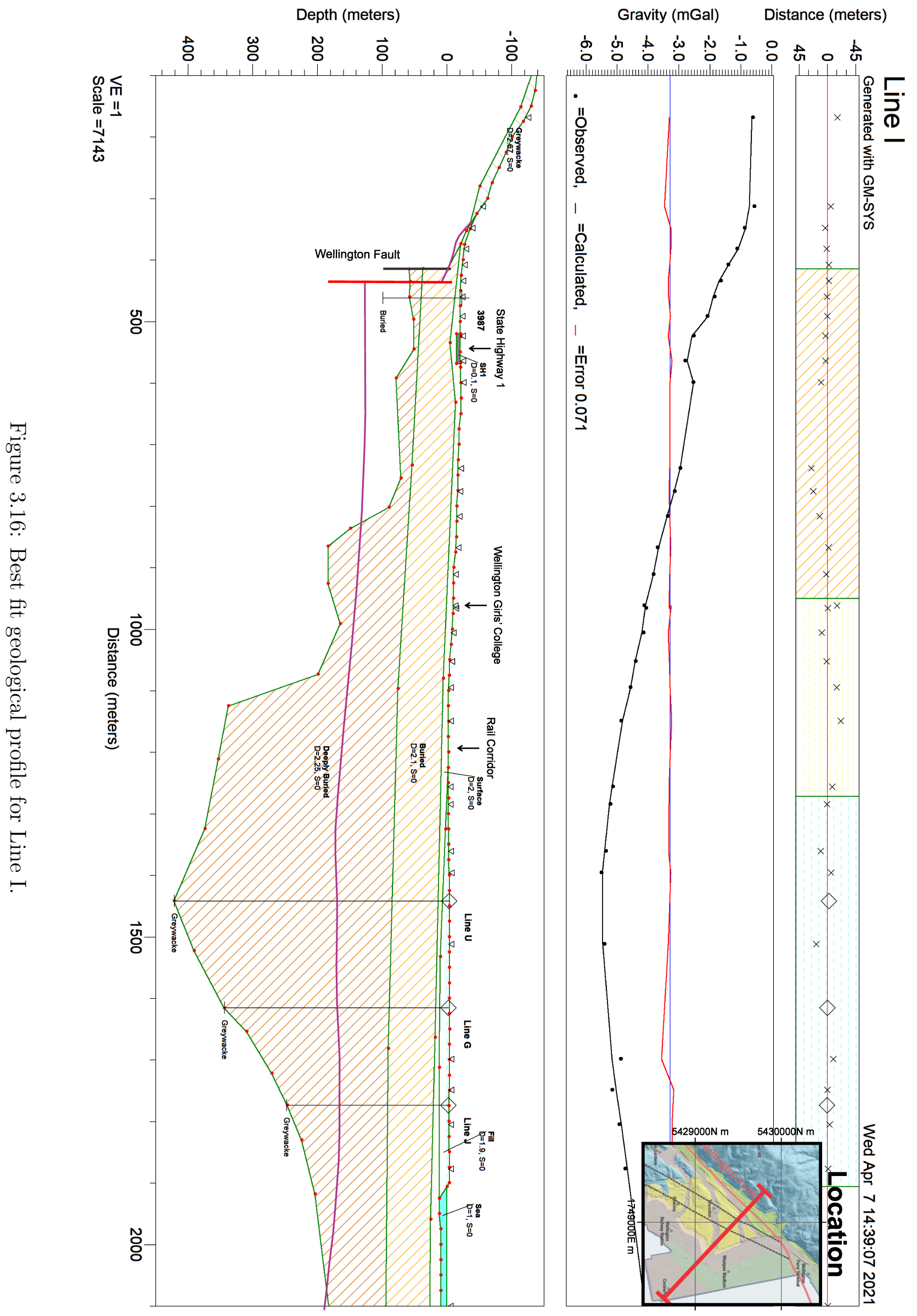




\subsubsection{Line J}

Profile Parameters

\begin{tabular}{c|c|c|c|c|c}
\hline $\begin{array}{l}\text { Length } \\
(\mathbf{m})\end{array}$ & \# Stations & $\begin{array}{l}\text { Max Anom. } \\
\text { (mGal) }\end{array}$ & $\begin{array}{l}\text { DC Shift } \\
\text { (mGal) }\end{array}$ & $\begin{array}{l}\text { RMS Error } \\
\text { (mGal) }\end{array}$ & $\begin{array}{l}\text { Max Depth } \\
(\mathbf{m})\end{array}$ \\
\hline 1,970 & 43 & -6.18 & -0.42 & 0.06 & 450
\end{tabular}

Line $\mathrm{J}$ is another tie-line, running roughly north-south. It starts on the Wadestown hillside, crossing the rail corridor under the State Highway 1 overpass, along Aotea Quay to the stadium, and then after a gap of $420 \mathrm{~m}$ continuing through the southern end of the CentrePort complex to finish at the southern shoreline (Figure 3.17). The gap crosses the logging yards, which were not accessible. The stations within the rail corridor were able to be measured as part of a GNS gravity survey in the area.

Line $\mathrm{J}$ shows the strongest anomaly of all the lines, up to a maximum magnitude of $6.18 \mathrm{mGal}$. The anomaly is a smooth bowl shape, steeper on the northern than southern side, centred around the stadium. The effect of the Wellington Fault on the anomaly appears overshadowed by the deep basin, but the fault is still required to obtain a good fit to the anomaly.

There are no deep boreholes on this line, only shallow ones on the upthrown side of the Wellington Fault, which are not displayed for confidentiality reasons. Offset on the fault is larger than for the other lines, at $120 \mathrm{~m}$.

South of the wave-cut platform the basin takes a deep bowl shape, to a maximum depth of $450 \mathrm{~m}$ near the location of the maximum anomaly. This is the greatest depth modelled onshore in this project. Similarly to Line I, the Hill et al. (2020) model has little control here, and predicts a fairly flat basement at $160-200 \mathrm{~m}$ depth. It is worth noting that the point of maximum depth in Hill et al. (2020) does coincide with the point of maximum depth modelled here.

A key result on Line $\mathrm{J}$ is the Wellington Fault position. The most likely position for an offset as determined by the anomaly is at the point of steepest gradient, marked as a possible Wellington Fault splay $160 \mathrm{~m}$ west of the fault position in Hill et al. (2020). However geological confidence is high in the Hill et al. position (Begg et al., 2008). Therefore, an offset has been modelled at both locations (Figure 3.17), a scenario which fits the anomaly, but which would not necessarily be suggested by it in the absence of any other information. 


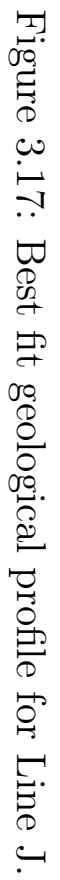

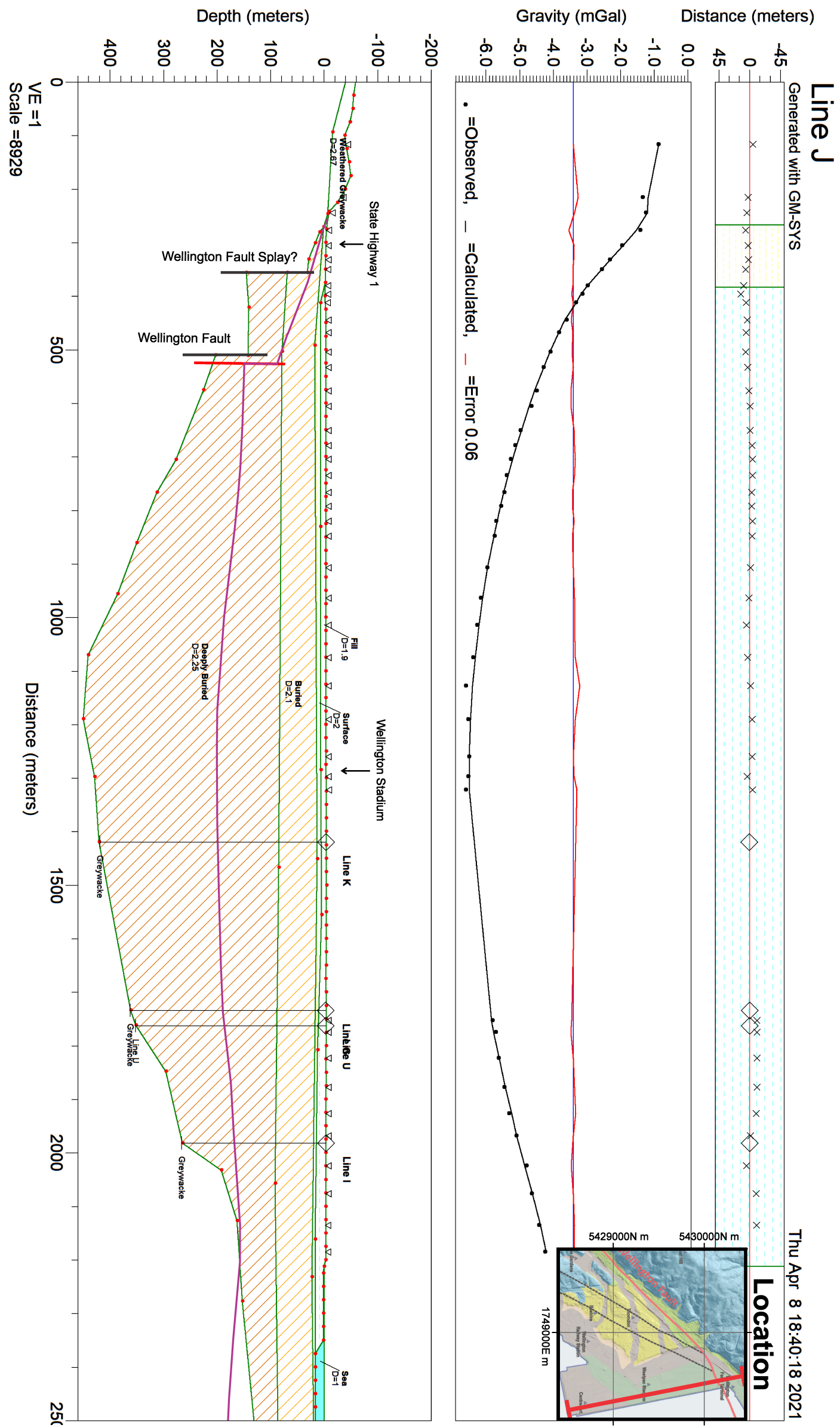




\subsubsection{Line $\mathrm{K}$}

Profile Parameters

\begin{tabular}{c|c|c|c|c|c}
\hline $\begin{array}{l}\text { Length } \\
(\mathbf{m})\end{array}$ & \# Stations & $\begin{array}{l}\text { Max Anom. } \\
\text { (mGal) }\end{array}$ & $\begin{array}{l}\text { DC Shift } \\
\text { (mGal) }\end{array}$ & $\begin{array}{l}\text { RMS Error } \\
\text { (mGal) }\end{array}$ & $\begin{array}{l}\text { Max Depth } \\
(\mathbf{m})\end{array}$ \\
\hline 1,116 & 16 & -5.85 & -0.30 & 0.04 & 450
\end{tabular}

Line $\mathrm{K}$ is parallel to Lines $\mathrm{H}$ and I, running from Te Ahumairangi Hill to Thorndon Quay (Figure 3.18). Past Thorndon Quay, the width of the rail corridor here and its oblique angle to the line mean a large gap of $510 \mathrm{~m}$ before two final stations on either side of Waterloo Quay, near the stadium. Additional stations were not able to be measured in CentrePort as that area of the port was inaccessible at the time.

The Line $\mathrm{K}$ model is similar in shape to those of Lines $\mathrm{H}$ and I. The steep dropoff to the maximum depth of $450 \mathrm{~m}$ is still seen, at near the same location as it is modelled in Line J. There are no boreholes available to be used as constraints for this model, and the Hill et al. (2020) model again shows a near constant basin depth for the whole profile length. At the point that this model shows $450 \mathrm{~m}$ depth, Hill et al. shows less than half that, at $190 \mathrm{~m}$. 


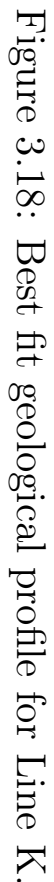

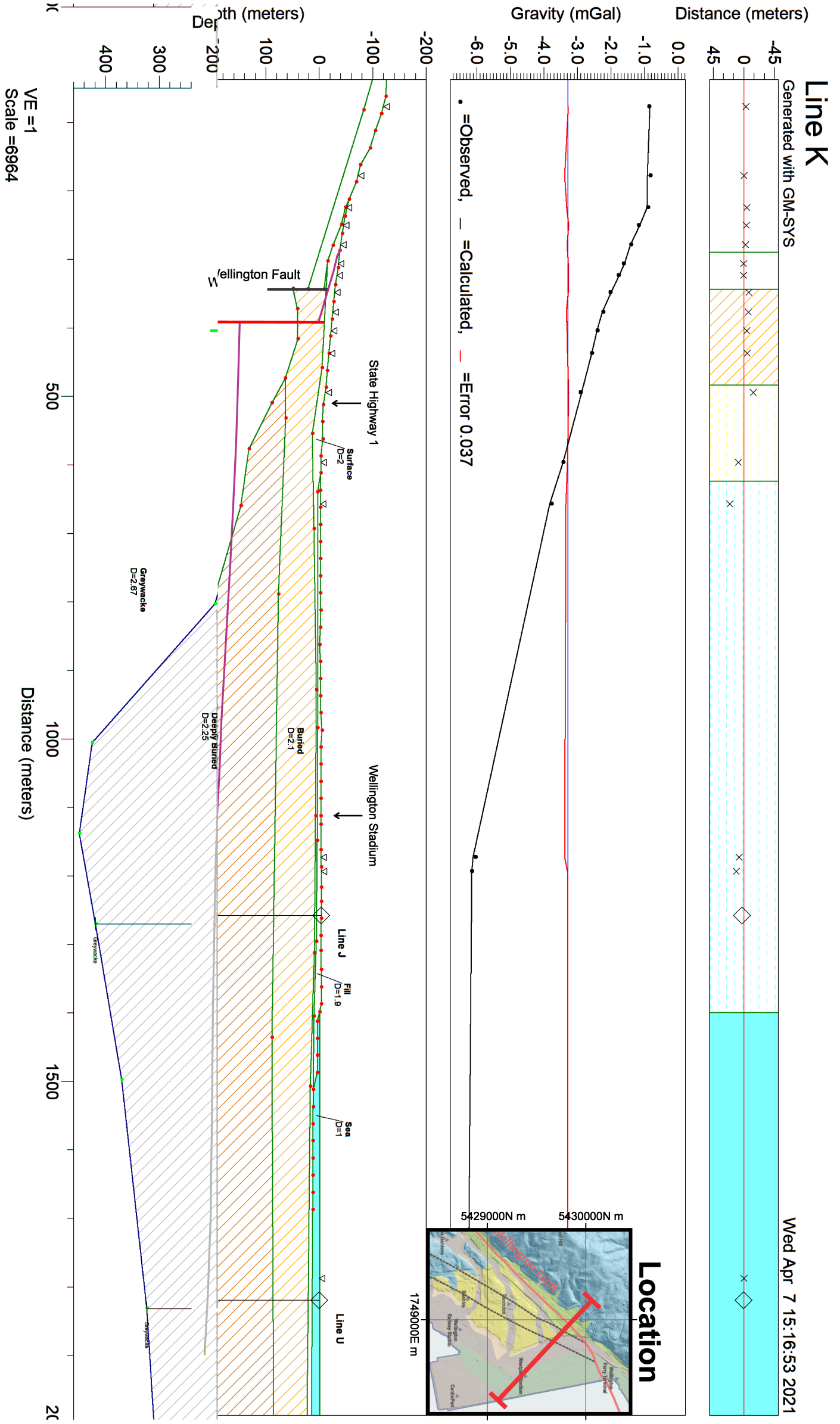




\subsubsection{Line $\mathrm{N}$}

Profile Parameters

\begin{tabular}{c|c|c|c|c|c}
\hline $\begin{array}{l}\text { Length } \\
(\mathbf{m})\end{array}$ & \# Stations & $\begin{array}{l}\text { Max Anom. } \\
(\mathbf{m G a l})\end{array}$ & $\begin{array}{l}\text { DC Shift } \\
(\mathbf{m G a l})\end{array}$ & $\begin{array}{l}\text { RMS Error } \\
(\mathbf{m G a l})\end{array}$ & $\begin{array}{l}\text { Max Depth } \\
(\mathbf{m})\end{array}$ \\
\hline 276 & 7 & -3.60 & -1.10 & 0.11 & 600
\end{tabular}

Line $\mathrm{N}$ is short, starting from the same street on the Wadestown hillside that Line $\mathrm{J}$ starts from, and running parallel to Line $\mathrm{K}$ down to the Interislander Ferry Terminal (Figure 3.19), a distance of $276 \mathrm{~m}$. This is the maximum length possible, given the narrow gap between the hills and the sea at this location. Nevertheless, it was important to include this line as it is perpendicular to the Wellington Fault at a key point, from both an infrastructure and from a tectonic perspective, as the Wellington Fault appears to splay in this area (Figures 3.1, 3.25).

As the maximum basin depth is expected to be almost as great as the line length, the model resolution is not expected to be good. However, it would still have been possible for Line $\mathrm{N}$ results to contradict the models of Lines $\mathrm{K}$ and J, which it does not.

The Line $\mathrm{N}$ anomaly shows a shallow gradient for the first four stations, and then a particularly steep one for the remainder, dropping from $-0.9 \mathrm{mGal}$ to $-3.6 \mathrm{mGal}$ over $150 \mathrm{~m}$, a rate of $-18 \mathrm{mGal} / \mathrm{km}$. An additional measurement included here, bringing the total of observations to eight, is a weighted average of two stations in the rail corridor (listed in Table 3.1) which lie either side of Line N.

The steep anomaly gradient necessitates a deep basin offshore, with a maximum depth of $600 \mathrm{~m}$. This depth carries a large uncertainty and the value itself should not be taken as accurate, but confidence is high that the basin is at least as deep as that modelled on Line J. The Hill et al. (2020) model at this location is again less than half that depth, smoothly increasing to $280 \mathrm{~m}$ depth at the same point. The relatively poor RMS error of $0.109 \mathrm{mGal}$ relates to attempts to model the shallowest possible basin in order to fit results from Line J.

The Wellington Fault is modelled with a large $260 \mathrm{~m}$ offset at the same position as in the Hill et al. (2020) model. This is poorly constrained in both position and size. A smaller offset is also modelled in line with the possible splay on Line J. Confidence is lower in this splay here, but it does fit the anomaly as well as alternative models. 

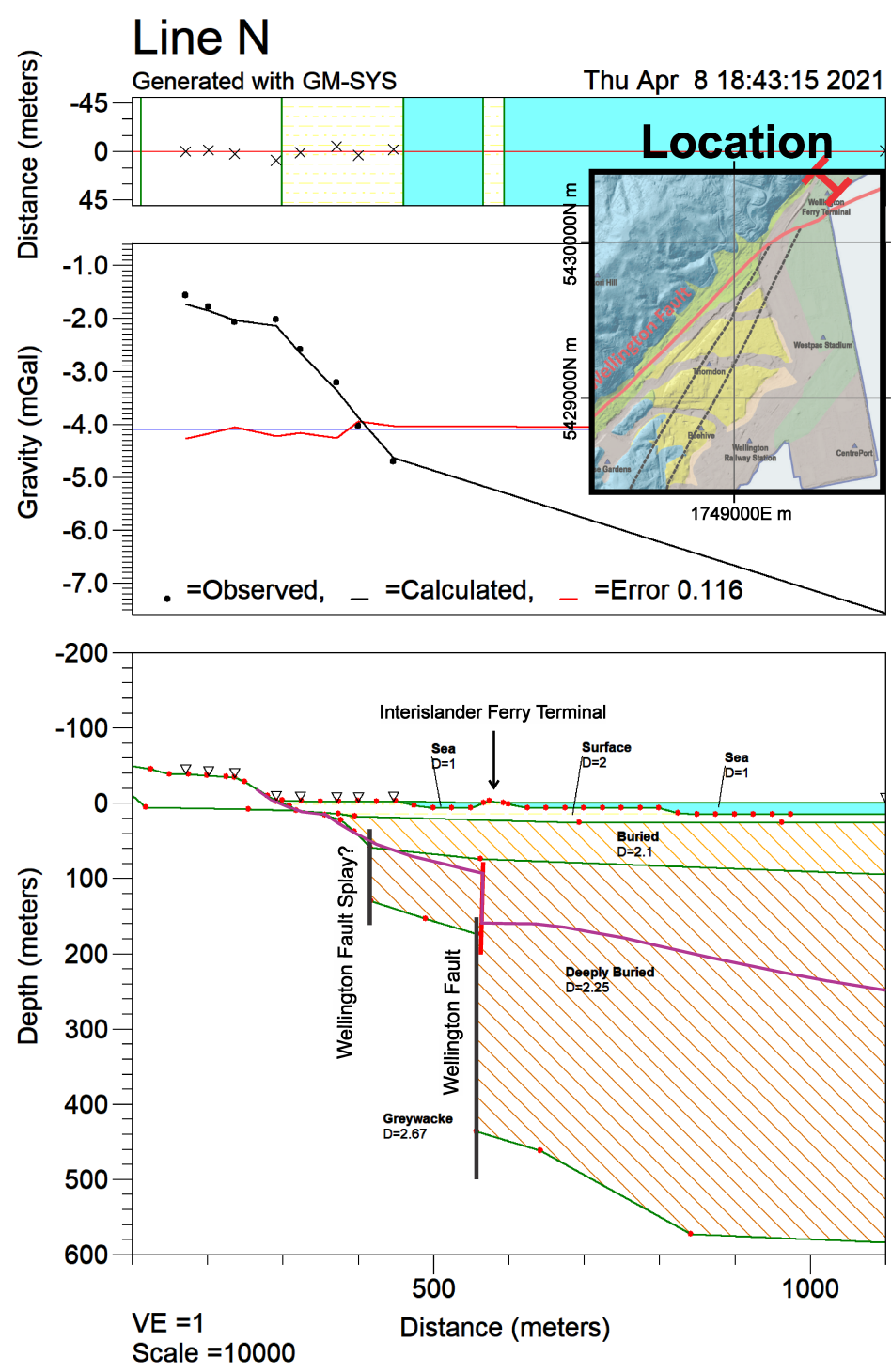

Figure 3.19: Best fit geological profile for Line N. 


\subsubsection{Line $\mathrm{T}$}

Profile Parameters

\begin{tabular}{c|c|c|c|c|c}
\hline $\begin{array}{l}\text { Length } \\
(\mathbf{m})\end{array}$ & \# Stations & $\begin{array}{l}\text { Max Anom. } \\
\text { (mGal) }\end{array}$ & $\begin{array}{l}\text { DC Shift } \\
\text { (mGal) }\end{array}$ & $\begin{array}{l}\text { RMS Error } \\
\text { (mGal) }\end{array}$ & $\begin{array}{l}\text { Max Depth } \\
(\mathbf{m})\end{array}$ \\
\hline 1,114 & 26 & -2.62 & -0.45 & 0.05 & 235
\end{tabular}

Line $\mathrm{T}$ is parallel to Lines $\mathrm{H}, \mathrm{I}, \mathrm{K}$ and $\mathrm{N}$, running from Te Ahumairangi Hill, crossing State Highway 1 and running through Parliament Grounds to finish near Queen's Wharf (Figure 3.20).

This line has more borehole constraints than any other in the Thorndon/Pipitea area. These mostly lie just up-dip of the line and so basement is modelled as slightly deeper than the intersections at these boreholes. As the Hill et al. (2020) model includes these constraints as well, agreement between that model and this is reasonable along most of the profile.

A notable point of difference is that greywacke outcrops between $280 \mathrm{~m}$ and $380 \mathrm{~m}$ along the profile in the Hill et al. (2020) model, while here the sediment is modelled as $35 \mathrm{~m}$ deep. The anomaly does not show evidence of outcrop here and it was not possible to fit a model including outcrop to the anomaly. 


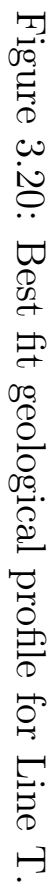

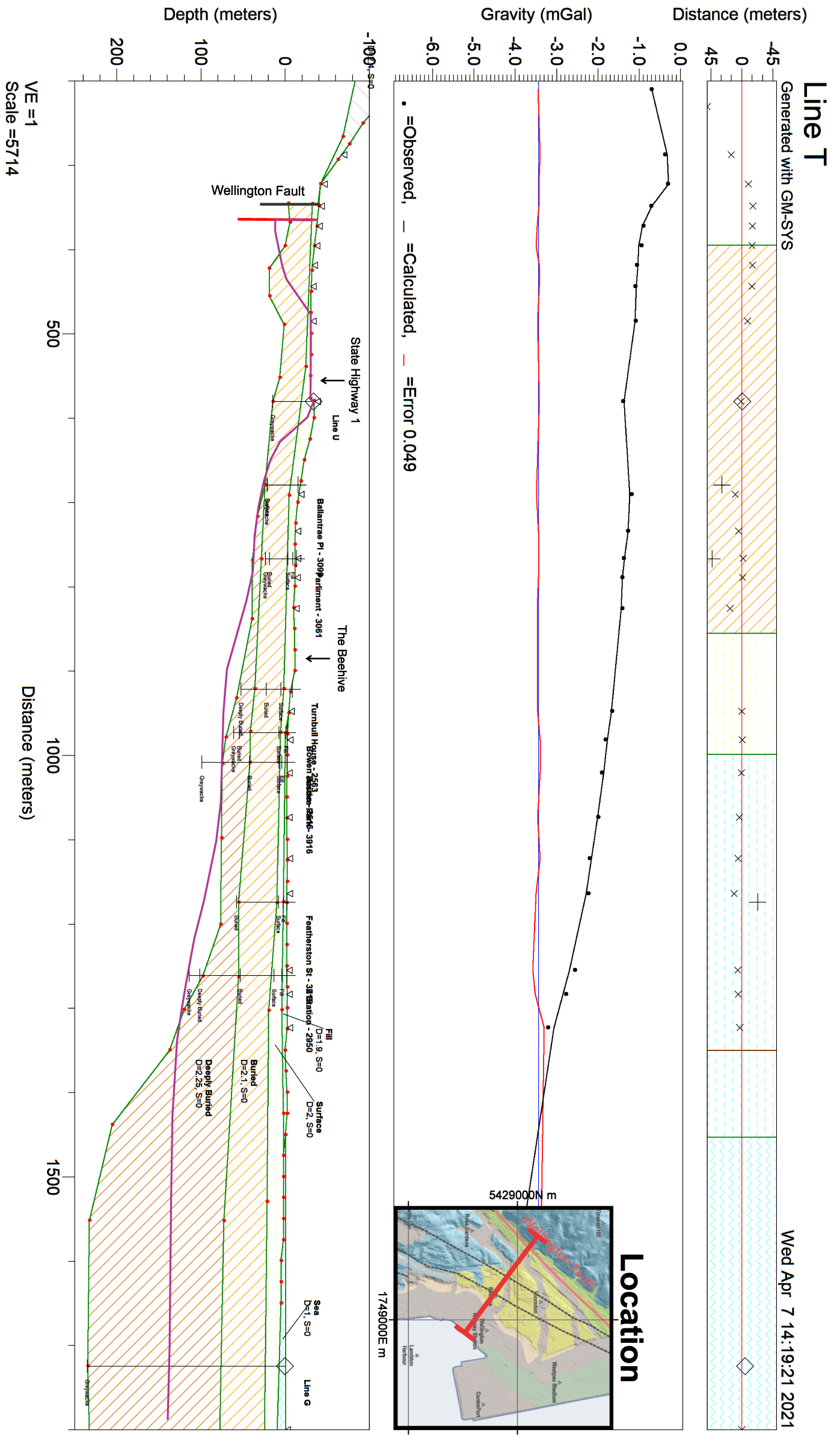




\subsubsection{Line $\mathrm{U}$}

Profile Parameters

\begin{tabular}{c|c|c|c|c|c}
\hline $\begin{array}{l}\text { Length } \\
(\mathbf{m})\end{array}$ & \# Stations & $\begin{array}{l}\text { Max Anom. } \\
\text { (mGal) }\end{array}$ & $\begin{array}{l}\text { DC Shift } \\
\text { (mGal) }\end{array}$ & $\begin{array}{l}\text { RMS Error } \\
\text { (mGal) }\end{array}$ & $\begin{array}{l}\text { Max Depth } \\
(\mathbf{m})\end{array}$ \\
\hline 1,595 & 34 & -5.48 & -0.70 & 0.03 & 425
\end{tabular}

Line $\mathrm{U}$ is the final tie-line. It runs W-E, starting on the hill behind the Prime Minister's Residence in Thorndon. It then runs along Hill street, crossing State Highway 1 and past the National Library of New Zealand to finish in CentrePort (Figure 3.21). This line crosses lines T, H, I and J, in that order.

The anomaly has a smooth gradient, which has translated to an excellent fit for the model with an RMS error of $0.025 \mathrm{mGal}$. The line starts east of the Wellington Fault and so there is no anomaly signature from that, but it is still included in the model, with a small offset of $30 \mathrm{~m}$. This is in keeping with the observed trend of an offset increasing to the north, and in agreement with the model of Hill et al. (2020).

This line crosses Line $\mathrm{H}$ at the location of the group of deep boreholes mentioned earlier in Section 3.3.9, and these are the best constraints for Line $\mathrm{U}$ as well. The only other borehole included on the profile for this line is on Hill Street, which records a greywacke intersection at $8.8 \mathrm{~m}$. This hole was drilled in 1950, and has not been assigned a data quality score in the GNS database, indicating insufficient data to do so. The model could not be made to fit both this borehole and the group of new deeper holes as well, so the presented model fits the latter only. As with the borehole on the Te Aro waterfront, this one records only a $1.2 \mathrm{~m}$ intersection which could have been misinterpreted as greywacke.

The Hill et al. (2020) model honours the 1950 borehole, and shows greywacke outcropping at the same area as it does on Line T. Again, the interpretation presented here contradicts this, with a minimum basement depth here of $30 \mathrm{~m}$. This line is also consistent with other Thorndon/Pipitea lines in interpreting an offshore basin over twice as deep as that of Hill et al. (2020). 


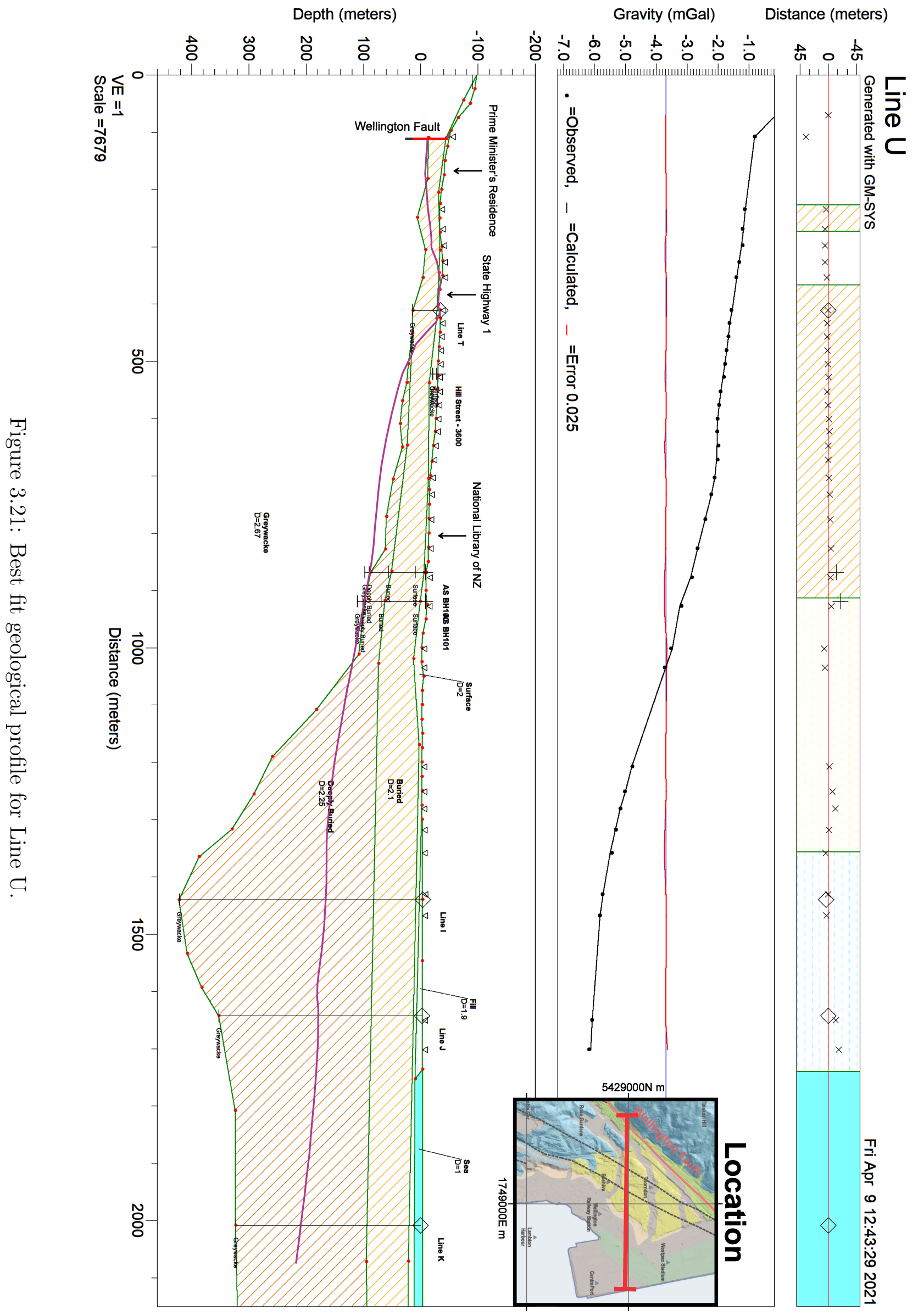




\subsubsection{Line $\mathrm{W}$}

Profile Parameters

\begin{tabular}{c|c|c|c|c|c}
\hline $\begin{array}{l}\text { Length } \\
(\mathbf{m})\end{array}$ & \# Stations & $\begin{array}{l}\text { Max Anom. } \\
\text { (mGal) }\end{array}$ & $\begin{array}{l}\text { DC Shift } \\
(\mathbf{m G a l})\end{array}$ & $\begin{array}{l}\text { RMS Error } \\
\mathbf{( m G a l )}\end{array}$ & $\begin{array}{l}\text { Max Depth } \\
(\mathbf{m})\end{array}$ \\
\hline 357 & 17 & -1.74 & -0.62 & 0.05 & 150 \\
\hline
\end{tabular}

Line $\mathrm{W}$ was measured along the waterfront next to Waitangi Park, as an exercise for undergraduate students. For the purposes of this project, the observations are primarily useful for the construction of the Bouguer and residual anomaly maps. As the line lies close to Line B, is only $350 \mathrm{~m}$ long and fairly curved, it does not make a good profile. However for completeness it is included here and in the 3D basin depth maps.

The profile does not start on bedrock and so there is a lot of leeway in the DC shift. A shift of $0.62 \mathrm{mGal}$ was applied, designed such that the Line $\mathrm{W}$ model matches that of Line $\mathrm{B}$ as well as possible. The anomaly carries the signature S shape of a fault, although the profile is a little too short to see its full extent. This also leads to the model having significant ambiguity. It was constructed with the same shape as the corresponding section of Line $\mathrm{B}$, but various other configurations of the fault(s) and the bedrock topography were found to fit equally well. Therefore this profile is little more than a confirmation of Line B. 

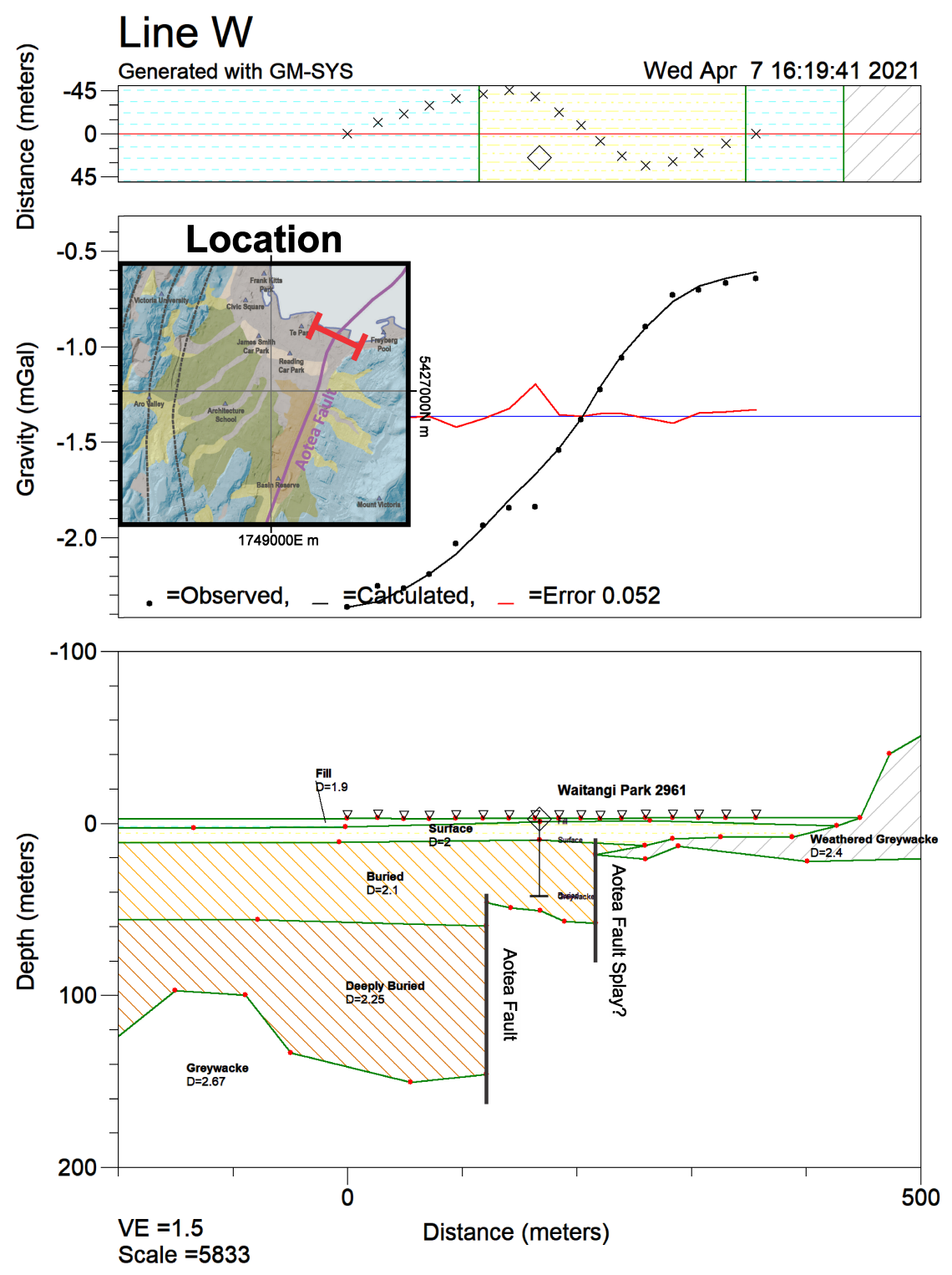

Figure 3.22: Best fit geological profile for Line W. 


\subsubsection{Profile Uncertainty}

To define the profile uncertainty, three different approaches were considered. Firstly, modelling within the formal uncertainty for the residual anomaly of each station, as described in Section 2.5.4. These uncertainties were found to be too small - in many cases the best fitting model did not fall within the error bounds of one or two stations per line. The second approach was to vary the adopted regional gravity field, and examine the effect this had on the residual anomalies and hence the models. Models were made for Lines B and $\mathrm{J}$, with more detail given in Appendix D, but as this approach resulted in less variance than the final approach it was not used.

The third approach, which was used, was to model the shallowest and deepest "geologically plausible" scenarios by varying the DC shift. As the choice of DC shift for each profile is a matter of "what fits", it was allowed to vary independently for each profile. Constraints such as boreholes and line intersections are still honoured. Because the goodness of fit for each profile to the observations is different, the RMS error of the shallow and deep scenario models has been allowed to vary by up to $10 \%$, rather than by an absolute value.

Resulting shallow and deep scenario models for Lines B and $\mathrm{J}$ are presented in Figures 3.23 and 3.24. These are compared with the best fit models of Figures 3.9 and 3.17, and with results from the second approach of varying the adopted regional gravity field.

Along roughly $90 \%$ of the Line B profile the depth range of the models derived from the second approach are encompassed by that of the third approach (Figure 3.23). This demonstrates why the latter is a better method of estimating depth uncertainty. The range between the shallow and deep scenario models is on the order of $30 \mathrm{~m}$ along most of the profile, with the exception of the area between the Te Papa borehole and the Aotea Fault, where the deep scenario reaches a maximum of $220 \mathrm{~m}$.

In the case of Line $\mathrm{J}$, the depth range of the models derived from the second approach is encompassed by that of the shallow and deep scenarios for only half of the profile. This is likely due to the fact that lines $G$ and $U$ were not re-modelled for the various regional scenarios, and so Line J could not be tied to them. Nevertheless, at the deepest point on this line, (which is also the deepest onshore point in the 3D model) the shallow scenario is still the shallowest at $410 \mathrm{~m}$, and the deep scenario the deepest at $585 \mathrm{~m}$. 


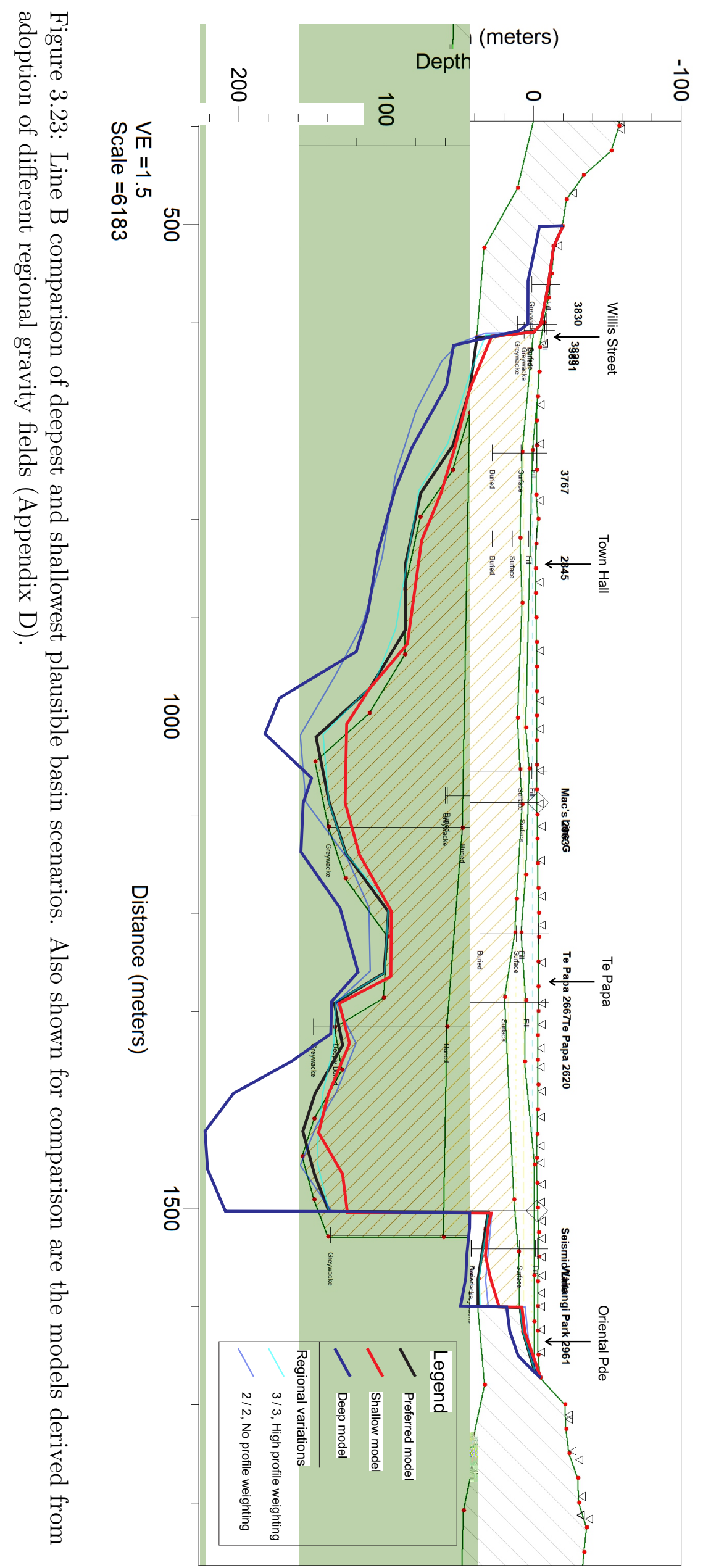




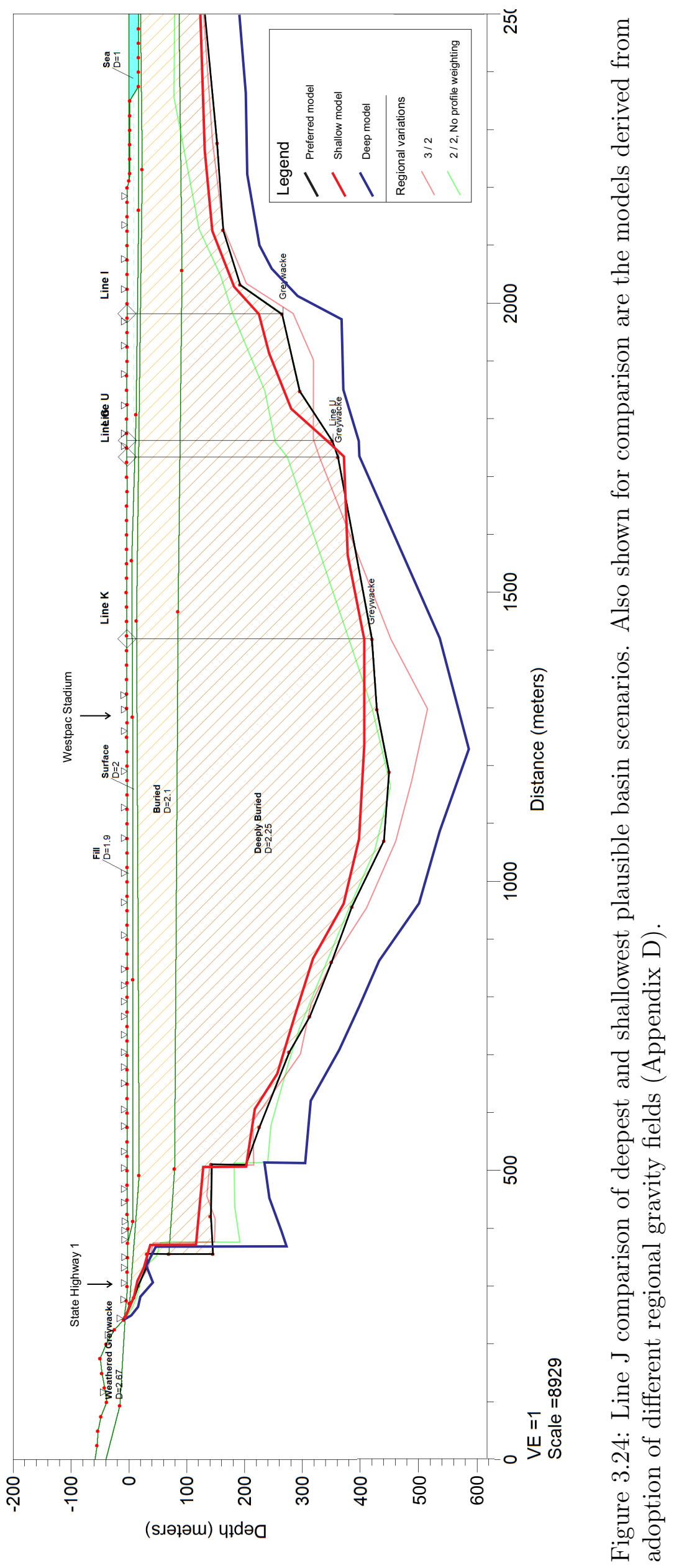




\subsection{Three-Dimensional Basin Depth Modelling}

Combining the 2D profiles as described in Section 2.7.2 results in the preferred 3D basin depth map (Figure 3.25). A higher resolution version is given in the supplementary data file "Depth_Map_HighRes.pdf", and a .TIF format version is also provided for use in GIS and 3D software: "Preferred_Basement_Depth.tif".

The depths in Te Aro increase smoothly to a maximum of $150 \mathrm{~m}$ adjacent to the Aotea Fault near the coastline. The basin continues to smoothly deepen to the north, to an overall maximum depth of $600 \mathrm{~m}$ below the seafloor offshore from Kaiwharawhara. The basement topography beneath most of Thorndon and Pipitea is relatively flat, with a steep dropoff approximately following the original shoreline, pre-reclamation. This drops down to a maximum onshore depth of 450 near the stadium. Both the Aotea and the Wellington faults have been interpreted with twin offsets.

The contour kinks in offshore areas in Figures 3.25 and 3.26 are due to the low resolution $(250 \mathrm{~m})$ of the bathymetry data (See Section 2.2.4).

The depth map of Kaiser et al. (2019) was subtracted from the preferred basin depth map to create a difference map (Figure 3.26). The most extreme difference seen is in the deep channel extending from the erroneously shallow borehole intersection at the waterfront (discussed in Section 3.3.4), NNE through CentrePort and offshore, with the depth difference increasing smoothly to a maximum of $350 \mathrm{~m}$. This is a result of the Kaiser et al. (2019) model increasing in depth only gradually offshore, while the model presented here increases more rapidly, but with roughly the same trend.

The other main difference is in Thorndon, much of which is shallower than in Kaiser et al. (2019), by up to $100 \mathrm{~m}$. Te Aro shows relatively minimal difference across most of the district. It is interesting to note that with the exception of Te Aro, the contours of the difference map (Figure 3.26) bear strong resemblance to those of the preferred basin depth map (Figure 3.25). This is a result of the greater resolution afforded by the gravity depth model, resulting in more complex topography in areas where the Kaiser et al. (2019) model lacks constraints, and is therefore smooth and featureless. 


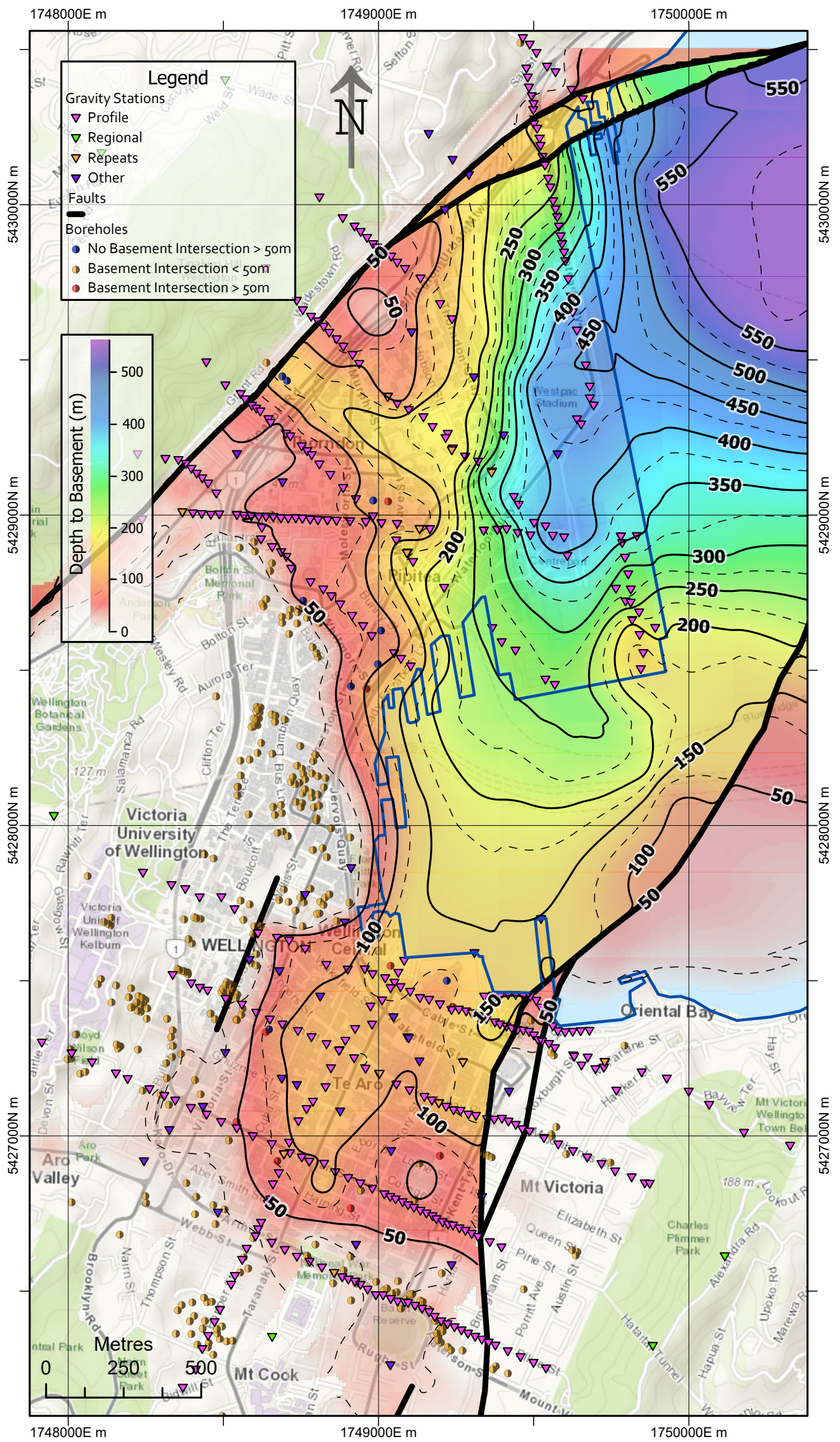

Figure 3.25: Preferred basin depth map, contoured in metres. 


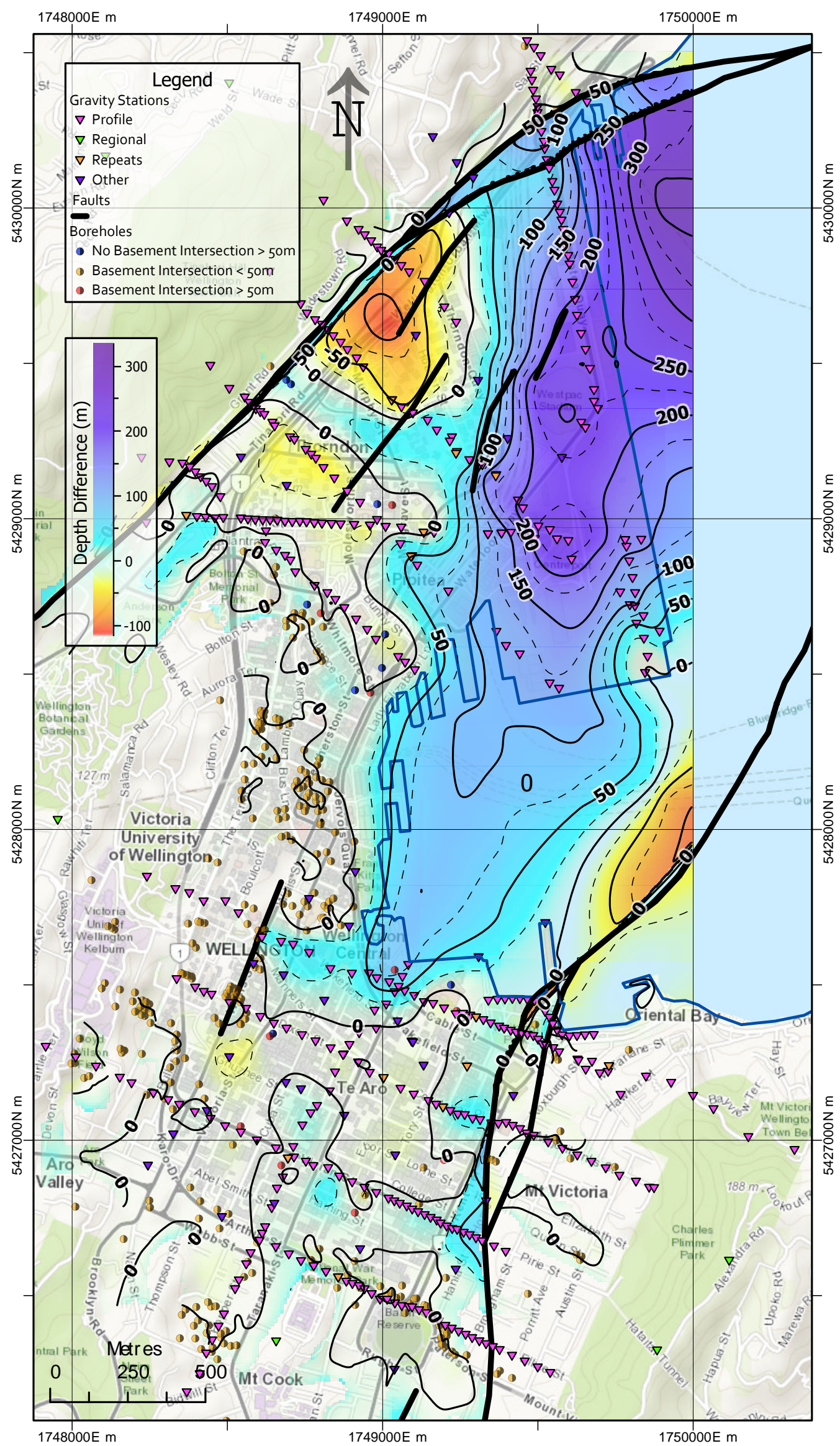

Figure 3.26: Difference map between preferred basin depth map of Figure 3.25 and that of Kaiser et al. (2019), contoured in metres. 


\subsubsection{Depth Uncertainty}

Basin depth maps have been constructed from the shallow and deep scenario profiles in the same manner as the preferred depth map. The preferred depth map of Figure 3.25 has then been subtracted from each. The results represent the uncertainty in basin depth in the deeper and shallower directions.

\section{Deep Scenario}

The 3D deep scenario model is provided in the supplementary file "Deep_Basement_ Depth.tif". The difference between the preferred and deep scenarios represents an estimation of the uncertainty in the positive (i.e. deeper) direction (Figure 3.27). Across most of the study area it is less than $50 \mathrm{~m}$, and less than $20 \mathrm{~m}$ in most of Te Aro.

In the east of Thorndon the difference is also mostly less than $20 \mathrm{~m}$, meaning that in the deepest plausible scenario the basin is still not deeper than the model of Hill et al. (2020) in this area. There is a rapid increase in positive depth uncertainty from Thorndon to Pipitea, to an onshore maximum of $135 \mathrm{~m}$ at the deepest onshore point beneath the stadium. The depth beneath the stadium may therefore be as much as $585 \mathrm{~m}$.

The standout feature in Figure 3.27 is the maximum in the NE area, offshore of the Interislander Ferry Terminal. This maximum of $250 \mathrm{~m}$ is unconstrained, meaning that it was found possible to continue increasing the depth while keeping the RMS error within the $10 \%$ of the preferred scenario. This inability to constrain maximum basement depths offshore is a limitation of this onshore gravity survey.

\section{Shallow Scenario}

The 3D shallow scenario model is provided in the supplementary file "Shallow_Basement_ Depth.tif". The difference between the preferred and shallow scenarios represents the uncertainty in the negative (i.e. shallower) direction (Figure 3.28). The amplitudes of the differences are almost all smaller than those in Figure 3.27. At the deepest onshore point near the stadium, the basement depth may be only $45 \mathrm{~m}$ shallower, at $410 \mathrm{~m}$.

The maximum difference is $-50 \mathrm{~m}$ at the deepest section of the study area, offshore of the Interislander Ferry Terminal. This means that while the maximum basin depth there is unconstrained, the minimum depth is estimated at $500 \mathrm{~m}$. This is a key result, as it is still $\sim 300 \mathrm{~m}$ greater than that given in Hill et al. (2020). 


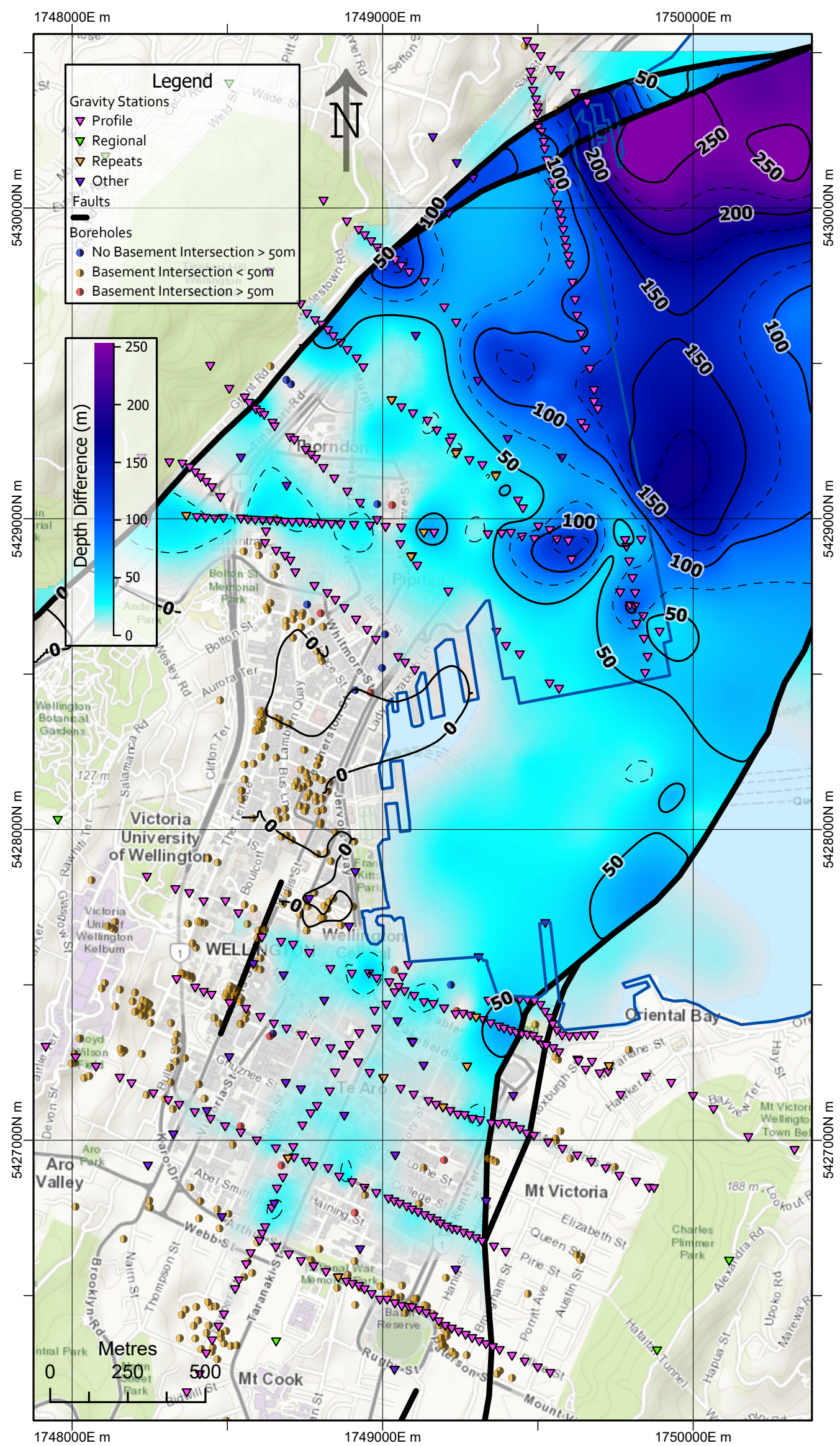

Figure 3.27: Difference between the preferred basin depth map and the basin depth map constructed from the deep scenario profiles, contoured in metres. 


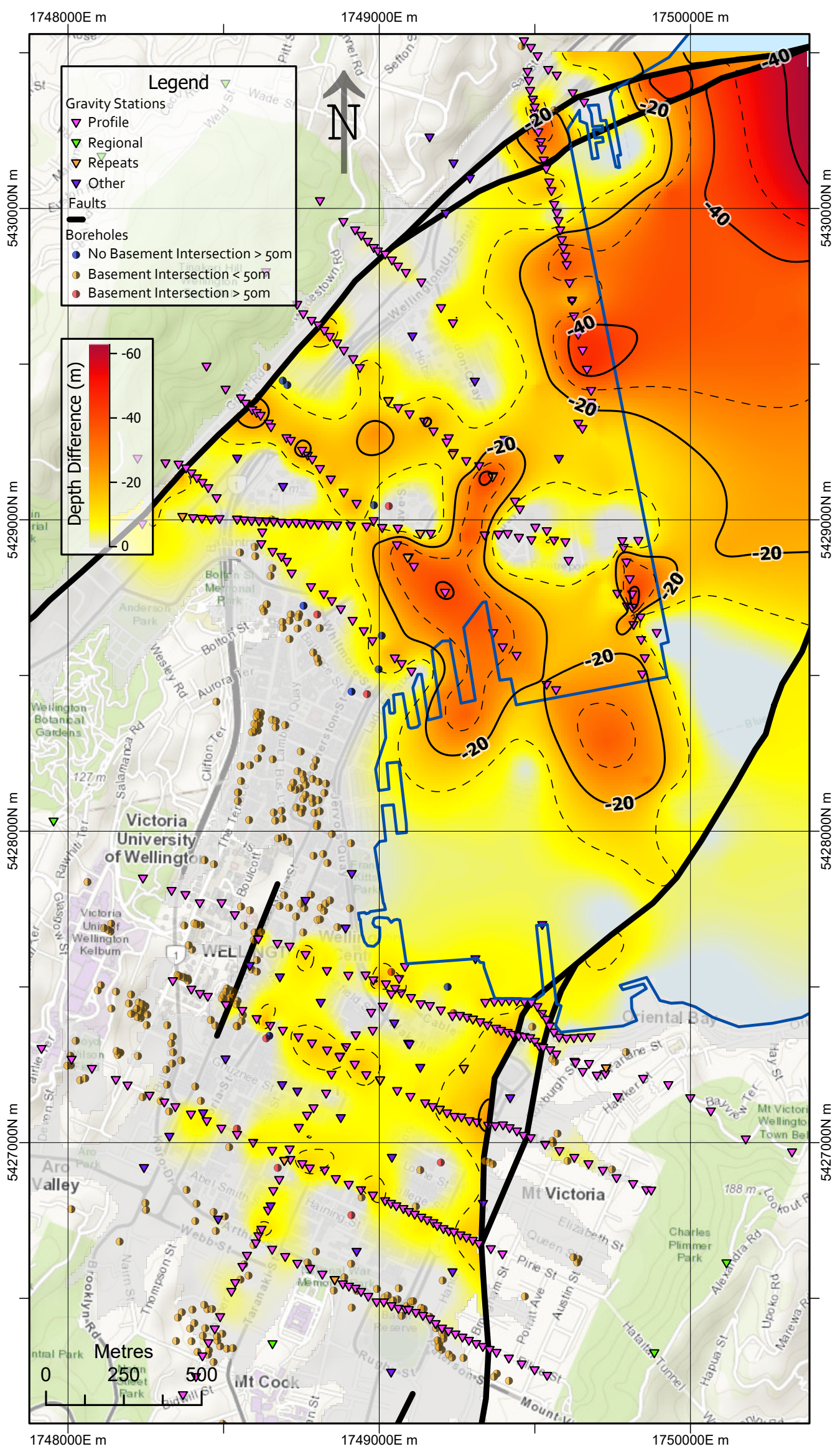

Figure 3.28: Difference between the preferred basin depth map and the basin depth map constructed from the shallow scenario profiles, contoured in metres. 


\subsection{Summary: Key Results}

- Residual anomalies are similar to those found by Hatherton and Sibson (1969), with a maximum amplitude anomaly of $-6.2 \mathrm{mGal}$ observed near the Wellington Stadium. The average uncertainty is $\pm 0.04 \mathrm{mGal}$.

- Basin depth in Te Aro was found to predominately be in agreement with Hill et al. (2020), with the exception of the foreshore area west of Te Papa, which is $30-85 \mathrm{~m}$ deeper than Hill et al.

- The Aotea Fault has been positively identified on the SE edge of Te Aro, with gravity anomaly gradients up to $8 \mathrm{mGal} / \mathrm{km}$ across it. It offsets basin sediments by up to $130 \mathrm{~m}$, and may consist of two or more separate strands or splays. It is interpreted to run further east of its expected trace along Kent Terrace. Its dip could not be constrained by this study.

- Basin depth in Thorndon was found to be predominately shallower than in Hill et al. (2020), by up to $110 \mathrm{~m}$. Depths are mostly $50-100 \mathrm{~m}$.

- Basin depth increases rapidly around the Thorndon/Pipitea boundary, with depths in Pipitea of 200 - $400 \mathrm{~m}$. This is significantly deeper than in Hill et al. (2020), by $100-200 \mathrm{~m}$.

- The area beneath the stadium was found to have the greatest onshore depth, of 450 $(+135 /-45) \mathrm{m}$. This is $250 \mathrm{~m}$ deeper than in Hill et al. (2020).

- The greatest basin depths in the study area were found to be offshore, east of the Interislander Ferry Terminal. This area is poorly constrained, but interpreted to be $600(+250 /-50) \mathrm{m}$ deep. This is $350 \mathrm{~m}$ deeper than in Hill et al. (2020).

- These deepest parts of the model, around Pipitea, CentrePort and offshore, all carry the largest uncertainty. However, this uncertainty is mostly in the positive direction - i.e. the basin could be significantly deeper, but not significantly shallower.

- The Wellington Fault is interpreted to run along its expected trace, but this position is less well constrained by modelling than that of the Aotea Fault. There is also a splay or secondary strand interpreted to the north of the main strand, in the north of Pipitea. Gravity anomaly gradients are up to $18 \mathrm{mGal} / \mathrm{km}$ across it. Offset on the Wellington Fault could be up to to $380 \mathrm{~m}$, but this is poorly constrained. 


\section{Chapter 4}

\section{Discussion}

\subsection{Depth Map Interpretation}

A simple interpretation of some of the basin topography in the Wellington City region shows a series of buried gullies and drainage channels, marked with dashed lines and arrows in Figure 4.1. A possible buried ridgeline extending NE from the exposed ridge at the site of the War Memorial, as mentioned in Section 3.3.5, is also marked. Faults interpreted in the profiles are solid lines, including the section of the Lambton Fault interpreted on Lines A and B. The buried wave-cut platform mentioned in descriptions of the Thorndon profiles is in green.

\section{Faults}

Double offsets are interpreted for both the Aotea and Wellington faults (Figures 3.25 and 4.1). In the case of the Aotea Fault the larger offset coincides with the fault position in Hill et al. (2020). The smaller offset is not necessarily required by the residual anomalies, but is included because it does slightly improve the model fit to the anomaly on Lines A and $\mathrm{B}$, and it aligns well with the single modelled offset positions on Lines $\mathrm{C}$ and $\mathrm{D}$. The Line $\mathrm{C}$ anomaly in particular does appear to require this offset position (Section 3.3.5).

The exact arrangement of these two proposed fault strands is uncertain. The true situation is likely to be more complex, for example as in the en-echelon arrangement illustrated in Figure 4.2, typical of locations where faults bend around corners. This interpretation may also align with the two traces inferred by Barnes et al. (2019) where the Aotea 
Fault approaches the shore. This level of detail is not able to be resolved by this survey, but the lateral position of the primary Aotea Fault strand is well constrained, to within $\sim 10 \mathrm{~m}$.

In the case of the Wellington Fault, the gravity anomaly best fits the northern offset in Figure 4.1, while the model of Hill et al. (2020) places the fault trace on the southern offset. Previous work has constrained the location of this southern trace with a good degree of certainty (Begg et al., 2008; Lewis, 1989), so profiles J and N have been adjusted to include it. The northern offset still appears to be necessary to fit the anomalies, so confidence in there being two strands of the Wellington Fault in this area is higher than in the equivalent area for the Aotea Fault.

Due to the difficulty of making accurate measurements to the NW of the Wellington Fault (on the steep-sided and forested Te Ahumairangi Hill), the lateral position of the Wellington Fault is less well constrained than the Aotea Fault. For the most part, however, the interpreted main trace does coincide with the Hill et al. (2020) model, and estimated uncertainty in its position is not more than $\sim 20 \mathrm{~m}$.

In both cases the dip of the faults were not able to be constrained, as noted for example in Section 3.3.5. Kaiser et al. (2019) models both faults with an $80^{\circ}$ dip. In the profiles created in this project both are modelled with $90^{\circ}$ dips, both for simplicity and because the $3 \mathrm{D}$ modelling method used does not allow for dips other than $90^{\circ}$, as mentioned in Section 2.7.2.

\section{Basin Depths}

Gravity data are good for identifying lateral density changes such as those representing a fault, but less so at absolute depths to basement. Because of compaction, density in a sedimentary sequence usually increases with depth, with the consequence that the gravity effect of deeper layers is reduced. A greater distance from an observation point on the surface means the measured gravity effect is reduced dramatically. Uncertainty in densities, either in the sedimentary sequence or in the greywacke itself (Section 4.2) is therefore likely to be the main source of uncertainty in depths, rather than the errors in the regional-residual separation.

Nevertheless, with external controls the method can produce credible results. This is evident from, for example, Lines A and B, which both fit multiple boreholes. Were only 
one borehole present, the basement intersections of the other boreholes would likely still be interpreted to a reasonable precision. In addition, the method is good for discounting scenarios that do not fit the data, such as the waterfront borehole on Line B (Section 3.3.4) and the Hill et al. fault location on Line C (Section 3.3.5).

The greater than expected basin depths in Pipitea and offshore is this project's most significant result. The shallowest limit shown in Figure 3.28 is particularly important, as it shows that for most of this area the shallow scenario is still approximately twice as deep as in Hill et al. (2020) (Figure 3.28). This gives confidence that the model of Hill et al. (2020) is too shallow, which will have significant ramifications for earthquake shaking models - greater depth of sediment usually means enhanced shaking both in duration and amplitude (Section 1.1.1).

The deep gully in Thorndon shown in Figure 4.1 is suggested by two boreholes on George street mentioned in the description of Lines H and I (Sections 3.3.9, 3.3.10). Neither of these boreholes intersect greywacke, even though modelling on Lines $\mathrm{H}$ and I suggest that they should have. This is most likely due to a three-dimensional feature such as the gully modelled. Features like this will tend to focus seismic energy, leading to greater amplification at the surface and greater seismic risk to structures.

\section{Erroneous Borehole Logs}

Two boreholes in particular have been identified in the course of this project as likely logging basement incorrectly - the 1969 borehole on the Te Aro waterfront on Line B and the 1950 borehole in Thorndon on Line U. Both have been noted as being possibly unreliable in the database via their data quality score, but in the absence of better information they have been used in the Kaiser et al. (2019) and Hill et al. (2020) models.

It is recommended that these boreholes should be re-logged if possible, although given their ages it may be unlikely that the core or cuttings are still available.

\subsection{Shift and Greywacke Weathering}

The requirement for a DC shift to be applied to residual anomalies during profile modelling stems from the regional-residual separation (Section 2.5.2). It is partially a consequence of the imperfect fit of the regional surface to the regional observations, which has an RMS 
error of $0.4 \mathrm{mGal}$. For most gravity surveys, for example that of Stern (1979) in the central North Island, where residuals are as large as $-65 \mathrm{mGal}$, this is not significant. For a high precision micro-gravity survey such as this one, residuals are an order of magnitude smaller and a $0.4 \mathrm{mGal}$ misfit is important.

However, this misfit does not fully explain all the DC shifts, as most are larger than the misfit, being up to $1.3 \mathrm{mGal}$. The second reason for this requirement is most likely the weathered greywacke zones, as modelled in the profiles.

A feature of the residual anomaly map is the variation in anomaly over bedrock, particularly in the the NW corner of Mount Victoria (circled in green in Figure 3.4) where values change by $\sim 0.4 \mathrm{mGal}$ over $300 \mathrm{~m}$. Ideally, the residual would be zero everywhere on basement rock. This is only achievable if the basement rock is of a uniform density. If it is not, as implied by the modelling, then the regional field will be pulled down where it is fitted to stations that lie on basement of less than "normal" $2.67 \mathrm{Mg} / \mathrm{m}^{3}$ density, causing residual anomalies to be too positive.

The degree of this error is determined by the degree of weathering and associated reduction in density. Therefore, the problem is addressed, line by line, with a negative DC shift applied to the residual anomalies.

\subsubsection{Weathering Mechanisms}

The 50 - $100 \mathrm{~m}$ weathered zone modelled on the profiles is relatively deep. Additional possible justifications for it are presented here, in addition to it being required by the residual anomalies.

This depth of weathering and associated reduction in rock density could be due to a combination of fault damage zones, exposure and under-saturation. Fault damage zones can be up to $200 \mathrm{~m}$ wide, as seen for example on the San Andreas continental transform fault (224 m, Jeppson and Tobin (2015)) or the greywacke-hosted Dryburgh Fault in Canterbury ( 190 m, Barrell (2016)). The possible en-echelon arrangement for the Aotea Fault in Figure 4.2 would be likely to cause a wide damage zone.

All locations where weathered greywacke is modelled are near a known fault trace - the Aotea Fault or Wellington Fault, or the splay Lambton and Terrace faults (Figure 1.7). Profiles for lines terminating on Te Ahumairangi Hill in Thorndon have relatively less 
weathering modelled than others, but this could be due to the Wellington Fault's geometry in this area, with a straight trace and splays on the basin (SE) side only.

Damage zones do not necessarily translate to a reduction in density though; downhole density measurements in the SAFOD borehole through the San Andreas Fault show an average density of $2.57 \mathrm{Mg} / \mathrm{m}^{3}$ across the $224 \mathrm{~m}$ damage zone, as compared to $2.60 \mathrm{Mg} / \mathrm{m}^{3}$ for the country rock (Jeppson \& Tobin, 2015; GFZ, 2005). However damage zones can facilitate weathering by allowing water ingress (Odling et al., 2004). Wellington hillsides are exposed to the region's wet, windy coastal environment, which combined with fault damaged rock and greywacke's highly jointed nature could allow deep weathering.

A review of the geomechanical parameters of Wellington region greywacke, as determined by laboratory testing, was conducted by Brideau et al. (2020). This compares density measurements to estimated weathering, and found that the $d r y$ density of greywacke sandstone is $2.29 \mathrm{Mg} / \mathrm{m}^{3}$ for moderately weathered, $2.02-2.54 \mathrm{Mg} / \mathrm{m}^{3}$ for highly weathered, and $1.50 \mathrm{Mg} / \mathrm{m}^{3}$ for completely weathered rock. This range easily encompasses the $2.40 \mathrm{Mg} / \mathrm{m}^{3}$ used for weathered greywacke in modelling in this project, and by Kellett et al. (2017) in Upper Hutt.

However, the bulk (in-situ) density was found to increase slightly with weathering - from $2.67 \mathrm{Mg} / \mathrm{m}^{3}$ for unweathered rock, up to $2.74 \mathrm{Mg} / \mathrm{m}^{3}$ for completely weathered rock. This implies that a density reduction will only be seen when the rock is less than $100 \%$ saturated. Given that the hillsides around Wellington City sit above the water table, this could explain why a low density zone is required on the hillsides and not beneath the basin. Weathering may be equally intense beneath the basin (e.g. Grose et al. (2015)), but confining pressure and 100\% saturation mean that there is no reduction in density.

\section{3. $\quad$ Future Work}

\section{Additional Observations}

The large spacing gaps left in Lines J (Section 3.3.11) and Line K (Section 3.3.12) would be beneficial to fill with additional stations, if access was able to be granted to the relevant areas of Centerport, the rail corridor and the stadium. Line $\mathrm{K}$ in particular could have stations added to the end of the line which may alter the trend of the final two stations. 


\section{Density Estimations}

The density of in-situ measurements is notoriously hard to measure, as the density of a sample changes when disturbed, and any point measurements made are unlikely to be representative of a large heterogeneous unit such as those in the Wellington sedimentary basin. Yet uncertainty in density can cause large errors in the modelling of gravity anomalies.

In order to refine the results from this project, the most important next step would be to examine the effect of varying the density of the sedimentary units. As a test, Line A was remodelled with all units given a density $0.1 \mathrm{Mg} / \mathrm{m}^{3}$ greater than those listed in Section 1.5.1 (Figure 4.3). This resulted in a lesser DC shift required, of -0.5 mGal as opposed to -0.85 mGal, and a reduced thickness of weathered greywacke required, by approximately half. Basin depths remain similar.

This may indicate the DC shift and weathering issues could be partially resolved by adjusting the densities used in modelling, and that the densities estimated in this project are too low. It would be valuable to recreate the basin depth map using higher assumed densities, or a density profile which increases smoothly with depth.

The Nettleton (1939) method could be used to estimate the density and degree of weathering of the greywacke hills around Wellington. This involves a gravity transect over a hill of a single lithological unit, and performing a Bouguer gravity reduction using a series of different Bouguer plate densities. The density which gives an anomaly closest to a flat line is the one closest to the true density - see for example Chetwin (1998), who used the method to find the density of a glacial moraine to be $2.35 \mathrm{Mg} / \mathrm{m}^{3}$ in the Mackenzie Country of the central South Island. 


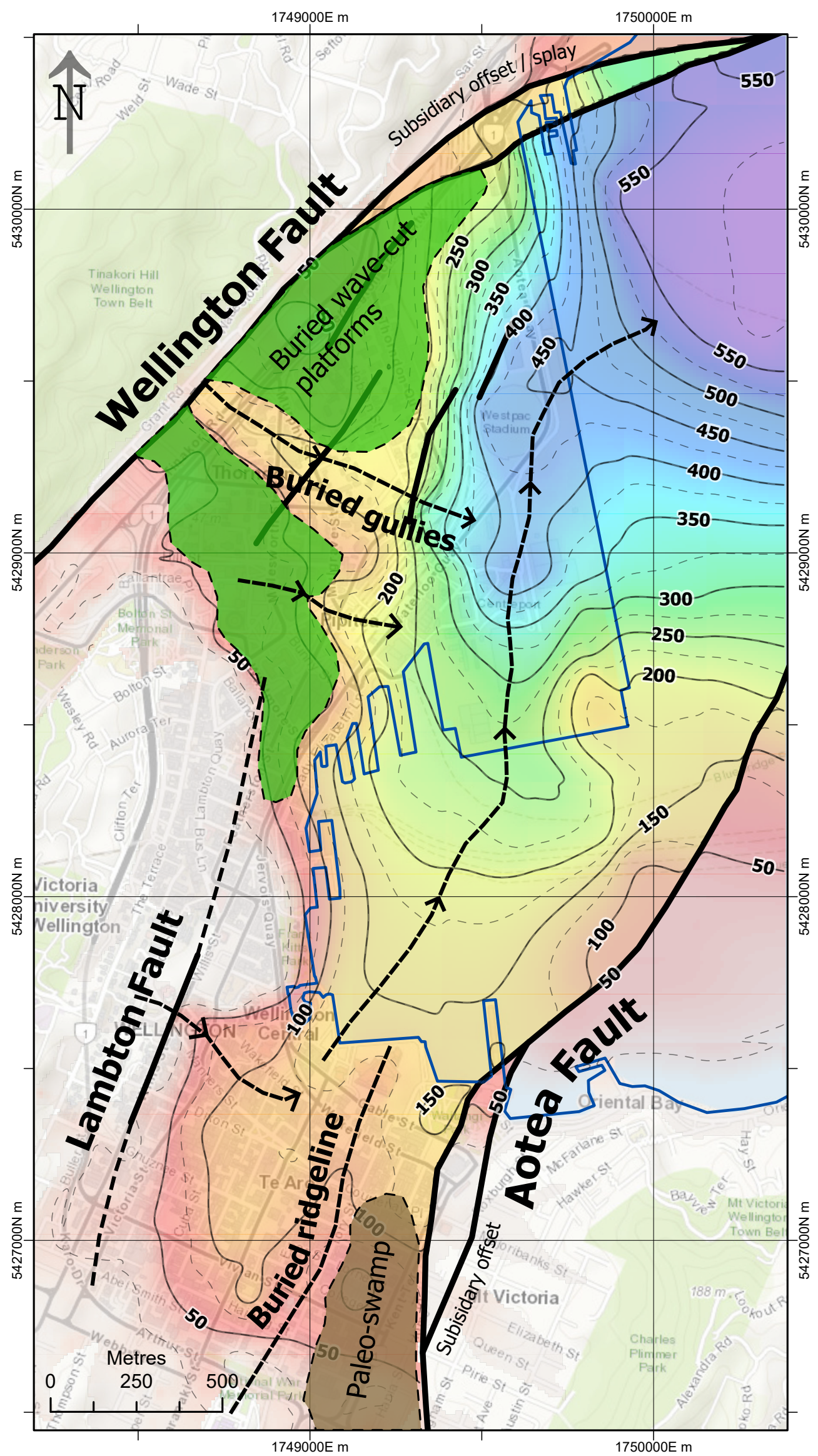

Figure 4.1: A simple interpretation of some basin topographic features in the Wellington CBD. 


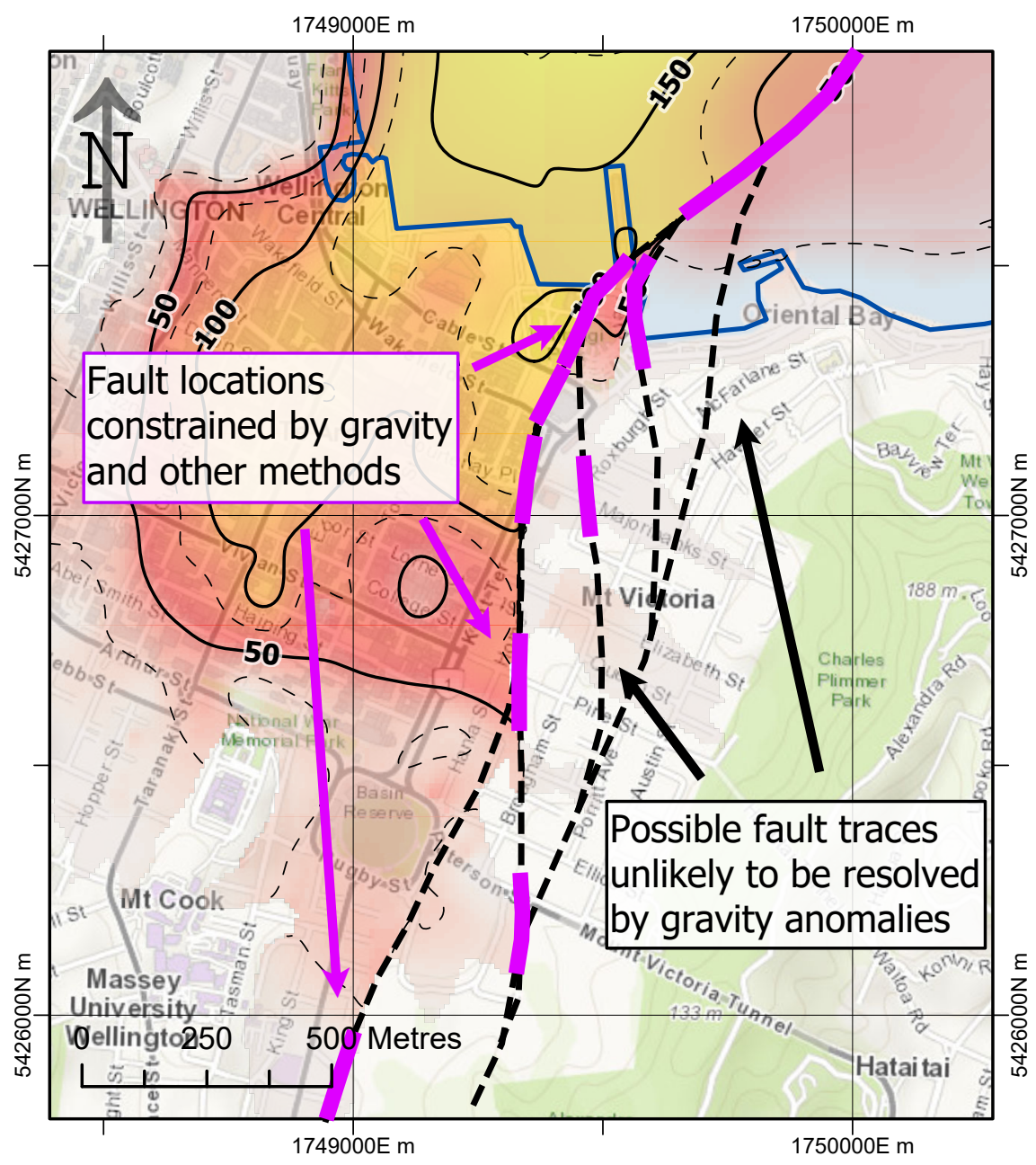

Figure 4.2: A possible en-echelon interpretation of the Aotea Fault. 

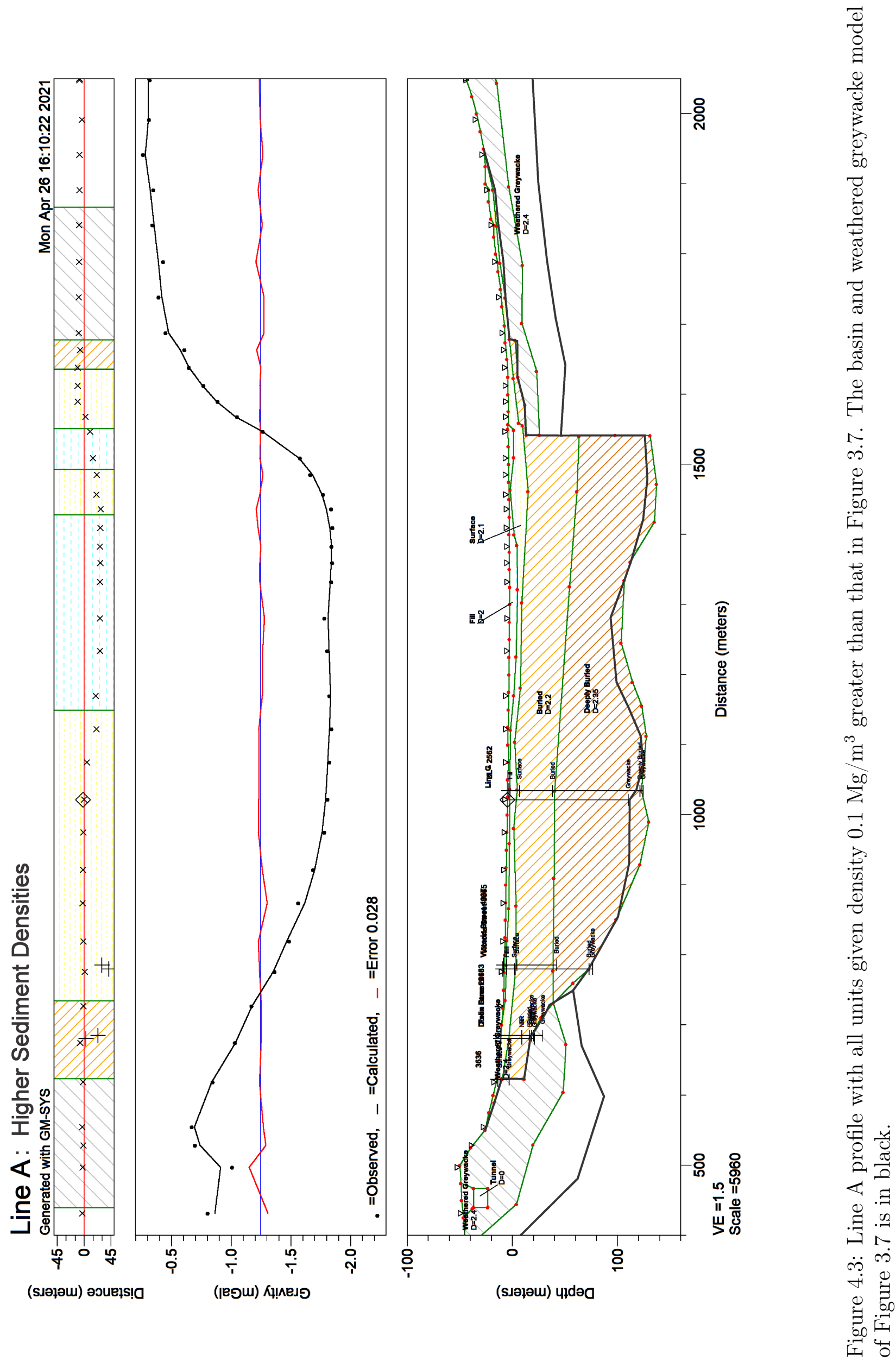


\section{Regional - Residual Separation}

Given that the wavelength separation of regional and residual gravity anomaly sources appears less clear than expected, an alternative method of regional - residual separation might better isolate the residual anomaly and remove some requirement for DC shifts. A Fourier analysis and filtering approach, such as that used by Dilalos et al. (2019) in Athens, could be employed.

In that survey the authors designed a highpass filter with a cutoff wavelength of $500 \mathrm{~m}$. The Bouguer anomaly grid was passed through a Fourier transform, the filter was then applied and the grid transformed back. The resultant residual anomaly grid contained only anomalies with wavelengths under $500 \mathrm{~m}$, mostly due to shallow structures, with amplitudes of $\sim 1.5 \mathrm{mGal}$. This approach avoids the need for regional stations, but does still require some judgement as to the filter used.

\section{Three-Dimensional Gravity Inversion}

Oasis has a 3D gravity extension, which has the capacity to perform 3D gravity inversions. In this process a 3D model is created comprising layers of assigned densities, and the gravity response calculated in 3D. This is then matched to a residual gravity anomaly grid such as in Figure 3.4, and the program automatically performs iterative adjustments to the 3D model to bring the calculated and observed gravity grids into alignment, thus "inverting" the observations to find the model.

This approach has the potential to produce a more accurate basin depth map. In 2D modelling any off-line variances in topography will be unaccounted for and introduce errors, as discussed for Line D (Section 3.3.6), but 3D modelling should avoid this problem. Testing of the 3D inversion was unsuccessful however, firstly because the weathered greywacke zones could not be modelled in 3D accurately enough, and secondly due to the complexity introduced by the varied line-by-line DC shifts; Oasis Montaj allows only a single shift for a model. More advanced 3D modelling software such as Leapfrog Geo might be used to create a workable model for 3D gravity inversion.

\section{Marine Gravity}

The finding that basement depths may reach $600 \mathrm{~m}$ or more immediately offshore of Wellington's port infrastructure is a critical point. These findings are internally con- 
sistent, but having been extrapolated from land based measurements they carry a wide uncertainty (Section 3.4.1). A marine gravity survey would help to constrain basement depths offshore.

This could be particularly important for the proposed redevelopment of the Interislander Ferry Terminal at Kaiwharawhara (WCC, 2020), a strategically important infrastructure project with an estimated cost of up to $\$ 1$ billion.

\section{Basin Depth Interpolation}

As explained in Section 2.7.2, interpolation between the modelled depths of the profiles was done using a spline function. This is a mathematical approach which may not produce the most topographically realistic outcome, but it was used as as it is the only interpolation method for which ArcGIS Pro allows the input of faults as barriers to interpolation. In addition, this method does not allow for fault dips other than $90^{\circ}$. Other software such as Leapfrog Geo would be able to create a more realistic interpretation which preserves likely topographical features such as gullies and ridges and does allow for dipping faults.

\section{Seismic Surveying}

Seismic surveys could be a method of obtaining additional depth constraints at low cost. As an example, Figure 4.4 shows a simple interpretation of results from an active source seismic survey undertaken by VUW undergraduate students in 2020 on Waitangi Park, near Line B. Average velocities have been found for the surface and buried sediment units from downhole shearwave logs (not shown for confidentiality reasons), and adopted to convert travel time to depth. Coherent reflections cease to be seen at $140 \mathrm{~m}$ depth, which is interpreted as basement. As greywacke is usually highly deformed and weakly bedded it does not return strong or coherent reflections, for example Barnes et al. (2019).

This depth of $140 \mathrm{~m}$ matches the interpretation on Line B profile for the downthrown side of the Aotea Fault (Figure 3.9). In addition, a strong double reflection is seen at $\sim 90 \mathrm{~m}$, interpreted to be a peat layer which corresponds with an organic layer logged at $82 \mathrm{~m}$ depth in the $152 \mathrm{~m}$ Te Papa borehole (Borehole ID 96717, NZGD). Peat is low density, giving it a particularly negative impedance contrast, and so is a strong reflector. These depth correlations give confidence to the interpretation and the possibility of using seismic surveys to constrain the gravity models in future work. 


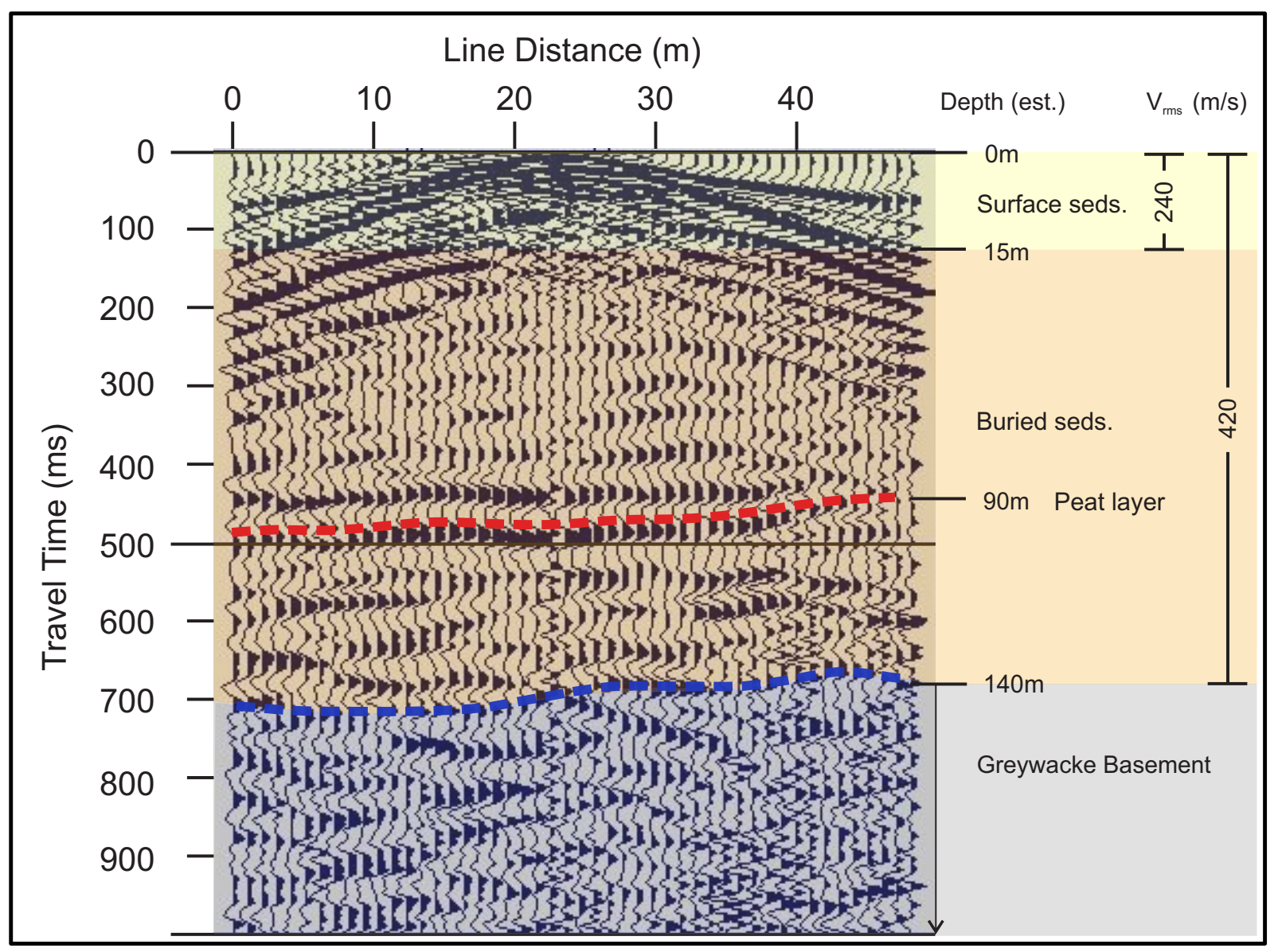

Figure 4.4: Interpretation of a five shot stack from an undergraduate active source seismic survey on Waitangi Park. Adopted interval velocities are given on the right.

\section{Boreholes}

This project has relied heavily on existing borehole data to constrain the models and deal with their non-unique nature (Section 1.5). The results presented here may help inform targets for any future stratigraphic drilling done in Wellington City. A single borehole in any of the deeper parts of Pipitea could dramatically improve confidence in the whole basin depth model, as well as providing an important reliability test. 


\subsection{Conclusions}

A micro-gravity survey was undertaken across the Wellington CBD, the first such survey since Hatherton and Sibson (1969). This survey gave the following primary results:

1. Five hundred and nineteen new high precision gravity measurements were made in and around the Wellington central business district. The measurements and corrections applied to them are all given in the supplementary data files so they are available for any future work.

2. A new residual gravity anomaly map for the Wellington CBD has been developed. Residual anomalies across the city are on the order of a few mGal. The strongest anomaly is near the stadium in Pipitea, at $6.2 \mathrm{mGal}$. Uncertainties are better than $\pm 0.1 \mathrm{mGal}$, with an average of $\pm 0.04 \mathrm{mGal}$.

3. Thirteen 2D geological profiles through the Wellington CBD were constructed to fit the observed residual gravity anomalies as well as existing borehole constraints.

4. A zone of lower than usual density greywacke $\left(2.40 \mathrm{mg} / \mathrm{m}^{3}\right)$ up to $100 \mathrm{~m}$ in depth is interpreted on the hillsides surrounding Wellington City. This may be a result of fault damage, exposure and weathering.

5. A basement depth map was constructed from these profiles for the Wellington sedimentary basin, which can be used for 3D earthquake simulations. The map incorporates boreholes used to construct existing basin depth maps as well as the new gravity data, which has resulted in significant divergence from previous maps in some areas of the city. Most of the study area has been interpreted to be deeper than the up-to-date model of Hill et al. (2020), with the area of greatest divergence being in Pipitea and offshore of CentrePort. In these areas the basin is interpreted to be up to $350 \mathrm{~m}$ deeper than in Hill et al.

6. An uncertainty range for the basin depth map was found by varying the DC shift applied to each profile. This resulted in possible depth ranges up to $50 \mathrm{~m}$ shallower than the preferred basin depth map, but with a maximum depth essentially unconstrained in the deepest parts of the study area. 


\section{Appendix A}

\section{Notes on Density}

Rock density can be measured in various ways, but it is in-situ, or wet bulk density $\left(\rho_{\text {wet }}\right)$ which needs to be considered in this project - the total mass of rock, water and air divided by the volume it occupies:

$$
\rho_{w e t}=\frac{M_{r}+M_{w}+M_{a}}{V_{r}+V_{w}+V_{a}}
$$

Or put in terms of densities:

$$
\rho_{\text {wet }}=\rho_{\text {particle }}(1-\phi)+\rho_{\text {water }} \phi \sigma+\rho_{\text {air }} \phi(1-\sigma)
$$

Where $\rho_{\text {particle }}$ is the particle density (the average density of the grains making up the

sediment), $\rho_{\text {water }}$ is the density of water, $\rho_{\text {air }}$ is the density of air, $\phi$ is the void ratio, which is the proportion of volume which is voids compared to total volume, and $\sigma$ is the saturation, or proportion of the voids which are full of water.

In the Wellington region, the sediments are almost entirely derived from local greywacke and so $\rho_{\text {particle }}=2.67 \mathrm{Mg} / \mathrm{cm}^{3}$. The density of brackish groundwater is $\rho_{\text {water }} \approx 1.01$ (Pawlowicz, 2013), and $\rho_{\text {air }} \approx 0$ and $\sigma \approx 1$. Equation A.2 can then be simplified to:

$$
\rho_{w e t}=2.67(1-\phi)+1.01 \phi
$$

Making it clear that the void ratio $\phi$ is the controlling factor in wet bulk density, as demonstrated in Figure A.1 from Hamilton (1970). 


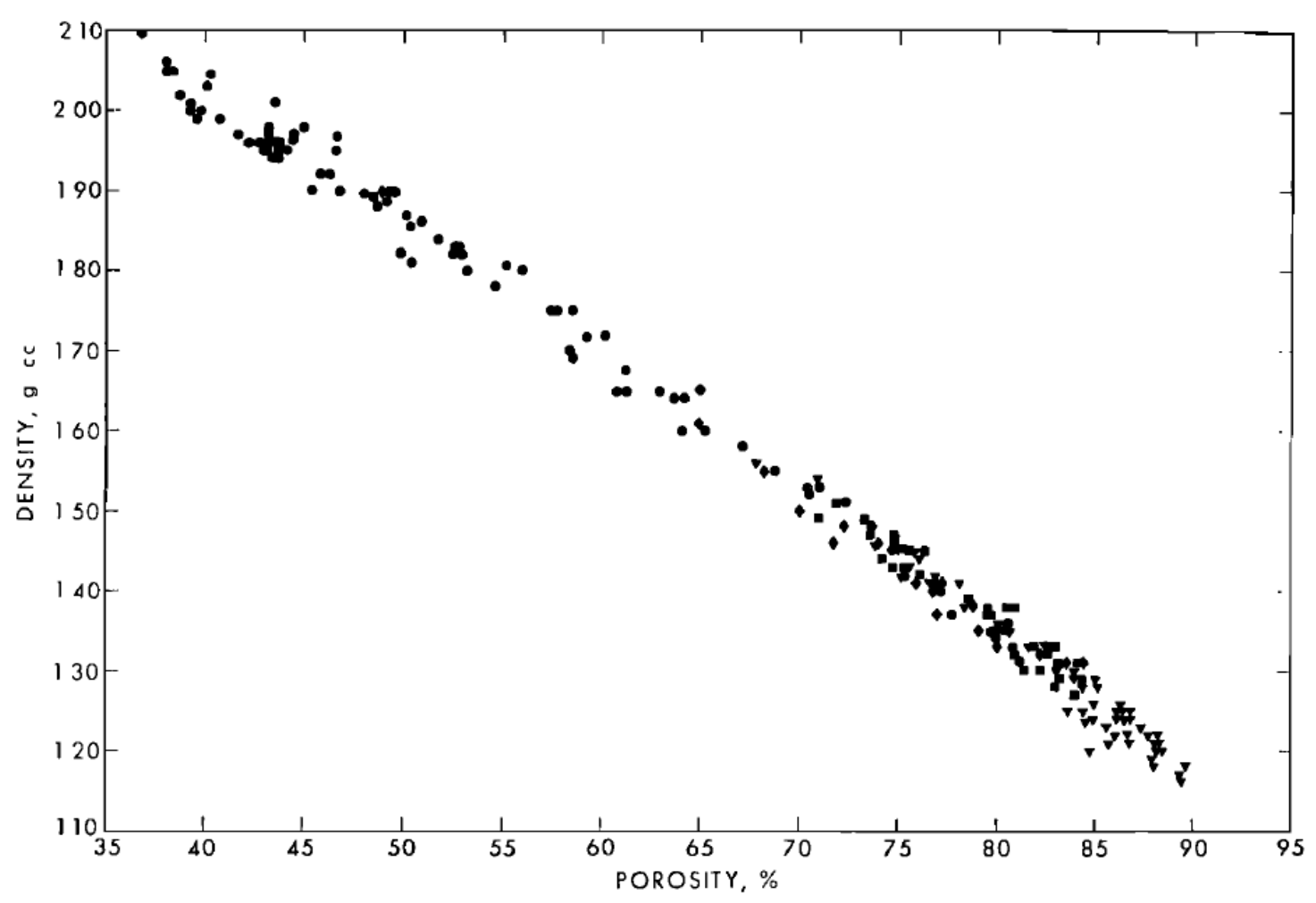

Figure A.1: Porosity plotted against density for 95 sediment samples from various marine environments. From Hamilton (1970). Note the high degree of correlation and linearity.

Void ratio is primarily a function of depth, due to increasing confining pressure from sediments above as depth increases. This is the reason that sediment densities are able to be estimated based on depth of burial rather than lithology, as is done in Section 1.5 .1 .

\section{A.0.1 Estimation Methods}

The criteria for the categorization scheme used in the GNS Leapfrog model (Section A) are (Matt Hill, pers. comm.):

- Anthropogenic Fill: Man-made fill, identified lithologically and from historical data.

- Surface: Near surface sediments with SPT N value $<30$

- Buried: Buried sediments with SPT N value $>30$

- Deeply Buried: Deeply buried sediments over 50 m deep and defined by change in $v_{s}$ to $\sim 600 \mathrm{~m} / \mathrm{s}$, or some other natural data break.

In most cases the resulting depth divisions, as entered into the GNS borehole database, are used in the modelling in this thesis. Densities are then estimated for each unit using 
one or more of the following methods.

\section{Standard Penetration Test (SPT)}

SPT is the most commonly used subsurface exploration test worldwide. The method involves a drill rig dropping a set weight onto a hollow sampling rod, and counting the number of blows required to move a set distance into the ground. This number is called the $\mathrm{N}$ value. The $\mathrm{N}$ values tend to be highly variable, but can be correlated roughly with density (Patel, 2019). Because this test is so widely used a large amount of data is available and SPT N values have therefore been used by GNS and in this project to make inferences about density.

Empirical relationships between SPT N values and density have been developed by several workers. Panjamani et al. (2016) used 364 SPT and density data pairs to find the following relationship:

$$
\rho_{\text {wet }}=1.232 N^{0.141}
$$

With $R^{2}=0.760$. SPT data for the deeper boreholes in the GNS database, where it exists, was averaged across the given surface/buried/deeply buried intervals and the average used in this relationship. This was found to give values not in agreeance with the direct measurements introduced below. However, Panjamani et al. show that the fit is improved if just fine or coarse grained sediments are considered and the coefficient and power altered.

With this in mind alternative coefficients and powers were tested while keeping the form of the equation, in order to bring the calculated density into close alignment with the measured average density of the surface sediments. The surface unit was chosen as it is the interval with the largest number of direct density measurements. The following adjusted equation was then used to calculate densities for the other three units:

$$
\rho_{\text {wet }}=1.470 N^{0.085}
$$

Average SPT N-values across the fill/surface/buried/ deeply buried intervals for six deep boreholes have been taken and equation A.5 used to find densities for those intervals. 


\section{Shear Wave Velocity}

The velocity of shear waves in rock is more closely correlated with density than is SPT. The relationship is roughly linear, known as Birch's Law (Fowler et al., 1990; Birch, 1960). However it is still dependent on various factors. Shearwave velocity, $v_{s}$, is given by:

$$
v_{s}=\sqrt{\frac{\mu}{\rho}}
$$

where $\mu$ is shear modulus and $\rho$ is density. The shear modulus is the ratio of shear stress to the strain (deformation) produced by that stress. In other words a measure of the force required to change the shape of an object without changing the volume. This generally increases with density at a greater rate than does density itself, and therefore $v_{s}$ actually increases with density, contrary to what one might think from equation A.6 (Mussett et al., 2000).

In geotechnical ground investigations downhole shearwave velocity logs are a more meaningful record of ground conditions than SPT or similar methods, but less often used due to the time and expense required.

The method involves weighting a plank or horizontal bar next to the collar of the borehole, and striking the ends with a hammer. The generated shearwaves are recorded by two or more horizontally oriented geophones, spaced $1 \mathrm{~m}$ apart down the hole, and spring loaded to ensure contact with the sides of the hole. Interval velocities between the two can then be calculated. The geophones are progressively lowered down the hole with a shot every 1-2 metres, giving a log of downhole shearwave velocity (Crice, 2011).

Panjamani et al. (2016) have made a similar correlation between $v_{s}$ and density as they have with SPT, using $354 v_{s}$ and density measurements:

$$
\rho_{w e t}=0.412 v_{s}^{0.262}
$$

with $R^{2}=0.781$. Similarly to the SPT relationship, this has been adjusted such that it gives values for surface sediments matching the direct measurements:

$$
\rho_{\text {wet }}=0.790 v_{s}^{0.160}
$$


Shearwave velocity logs are available for four deep boreholes in the study area, and equation A.8 was used to find densities for these boreholes.

\section{Direct Measurements}

Direct density measurements of sediments within the Wellington CBD are rare. This is due to lack of surface exposure, a lack of deep boreholes, and the difficulty of making density measurements of unconsolidated sediments. Those that exist are mostly from shallow depths.

Direct measurements of density are available from three sources:

\section{Petlab}

Petlab is New Zealand's online rock sample database, maintained by GNS (Strong et al., 2016). The database has records for 40 density samples of Quaternary sedimentary rocks in and near the Wellington region. Half of these were from two boreholes in Wellington, while the others were a mix of hand samples and other boreholes. An average depth for the interfaces between the Surface, Buried and Deeply Buried units was found from boreholes in the GNS database, and average densities from the Petlab data found for those depth intervals.

\section{Semmens (2010)}

Semmens (2010) includes a geotechnical data sheet, which contains 714 measurements of dry bulk density and moisture content, from which wet bulk density can be found. These were divided up by depth similarly to the Petlab data.

\section{Hatherton and Sibson (1969)}

Hatherton and Sibson (1969) give a plot of densities from boreholes against depth. The original source of this data is not given, but the points have been digitized and divided by depth as well. 


\section{Appendix B}

\section{Wellington Seismic Response}

\section{Observations}

Observations of ground motions in Wellington and Lower Hutt during the Kaikôura 2016 Earthquake showed significant amplification due thickness of sediment, a 1D effect. Figure B.1 from Bradley et al. (2017) shows the spectral acceleration (ground acceleration as a function of period), for seismic stations around Wellington. Note that in B.1 c, sites marked as deep fill have consistently greater acceleration across almost all periods than those marked as shallow fill, and the rock site (POTS) shows the lowest acceleration across all periods.

Figure B.2 shows the spectral acceleration for those same stations, broken into three orthogonal components, and coloured by location: within the Thorndon basin, the Te Aro basin, or on rock. The Wellington basin is sometimes split into separate Te Aro and Thorndon basins roughly defined by the location of those areas (Figure 1.3), as is done here. Note greater amplification in the N-S component for the Thorndon basin (B.2 a) than the Te Aro basin (B.2 b), particularly at longer periods. Given that the Thorndon and Te Aro basins are filled with the same sediment, and the source-to-site path is essentially the same, this unequal amplification in the Thorndon basin is interpreted by Bradley et al. (2017) to be due to those station's proximity to the Wellington Fault. The Te Aro stations by contrast are located further from basin-bounding faults.

Figure B.2 c shows there was also greater amplification for Thorndon basin stations than Te Aro in the vertical direction. Bradley et al. (2017) interpret this as due to converted 


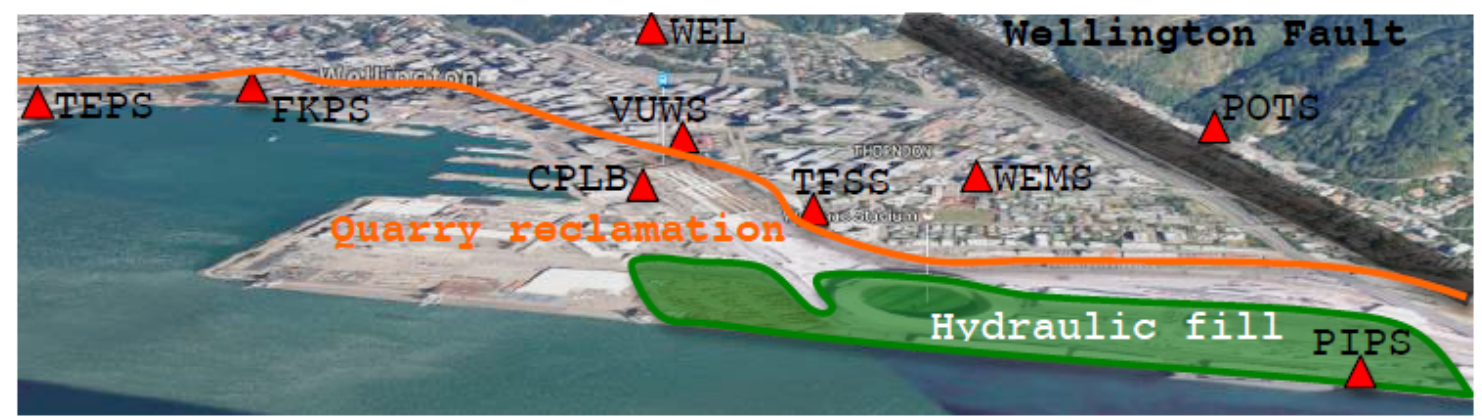

(a)
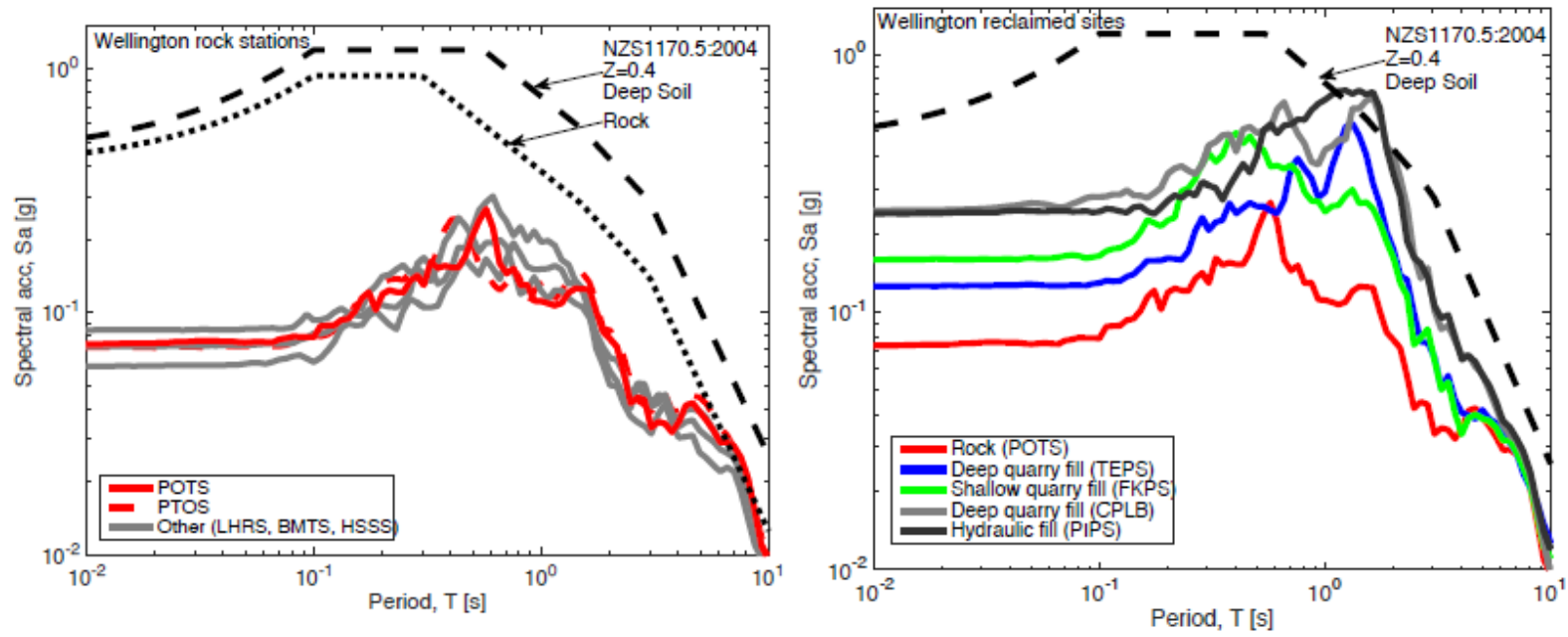

Figure B.1: Spectral accelerations for Wellington seismic stations in the Kaikōura earthquake, grouped by station location and subsurface sediment type. Also shown are the expected amplifications for rock, deep soil and shallow soil sites as proscribed by New Zealand Standard 1170.5:2004. a) Location map for Wellington CBD stations. b) Hard rock stations. Note similar responses. c) Stations on reclaimed land, with their underlying sediment type identified. From Bradley et al. (2017).

Rayleigh waves from the Wellington Fault, which have a vertical component. These observations all indicate that the basin edge geometry could play an important role in spectral amplification.

Similar observations were made for the 2013 Cook Strait earthquake (Francois-Holden et al., 2013). Figure B.3 shows the recorded spectral amplification of the Cook Strait earthquake as compared with the Kaikōura earthquake. The similar pattern of amplification illustrates an important point - that for earthquakes with approximately the same source azimuth, the spectral amplification is controlled by the nature of the sedimentary basin, and not that of the earthquake. Similar patterns of amplification can therefore be expected in future earthquakes.

Previous work has also noted the possible importance of basin edge effects in the Hutt Valley, such as that of Adams (2000), who modelled shear waves in 2D cross-sections 


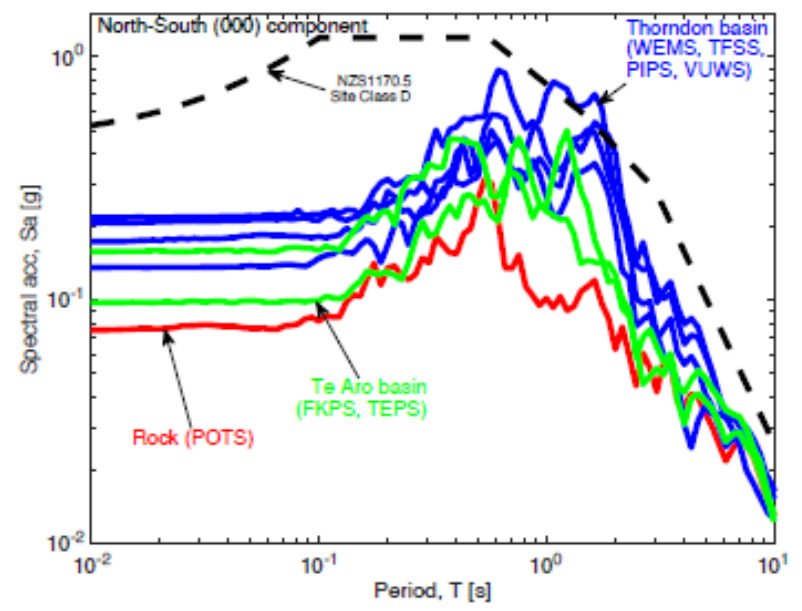

(a)

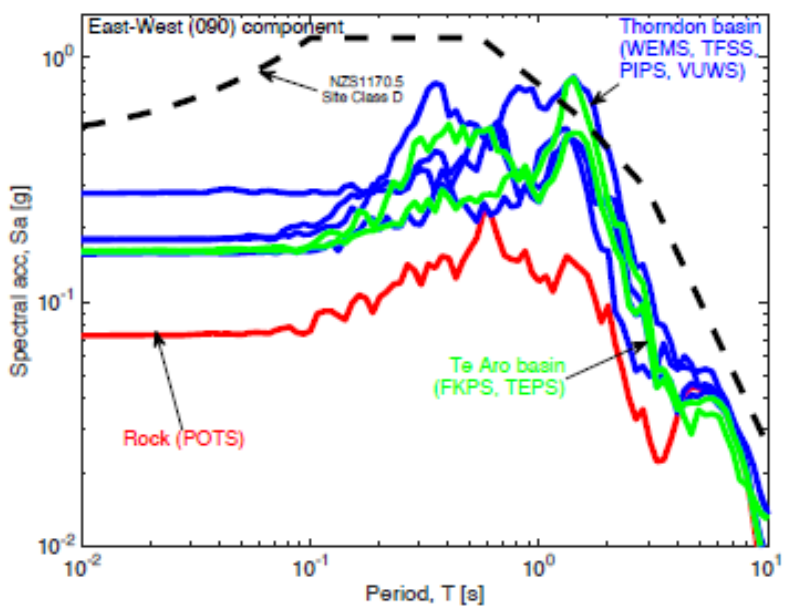

(b)

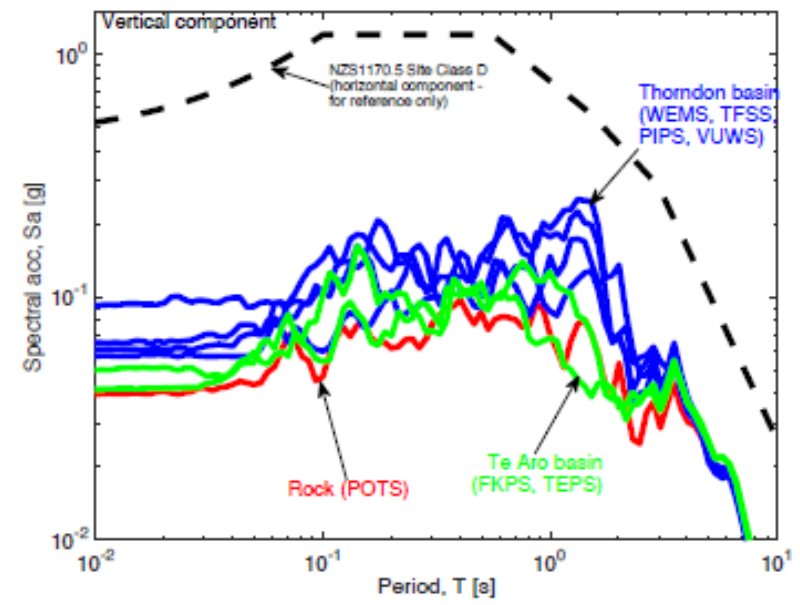

Figure B.2: Spectral accelerations recorded by Wellington seismic stations during the Kaikōura earthquake, broken into north-south (a), east-west (b) and vertical (c) components. Note greater north-south and vertical acceleration for the Thorndon basin than the Te Aro basin. From (Bradley et al., 2017).

of the Hutt Valley, observing surface waves generated at the Wellington Fault bounded edge. Adams et al. (2003) also observed patterns of unequal amplification in weak motion records of Hutt Valley stations and identified Love waves, attributing these to basin edge effects. Finally, during 3D modelling of Wellington Fault rupture scenarios, Benites and Olsen (2005) note patterns of amplification in both Wellington and the Hutt Valley which they ascribe to basin geometry.

\section{B.0.1 New Zealand Standard 1170.5:2004}

New Zealand Standard 1170.5:2004 defines site subsoil classes, labelled A through E. These are the primary determinant of building requirements for seismic loading at a given site. Each class is defined by some combination of geotechnical factors: shear strength, shear wave velocity, depth, fundamental period, and SPT N - value. 


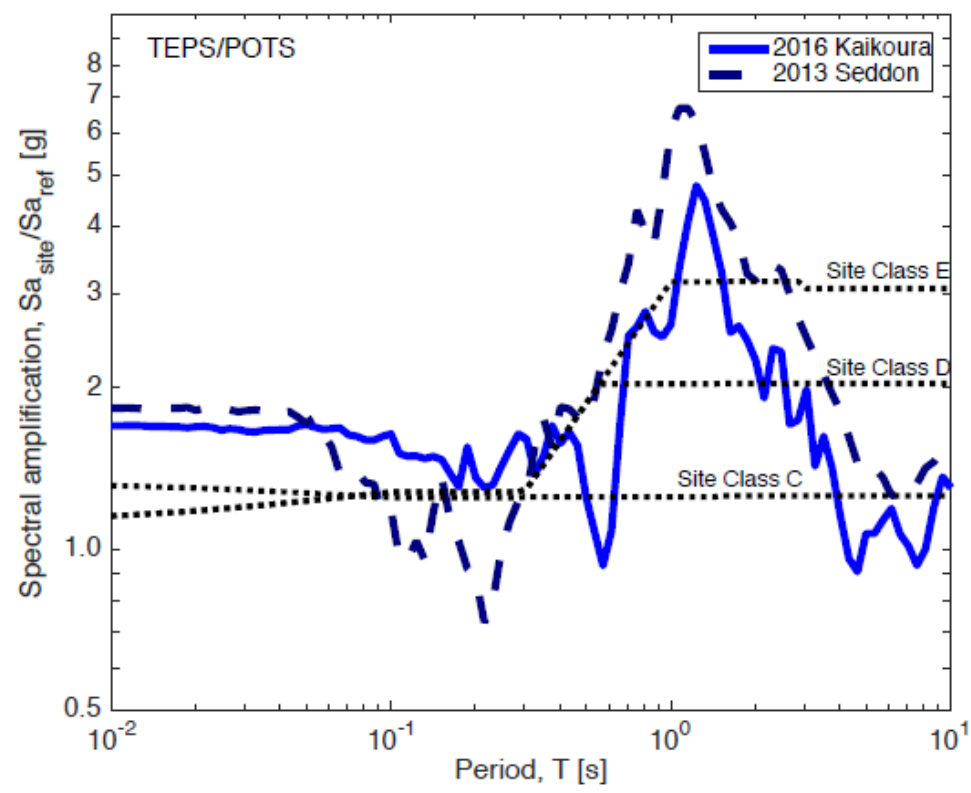

Figure B.3: Spectral amplification at the TEPS station in the Te Aro basin for the Cook Strait (here called Seddon) and Kaikōura earthquakes. Amplification has been calculated by dividing spectral acceleration at TEPS by spectral acceleration at a hard rock reference station, POTS. Note similar shape to both curves. Also marked are the building code prescriptions for maximum amplification expected for soil class sites C, D and E. From (Bradley et al., 2017).

The preferred parameter for definition of site class for C, D and E is "natural period", meaning the fundamental resonance frequency, a 1D amplification effect. The other parameters also do not make any reference to lateral changes in geology - and so 2D and 3D amplification effects are not accounted for by the standard.

The results of this approach can be seen in Figures B.1 and B.2. The spectral accelerations proscribed by NZS 1170.5:2004 were surpassed by the records from some stations - notably the CPLB and PIPS sites, both of which lie on deep reclamation. These sites are classed as D - soft soil sites, but surpassed the prescription for site class D at certain periods. This may mean only that this area should be categorized as E - Very Soft Soil.

However Figure B.3 shows that at TEPS, while the ground acceleration did not surpass the code prescriptions, the spectral amplification across most periods did, even for site class E, which occurred for both Cook Strait and Kaikoura earthquakes. If the argument that amplification will tend to be similar between different earthquakes at moderate distances is accepted, then spectral amplification is the key parameter. Were a $M_{w} 8.0$ earthquake to occur regionally, ground accelerations would far exceed the prescriptions of the current standard. 


\section{Appendix C}

\section{Errors in Historical Gravity}

\section{Observations}

As an exercise to identify the source the source of the variance between historical and new measurements, the variance in Bouguer anomaly between pairs of stations in Table 3.2 was plotted against the errors in terrain correction and in height for those historical stations (Figure C.1). Given that modern techniques are significantly more accurate than historical ones (Sections 2.2.4, 2.3.1), the variances between historical and new observations are assumed to be due to historical errors.

There is only a rough correlation between error in terrain correction and Bouguer anomaly, with approximately two thirds of the points falling on a line. There is no clear correlation between error in heights and in Bouguer anomaly. The variances between historical observations and new ones cannot therefore be ascribed to any single factor, and are probably due to a combination of different errors for each observation. 

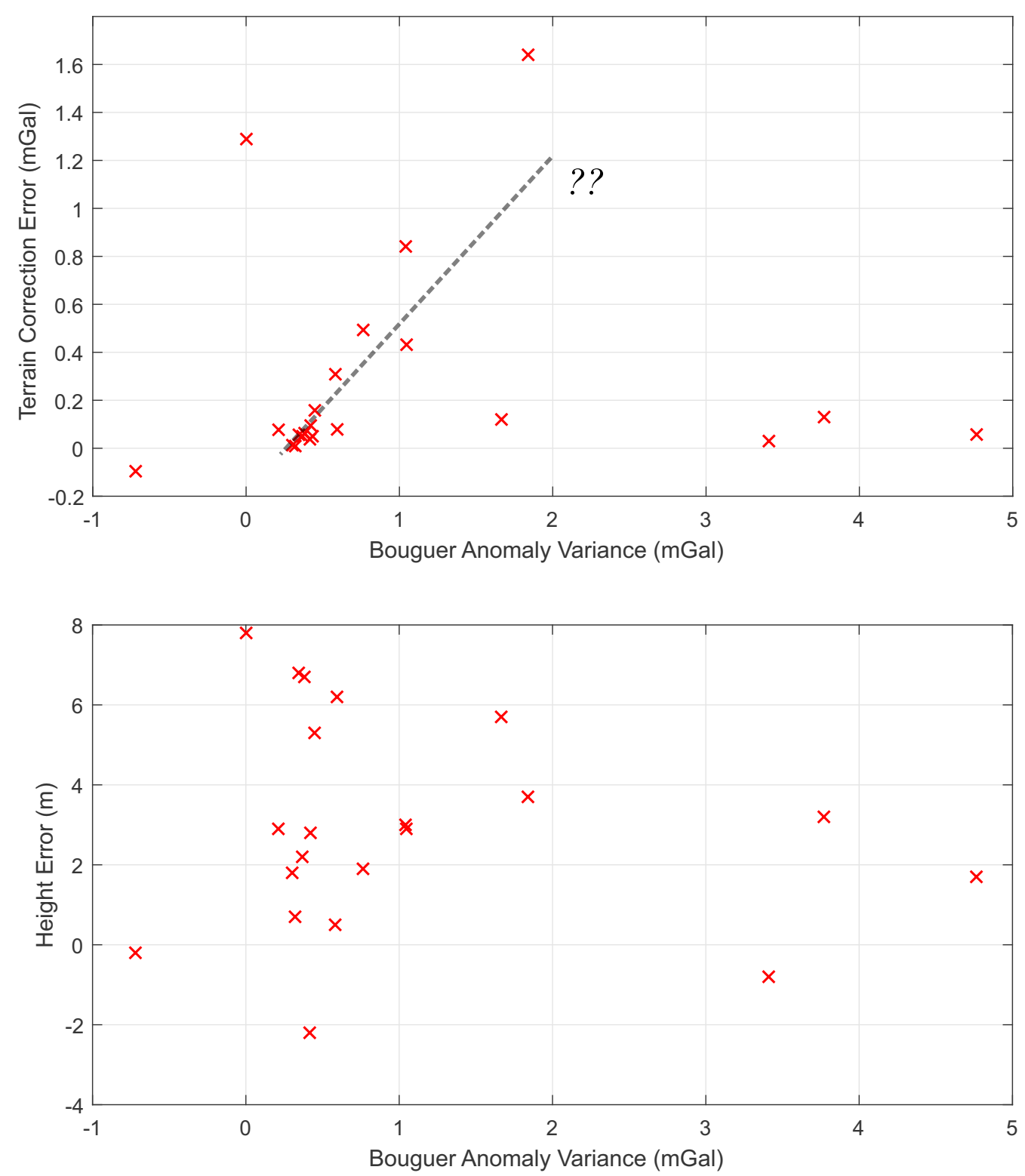

Figure C.1: Variance in Bouguer anomaly between historical and new stations as a function of error in historical terrain correction and in historical height observations. 


\section{Appendix D}

\section{Uncertainty in Regional-Residual Separation}

The adoption of a regional gravity field to subtract from the Bouguer anomaly is a matter of interpretation, as explained in Section 2.5.2. Changing the regional gravity field changes the residual anomaly, and therefore this can have a large effect on the resulting profile models. To test the significance of this, a range of different regional polynomials were fitted and models made for the corresponding residual anomalies for two profiles, Lines B and J. These were selected as they are the two which exhibited the greatest differences from each other, in terms of depth, available controls and orientation.

The test polynomials varied in the polynomial order in the $\mathrm{X}$ and $\mathrm{Y}$ directions, and in the weighting given to the stations. They are as follows:

1. Order $2 / 2$ (2 in the $\mathrm{X}$ direction and 2 in the $\mathrm{Y}$ direction)

2. Order $3 / 2$

3. Order $2 / 3$

4. Order $3 / 3$, with weightings as used in the preferred models

5. Order $3 / 3$, with all stations weighted the same

6. Order $3 / 3$, with profile line stations weighted at 0.1 and regional stations at 1

7. Order $3 / 3$, with profile line stations weighted at 1 and regional stations at 0.1 
8. Order $3 / 3$, without profile line stations

9. Order $2 / 2$, without profile line stations

Results are discussed separately below for Lines B and J.

\section{Line B}

Figure D.1 gives the residual anomalies for Line B, for each of the regional fields listed above.

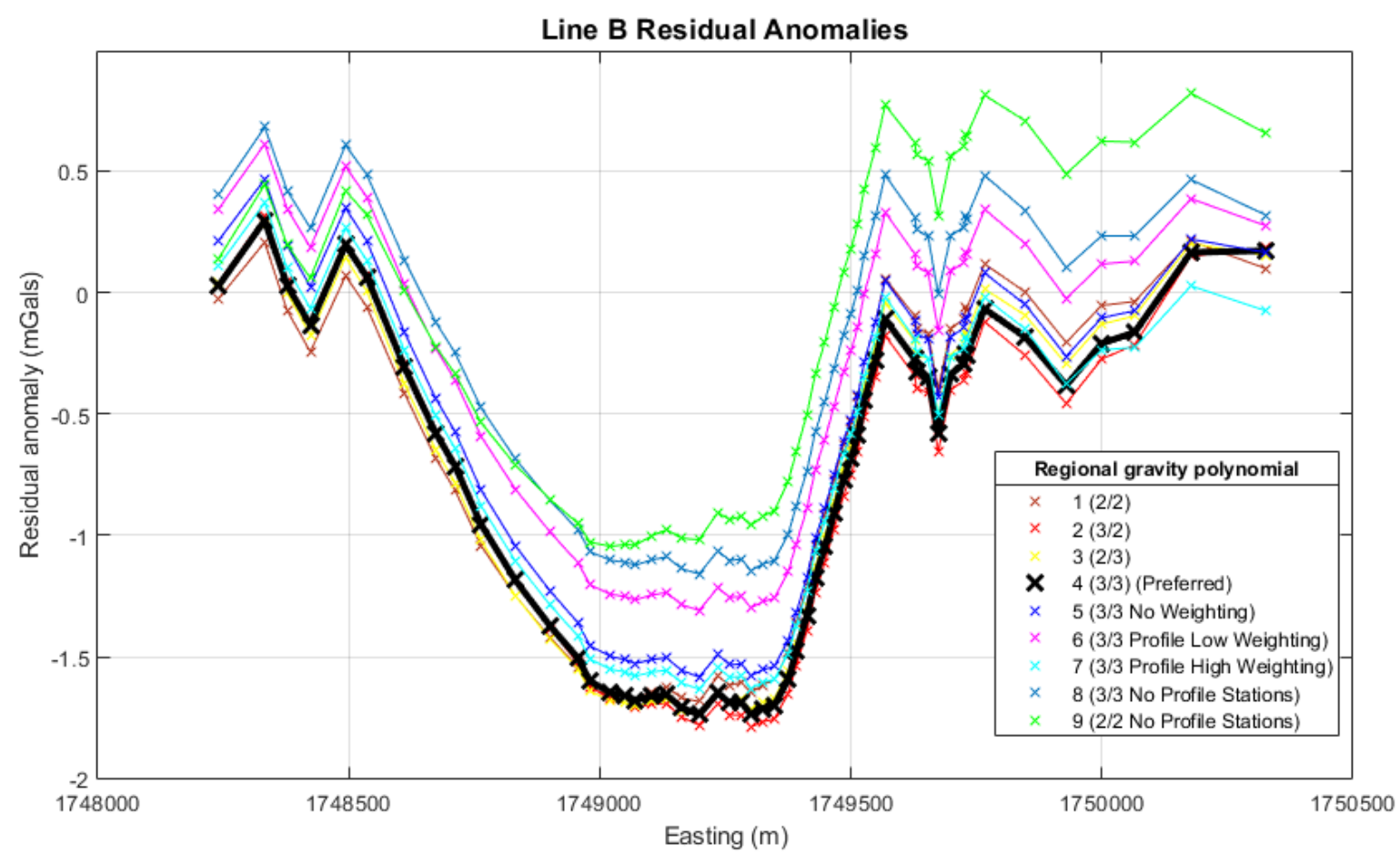

Figure D.1: Residual anomalies for Line B which result from the adoption of different regional gravity fields. The regional fields are numbered as in the list above. The preferred regional which has been used is in bold.

A significant range is apparent in the magnitude of the residual anomaly, from $\sim 1.0 \mathrm{mGal}$ to $\sim 1.7 \mathrm{mGal}$. The preferred regional field gives near the maximum magnitude residual anomaly, while the second order polynomial which disregards the profile stations gives the minimum. This is logical given that end profile stations were added to the regional calculation in order to bring the residual closer to zero at the profile ends (Section 2.5.2).

A constant shift to the magnitude of the anomaly is equivalent to a DC shift in modelling, and as the DC shift is selected on a per-profile basis, a constant regional shift will actually have no impact on the model. However a change in the regional gradient, visible in Figure D.1 as a 'twisting' to the residual anomaly, will affect the model. 
The two residual anomalies which represent the end-members of the possible regional gradients are numbers 7 (order $3 / 3$ and high weighting to profile stations) and 9 (order $2 / 2$ and no weighting to profile stations). Figure D.2 compares the resulting basin depths from modelling of these with that of the preferred model. It can be seen that both new models have at least as good a fit to their observations as the preferred model.

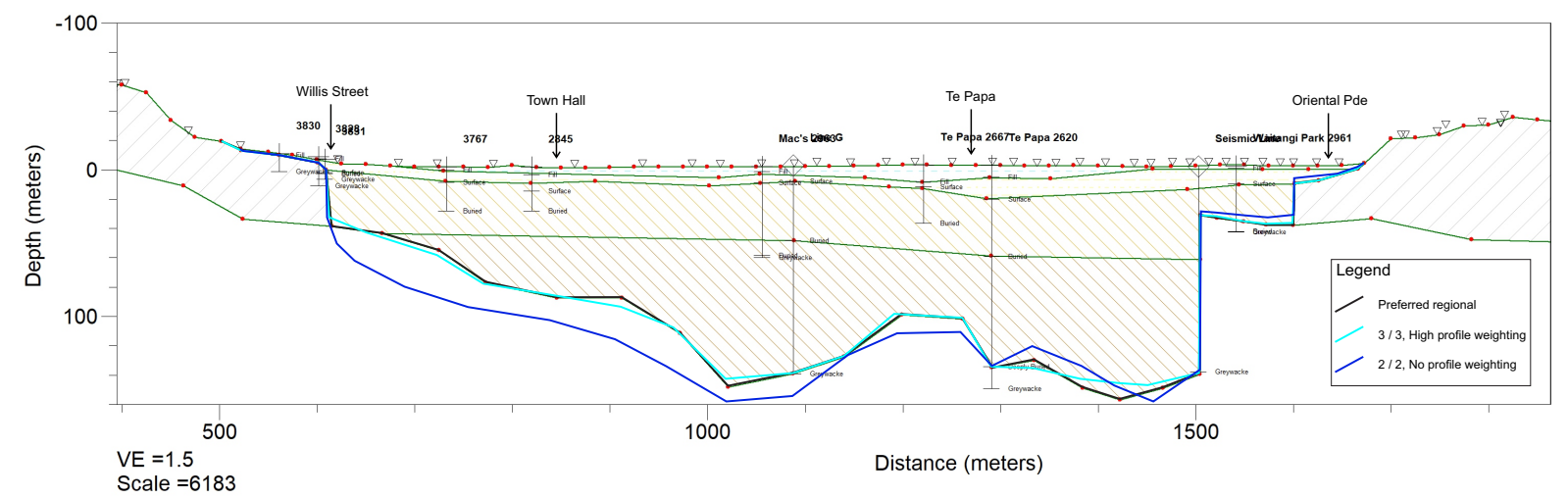

Figure D.2: Comparison of basin depths on Line B resulting from the adoption of different regional gravity fields.

The basin depths resulting from adoption of the $\# 7$ regional field differ only slightly from those of the preferred regional field, the two being within $10 \mathrm{~m}$ of each other across the whole of the Line B profile. Those resulting from adoption of the $\# 9$ regional field differ more, at up to $30 \mathrm{~m}$ deeper at the western end of the profile.

\section{Line J}

Figure D.3 gives the residual anomalies for Line J, for each of the regional fields listed above.

The Line J residual anomalies show less variance with adoption of different regional fields than do those of Line B. The range of anomalies is $\pm \sim 1 \mathrm{mGal}$. Again, the two options representing the greatest range in gradient have been selected for profile modelling numbers 2 and 9. The models are shown in Figure D.4

Because Line $\mathrm{J}$ has less constraints, the resulting models vary more than do those of Line $\mathrm{B}$ - up to $60 \mathrm{~m}$ deeper in the case of regional \#2, and $50 \mathrm{~m}$ shallower for regional $\# 9$.

For both Lines $\mathrm{B}$ and $\mathrm{J}$ these depth variances are usually less than those found for the approach of varying the DC shift, as described below. Varying the adopted regional field would also be a more labour-intensive approach of finding uncertainties, which is why it 


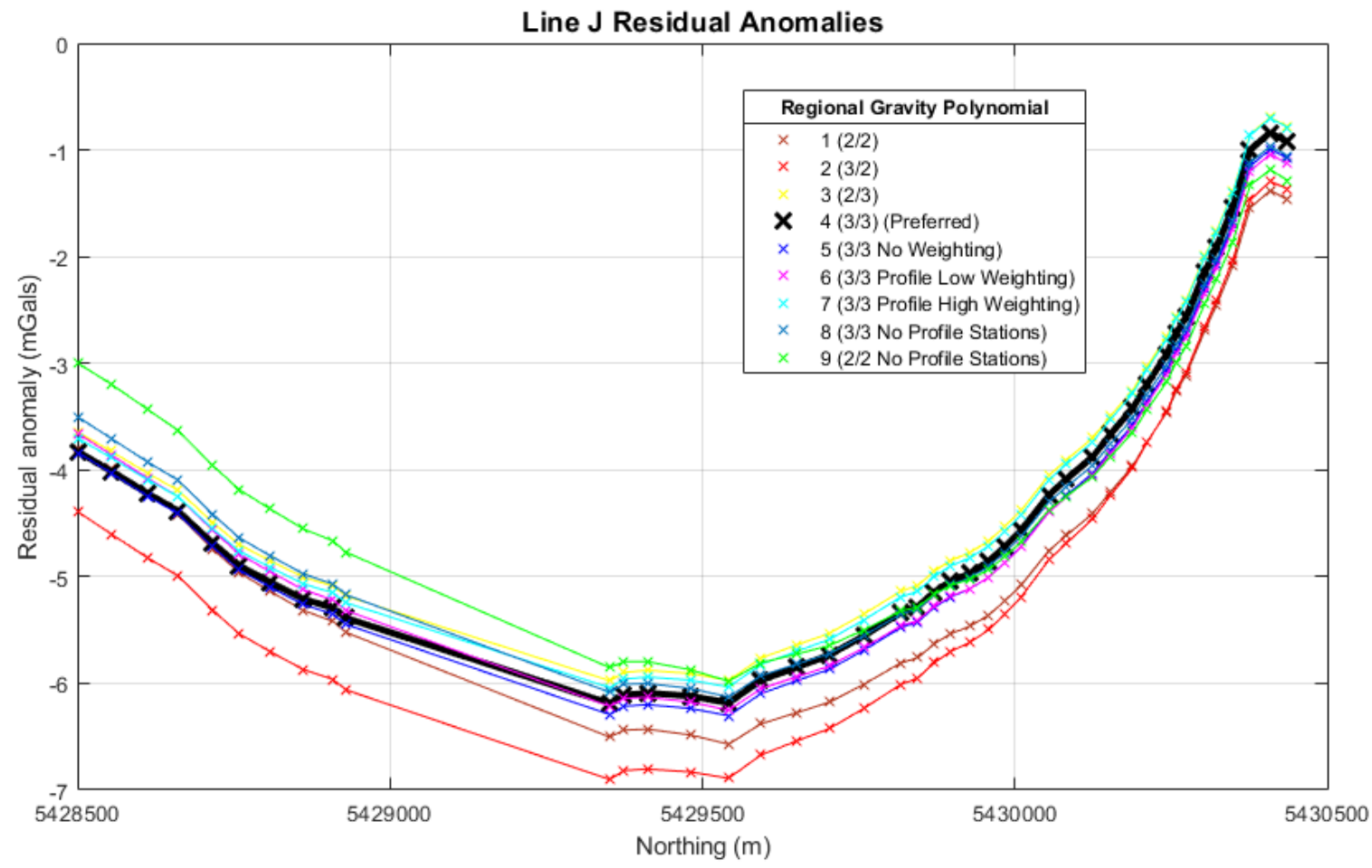

Figure D.3: Residual anomalies for Line $\mathrm{J}$ which result from the adoption of different regional gravity fields. The regional fields are numbered as in the list above. The preferred regional which has been used is in bold.

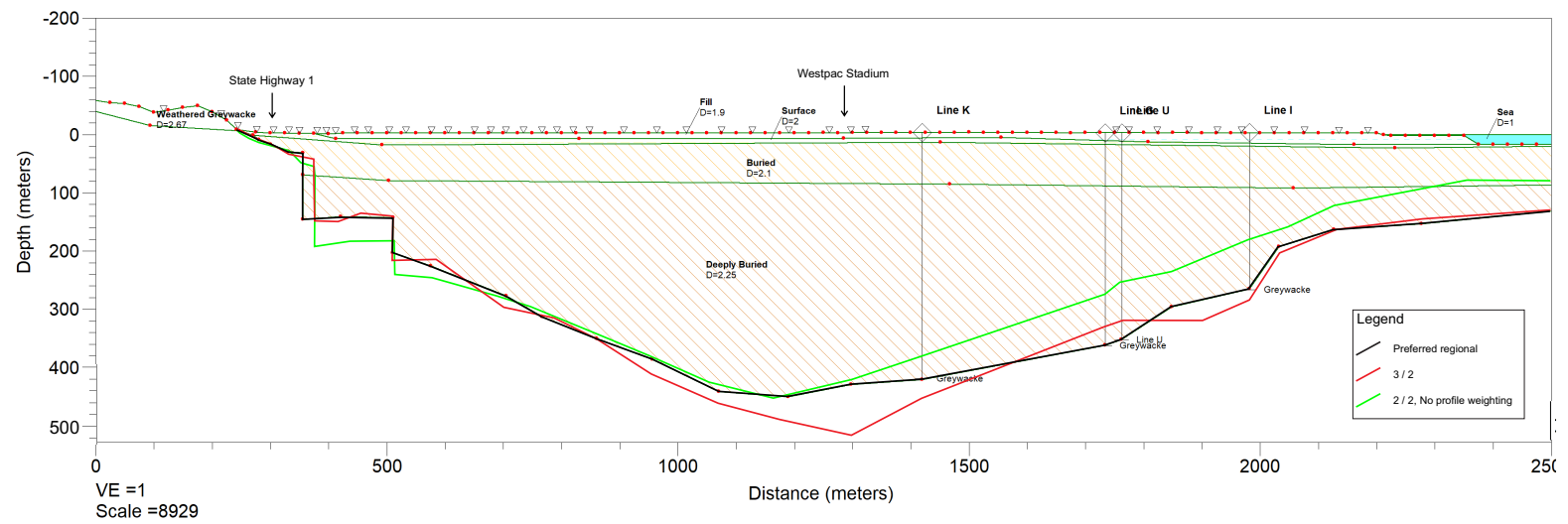

Figure D.4: Comparison of basin depths on Line J resulting from the adoption of different regional gravity fields.

has not been done for all profiles. However it is expected that other profiles would show similar results. 


\section{Bibliography}

Adams, B. M. (2000). Basin-edge effects from sh-wave modelling with reference to the Lower Hutt Valley, New Zealand. (Master's thesis). University of Canterbury.

Adams, B. M., Osborne, N. M., \& Taber, J. J. (2003). The Basin-Edge Effect from Weak Ground Motions Across the Fault-Bounded Edge of the Lower Hutt Valley, New Zealand. Bulletin of the Seismological Society of America, 93(6), 2703-2716. https: //doi.org/10.1785/0120010277

Ahlberg, J. H., Nilson, E. N., \& Walsh, J. L. (1967). The theory of splines and their applications. Academic Press.

Ballance, P. (2017). New Zealand geology: An illustrated guide. Geoscience Society of New Zealand.

Barnes, P. M., Nodder, S. D., Woelz, S., \& Orpin, A. R. (2019). The structure and seismic potential of the Aotea and Evans Bay Faults, Wellington, New Zealand. New Zealand Journal of Geology and Geophysics, 62(1), 46-71. https://doi.org/10. $1080 / 00288306.2018 .1520265$

Barrell, D. J. A. (2016). General distribution and characteristics of active faults and folds in the Waimate District and Waitaki District, South Canterbury and North Otago. GNS Science Consultancy Report, 2015/166, 124.

Beanland, S. (1995). The North Island Dextral Fault Belt, Hikurangi subduction margin, New Zealand (Master's thesis). Victoria University of Wellington.

Begg, J. G. (1996). Geology of the Wellington area / geology by J. Begg and C. Mazengarb.

Begg, J. G., Brown, L. J., \& Huber, P. H. (1992). Stratigraphic drillhole completion report, Polo Ground, Miramar, Wellington, New Zealand. N.Z.G.S. Report, G161, 112.

Begg, J. G., \& Johnston, M. R. (2000). Geology of the Wellington area.

Begg, J. G., Langridge, R., Dissen, R. V., \& Little, T. (2008). Wellington Fault: neotectonics and earthquake geology of the Wellington-Hutt Valley segment. Geo- 
sciences 2008: Geological Society of New Zealand, New Zealand Geophysical Society, New Zealand Geochemical \& Mineralogical Society joint annual conference field trip guide.

Benites, R., \& Olsen, K. B. (2005). Modeling Strong Ground Motion in the Wellington Metropolitan Area, New Zealand. Bulletin of the Seismological Society of America, 95(6), 2180-2196. https://doi.org/10.1785/0120040223

Berryman, K. (1990). Late quaternary movement on the Wellington Fault in the Upper Hutt area, New Zealand. New Zealand Journal of Geology and Geophysics, 33, 257270 .

Birch, F. (1960). The velocity of compressional waves in rocks to 10 kilobars: 1. Journal of Geophysical Research (1896-1977), 65(4), 1083-1102. https://doi.org/https: //doi.org/10.1029/JZ065i004p01083

Bradley, B., Wotherspoon, L., \& Kaiser, A. (2017). Ground motion and site effect observations in the Wellington region from the 2016 Mw7.8 Kaikōura, New Zealand earthquake. Bulletin of the New Zealand Society for Earthquake Engineering, 50, 94-105. https://doi.org/10.5459/bnzsee.50.2.94-105

Bradley, B., Wotherspoon, L., Kaiser, A., Cox, B., \& Jeong, S. (2018). Influence of Site Effects on Observed Ground Motions in the Wellington Region from the Mw 7.8 Kaikoura, New Zealand, Earthquake. Bulletin of the Seismological Society of America, 108. https://doi.org/10.1785/0120170286

Brideau, M.-A., Massey, C., Carey, J., \& Lyndsell, B. (2020). Geomechanical characterisation of discontinuous greywacke from the Wellington region based on laboratory testing. New Zealand Journal of Geology and Geophysics. https://doi.org/10.1080/ 00288306.2020 .1853181

Chetwin, E. (1998). Active Faulting and Subsurface Structure in the Mackenzie Basin: an investigation using gravity and seismic (Master's thesis). Victoria University of Wellington.

Cotton, C. A. (1957). Tectonic features in a coastal setting at Wellington. Transactions of the Royal Society of New Zealand, 84.

Cowan, M., \& Hatherton, T. (1968). Gravity surveys in Wellington and Hutt Valley. New Zealand Journal of Geology and Geophysics, 11(1), 3-15. https://doi.org/10.1080/ 00288306.1968.10423670 
Crice, D. (2011). Near-surface, downhole shear-wave surveys: A primer. The Leading Edge, 30, 164-171. https://doi.org/10.1190/1.3555327

Cubrinovski, M., McManus, K., Price, C., Scott, J., Seve, G., Stannard, M., Traylen, N., \& Wentz, R. (2016). Earthquake geotechnical engineering practice. Module 1: Overview of the Guidelines (tech. rep.). Ministry of Business, Innovation and Employment. https:// www . building . govt.nz / assets / Uploads / building-code-compliance / bstability/b1-structure/geotechnical-guidelines/geotech-module-1.pdf

Dilalos, S., Alexopoulos, J., \& Tsatsaris, A. (2018). Calculation of Building Correction for urban gravity surveys. A case study of Athens metropolis (Greece). Journal of Applied Geophysics, 159. https://doi.org/10.1016/j.jappgeo.2018.09.036

Dilalos, S., Alexopoulos, J. D., \& Lozios, S. (2019). New insights on subsurface geological and tectonic structure of the Athens basin (Greece), derived from urban gravity measurements. Journal of Applied Geophysics, 167, 73-105. https://doi.org/https: //doi.org/10.1016/j.jappgeo.2019.04.024

Edbrooke, S. W., Heron, D. W., Forsyth, P. J., \& Jongens, R. (2017). The geological map of New Zealand.

El-Batroukh, S. I., \& Zentani, A. S. (1980). Gravity interpretation of raguba field, sirte basin, libya. Geophysics, 45(7), 1153-1163. https://doi.org/10.1190/1.1441114

Esri. (2020a). How spline works. https://pro.arcgis.com/en/pro-app/tool-reference/3danalyst/how-spline-works.htm (accessed: 14.12.2020)

Esri. (2020b). How topo to raster works. https://pro.arcgis.com/en/pro-app/toolreference/3d-analyst/how-topo-to-raster-works.htm (accessed: 13/11/2020)

Fowler, C. M. R., Fowler, C. M. R., \& Fowler, M. (1990). The Solid Earth: An Introduction to Global Geophysics. Cambridge University Press.

Fraczek, W. (2003). Mean Sea Level, GPS, and the Geoid. https://www.esri.com/news/ arcuser/0703/geoid1of3.html (accessed: 13/11/2020)

Francois-Holden, C., Kaiser, A., Van Dissen, R., \& Jury, R. (2013). Sources, ground motion and structural response characteristics in Wellington of the 2013 Cook Strait earthquakes. Bulletin of the New Zealand Society for Earthquake Engineering, 46, 188-195. https://doi.org/10.5459/bnzsee.46.4.188-195

Gao, S., Liu, K., Davis, P., \& Knopoff, L. (1996). Localized Amplification of Seismic Waves and Correlation with Damage due to the Northridge Earthquake: Evidence for Focusing in Santa Monica. Bulletin of the Seismological Society of America, 86. 
Gasston, C., Lindsay, J. M., Eccles, J. D., Brook, M., Hill, M., \& Kenny, J. (2021). A geophysical and geomorphological investigation of large-offset normal faulting in beachlands, auckland. New Zealand Journal of Geology and Geophysics, 64(1), 3748. https://doi.org/10.1080/00288306.2020.1734032

Geomatrix Earth Science Ltd. (2020). Cg-6 Autograv Data Sheet. https://www.geomatrix. co.uk/land-products/gravity/cg6/ (accessed: 28.01.2020)

Gerstenberger, M. C., Kaneko, Y., Fry, B., Wallace, L., Rhoades, D., Christophersen, A., \& Williams, C. (2017). Kaikoura Earthquake Short-Term Project: Probabilities of Large Earthquakes in Central New Zealand (tech. rep.). GNS Science. https://www. naturalhazards . org. nz / NHRP / Publications / Research- Publications / KaikouraEarthquake

GFZ. (2005). SAFOD Main Hole downhole logging data phase 2 (2005), 2975-3387m. https:// dataservices.gfz-potsdam.de/SDDB/showshort.php?id=escidoc: 76207 (accessed: 01/04/2021)

GNS. (2021). E Tuhura - Explore Zealandia. https://data.gns.cri.nz/tez/index.html? map=TEZ-Geoscience (accessed: 26/02/2021)

Granser, H. (1987). Three-dimensional interpretation of gravity data from sedimentary basins using an exponential density-depth function*. Geophysical Prospecting, 35(9), 1030-1041. https://doi.org/https://doi.org/10.1111/j.1365-2478.1987.tb00858.x

Grant-Taylor, T. L., Adams, R. D., Hatherton, T., Milne, J. D. G., Northey, R. D., \& Stephenson, W. R. (1974). Microzoning for earthquake effects in Wellington. DSIR Bulletin 213.

Grapes, R., \& Downes, G. (1997). The 1855 Wairarapa, New Zealand, earthquake - Analysis of historical data. Bulletin of the New Zealand Society for Earthquake Engineering, 30(4). https://doi.org/10.5459/bnzsee.30.4.271-368

Grose, D. T., Knappstein, M. A., Peters, N. C., \& Symmans, B. S. (2015). Geological characteristics of a completely weathered rock ridge, and its effect on the design and construction of an underpass at Buckle Street, Wellington. Proceedings of the 12th Australia New Zealand Conference on Geomechanics.

Hamilton, E. L. (1970). Sound velocity and related properties of marine sediments, North Pacific. Journal of Geophysical Research (1896-1977), 75(23), 4423-4446. https: //doi.org/https://doi.org/10.1029/JB075i023p04423 
Hamling, I., Hreinsdottir, S., Clark, K., Elliott, J., Liang, C., Fielding, E., Litchfield, N., Villamor, P., Wallace, L., Wright, T., D’Anastasio, E., Bannister, S., Burbidge, D., Denys, P., Gentle, P., Howarth, J., Mueller, C., Palmer, N., Pearson, C., \& Stirling, M. (2017). Complex multifault rupture during the 2016 m w 7.8 Kaiköura earthquake, New Zealand. Science, 356, eaam7194. https://doi.org/10.1126/ science.aam7194

Hammer, S. (1939). Terrain corrections for gravimeter stations. Geophysics, 4(3), 184-194.

Hatherton, T., \& Leopard, A. (1964). The densities of New Zealand rocks. New Zealand Journal of Geology and Geophysics, 7(3), 605-625. https://doi.org/10.1080/ 00288306.1964.10422108

Hatherton, T., \& Sibson, R. (1969). A gravity survey of Wellington city. Geophysics Division Report No. 57, 7.

Henrys, S., Wech, A., Sutherland, R., Stern, T., Savage, M., Sato, H., Mochizuki, K., Iwasaki, T., Okaya, D., Seward, A., Tozer, B., Townend, J., Kurashimo, E., Iidaka, T., \& Ishiyama, T. (2013). SAHKE geophysical transect reveals crustal and subduction zone structure at the southern Hikurangi margin, New Zealand: Sahke Geophysical Transect. Geochemistry, Geophysics, Geosystems, 14, 2063-2083. https: //doi.org/10.1002/ggge.20136

Hill, M., Kaiser, A. E., Bourguignon, S., \& Bruce, Z. R. (2020). Wellington City Council Seismic Microzonation Map - Adoption of NZS1170.5 Subsoil Classifications. GNS Science Consultancy Report, 2020/119, 68.

Hinze, W. J. (2003). Bouguer reduction density, why 2.67? Geophysics, 68(5), 1559-1560. https://doi.org/10.1190/1.1620629

Hochstein, M. P., \& Davey, F. J. (1974). Seismic measurements in wellington harbour. Journal of the Royal Society of New Zealand, 4 (2), 123-140. https://doi.org/10. $1080 / 03036758.1974 .10426435$

Howarth, J. D., Barth, N. C., Fitzsimons, S. J., Richards-Dinger, K., Clark, K. J., Biasi, G. P., Cochran, U. A., Langridge, R. M., Berryman, K. R., \& Sutherland, R. (2021). Spatiotemporal clustering of great earthquakes on a transform fault controlled by geometry. Nature Geoscience. https://doi.org/10.1038/s41561-021-00721-4

Hugill, A. (2011). Gravimeters. Encyclopedia of Solid Earth Geophysics. https://doi.org/ https://doi.org/10.1007/978-90-481-8702-7_87 
Ibrahim, A., \& Hinze, W. J. (1972). Mapping buried bedrock topography with gravity. Groundwater, 10(3), 18-23. https://doi.org/https://doi.org/10.1111/j.17456584.1972.tb02921.x

Investigation into the performance of Statistics House in the 14 November 2016 Kaikoura Earthquake. (2017). https://www.mbie.govt.nz/assets/058a9fcb92/investigationinto-the-performance-of-statistics-house.pdf (accessed: 16.04.2020)

Jacob, T., Pannet, P., Beaubois, F., Baltassat, J., \& Hannion, Y. (2020). Cavity detection using microgravity in a highly urbanized setting: A case study from Reims, France. Journal of Applied Geophysics, 179, 104113. https://doi.org/https://doi.org/10. 1016/j.jappgeo.2020.104113

Jeppson, T. N., \& Tobin, H. J. (2015). San Andreas fault zone velocity structure at SAFOD at core, log, and seismic scales. Journal of Geophysical Research: Solid Earth, 120(7), 4983-4997. https://doi.org/https://doi.org/10.1002/2015JB012043

Kaiser, A., Bourguignon, S., Hill, M., Wotherspoon, L., Bruce, Z., Morgenstern, R., \& Giallini, S. (2019). Updated 3d basin model and the NZS 1170.5 subsoil class and site periods maps for the Wellington CBD. Project 2017-GNS-03-NHRP. GNS Science Consultancy Report, 2019/01, 48.

Kane, M. F. (1962). A comprehensive system of terrain corrections using a digital computer. Geophysics, 27(4), 455-462. https://doi.org/10.1190/1.1439044

Kawase, H. (1996). The Cause of the Damage Belt in Kobe: "The Basin-Edge Effect," Constructive Interference of the Direct S-Wave with the Basin-Induced Diffracted/Rayleigh Waves. Seismological Research Letters, 67, 25-34. https://doi.org/10.1785/gssrl. 67.5 .25

Keary, P., \& Brooks, M. (1992). An introduction to exploration geophysics. Blackwell series, London.

Kellett, R. L., Black, J. A., Brune, R., Stagpoole, V. M., \& O’Brien, G. (2017). Gravity survey of the Hutt Valley: Modelling the Wellington Fault. GNS Science Consultancy Report, 2017/24, 23.

Lamb, S., Smith, E., Stern, T., \& Warren-Smith, E. (2015). Continent scale strike-slip on a low-angle Fault beneath New Zealand's southern alps: Implications for crustal thickening in oblique collision zones. Geochemistry, Geophysics, Geosystems, 16. https://doi.org/10.1002/2015GC005990 
Langridge, R., Ries, W., Litchfield, N., Villamor, P., Dissen, R. V., Barrell, D., Rattenbury, M., Heron, D., Haubrock, S., Townsend, D., Lee, J., Berryman, K., Nicol, A., Cox, S., \& Stirling, M. (2016). The new zealand active faults database. New Zealand Journal of Geology and Geophysics, 59(1), 86-96. https://doi.org/10. $1080 / 00288306.2015 .1112818$

Langridge, R., Van Dissen, R., Rhoades, D., Villamor, P., Little, T., Litchfield, N., Clark, K., \& Clark, D. (2011). Five thousand years of surface ruptures on the Wellington Fault, New Zealand: Implications for recurrence and Fault segmentation. Bulletin of The Seismological Society of America, 101, 2088-2107. https://doi.org/10.1785/ 0120100340

Leão, J. W. D., Menezes, P. T. L., Beltrão, J. F., \& Silva, J. B. C. (1996). Gravity inversion of basement relief constrained by the knowledge of depth at isolated points. Geophysics, 61 (6), 1702-1714. https://doi.org/10.1190/1.1444088

Lee, W. H., Kanamori, H., Jennings, P. C., \& Kisslinger, C. (2003). International Handbook of Earthquake and Engineering Seismology, Part B (Vol. 81). Academic Press.

Lewis, K. B. (1989). A reversal of throw and change of trend on the wellington fault in wellington harbour. New Zealand Journal of Geology and Geophysics, 32(2), 293298. https://doi.org/10.1080/00288306.1989.10427590

Li, X., \& Götze, H.-J. (2001). Ellipsoid, geoid, gravity, geodesy, and geophysics. Geophysics, 66 (6), 1660-1668. https://doi.org/10.1190/1.1487109

Lillie, R. J. (1999). Whole Earth Geophysics. Prentice-Hall Inc.

LINZ. (2020). Nz building outlines. https://data.linz.govt.nz/layer/101290-nz-buildingoutlines/ (accessed: 09/03/2020. Sourced from the LINZ Data Service and licensed for reuse under CC BY 4.0)

LINZ. (2021a). Local mean sea level datums. https://www.linz.govt.nz/data/geodeticsystem / datums- projections- and-heights / vertical-datums / local- mean-sea- leveldatums (accessed: 25/02/2021)

LINZ. (2021b). Tide predictions. https://www.linz.govt.nz/sea/tides/tide-predictions (accessed: 24/02/2021)

Litchfield, N., Dissen, R. V., Langridge, R., Heron, D., \& Prentice, C. (2004). Timing of the most recent surface rupture event on the ohariu fault near paraparaumu, new zealand. New Zealand Journal of Geology and Geophysics, 47(1), 123-127. https://doi.org/10.1080/00288306.2004.9515041 
Lowrie, W. (2007). Fundamentals of geophysics, 2nd ed. Cambridge University Press.

Ma, R. (2005). Dem generation and building detection from lidar data. Photogrammetric Engineering Remote Sensing, 71, 847-854. https://doi.org/10.14358/PERS.71.7. 847

Mallick, K., \& Sharma, K. K. (1997). Computation of regional gravity anomaly — a novel approach. Proceedings of the Indian Acadamy of Sciences - Earth and Planetary Sciences, 106, 55-59. https://doi.org/10.1007/BF02841751

Mallick, K., Vasanthi, A., \& Sharma, K. K. (2011). Gravity data, regional-residual separation. Encyclopedia of Solid Earth Geophysics. https://doi.org/https://doi.org/ 10.1007/978-90-481-8702-7_90

Martínez-Moreno, F., Galindo-Zaldívar, J., Pedrera, A., González-Castillo, L., Ruano, P., Calaforra, J., \& Guirado, E. (2015). Detecting gypsum caves with microgravity and ert under soil water content variations (sorbas, se spain). Engineering Geology, 193, 38-48. https://doi.org/https://doi.org/10.1016/j.enggeo.2015.04.011

McNally, K. C., González-Ruiz, J. R., \& Stolte, C. (1986). Seismogenesis of the 1985 Great $(\mathrm{Ms}=8.1)$ Michoacan, Mexico Earthquake. Geophysical Research Letters, 13(6), 585-588. https://doi.org/https://doi.org/10.1029/GL013i006p00585

Milne, J. (1898). Seismology, first ed. K. Paul, Trench, Trübner Company, Limited.

Montaj, G. O. (2004). Gm-sys version 7.0 gravity and magnetic modeling software user guide. beaverton: Northwest geophysical associates.

Moritz, H. (1984). Geodetic reference system 1980. Bulletin géodésique, 58(3), 388-398. https://doi.org/10.1007/BF02519014

Mortimer, N., Campbell, H., Tulloch, A., King, P., Stagpoole, V., Wood, R., Rattenbury, M., Sutherland, R., Adams, C., Collot, J., \& Seton, M. (2017). Zealandia: Earth's Hidden Continent. GSA Today, 27. https://doi.org/10.1130/GSATG321A.1

Mussett, A., Khan, M., \& Button, S. (2000). Looking into the Earth: An Introduction to Geological Geophysics. https://doi.org/10.1017/CBO9780511810305

Nagy, D. (1966). The gravitational attraction of a right rectangular prism. Geophysics, 31(2), 362-371. https://doi.org/10.1190/1.1439779

Nettleton, L. L. (1939). Determination of density for reduction of gravimeter observations. Geophysics, 4(3), 176-183. https://doi.org/10.1190/1.0403176 
Odling, N., Harris, S., \& Knipe, R. (2004). Permeability scaling properties of fault damage zones in siliclastic rocks. Journal of Structural Geology, 26, 1727-1747. https://doi. org/10.1016/j.jsg.2004.02.005

Oldow, J. S., \& Sprenke, K. F. (2006). Gravity acquisition and depth to basement modeling of the spokane valley and rathdrum prairie aquifer, northeastern washington and northwestern idaho (tech. rep.). Idaho Department of Water Resources, Washington State Department of Ecology. https://idwr.idaho.gov/files/projects/spokanevalley-rathdrum-prairie/2006-SVRP-Report.pdf

Oliver, M., \& Webster, R. (2014). A tutorial guide to geostatistics: Computing and modelling variograms and kriging. CATENA, 113, 56-69. https://doi.org/https://doi. $\operatorname{org} / 10.1016 /$ j.catena.2013.09.006

Panisova, J., Fraštia, M., Wunderlich, T., Pašteka, R., \& Kušnirák, D. (2013). Microgravity and ground-penetrating radar investigations of subsurface features at the st catherine's monastery, slovakia. Archaeological Prospection, 20(3), 163-174. https: //doi.org/https://doi.org/10.1002/arp.1450

Panjamani, A., Uday, A., Moustafa, S., \& Alarifi, N. (2016). Correlation of densities with shear wave velocities and spt n values. Journal of Geophysics and Engineering, 13, 320-341. https://doi.org/10.1088/1742-2132/13/3/320

Patel, A. (2019). Geotechnical investigations and improvement of ground conditions. Woolhead Publishing.

Pawlowicz, R. (2013). Key physical variables in the ocean: Temperature, salinity, and density. https://www.nature.com/scitable/knowledge/library/key-physical-variablesin-the-ocean-temperature-102805293/ (accessed: 14.12.2020)

Pawlowski, R. S. (1994). Green's equivalent-layer concept in gravity band-pass filter design. Geophysics, 59(1), 69-76. https://doi.org/10.1190/1.1443535

Pratt, T. L., Horton Jr., J. W., Muñoz, J., Hough, S. E., Chapman, M. C., \& Olgun, C. G. (2017). Amplification of Earthquake Ground Motions in Washington, DC, and Implications for Hazard Assessments in Central and Eastern North America. Geophysical Research Letters, 44(24), 12, 150-12, 160. https://doi.org/https: //doi.org/10.1002/2017GL075517

QuakeCoRE. (2019). Quakecore: Flagship programme 1. http://www.quakecore.nz/ research/fp1/ (accessed: 27.01.2021) 
Reid, H. F. (1910). The Mechanics of the Earthquake, in The California earthquake of April 18, 1906 (tech. rep. No. 87). Carnegie Inst. Of Washington. http://activetectonics. asu.edu/Active\%7BF\%7DaultingSeminar/Papers/Reid_1910.pdf.

Reilly, W. (1972). New zealand gravity map series. New Zealand Journal of Geology and Geophysics, 15(1), 3-15. https://doi.org/10.1080/00288306.1972.10423942

Rhoades, D., Van Dissen, R., Langridge, R., Little, T., Ninis, D., Smith, E., \& Robinson, R. (2011). Re-evaluation of conditional probability of rupture of the WellingtonHutt Valley segment of the Wellington Fault. Bulletin of the New Zealand Society for Earthquake Engineering, 44. https://doi.org/10.5459/bnzsee.44.2.77-86

Robertson, E. I., \& Reilly, W. I. (1960). The New Zealand primary gravity network. New Zealand Journal of Geology and Geophysics, 3(1), 41-68. https://doi.org/10.1080/ 00288306.1960 .10423143

Rodgers, D. W., \& Little, T. A. (2006). World's largest coseismic strike-slip offset: The 1855 rupture of the Wairarapa Fault, New Zealand, and implications for displacement/length scaling of continental earthquakes. Journal of Geophysical Research: Solid Earth, 111 (B12). https://doi.org/https://doi.org/10.1029/2005JB004065

Semmens, S. B. (2010). An Engineering Geological Investigation of the Seismic Subsoil Classes in the Central Wellington Commercial Area. (Master's thesis). University of Canterbury.

Septentrio NV. (n.d.). Septentrio altus nr3 user manual. https:// www .apglos.eu/ downloads/manuals/altus-nr3-user-manual.pdf (accessed: 01.12.2020)

Stagpoole, V. (2018). Description of the data in the GNS gravity database (tech. rep.). GNS Science.

Standards New Zealand. (2004). Structural design actions - Part 5: Earthquake actions New Zealand (nzs 1170.5:2004) (tech. rep.). Standards New Zealand. https://shop. standards.govt.nz

Stern, T. A. (1979). Regional and residual gravity fields, central North Island, New Zealand. New Zealand Journal of Geology and Geophysics, 22(4), 479-485. https://doi.org/ $10.1080 / 00288306.1979 .10424156$

Stirling, M., McVerry, G., \& Berryman, K. (2002). A new seismic hazard model for New Zealand. Bulletin of the Seismological Society of America, 92, 1878-1903. 
Strong, D., Turnbull, R., Haubrock, S., \& Mortimer, N. (2016). Petlab: New Zealand's national rock catalogue and geoanalytical database. New Zealand Journal of Geology and Geophysics, 59(3), 475-481. https://doi.org/10.1080/00288306.2016.1157086

Suneson, N. H. (1993). The geology of the torlesse complex along the wellington area coast, north island, new zealand. New Zealand Journal of Geology and Geophysics, 36 (3), 369-384. https://doi.org/10.1080/00288306.1993.9514582

Tassara, A., \& Echaurren, A. (2012). Anatomy of the Andean subduction zone: threedimensional density model upgraded and compared against global-scale models. Geophysical Journal International, 189(1), 161-168. https://doi.org/10.1111/j. 1365-246X.2012.05397.x

Tirel, C., Gueydan, F., Tiberi, C., \& Brun, J.-P. (2004). Aegean crustal thickness inferred from gravity inversion. geodynamical implications. Earth and Planetary Science Letters, 228(3), 267-280. https://doi.org/https://doi.org/10.1016/j.epsl.2004.10. 023

Ulrych, T. J. (1968). Effect of wavelength filtering on the shape of the residual anomaly. Geophysics, 33(6), 1015-1018. https://doi.org/10.1190/1.1439979

Van Camp, M., de Viron, O., Watlet, A., Meurers, B., Francis, O., \& Caudron, C. (2017). Geophysics from terrestrial time-variable gravity measurements. Reviews of Geophysics, 55(4), 938-992. https://doi.org/https://doi.org/10.1002/2017RG000566

Van Dissen, R. J., \& Berryman, K. R. (1996). Surface rupture earthquakes over the last 1000 years in the wellington region, new zealand, and implications for ground shaking hazard. Journal of Geophysical Research: Solid Earth, 101 (B3), 5999-6019. https:/ / doi.org/https://doi.org/10.1029/95JB02391

Vanicek, P., Novak, P., \& Martinec, Z. (2001). Geoid, topography, and the bouguer plate or shell. Journal of Geodesy, 75, 210-215.

Vantassel, J., Cox, B., Wotherspoon, L., \& Stolte, A. (2018). Mapping depth to bedrock, shear stiffness, and fundamental site period at centreport, Wellington, using surfacewave methods: Implications for local seismic site amplification. Bulletin of the Seismological Society of America, 108. https://doi.org/10.1785/0120170287

Walcott, R. I. (1987). Geodetic Strain and the Deformational history of the North Island of New Zealand during the Late Cainozoic. Philosophical Transactions of the Royal Society of London. Series A, Mathematical and Physical Sciences, 321(1557), 163181. http://www.jstor.org/stable/37727 
Wallace, L. M., Barnes, P., Beavan, J., Van Dissen, R., Litchfield, N., Mountjoy, J., Langridge, R., Lamarche, G., \& Pondard, N. (2012). The kinematics of a transition from subduction to strike-slip: An example from the central New Zealand plate boundary. Journal of Geophysical Research: Solid Earth, 117(B2). https://doi.org/https: //doi.org/10.1029/2011JB008640

Wallace, L. M., Beavan, J., Mccaffrey, R., \& Darby, D. (2004). Subduction zone coupling and tectonic rotations in the North Island, New Zealand. J. geophys. Res., 109, B12406.

Wallace, L. M., Reyners, M., Cochran, U., Bannister, S., Barnes, P. M., Berryman, K., Downes, G., Eberhart-Phillips, D., Fagereng, A., Ellis, S., Nicol, A., McCaffrey, R., Beavan, R. J., Henrys, S., Sutherland, R., Barker, D. H. N., Litchfield, N., Townend, J., Robinson, R., ... Power, W. (2009). Characterizing the seismogenic zone of a major plate boundary subduction thrust: Hikurangi margin, New Zealand. Geochemistry, Geophysics, Geosystems, 10(10). https://doi.org/https://doi.org/ 10.1029/2009GC002610

Watson, C., \& Norton, K. (2015). Following in Cotton's footsteps (tyre tracks): Origin and evolution of the Wellington K Surface by mountain bike. Geosciences 2015: Field Trip Guides.

WCC. (2019). Wellington Lifelines Project: Protecting Wellington's Economy Through Accelerated Infrastructure Investment Programme Business Case (tech. rep. No. 3). Wellington City Council.

WCC. (2020). Ordinary Meeting of Wellington City Council Agenda, 16th December, 2020. Wellington City Council Minutes.

Wood, H. (1910). Distribution of apparent intensity in San Francisco, in the California earthquake of april 18, 1906 (tech. rep. No. 87). Carnegie Inst. Of Washington. http: / / activetectonics.asu. edu / Active\% 7BF\% 7DaultingSeminar / Papers / Reid 1910.pdf.

Yu, D. (2014). The Influence of Buildings on Urban Gravity Surveys. Journal of Environmental and Engineering Geophysics, 19(3), 157-164. https://doi.org/10.2113/ JEEG19.3.157

Zachariasen, J., Berryman, K., Langridge, R., Prentice, C., Rymer, M., Stirling, M., \& Villamor, P. (2006). Timing of late Holocene surface rupture of the Wairau Fault, 
Marlborough, New Zealand. New Zealand Journal of Geology and Geophysics, 49, 159-174. https://doi.org/10.1080/00288306.2006.9515156 
